\title{
How do small rural food-processing firms compete? A resource-based approach to competitive strategies
}

Sari Forsman

MTT Agrifood Research Finland, Economic Research,

Luutnantintie 13, FIN-00410 Helsinki, Finland, e-mail: sari.forsman@mtt.fi

ACADEMIC DISSERTATION

To be presented, with the permission of the Faculty

of Agriculture and Forestry of the University of Helsinki,

for public examination in Auditorium 2041, Biocentre 2, Viikinkaari 5, Helsinki,

on August 20 ${ }^{\text {th }}$ 2004, at 12 noon 
Supervisors: Dr. Sirpa Tuomi-Nurmi

Department of Economics and Management

University of Helsinki, Finland

Professor Markku Koskela

Department of Economics and Management

University of Helsinki, Finland

Reviewers: Professor Odd Jarl Borch

Bodø Graduate School of Business, Norway

Professor Hannu Niittykangas

School of Business and Economics

University of Jyväskylä, Finland

Opponent: Professor Asko Miettinen

Institute of Industrial Management

Tampere University of Technology, Finland 


\section{Preface}

Many persons have contributed to this work directly or indirectly. I wish to express my sincere gratitude to Dr. Sirpa Tuomi-Nurmi for her encouraging support, guidance and constructive comments at all stages of the study. I am also greatly indebted to Professor Markku Koskela who has guided me through this process and informed me of the formal requirements.

I would like to express my gratitude to the pre-examiners of this dissertation. Professors Odd Jarl Borch and Hannu Niittykangas carefully reviewed the manuscript and gave me valuable and constructive comments at the final stage. I am also grateful to Professor Asko Miettinen for agreeing to be my public examiner.

The present study has also benefited from the comments and support of many scholars. At the early stages of my research, Professor Arto Rajala and Professor Saara Hyvönen gave me valuable insights, for which I am extremely grateful. I am likewise thankful to Professor Kent Eriksson for his inspiring and practical LISREL technique course. I also wish to thank Professor Ahti Lehtomaa, Dr. Mika Pasanen and Lic.Sc. Leena Rantamäki-Lahtinen for their constructive comments on an earlier draft of this work.

This research has been funded jointly by MTT Agrifood Research Finland, Economic Research former known as Agricultural Economics Research Institute; the Ministry of Agriculture and Forestry, Rural Policy Committee; Foundation of Economic Education, and August Johannes and Aino Tiura Foundation of Agricultural Research. I acknowledge, with the deepest gratitude, for the financial support from these institutions.

I am grateful to Marlene Broemer, M.A., for her highly professional revision of English language of this work. I am likewise grateful to scientific editor Sari Torkko for editorial assistance. I would also like to thank the editorial board of Agricultural and Food Science for accepting this study to be published in their journal.

MTT Economic Research has provided excellent facilities for this work, for which I am especially thankful to Professor Kyösti Pietola. My thanks are also due to all my colleagues and friends who have supported and helped me during this project.

I am especially grateful for the support of my family. I am thankful for my mother Kyllikki and sister Satu for being there when needed. Finally, my deepest thanks go to you, Markku, for your love, support and encouragement. 


\section{Contents}

Abstract

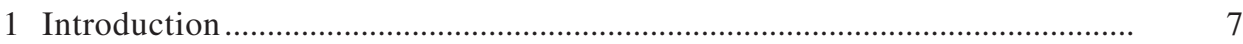

1.1 Background and relevance of the topic ..................................................

1.2 Objectives and research tasks ................................................................. 12

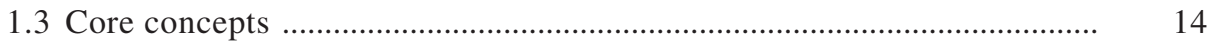

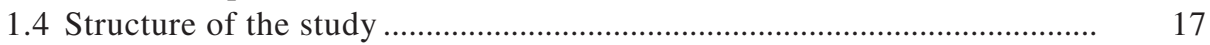

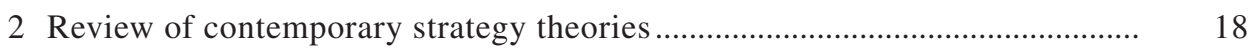

2.1 Concept of strategy .............................................................................. 19

2.2 Review of two major strategy theories ................................................... 21

2.2.1 Industry-based theory ................................................................. 22

2.2.2 Resource-based view .................................................................... 23

2.3 Towards a synthesis ........................................................................ 26

3 Creation of competitive advantage from the resource-based view ................. 27

3.1 Resources .................................................................................... 28

3.1.1 Various definitions and classifications of resources and related concepts .............................................................................. 29

3.1.2 Tangible and intangible resources ................................................. 31

3.1.3 Resources as potential sources of competitive advantage .............. 32

3.1.4 Distinction between strategic resources and basic resources ......... 34

3.2 Competitive advantage ....................................................................... 38

3.2.1 The concept of competitive strategy ............................................. 38

3.2.2 Strategies to create competitive advantages .................................. 39

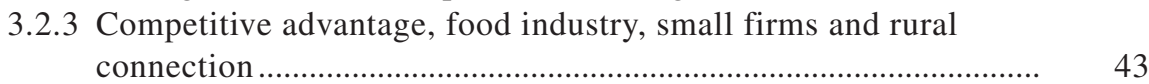

3.3 Performance outcomes of competitive advantage ...................................... 47

3.3.1 Resource-based view of success ..................................................... 48

3.3.2 Small firm success ........................................................................ 48

3.4 Summary: Elaborating a conceptual framework of the study .................. $\quad 50$

4 Survey instrument and data ...................................................................... 53

4.1 Methodological challenges ...................................................................... 54

4.2 Research design and data collection .................................................... 54

4.3 Operationalisation of the theoretical constructs ..................................... 55

4.3.1 Resources ................................................................................. 56

4.3.2 Competitive advantage ................................................................. 59

4.3.3 Small firm success ..................................................................... 61

4.3.4 Business environment .................................................................... 63

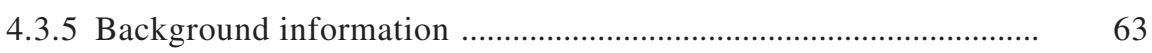

4.4 Reliability and validity of the study and the results ............................... 63 


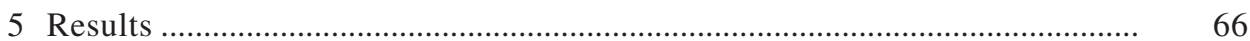

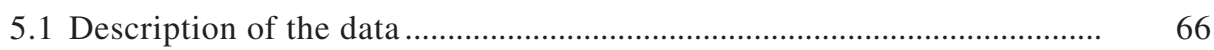

5.1.1 Background characteristics of the data ............................................ 66

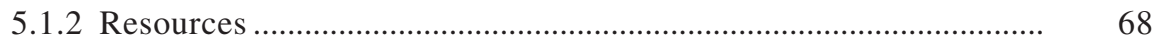

5.1.3 Competitive-advantage related variables ....................................... 74

5.1.4 Performance .................................................................................. 77

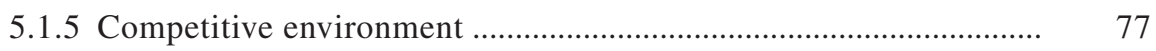

5.1.6 Summary …................................................................................... 80

5.2 Linkages between resources, the position of competitive advantage and success: cluster analysis application ..................................................... 81

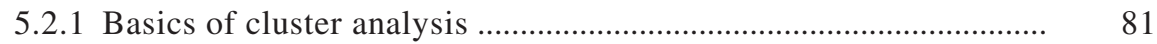

5.2.2 Success clusters ........................................................................... 84

5.2.3 Validation of success clusters ........................................................ 88

5.2.4 Competitive advantage clusters .................................................... 92

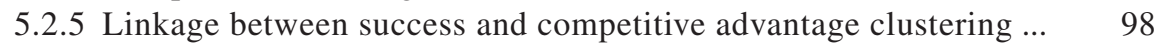

5.3 Causal linkages between resources and success: LISREL application .... 101

5.3.1 Basics of LISREL modelling ..................................................... 101

5.3.2 LISREL model of linkages between resources and success ........... 105

6 Discussion and conclusions ........................................................................... 111

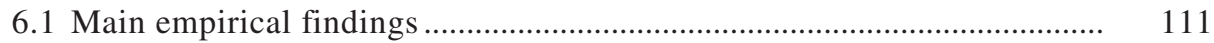

6.2 Theoretical and methodological implications ........................................... 114

6.3 Managerial implications ...................................................................... 117

6.4 Limitations of the study and suggestions for further research ................. 118

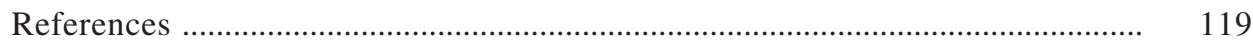

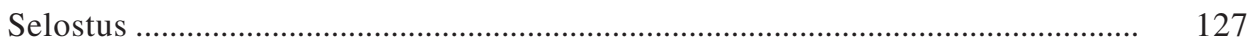

Appendices

Appendix A. Number of establishments in the food industry

Appendix B. The set of questions utilised in the study

Appendix C. Cluster and discriminant analysis output for the success cluster solution

Appendix D. Cluster and discriminant analysis output for the positioning strategy cluster solution

Appendix E. LISREL output of the final model 


\title{
How do small rural food-processing firms compete? A resource-based approach to competitive strategies
}

\author{
Sari Forsman \\ MTT Agrifood Research Finland, Economic Research,
}

Luutnantintie 13, FIN-00410 Helsinki, Finland, e-mail: sari.forsman@mtt.fi

The study was concerned with the competitive strategies of small food-processing firms in rural Finland and their ability to achieve and maintain a competitively advantaged position in relation to larger food companies in the dynamic and mature food market. Competitive strategies were approached from the resource-based view (RBV) that emphasises internal firm factors as sources of competitive advantage and long-term success. As strategic choices, differentiation was specifically considered. The main objective was to explain the relationships between resources, competitive advantage and firm success. To understand the ambiguous nature of the resources in the small-scale food production context, the study introduced a distinction between strategic resources and basic resources and the strategic relationship between them.

The empirical part of the study was based on quantitative analyses of the survey data collected from 238 small (less than 20 persons), food-processing firms in rural Finland. The sample firms represented different branches of the food industry and 39\% of them operated in connection with a farm. The linkage between resources, competitive advantage and firm success was investigated by means of cluster analysis, mean comparisons and LISREL modelling.

The results demonstrated that there are some typical features relating to small-scale food production in Finland. The results also revealed that small-scale, rural food processing firms do not constitute a homogenous group of their own, but that different strategies among small firms can be identified as well. The analyses proved that a linkage between resources, competitive advantage and firm success can be identified, which is consistent with resource-based logic. However, according to the findings, following a particular strategy does not automatically ensure that a firm will achieve success. The analysis also showed that strategic resources and basic resources are strongly interlinked and that the relationship between basic resources and success was, however, considerably stronger than the link between strategic resources and success. The study concludes that resource deployment - in terms of both strategic resources and basic resources - should be balanced in order for a small food-processing firm to have the opportunity to establish a relatively favourable position in the market. Based on the results, theoretical, methodological and managerial implications are suggested and ideas for the further research are provided.

Key words: competitive strategy, resources, competitive advantage, success, small firms, food industry, rural areas, resource-based view, multivariate data analysis, LISREL 


\section{Introduction}

Small-scale food production and entrepreneurship in rural areas in Finland has been the subject of extensive research and development during the last decade. From the viewpoint of foodmarket dynamics, small food-processing firms have an important function in diversifying food selections in the market, which is becoming more heterogeneous and fragmented. The subject of the study is competitive strategies of small food processors located in rural areas and their ability to achieve and maintain competitively advantaged position in the marketplace in relation to larger food companies. A principal question to be addressed in this dissertation is how small, rural food-processing firms compete in the market. The study will focus on the relationships between resources, competitive advantage and success, and draw on the relevant research in the field of strategic management. Competitive strategies are approached from the resource-based view that is one of the current strategy theories emphasising internal firm factors as sources of competitive advantage and long-term success.

\section{I.I Background and relevance of the topic}

During the last decade, the Finnish food sector has experienced radical and rapid change in the market environment. Structural adjustment and rationalisation has been rapid since the end of the 1980s when food companies began to prepare for the membership in the European Union (EU). After Finland's EU-membership in 1995, import-restricted food markets enlarged into EUwide markets. Due to this together with the gradual liberalisation of world trade, the import of food products increased which caused pressures to domestic food industry to increase cost-effi- ciency to be competitive on both the national and international level. In addition, in the early 1990 s Finland's economy suffered an economic recession, which also increased pressure to exploit scale advantages that were largely achieved by structural development within the sector. Because of these challenges, activities were centralised and the number of production plants decreased. Moreover, many large firms reduced the number of products in order to focus more on their core national or international products and brands. This trend, in turn, has provided opportunities for smaller firms to fill niches left by larger firms. Particularly after the recession at the end of 1990s, a clear trend began to emerge among some consumer segments toward food products that were differentiated in some way from bulk products. As a result, the number of establishments of large companies has clearly decreased. Yet, the total number of the establishments has not decreased since there were previously many small food business establishments in the 1990s (Volk et al. 1996, 2000, Hyvönen and Kola 1998). As a consequence of this development, the Finnish food sector has become increasingly polarised. On the one hand, there are national and international companies producing and marketing food products in large volumes within the whole country as a market area. On the other hand, there are small firms that operate mainly in the local market and try to differentiate their products from those provided by their larger counterparts.

The food industry is currently the fourth largest branch of industry in Finland. The main branches of the food industry are meat processing, dairy and bakery industries. Eighty-five percent of the raw material used by the Finnish food industry is domestic. Similarly, the market share of Finnish food products in Finland is 85\% (Finnish Food and Drink Industries' Federation 2003). The food sector has two features that distinguish it from other industries (Hernesniemi et al. 1996, Volk et al. 1996, p. 151, Hyvönen and Kola 
Forsman, S. How do small rural food-processing firms compete?

1998). Firstly, the food sector is a mature industry with relatively slow growth potential. Secondly, the common agricultural policy of the EU sets the institutional standpoints, not only for agriculture, but for the whole food industry.

In comparison to European markets the Finnish food market is relatively small. The Finnish food industry can also be characterised as oligopolistic because of the high concentration of large firms within different branches (Marttila 1996, p. 25). In addition, the Finnish food market is characterised by a large number of small firms. According to Statistics Finland (2003, p. $29)$, in 2002 a total of 2,388 establishments existed within the food industry $\left(\mathrm{SIC}^{1} 15\right)$ that consists of manufacturing of food-stuffs and beverages. The majority of the firms (establishments) within the industry is small according to personnel size. Of the total number of establishments, 93\% employ fewer than 50 persons annually. Eighty-six percent of firms employ fewer than 20 persons, and altogether $68 \%$ employ fewer than five persons. Accordingly, in terms of the number of establishments the Finnish food industry is highly small-business oriented. In this respect the structure of the Finnish food sector is very similar to that of other European countries: small-scale firms (less than 10 employees) dominate in terms of the number of establishments (Traill 1998).

The last decade has actually been quite favourable for the establishment of a small foodprocessing venture in the food sector. To strengthen and increase their international competitiveness, large food companies have cut down their product ranges. This has provided opportunities to new small business establishments to fill market niches and narrow customer segments ignored by large-scale firms. When looking at the number of new food-processing ventures in recent years, it may seem that access to the market is relatively easy. To succeed or even to survive in the food sector, however, is not necessarily that easy since competition within the sec-

1 Standard Industrial Classification tor is more intense than ever. The negotiation power of the small firms against large food companies and the retail sector is undoubtedly weak. The power of the retail sector has increased in recent years and it can be expected to continue to grow (Grievink et al. 2002, p. 19-21, Hyvönen 2004). This power is largely based on the efficiency of logistics; mainly a few retail chains control the distribution and logistics of the food products nowadays. For small food processors the concentrated structure of the retail level is a central entry barrier. Moreover, the market share of private label products is expected to increase in the near future, which is likely to increase competition within the food industry. For rural food processors located far away from big customer streams, retail stores would, however, be important marketing channels from the point of view of the accessibility of the potential customers. Recently there have been substantial efforts to establish alternative marketing governances, particularly relating to local food production, but so far alternative marketing channels in Finland are relatively undeveloped.

In addition to the fact that firms in the food sector are small, approximately half of the small food-processing firms in Finland are located in rural areas. The significance of food-processing business as a rural industry has increased markedly since the end of the 1980s. The trend has been very similar in other Nordic countries (Bergsten 1998, Borch 1998). Food-processing is at present one of the most rapidly growing rural industries in Finland (MTT Agrifood Research Finland 2002, p. 16). According to the Agricultural Census 2000 (Tike 2001), the number of farms engaged in the food-processing business was 1,065 . One of the main reasons for new-venture creation at the farm level is that farmers, in particular, have taken the initiative for on-farm food-processing as they seek new sources of income. Interest in food entrepreneurship among the farm entrepreneurs increased particularly due to the fall in production prices of agricultural products and changes within the competitive environment resulting from Finland's EU membership. By increasing the degree of processing 
Vol. 13 (2004): Supplement 1.

at the farm level, farmers have sought better prices for their self-produced agricultural products compared to selling them through traditional channels. According to a survey by RantamäkiLahtinen (2004), for $75 \%$ of the farms running food businesses, getting a better price for agricultural products was one of the main reasons for starting the on-farm processing business.

The interest in small-scale food-processing business, however, is not a farm-based phenomenon alone. In point of facts the majority of the rural food-processing firms have no farm-connection. A need to study rural firms separately from other small firms is largely based on the interests of the Finnish rural policy to maintain rural areas as vital and inhabited (Uusitalo 1998, Finnish Rural Policy Committee 2000). Active and diversified entrepreneurship is one of the characteristics that determines the vitality of rural areas (Niittykangas 1992, p. 15). The importance of small businesses is based on their role as a mechanism of job creation and the long-term development of economies (Storey 1994, p. 7).

There are many business opportunities for small and entrepreneurial firms in the food market. During the last decade the significance of small firms as providers of niche and speciality products has strengthened. This is quite a natural trend since large food companies are continuously cutting their product selections to achieve and maintain their national and international competitiveness. On the other hand, consumers with complex eating patterns (e.g., Mäkelä 2002) demand differentiated and diversified food products. Moreover, there are new market trends such as an increased interest towards the transparency of the food chain, healthy foods, organic foods and local foods that may provide business opportunities for small-scale producers.

It is evident that in the long-term small firms in the food industry cannot be competitive with larger firms with similar offerings due to the lack of economies of scale and limited resources. Hence, small food-processing firms have tried to differentiate their products and associated services from those provided by larger national and international food companies. The food sec- tor provides plenty of opportunities for differentiation. Differentiation is often based on factors such as unique or long-time family recipes, manufacturing methods, high-quality raw materials, environmentally-sound production modes or fast deliveries. Despite the many differentiation opportunities, it is a challenging task for a small firm to achieve competitive position in the mature industry. The bargaining position of the small-scale food producers particularly in price setting is often weak compared to larger food companies due to the lack of scale advantages as well as sufficient business and marketing expertise. With small production volumes and often inefficient cost control a small actor has often difficulties to meet retailers' volume requirements and hence is easily displaced by a larger counterpart when competing for shelf space in retail stores. Moreover, rural small-scale food producers are often located far away from big customer streams. Because of the long distances and often non-centralised distribution, the share of the transportation cost per unit of the product is often relatively high implying inefficient cost control.

However, there are many examples of small food producers that have succeeded in gaining market share locally, regionally, or even nationally and that can be regarded competitive and successful. Some have even gained access to the international markets with highly specialised products. This raises the question of why some small firms manage to create success while others fail to do so. It can be assumed that external industry circumstances (e.g., price competition) are quite similar to all the small food-processing firms in the particular field of the food industry. This, in turn, calls attention to the question whether firm success is influenced more by internal firm factors than external environmental factors.

The idea to look at firms in terms of their internal firm factors is based on the resourcebased view (e.g., Wernefelt 1984, Barney 1991, Grant 1991, Foss 1997a). Internal firm factors refer to a firm's resources and competences. The core idea of the resource-based view (the RBV) 
Forsman, S. How do small rural food-processing firms compete?

is on distinctive or unique resources as sources of competitive advantage and, further, long-term success. That is to say, a firm may achieve high performance by building or acquiring certain set of resources and competences (Foss 1997a). Resources and competencies are related to competitive strategy and strategic behaviour such that in order to achieve competitive advantage and success a strategy should be supported with an idiosyncratic set of resources (see Snow and Hrebniak 1980).

So far much of the focus of research within the RBV has been on larger firms (Barney et al. 2001). Recently this perspective has also been adopted and used within entrepreneurship and small business research (Borch 1999, Alvarez and Busenitz 2001, Barney and Arikan 2001, Sirmon and Hitt 2003). Yet, there are comparatively few studies addressing the role of resources and resource-based strategies in very small firms (e.g., Greene et al. 1997). The RBV, however, might provide substance and standpoints that make it well fit in the small business context, too (Rangone 1999). In general, resources are seen as essential to new venture creation and small firm growth (Greene et al. 1997). Small firms are often argued to be very dependent on their business environment, and they have limited ability to shape their environment (Smallbone et al 1999). Hence, the strategic adaptability of smaller firms will largely depend on the resources developed within their present industrial setting (Borch et al. 1999). An important research question in the food market context is how younger and entrepreneurial firms accumulate competitive strength in a mature market characterised by harsh competition in both price and quality.

The significance of resources in small foodprocessing firms can be assumed to be ambiguous. When looking at small firms or new ventures, resources are often considered from a negative perspective; it is often the scarcity of resources of small firms that is mentioned (e.g., Ireland et al. 2003, McCartan-Quinn and Carson 2003, Sirmon and Hitt 2003). Limited financial resources (Weinrauch et al. 1991) or a lack of expert knowledge, for example in marketing (Kupiainen 1996, Äyväri and Möller 1999, McCartan-Quinn and Carson 2003), are usually seen as factors that reduce a small firm's opportunities to carry out their activities (e.g, marketing, distribution) as effectively as their larger counterparts. Because of the resource constraints, small and younger entrepreneurial firms might be expected to have few internal resources and therefore be more dependent on external resources such as co-operation or government support programmes. That is, they must strive to develop their capabilities or gain access to the necessary resources in other ways (Sirmon and Hitt 2003). In Finland, small rural firms can obtain financial support for business start-ups, investments and business development actions. Financial support programmes thus improve their position in resource acquisition in comparison to larger companies.

On the one hand, small firms are often associated with some kind of special resources based on which they try to differentiate themselves from larger firms. These special resources and competences can, thus, be assumed to form a basis for differentiation and competitive advantage. There are also some common key strengths such as high product quality, delivery reliability and flexibility that small firms used to stress as competition tools in comparison to larger firms. Yet, all firms are not as successful. Hence, it can be assumed that, in spite of the key strengths typical of smaller firms, there must be some differences between firms in terms of resources, competences and capabilities in order to create a position in the market that will lead to profitable business.

In this study, the focus is specifically on those small food-processing firms that are located in rural areas. Food-processing business provides a potential and new income source for current or former farmers as well as other inhabitants with entrepreneurial capabilities living in rural areas. From the resource perspective, a firm's rural location may have some influences, both positive and negative, on its prospects of the food-processing business. These aspects include: 
Vol. 13 (2004): Supplement 1.

the size and nature of local market opportunities; opportunities for the local sourcing of inputs and subcontracting; size, structure, and characteristics of the local labour market, as well the local transport and communications infrastructure (Smallbone et al. 1999). A rural location may provide resources such as rural food traditions, regional heritage and agricultural expertise that can represent strategic value aspects in products and associated services.

Farm connection is one the main features relating to rural aspect. In on-farm food-processing businesses a rural location is obviously an important matter to a firm. The present farm capability may provide benefit in the development of new food products by re-utilisation of existing resources (Carter 1998, 1999). Farm entrepreneurs starting a food-processing business may have access to resources that may be valuable resources for food-processing such as raw material, buildings, land and equipment and practical experiences (Alsos and Ljunggren 2003). Access to these resources may be relatively inexpensive and risk-free (Carter 1999). Also the roots in the agri-food sector may promote the business start-up.

In rural areas local markets are usually small. A significant threat for rural small firms is continuous migration to growth centres, which decreases local purchasing power and skilled labour. Long distances from large customer streams, on the other hand, increase the logistics costs in comparison to firms located close to growth centres. A big problem in rural areas is the availability of a skilled labour force due to the smaller and more dispersed labour market compared to urban areas (Patterson and Anderson 2003). According to Hautamäki (2000), the central requirement of rural firms is capable and permanent labour and the main impediment to success is the skilled labour shortage. This is serious problem particularly in growth-oriented firms. Employing unskilled workers may restrict the emergence of new, innovative ideas (Kaikkonen 2003). Additionally, access to training facilities may also be limited in remote rural areas (Patterson and Anderson 2003).
Yet, it is not relevant to draw the urban-rural dichotomy too sharply. Many of the problems of operating a business faced by small entrepreneurs are very similar irrespective of the geographical location of a firm (Curran and Storey 1993). Thus, dividing firms into rural and urban, non-rural firms is, in point of the fact, quite artificial. Rural areas are not homogenous areas; there are doubtless better development opportunities in urban-adjacent rural areas than in isolated areas. Yet, rural firms do have some features that distinguish them from urban firms. These separated factors can be viewed, on the one hand, as strengths (e.g., own raw material production) and, on the other hand, as weaknesses (e.g., non-favourable location in terms of proximity to potential customers). Moreover, there are often differences between rural and urban firms in the type of business and also motivations for starting a business. For example, rural entrepreneurs often establish a craft business or very specialised type of business (Curran and Storey 1993).

Consequently, the RBV may provide a fruitful point of departure to approach the strategic behaviour of small food-processing firms and, in particular, their competitive strategies in the marketplace in relation to larger food companies. This study is made challenging by the fact that competitive strategies of small firms, and particularly in the food sector have not been widely studied. Strategies of small firms in the food sector have typically been investigated in the context of the whole industry setting (e.g. Hyvönen and Kola 1995, 1998, Traill 2000, Hyvönen 2001). This may offer a too one-sided picture of the strategic orientation of small-scale food production businesses since as a result of this type of empirical research frame the smallest foodprocessing firms are often grouped under one label. For example, in the study by Hyvönen and Kola (1995), the smallest food-processing firms were included in the cluster called "Productionand cost-oriented strategists lacking trade marketing competence”. Similarly, Traill (2000) when studying strategic groups of EU food manufacturers used a cluster categorisation where the 
Forsman, S. How do small rural food-processing firms compete?

smallest food manufactures were identified as local unbranded suppliers. The present study, instead, takes a view that there are different types of strategies or strategic orientations within small-scale food production businesses due to both the heterogenous nature of small firms and the different types of resource configurations that firms may own or control. This requires that small-scale firms are investigated as a group of their own. Only recently have studies that focus specifically on the strategy choices and issues of small food-processing firms been done (e.g., Hyvönen et al. 1995, Borch and Iveland 1998, Forsman 1999, Hyvönen and Erälinna 2002).

The study is made challenging also by the fact that strategy literature has largely developed from the needs and approaches of large firms. This means that the knowledge base about strategies and strategic behaviour of small firms is quite limited (Olson and Bokor 1995, Lee et al. 1999). Moreover, when looking at micro-sized firms or small start-ups, the possibility of exploiting existing strategy literature and research is even smaller (Smith 1998). In addition, what comes to rural small businesses, the utilisation of existing literature and studies is even more limited, because farm-based entrepreneurship as well as rural entrepreneurship has been ignored generally in entrepreneurship and small business research (Carter 1998, see also articles in Landström et al. 1997). This implies that concepts and theories as such will not necessarily apply to very small firms that, by their nature, differ from their larger counterparts (e.g., Carson 1995, p. 61).

\section{I.2 Objectives and research tasks}

The aim of the study is to increase our understanding of how small, rural food-processing firms compete in the market. More specifically, the main objective is to examine the relationships between resources, competitive advantage and firm success in small-scale food production. Following resource-based logic, a special focus is, on the one hand, on resources as drivers of competitive advantage and success and, on the other hand, on how small food-processing firms are positioned in the market. As a strategic choice, differentiation is specifically considered. The research phenomenon is approached from the viewpoint of a firm entity.

The study comprises theoretical and empirical parts. The theoretical part has the following objectives:

1) To consider critically to what extent current strategy theories apply a to small business context;

2) To study opportunities and conditions of small rural food-processing firms to achieve competitive advantage in the mature food markets, and

3) To provide a classification scheme for studying resources in small rural food-processing firms.

The aim of the first research task is to anchor the study in the research traditions within the field. The study is positioned in the research field of strategic management, particularly on competitive strategies. The aim is to critically ponder to what extent the current strategy theories apply to the small business context considering the strategic behaviour typical of small firms. The leading theory adapted in the study is the RBV. The development of the RBV has evolved largely as the countermovement to industry-based theories (Hoskisson et al. 1999). The discussion in this study is based on contrasting the RVB and the industry-based approach and trying to find points of integration between them. The research phenomenon is also, to some extent, related to marketing discipline that has been influenced by the resource-based logic. Competitive strategies are very marketoriented and because of that it may be difficult to draw a line between strategic management and marketing. Moreover, the research phenomenon relates also to the field of research on entrepreneurship that can be seen as a complementary, supportive discipline to strategic manage- 
Vol. 13 (2004): Supplement 1.

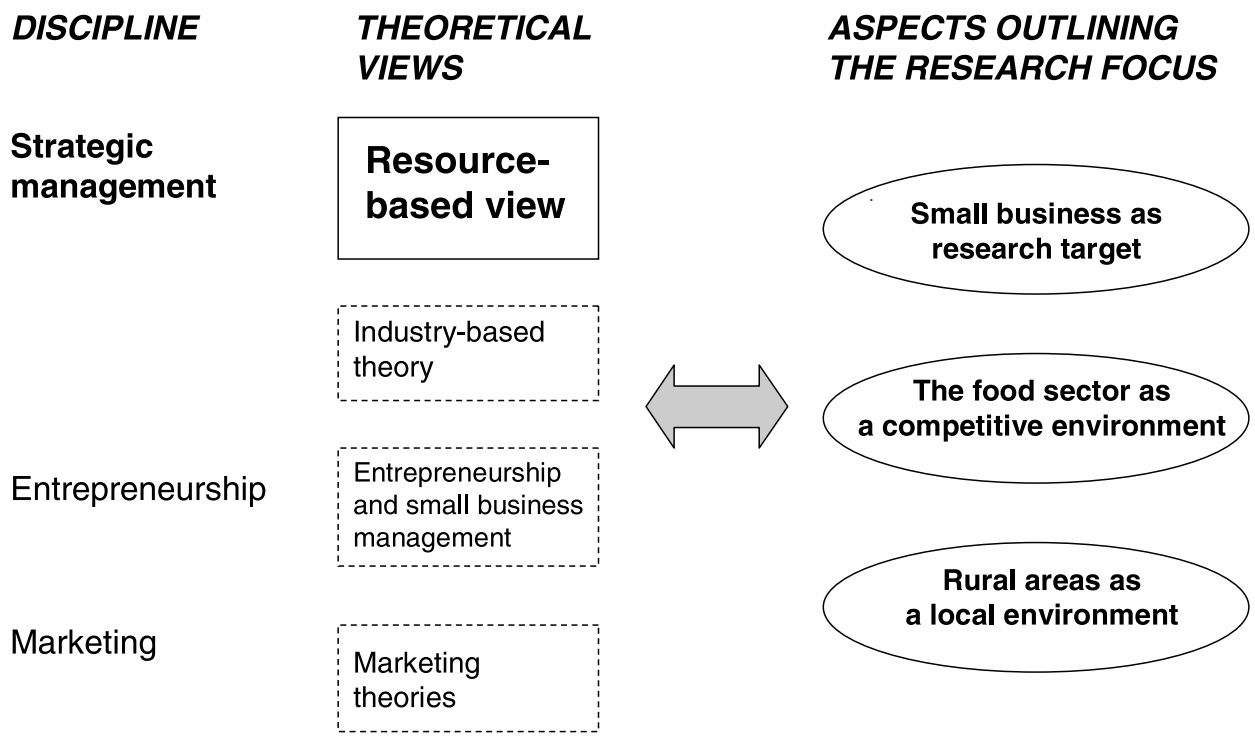

Fig. 1. Disciplines, theoretical views and aspects outlining the research focus of the study.

ment $^{2}$ (Hitt et al. 2001, Ireland et al. 2003). In addition, there are three aspects to discussion: small business as a research target; the food sector as a competitive environment, and rural areas as a local environment. Figure 1 summarises the disciplines, theoretical views and aspects outlining the research focus of the study.

The purpose of the second research task is to outline the resource-based competitive strategies in small rural firms operating in the mature food sector characterised by a polarised market structure. It can be assumed that small firms operate differently in different situations and that the significance and contributions of different resources is largely context-dependent. Thus, attention is paid to contextual factors such as farmconnection, branch within food industry, firms' life cycle and market arena. Finally, the aim of the third research task is to outline the relevant resource classifications and provide a classifi-

\footnotetext{
2 Both strategic management and entrepreneurship are concerned with growth and wealth creation (Ireland et al. 2003).
}

cation scheme of resources to be applied in the present research context.

The empirical part of the dissertation is crosssectional in nature. It is based on the quantitative analyses of the survey data collected from 238 small food-processing firms in rural Finland. The research objectives for the empirical part are as follows:

1) How do small food-processing firms stress different resources as differentiation tools?

2) What types of competitive strategies can be identified among the sample firms?

3) How are resources, competitive advantage and firm success linked?

The aim of the empirical part is to consider and identify features that are common to the strategic behaviour of small food processors, in general, in relation to larger food companies. Another purpose is to study and understand differences between small food processors in terms of resources, competitive advantage and success.

The study also has a methodological contribution. The goal is to model relationships between resources, competitive advantage and success by using more advantage techniques for 
Forsman, S. How do small rural food-processing firms compete?

handling quantitative data. LISREL modelling, which represents structural equation modelling, makes it possible to investigate the structure of several relations simultaneously and consequently has been used as a supplementary statistical method in the study.

Considering the scope of the research, the research is quite analytical and exploratory. The study has both deductive and inductive features. The study has its roots in empirical observations of the research phenomenon based on previous studies within the field. These observations have led to preliminary propositions that in turn have led to the relevant theories and strategies within the strategy field. The theoretical part suggests propositions to be tested by the empirical data. In this respect, the study is hypothetical-deductive. However, the research results and contribution of the study result from the theoretical discussion and the empirical results, that is, the empirical results are considered in relation to theoretical standpoints. This brings some inductive features to the study.

The methodological approach of the study is quantitative. The quantitative approach was chosen because the purpose of this study is to reach an understanding of how small food-processing firms compete in general, that is to say, the purpose was to produce findings that are, at least to some extent, generalisable. The quantitative approach also makes it possible to use more advanced statistical methods than a qualitative approach. Accordingly, the research phenomenon is considered at a holistic and general level, which supports the choice of quantitative approach.

\subsection{Core concepts}

The core concepts and terms of the study are briefly defined in this section. The concepts and terms may have several meanings and interpretations depending on the context. The aim of the concept definition is to provide on overview of how the core concepts and terms are interpreted in the present study. Some of the concepts are discussed in more detail in Chapters 2 and 3.

Small firm or small business includes a very heteregenous group of firms and is thus difficult to define. In most cases, firms are classified into small-sized enterprises according to the number of employees, although this definition varies by country and industry (Tainio 1992). For example, compared to international firms, many large Finnish firms may be regarded as small. Businesses employing less than 100 persons are often considered small firms. Within this category one can further distinguish micro firms employing under 10 or 20 persons and self-employed businesses referring to businesses with only one person (Bridge et al. 1998, p. 103). At the EU level a new definition of small firm will be introduced at the beginning of 2005. Small-sized firms will then refer to enterprises employing less than 50 persons and the turnover or balance sheet total of which is not more than 10 million euros, whereas micro-sized firms will refer to enterprises employing less than 10 persons and the turnover of balance sheet total of which is not more than 2 million euros (The European Commission 2003). In this study a small firm or small business is defined, in terms of the number of employees, as a firm employing less than 20 persons. However, more important than the strictly limited number of employees or other quantitative definitions, are the quality aspects that distinguish small actors from their larger counterparts in a particular industry (see Storey 1994, p. 11). The relative size of a small business compared with larger firms within an industry is small. It has a comparatively small market share and it often operates in local markets. Moreover, management of the business is usually independent and a business is owned by one person or by a small group of people. Usually the manager is also the owner (Bridge et al. 1998, p. 103-104). In addition, an owner-manager or entrepreneur is usually involved in every aspect of management of the business, particularly in very small firms (Juutilainen 2001, p. 116). All key roles of a firm may thus be enacted by one indi- 
Vol. 13 (2004): Supplement 1.

vidual. This implies that in many cases there is no separation between ownership and control, which can lead to efficient self-monitoring ( $\mathrm{Yu}$ 2001) and simpler organisation structures and more unified cultures (Pelham and Wilson 1996).

The definition of food-processing is based on the Standard Industrial Classification (SIC) system. Food-processing includes manufacture of food products and beverages (SIC 15). It distinguishes 39 food-processing industries (Statistics Finland 2003). A small food-processing firm then refers to a firm operating in the food industry (SIC 15) and employing less than 20 persons. In practice, the majority of small food-processing firms are really micro-sized firms with less than one man-year to two or three man-years. Processing in this context requires that a firm is engaged in food-related value-added activities including packaging. Traditional farm enterprises are excluded. The degree of processing may range from peeled potatoes and fresh meat to highly processed meat and vegetable products. Typical examples of processed food products provided by small-scale firms are fresh processed meat and fish products, bakery products, flours, jams, cheese and pre-processed vegetables. The division of the establishments in different branches within the food industry is shown in Appendix 1 .

A special focus in this study is on small foodprocessing firms that are located in rural areas. Small, rural food-processing firms can be divided into two groups (Fig. 2): (1) firms that are located on a farm and are run by a farmer or by family member(s), and (2) firms that are located in rural areas but have no farm-connection. $\mathrm{Ru}$ ral areas are usually distinct from urban, nonrural areas by some typical features. In Finland distinctive features characterising rural areas include scattered settlement, strong position of primary production and distant location from big population centres (Working Group on UrbanRural Interaction 2002, p. 3). Moreover, a lack of industrial traditions is often typical of rural areas (Niittykangas 1992, p. 13-14). There are also different rural areas. The National Rural Programme (1991) has divided the Finnish countryside into three categories: urban-adjacent ru-

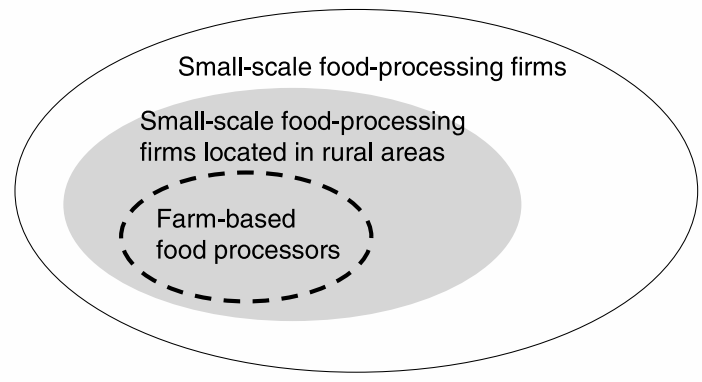

Fig. 2. Classification of small food-processing firms.

ral areas, rural heartland areas and isolated areas. Rural areas can thus be defined at several different levels. For the purpose of this study, the same definition that was used in the creation of the Rural Business Register in Finland is followed. This definition was based on population density. If population density within a certain zip code area is less than 50 persons per $\mathrm{km}^{2}$, the area is determined as a rural area (RantamäkiLahtinen 1999). This definition was chosen mainly because for the empirical part of the study a basis to create a sample of the rural foodprocessing firms was needed. From the theoretical perspective, typical features that characterise rural areas in comparison with urban areas are more important than strictly defined population densities.

Depending on the context one can also find different definitions in the literature and beliefs related to the terms entrepreneur and entrepreneurship (cf. entrepreneurial orientation ${ }^{3}$ ) (Gartner 1990). The terms "small business" and "entrepreneurship" are often used interchangeably and, although they overlap to some extent, (Bridge et al. 1998) these terms are not syno-

\footnotetext{
3 While entrepreneurship can be equated with a new entry, i.e., with going into business, entrepreneurial orientation refers more to entrepreneurial processes, i.e., how new entry is carried out. Key dimensions characterising entrepreneurial orientation include innovativeness, autonomy, risk taking, proactiveness, and competitive aggressiveness (Lumpkin and Dess 1996).
} 
Forsman, S. How do small rural food-processing firms compete?

nyms. The central ideas underlying the concept of entrepreneurship are the presence of innovation (e.g., Covin and Miles 1999) and new entry, that is, entering new or existing markets with new or existing products (Lumpkin and Dess 1996). According to Sharma and Chrisnan (1999), most scholars seem to base their definitions of an entrepreneur or entrepreneurship on Schumpeter (1934) or Gartner (1988). For Schumpeter (1934 ref. Sharma and Chrisnan 1999), an entrepreneur is a person who carries out new combinations in terms of products, processes, markets, organisational forms or sources of supply. Entrepreneurship refers, then, to the process of initiating new combinations. For Gartner (1988) the difference between an entrepreneur and a non-entrepreneur is that the former creates organisations while the latter does not. Entrepreneurship involves, accordingly, the creation of organisations. Building upon the abovementioned definitions, Sharma and Chrisnan (1999, p. 17) have tried to further clarify the terminology. They offer the following definitions: "Entrepreneurs are individuals or groups of individuals, acting independently or as part of corporate system, who create new organisations, or instigate renewal or innovation within an existing organisation. Entrepreneurship encompasses acts of organizational creation, renewal, or innovation that occur within or outside an existing organization".

The definitions provided by Sharma and Chrisnan serve the purpose of this study. However, because the focus of this study is largely on existing firms, a renewal or innovation perspective is more important than the creation of new organisations. Additionally, when defining entrepreneurship the focus on smaller firms and relative new ventures (cf. corporate entrepreneurship in older and/or larger organisations ${ }^{4}$ ) is specifically emphasised in the present study. Moreo-

\footnotetext{
4 The concept of entrepreneurship has been applied to individuals, groups and whole organisations (corporate entrepreneurship) (Lumpkin and Dess 1996).
}

ver, the owner-manager perspective is underlined by adopting a view that the role of owner-manager can also be an important characteristic of entrepreneurship (Gartner 1990). A small firm can be regarded "an extension of the individual who is in charge" of the business (Lumpkin and Dess 1996, p. 138).

An entrepreneur, as owner-manager of a single firm, might consist of more than one person such as a couple, for example, or small family. Owner-managers can be divided into single-venture entrepreneurs and multiple-business entrepreneurs such as portfolio entrepreneurs (Pasanen 2002). An example of a portfolio entrepreneur is an on-farm entrepreneur who concurrently practises conventional agricultural production and a food-processing business.

For decades, strategy has been a frequently used word in business. According to the contemporary strategic management discipline, strategy can be viewed as a link between a firm and its environment. Strategy is typically related to success in the market and, thus, is seen as an important determinant of success (Grant 1998, p. 12, 26). Hence, strategy can be defined "as a firm's theory how to compete successfully" (Barney 2002, p. 6). The focus of this study is particularly on business strategy level and, more specifically, on competitive strategies. Competitive strategy is concerned with how a firm competes in the market, that is, how it achieves and maintains a position of competitive advantage (Hofer and Schendel 1978, p. 15, Day 1990, p. 5, Teece et al. 1997). Following a resource-based approach (e.g., Barney 1991, Barney and Arikan 2001), competitive strategy can be defined as identifying valuable firm resources and translating them into a position of competitive advantage. A core of the resource-based strategy is the linkage between resources, competitive advantage and success. Strategy and competitive strategy are discussed in more detail throughout this work.

Resources is the key concept of the RVB. They can be broadly defined as strengths or weaknesses for a firm (Wernefelt 1984). They are assets that firms use to develop and imple- 
Vol. 13 (2004): Supplement 1.

ment their strategies (Ray et al. 2004). In the $\mathrm{RBV}$, valuable firm resources are seen as potential sources of competitive advantage. Resources can be tangible or intangible (Hall 1992, 1993) and they can be either firm-specific or firm-addressable (Sanchez et al. 1996, p. 7-8). Some authors (e.g., Ray et al. 2004) use the terms resources and capabilities interchangeably while other authors (e.g., Grant 1991, Javidan 1998, Rosenbröjer 1998) take a view that resources and capabilities are distinct concepts. Resources are then considered as tangible or intangible inputs in a firm's value chain (Javidan 1998) whereas capabilities (competences) are regarded as combinations of resources to carry out some activity or task (Grant 1991). In this study, the term resources is used in two meanings. On the other hand, it is used as a general sense covering any assets, capabilities or competences a firm owns or control. On the other hand, it may also refer to specific resources such as equipment or skill of a particular employee. Moreover, in this study the terms capability and competence are used interchangeably. The term resources and associated concepts are further discussed and elaborated in Section 3.1.

Competitive advantage is together with resource deployments the most important component of competitive strategy. Competitive advantage refers to superiority over rivals in a particular market. It is a kind of unique position vis à vis competitors (Hofer and Schendel 1978, p. 27$29,251)$. Traditional types of competitive advantage are low-cost advantage and differential advantage (Porter 1985, Mathur 1992). In the present study, competitive advantage is approached from the standpoint of resource-based logic. A firm can achieve a competitive advantage if it follows value-added strategies that, on the one hand, are based on resources that are valuable, rare, costly to copy and difficult to substitute and, on the other hand, are not imitable by competitors (Barney 1991, 2002). The study also takes the view that the nature of the competitive advantage in small businesses is relative rather than absolute. In addition, competitive advantage is looked at mainly from a differenti- ation perspective. Competitive advantage is discussed in more detail in Section 3.2.

Firm success is considered to be an outcome of competitive strategy. Traditionally, success has been measured in terms of financial indicators. In the case of small firms and relatively new ventures, success, however, is a very complex and problematic concept. Instead of financial perspectives, small firm success has been investigated in various ways, among others, in terms of growth (Wiklund 1998), target goal achievement, (Littunen et al. 1998) and long-term customer relationships (Komppula 2002). In the present study, the multidimensional nature of firm success is adapted. Considering success from several perspectives may help to identify and understand the link between resources, competitive advantage and success. It is also accepted that a small firm is not necessarily a profitmaximising entity. Moreover, firm success, in this study, refers to relative rather than absolute superiority. The terms success and performance are used interchangeably in this study (cf. Pasanen 2003). Firm success is further discussed and elaborated in Section 3.3.

\section{I.4 Structure of the study}

The study will be organised in the following way. The aim of Chapter 2 is to anchor the study in the research traditions within the field. First the concept of strategy is discussed. After that the two major competitive strategy theories characterising contemporary strategy debate are briefly reviewed. At the end of the chapter, there will be a synthesis of these two theories and an explanation of how this integration can serve as a theory platform for this study.

The purpose of Chapter 3 is to outline the resource-based competitive strategies. The competitive strategy discussion is approached in terms of three components: sources of competitive advantage (resources), position of competitive advantage and success. In this chapter, the 
Forsman, S. How do small rural food-processing firms compete?

relevant resource classifications are outlined and the potential of resources as sources of competitive advantage are considered. Additionally, a classification scheme of resources to be applied in the present research context is established and argued. In the competitive advantage section, the nature, creation and position of competitive advantage is considered. It is also considered critically how the competitive strategy discussion can be related to the setting of the food industry, small firms and rural areas. The chapter also includes a brief overview of the performance outcome of competitive advantage, i.e., success. The chapter concludes with a proposal framework for the study and some propositions to be tested in the empirical part of the study.

Chapter 4 leads us to the empirical part of the study. The empirical part of the study is crosssectional in nature, designed to look at relationships between resources, competitive advantage and firm success. The chapter begins with some methodological challenges related to the RBV. Then research design and data collection proce- dures are described. After that, key constructs and variables measuring them are operationalised and derived. Finally, the reliability and validity of the study and results are discussed.

Chapter 5 presents the main results of the study. First, data are described in terms of frequencies, means, etc. In addition, the data are summarised for the central variables of the study by using factor analysis and based on the factors summated scale variables are created. After that, two cluster analyses are conducted: success clustering and competitive advantage clustering. The cluster solutions are validated by analysing their relationships to resources and some other key variables. Moreover, the linkages between the two clusterings are investigated in more detail. Finally, central relationships of the constructs are modelled by using the LISREL application.

Chapter 6 concludes the study. This chapter discusses the main findings, implications and limitations of the study and suggests the conclusions and implications for further research.

\section{Review of contemporary strategy theories}

The purpose of this chapter is to outline the contemporary competitive strategy discussion in the field of strategic management in general. Central questions within strategic management are how firms achieve and sustain competitive advantage (Teece et al. 1997) and why certain firms continually are better in terms of performance than others (Barney and Arikan 2001). The focus is mainly on the strategic choices made by the individual firm and these choices are viewed as critical decisions to firm survival (Stubbart and Wilson 1992). Research on strategy has mainly concentrated either on strategy process or on the content of strategy (see Fahey and Christensen 1986), of which the latter is a focus in the present study.
The chapter is organised as follows. First, the concept of strategy is defined and discussed. The purpose is to understand how the concept of competitive strategy is positioned in the overall strategy discussion. Second, a brief review of two major competitive strategy theories characterising the contemporary strategy debate will be provided: an industrial economics approach and a resource-based view. The discussion includes background, essence and criticism of these two approaches. Finally, there will be a synthesis of these two theories so that their integration can serve as a theory platform for this study. A more detailed review and discussion of competitive strategy will continue in Chapter 3. 
Vol. 13 (2004): Supplement 1.

\section{I Concept of strategy}

For decades, strategy has been a frequently-used word in business. The concept of strategy has been defined in various ways and it is often used loosely. The meaning and content of strategy has also developed during the evolution of strategic management. ${ }^{5}$ As summarised by Mintzberg et al. (1998, p. 9-15, see also Mintzberg 1994, p. 23-28), a strategy is most often considered as a plan, a pattern, a position, a perspective, or a ploy (five p's). Strategy as a plan refers to a future course of action (intended strategy). Strategy as a pattern means consistency in behaviour over time (realised strategy). Strategy as a position refers to determining the position of particular products in a particular market. Strategy as a perspective, on the other hand, refers to an organisation's way of doing things. Strategy as a ploy refers to a kind of tactical behaviour that is intended to outwit competitors.

Strategy aims at a certain outcome. Creating and implementing strategies is thus very goaloriented behaviour. In business life a strategy is typically related to success in the market. Strategy is, therefore, an important determinant of success (Grant 1998, p. 26). By following the contemporary strategic management discussion, strategy can be defined "as a firm's theory about how to compete successfully". Said differently, strategies are "the means through which firms accomplish their mission and objectives" (Barney 2002, p. 6, 13). Companies need strategies and "strategic thinking" because they are tied

\footnotetext{
5 See Sanchez and Heene 1997a, Hoskisson et al. 1999 and Hunt 2000a for an overview of the development of strategic management field. The evolution of strategy can also be outlined by looking at different strategy schools. Mintzberg et al. (1998, p. 5) have listed ten strategy schools that have appeared at the different stages in the development of the strategic management field.

6 The term "strategic thinking" is used by Näsi (1991). He has even suggested that strategic thinking should be used as on overall concept instead of the term strategy. By strategic thinking Näsi covers strategic analysis, strategic planning, organisation and control, and strategic leadership.
}

to their competitive environment. This means that a business cannot be managed only by looking inward, there must also be an understanding of the interaction between a firm and its competitive environment. Therefore, a firm needs to establish a clear and consistent course of action that will be accepted by the customers and other interest groups (Vanhala et al. 1994, p. 25-26).

The best-known strategy researcher is probably Igor Ansoff who published the book Corporate Strategy in 1965. Ansoff presented a portfolio strategy that specifies the combinations of different strategic business areas in which a firm will seek to achieve its goals. Ansoff's matrix comprises, on the one hand, present and new products and, on the other hand, present and new missions. On this matrix there are four possible portfolio strategies. They are: market penetration (present product - present mission); product development (new product - present mission); market development (present product new mission), and diversification (new product - new mission) (Ansoff 1987, p. 108-111).

Hofer and Schendel (1978), well-known strategy scholars as well, were first to include resource deployments as a strategy component in their definition of strategy. According to them, an organisation's strategy is the "fundamental pattern of present and planned resource deployments and environmental interactions that indicates how the organisation will achieves its objectives" (p. 25). Consequently, these authors highlighted the role or resources and distinctive competencies even before the RBV became a dominant view in the field of strategic management.

Hofer and Schendel (1978, p. 25-26) outlined the strategy concept in terms of four components: scope, resource deployments, competitive advantage, and synergy. Scope refers to the extent of a firm's interactions with its environment. It is often defined in terms of product or market segments and sometimes in terms of geography, technology, or distribution channels. Resource deployments is a firm's resource and skill collections that will help a firm achieve its objectives. The authors emphasised the role of resourc- 
Forsman, S. How do small rural food-processing firms compete?

es in strategy because a firm cannot achieve its goal without some basic resources and skills. Moreover, resources should be employed in ways that cannot be imitated easily by competitors. Competitive advantage refers to unique positions that a firm develops vis-à-vis its competitors through resource deployments and scope decisions. Finally, synergy is the joint effect that a firm pursues through its resource deployments and scope decisions. Hofer and Schendel also suggested that resource deployments and competitive advantage may have a more important role than scope in determining success.

In contemporary strategy literature, strategy is viewed as a link between a firm and its external environment. Internal firm characteristics include its goals and values, its resources and capabilities and its organisational structure and systems. For a strategy to be successful, these key characteristics should be consistent with each other and, in addition, with a firm's external environment. The external environment includes a number of factors that influence a firm's decisions and success. A firm's industry is often the core of the external environment, particularly a firm's relationships with customers, competitors, and suppliers (Grant 1998, p. 12-13).

Strategies are often considered from a hierarchical perspective and then divided into three levels: corporate, business and functional level strategies. Corporate strategy concerns the whole enterprise. It defines the businesses in which a firm will compete (Andrews 1997) or actions to achieve competitive advantage in multiple businesses (Barney 2002, p. 368). Strategic decisions at this level concern diversification, way of entry into new businesses, removal of existing business and way of exit (Varadarajan and Clark 1994). Bamberger and Bonacker (1994, p. 36-50) suggest that strategies of small firms at the corporate level can be determined by the different product-market combinations and their interrelations. They state that some basic types of corporate strategies for small firms include specialisation and diversification, internationalisation, and vertical integration or subcontracting. A firm should determine its "strate- gic posture" with regard to these three dimensions of strategies.

The second level is business strategy. Hofer and Schendel (1978) have stated that a business strategy includes three interrelated sub-strategies: investment, competitive and political strategies. In addition to competitive strategies, Barney (2002, p. xvi) also includes vertical integration, flexibility, and cooperative strategies as business level strategies. Most of the research and theory development has, however, focused on competitive sub-strategies. The terms business strategies and competitive strategies have even been used interchangeably (e.g., Varadarajan and Clark 1994, Grant 1998, p. 316, Hyvönen 2001), which is also the case in this study.

In general, a competitive strategy specifies how a business intends to compete in a particular market (Hofer and Schendel 1978, p. 15, Day 1990, 5) and position itself among its competitors (Andrews 1997). The goal is to achieve and maintain competitive advantage in specific product-market areas (Varadarajan and Jayachandran 1999). Hence, resource deployments and competitive advantage are the most important components of strategy at this level (Hofer and Schendel 1978, p. 27-29). In the case of small firms Bamberger and Bonacker (1994, p. 50) propose that competitive strategy is more about how to compete and how to succeed with a particular product group in a specific market area. They further suggest that competitive strategy may be defined with regard to this specific product-market mixture or with regard to a firm's all strategic activities.

The third level is represented by functionalarea strategies such as marketing strategies. The main focus is on the maximisation of resource productivity. Hence, the main components of strategy at this level are the development of distinctive competencies and synergy (Hofer and Schendel 1978, p. 29). Functional strategies are developed to ensure that a firm's or business unit's competitive strategies are implemented (Javidan 1998).

Considering strategies in terms of different hierarchical levels does not necessarily work in 
Vol. 13 (2004): Supplement 1.

the case of small-scale firms where the strategy levels may be difficult to identify and separate from each other. In small enterprises the same person is usually responsible for all the decisions concerning the business. Because decision making is concentrated, the strategy levels, particularly competitive and functional level strategies, are presumably developed at the same time (see Varadarajan and Clark 1994) and are, thus, overlapping and interrelated. Similarly, corporate strategy and competitive strategy are closely linked since the scope of the business has implications for the sources of competitive advantage (see Grant 1998, p. 20). Thus, different levels of strategies are strongly interlinked, which becomes evident when implementing strategies. Competitive strategy is, in a way, a part of the implementation of corporate strategy, whereas functional area strategies implement the competitive strategy (Rajala 1994, p. 6).

Bamberger and Bonacker (1994, p. 34), however, suggest that the hierarchy of strategies is not necessarily related to different organisational levels. Corporate, competitive, and functional level strategies can also be determined on the same organisational level. They further argue that although small firms seldom have strategic business units in the sense of autonomous units such as larger firms may have, they often have certain product/market combinations. Different product/market combinations may have specific characteristics and, thus, they may need to differentiate the strategic behaviour according to these specific features. Therefore, to conclude the discussion about the hierarchical strategy levels in small businesses it is proposed that the different strategy levels, although not necessarily intended or explicit, can also be identified in a small firm. In the remainder of this study, the focus will be principally on competitive level strategies.

\subsection{Review of two major strategy theories}

The traditional concept of strategy was expressed in terms of strengths and weaknesses of a firm. (Andrews 1971, ref. Wernefelt 1984). This led to the introduction of the well-known SWOT Strengths, Weaknesses, Opportunities, Threats framework, upon which modern competitive strategy is based. This framework makes a distinction between a firm's internal environment (strengths and weaknesses) and external environment (opportunities and threats) (Grant 1998, 12, Hunt 2000a, p. 67). Underlying the SWOT framework is the idea of viewing competitive strategy as the match between a firm's internal resources and skills and the opportunities and risks created by its external environment. Alternative strategies for a firm are then developed through an assessment of both the external factors it faces in the market and the internal factors. Good strategies in this view are those that are explicit and achieve a good fit between the external and internal factors (Hunt 2000a, p. 6768).

Since the development of the SWOT framework, strategy literature, however, has advanced significantly. Two major perspectives dominate contemporary strategy literature and research: an industry-based approach and a resource-based view of the firm. The famous Porter generic strategy framework traces largely to industry-based theories emphasising external firm factors and the market power element as factors affecting a firm's choice of strategy and performance. A more recent resource-based view of the firm, on the other hand, has shifted focus from external industry factors to internal firm factors as a foundation for strategy and performance. In the following, these two perspectives, their background, central premises, focus and critique are briefly presented. 
Forsman, S. How do small rural food-processing firms compete?

\subsection{Industry-based theory}

Contemporary business strategy research traces largely to industrial organization-theory (Parnell 2000). In the 1980s industry-based theories of strategy became dominant in strategy literature. One of the most well-known strategy theorists is Michael E. Porter who introduced the Five Forces Framework and established a classification of generic strategies: cost leadership, differentiation and focus (Porter 1985). The Porterian view is based on industrial organisation economics and more specifically on the SCP-paradigm (see Hunt 2000a, p. 73).

According to the SCP Paradigm (Structure Conduct - Performance), structure determines conduct, which in turn determines performance. Structure refers to an industry structure that can be characterised by a number of competitors in an industry, the heterogeneity of products, cost structure, entry barriers and vertical integration. Conduct refers to specific actions taken by firms in an industry including price taking, product differentiation, tacit collusion and exploiting market power. Performance refers to an industry's performance which depends on the performance of individual firms (Scherer and Ross 1990, p. 4, Barney 2002, p. 75). The dynamics of SCP causality varies depending on the competitive structure of industries, that is, whether industries can be described as perfectly competitive, monopolistically competitive, oligopolistic or monopolistic (Barney 2002, p. 76).

Drawing on industrial organisation economics and taking a view that industry factors have a strong influence on the competition and performance of the firms in an industry, Porter (1980), one of the pioneers within the modern strategic management field, introduced a famous analytical tool, the Five Forces Framework, to assess the attractiveness of a particular industry and to facilitate competitor analysis in order to forecast industry profitability. In this framework competition in an industry is affected by the threat of new entrants, the threat of substitute products or services, the bargaining power of the suppliers, the bargaining power of the custom- ers and the intensity of the competition among the existing firms. Based on this view, the function of a strategy should be altering industry structure by, among other tactics, creating entry barriers (Porter 1980). Most important structural entry barriers such as economies of scale, product differentiation and absolute cost advantage were already paid attention to in the $1950 \mathrm{~s}$ by Bain (1956, p. 53, 1968, p. 255).

The function of the Five Forces Framework is to help determine a competitive strategy for a firm. The underlying premise is that the basis of and opportunities for competitive advantage requires an understanding of the competition in the industry. The Porterian view suggests that two basic types of competitive advantage exist for a firm: low-cost advantage or differentiation advantage. Porter's generic strategies are derived from industrial-organisation literature and Porter thus argues that cost advantage and differentiation result from industry structure. Under this dichotomy, according to Porter, a firm cannot simultaneously employ both of these strategies, except in some special conditions. Porter also makes a distinction between industry-wide strategies and focus strategies. The two basic types of competitive advantage combined with the scope of activities for which a firm seeks to achieve them lead to three generic strategies for achieving performance level above average: cost leadership, differentiation, and focus. Moreover, the focus strategy has two variants: cost focus and differentiation focus (Porter 1985, p. 11-26). This distinction, in terms of population ecology, refers to generalists versus specialists. In narrow niche markets, a specialist outcompetes a generalist (Stubbart and Wilson 1992). Niche specialisation is, according to Porter, a relevant strategy in a fragmented industry with low entry barriers. Accordingly, in order to achieve a position of competitive advantage a firm must make a choice between these generic strategies. Otherwise it will be "stuck in the middle" (Porter 1985, p. 17).

Consequently, according to Porter (1991), firm success is a function of the attractiveness of the industry in which a firm competes and its 
Vol. 13 (2004): Supplement 1.

relative position in that industry. A firm can be thought of as a collection of activities and a firm's strategy, then, determines its configuration of activities and how they interrelate. The role of resources becomes meaningful only after strategies have been chosen.

Soon after launching, Porter's typology became a dominant paradigm in the business literature (Hill 1988). In spite of its popularity, Porter's contribution has received a lot of criticism. In particular, the focus on external industry factors instead of a firm's internal factors has been questioned by many business strategy theorists (see Hunt 2000a, p. 74-75). Moreover, the focus of strategy as viewed by Porter is quite narrow; competitive strategy is seen as a generic position instead of a unique perspective. The Porterian view of strategy represents the positioning school that is typically characterised by identifying only a few desirable key strategies that are generic and exist a priori (Mintzberg et al. 1998, p. 116). In addition, one of the major critiques against the generic strategy typology is the argumentation that cost leadership and differentiation are not necessarily alternative, mutually exclusive strategies (Hill 1988, Murray 1988, Faulkner and Bowman 1992, Miller and Dess 1993). Porter's conceptualisation has also been regarded as oversimplified (Hill 1988), not collectively exhaustive because it excludes stuckin-the-middle strategies (Chrisman et al. 1988) and lacking generalisability (Miller and Dess 1993).

In spite of the criticism, the generic strategy model has still been applied. However, the discussion has advanced in two directions: towards mixed strategies that combine both differentiation and cost leadership (Hill 1988, Murray 1988, Faulkner and Bowman 1992, Miller 1992), and redeveloped generic strategies (Faulkner and Bowman 1992, Miller and Dess 1993, Chrisnan et al. 1993, Parnell 2000). Along with this discussion, the criticism faced by the industry-based theories led to a counter-movement by shifting emphasis from external industry factors to internal firm-level characteristics. This resulted in the emergence of the resource-based approach.

\subsubsection{Resource-based view}

Although industrial organisation applications (SCP-paradigm, Five Forces Model) brought new and significant insights to the field of strategic management, the focus began gradually to shift from the industry level to the firm level. Research had shown that some firms succeeded better than other firms in the same industry or within the same strategic group ${ }^{7}$. This led strategy theorists to take notice of firm level characteristics (Hoskisson et al. 1999).

In the 1990s, a resource-based perspective became the dominant view in studying competitive strategies. The resource-based view (RBV) looks at firms and organisations as a broad set of resources (Wernefelt 1984). Firms own different types of resources that make it possible for them to create different type of strategies (Javidan 1998). Hence, the RBV emphasises the internal aspects of firms as a foundation for a strategy (Hoskisson et al. 1999) instead of external industry factors. This view is based on two premises. First, a firm's internal resources and capabilities offer the key direction for its strategy. This is further based on the view that in the continuously changing environment, a firm's own resources and capabilities, in terms of what a firm is capable of doing, provide a more stable basis for a strategy than the needs of external business environment. The second premise is that resources and capabilities constitute the principal source of the firm profit. This, in turn, is based on the view that differences in profits between firms results from the resource positions of a firm's underlying competitive advantage rather than from the conditions of the external environment (Grant 1991).

The core of the RBV is that the potential for sustainable competitive advantage lies in valua-

\footnotetext{
${ }^{7}$ A strategic group refers to a group of firms in the same industry following the similar strategies (Porter 1980, p. 129). Examples of generic strategic groups include niche players, pioneers, local producers and dominant firms (Mintzberg et al. 1998, p. 109).
} 
Forsman, S. How do small rural food-processing firms compete?

ble resources that are rare, costly to copy and difficult to substitute and that firm resources are both heterogeneous and immobile (Barney 1991, 2001). The RBV emphasises exploiting the differences between firms as a key to long-term competitiveness and success (Grant 1998, p. 111). Performance differences between firms are seen as the results of differences in efficiency, not differences in market power (Foss et al. 1995, p. 8). Moreover, the more dynamic a firm's external environment is, the more likely internal firm factors play a significant role in the longterm strategy foundation (Grant 1998, p. 108). The particular interest of the RBV is under what circumstances in the long run a resource will lead to high returns (Wernefelt 1984) and how a firm's internal characteristics and performance are linked. The RVB provides no ex ante generic competitive strategies resulting in the position of competitive advantage if compared to the Porterian view, but rather sees strategies as unique for firms (Mintzberg et al. 1998).

Nowadays, the RBV is seen as "the most influential framework for understanding strategic management" (Barney et al. 2001). Nevertheless, the RBV is not a new view ${ }^{8}$. The relationship between a firm's special resources and performance was already noted by early theorists in the strategic management field. For instance, Selznick's idea of a firm's "distinctive competence" is directly related to the RBV (Hoskisson et al. 1999). The roots of the RBV, however, can be traced mainly to a seminal work of E. T. Penrose (1959) whose classic book, The Theory of the Growth of the Firm, was an attempt to bridge economics and management (Kor and Mahoney 2000). Her founding idea, from the viewpoint of the RBV, was viewing a firm as a bundle of resources (see Hoskisson et al. 1999). Penrose (1959, p. 24) perceived a firm as more than an

\footnotetext{
${ }^{8}$ Prior theoretical work in developing the RBV include, according to Barney and Arikan (2001), four sources: 1) traditional work on distinctive economics; 2) Ricardian economics; 3) Penrosian economics, and 4) the anti-trust implications of economics.
}

administrative unit. She stated that "it [a firm] is also a collection of productive resources the disposal of which between different uses and over time is determined by administrative decision". Since Penrose ${ }^{9}$, a number of authors (see Barney and Arikan 2001 for the summary) have contributed to the foundations of the theory and develop its applications and implications. Among contributors to the RBV within last two decades the following can be named: Wernefelt (1984), Dierickx and Cool (1989), Barney (1991, 2001a, b), Conner (1991), Grant (1991), Peteraf (1993) and Mahoney (1995, 2001).

The main contribution of the RBV, according to Rugman and Verbeke (2002) may be its ability to synthesise several strings of research in economics, industrial organisation, organisation science, and strategy itself. Moreover, they state that in the field of strategy, the RBV contributes by bringing complementary approach to the strategic positioning school. The RBV, on the contrary, represents predominantly the cultural school with emphasis on capabilities rooted in culture (Mintzberg et al. 1998, p. 276-283, 362).

Similar to the Porterian "outside-in" view, the RBV, "inside-out" view has also been widely criticised. While the Porterian view and IO economics in general is judged for putting too much focus on external industry factors, the RBV is criticised for putting too much focus on internal resources and ignoring the dynamics of the competitive environment. The RBV is also blamed for explaining too easily what already exists (ex post perspective) rather than studying what is coming into being (ex ante perspective) (Mintzberg et al. 1998, p. 280-283). In spite of the criticism, the RBV has continued to develop as a theory and at the same time has inspired the development of related views.

The "dynamic capabilities" approach is closely related to the RBV (Teece et al. 1997, Eisenhardt and Martin 2000, Makadok 2001).

\footnotetext{
9 See e.g., Kor and Mahoney (2000) for Penrose's work and influence on the RBV.
} 
Vol. 13 (2004): Supplement 1.

This approach stresses dynamic capabilities as an ability to generate new forms of competitive advantage. Dynamic capabilities can be defined as "the firm's ability to integrate, build, and reconfigure internal and external competence to address rapidly changing environments" (Teece et al. 1997, p. 516). The focus is on the productive deployment of resources through a capability-building mechanism. A capability affects firm profitability by improving the productivity of the other resources that a firm possesses or controls. From the rent-generation perspective capabilities themselves have no value; they can only generate profit after a firm has acquired those resources that are to be enhanced (Makadok 2000).

There are also other views that are closely related to the RBV but have emerged and developed more or less independently of the RBV. In the 1990 s there was a development towards core competences and competence-based competition in strategic management. Organisational competences were identified as new sources of competitive advantage, which had not been adequately addressed by traditional strategy theory (Sanchez and Heene1997a). Prahalad and Hamel (1990, p. 82, see also Hamel and Prahalad 1996, Hamel 2000), among others, introduced core competence at the corporate level as a concept that refers to "the collective learning in the organization, especially how to co-ordinate diverse production skills and integrate multiple streams of technologies". Stimulated by the core competence perspective, Sanchez et al. (1996, also Heene and Sanchez 1997, Sanchez and Heene 1997a,b) have advanced a competence-based view in which organisational competences were identified as new sources of competitive advantage as the importance of a competitive environment has increased. The competence-based view tries to take a more holistic approach to strategic management including dynamic, systemic and cognitive perspectives and, thus, views a firm as an open system by linking a firm's internal processes and their interactions with the external competitive environment.

A firm achieves competence if it is able to maintain "co-ordinated deployments of resourc- es" in a way that it can achieve its goals. A firm may pursue its goals by either competence leveraging or competence building. Competence leveraging means that a firm deploys its existing competences either to current or new market opportunities, without any qualitative changes in its resources. Competence building, on the other hand, means that a firm uses or acquires qualitatively different resources including ways to co-ordinate them. For each firm there will be a distinctive mix of both competence-building and competence-leveraging activities. Moreover, the competence-based view emphasises a supplyside dimension to industry dynamics since firms compete to acquire inputs of resources for competence building and leveraging. This, in turn, stresses the importance of the interdependency between a firm and its competitive environment. In addition, the competence-based view underlines a cognitive dimension of strategic management. Firms need to continuously interact with providers of resources (e.g., other firms, financial institutions, etc.) Thus, a central concern is to understand how managers conceptualise and communicate about new opportunities to compete and co-operate. In this continuous learning processes and their development play a significant role.

The resource-advantage theory (Hunt and Morgan 1995, 1996, 1997, Hunt 2000a,b, Hunt and Duhan 2002) of competition shares also some common features with the RBV, but in addition to the RBV it has roots in several other traditions. It is thought of as an interdisciplinary theory of competition which, contrasted with the neoclassical view, adopts a view that firms are bundles of heterogeneous, imperfectly mobile resources. The resource-advantage theory of competition focuses especially on the comparative advantage that a firm may have in its resources that are historically situated in time and space. This theory also assumes that there are different market segments in the same industry due to heterogeneous demand and that different market offerings for different market segments are required. Comparative advantage (disadvantage) in resources may lead to the position of compet- 
Forsman, S. How do small rural food-processing firms compete?

itive advantage (disadvantage) in some market segment(s) and, further, superior (inferior) financial performance. In order to clarify the nature and process of the resource-advantage competition, Hunt and Morgan (1997) have introduced a competitive position matrix that shows nine possible competitive positions for a firm (see details in Section 3.2.1.

\subsection{Towards a synthesis}

Strategic management theory has during the last decades fragmented into several research streams. In the contemporary strategy discussion two mainstreams can be identified: industrybased theories (the SCP-paradigm, Porter's generic strategies) and the RBV and related views. The former emphasises external industry factors as having a strong influence on the competition and performance within a particular industry whereas the RBV stresses internal firm factors as the principal sources of competitive advantage and rent-generation. In conclusion, these two mainstreams are in many respects quite con- trary to each other. The salient characteristics of these two mainstream strategies on main dimensions are summarised in Table 1.

Although the present study is theoretically built upon the RBV, the purpose is not, however, to adopt a black-and-white pattern of thought. This means that even though the significance of internal firm factors is underlined, the industry effect cannot be totally excluded (see e.g., Bamberger and Wrona 1994, p. 205, Borch et al. 1998, Smallbone et al. 1999). As described in the Introduction, the focus in this study is on firms operating in the mature industry with a high degree of concentration both in the food industry and the retail sector. The possible industry effect, however, is not taken as given. Accordingly, argumentation between these two mainstream views will follow throughout this work. Generally speaking, it is obvious that the strategy discussion will proceed in critical interplay with other theories and views. This is also consistent with a more recent view that considerers the importance of both industry and firm-specific effects on firm performance (e.g., Amit and Schoemaker 1993, Spanos and Lioukas 2001, Barney 2002). For example, Amit and Schoemaker (1993) have stated that the RBV can be

Table 1. Salient characteristics of the mainstream strategy theories.

\begin{tabular}{lll}
\hline & Industry-based approach & Resource-based view \\
\hline $\begin{array}{l}\text { Analogy with the SWOT framework } \\
\text { View of the firm }\end{array}$ & Opportunities and threats & Strengths and weaknesses \\
Unit of analysis & As a bundle of strategic activities & As a bundle of resources \\
Role of industry structure & Industries, firms, products & Firms, resources \\
Characteristic to resources & Exogenous & Endogenous \\
Nature of strategies & Identical, high mobility & Heterogeneity, immobility \\
Time line of strategy & Generic & Unique \\
$\begin{array}{l}\text { Determinants in the choice of } \\
\text { competitive strategy }\end{array}$ & Ex ante & Ex post \\
Source of rents & relative position within the industry & Internal firm factors \\
& $\begin{array}{l}\text { Profits from product market } \\
\text { positioning }\end{array}$ & Unique firm-specific resources and \\
Nature of rents & Monopoly-type rents & Ricardian rents \\
\hline
\end{tabular}


Vol. 13 (2004): Supplement 1.

thought of as a complement to the industry-based theory. Barney (2002, p. 160), on the other hand, takes a view that industry-based models including environmental threats and opportunities are complements to resource-based models of internal firm-factors. Spanos and Lioukas (2001), in turn, argue that drawing insights from both perspectives may result in a more balanced view on the sources of sustainable competitive advantage. In the empirical examination of the causal logic of rent generation they found that both industry and firm-level influences are significant determinants of performance.

Consequently, the standpoint for the study is that a firm's strategic choices such as competitive strategies and, further, success are based on the deployments of its unique and valuable resources. Moreover, it is assumed that differences in small rural food-processing firms' strategies and success can, to a great extent, be explained by differences in resource deployment, which is accordant with the RBV. Resources cannot, however, be managed in isolation from the competitive environment. The fact is that, in addition to the characteristics of resources and how they are combined, there are also other unforeseen events such as competition, industry and environment that may influence resources and strategies (Borch et al. 1999). Unlike Porter $(1985$, p. 2) who states that "both industry attractiveness and competitive position can be shaped by a firm" this study takes a view that a small firm can by its resources and competences adapt to its competitive environment (see Pasanen 1999, Smallbone et al. 1999) and this way find an appropriate competitive position in the market. This standpoint can be argued as follows. First, if the industry structure, for example concentrated retail level in the food sector, mainly determined the strategic behaviour and performance of the firms within the food industry, would it be possible to such a large number of smallscale firms to operate in food business and compete among large food companies? Second, can a small firm with a marginal market share have the ability to shape its competitive environment compared with larger firms?

Consequently, it is assumed in this study that firm success is determined more by the internal firm factors than by the structural conditions of an industry. Moreover, the dynamic nature of the relationships between a firm and its environment is of utmost importance. By acquiring appropriate resources and combining them in a creative and different way, a small firm may find a favourable position even in highly competitive markets. This, however, requires the active adaptation of the resources.

Having discussed the concept of strategy and reviewed the two dominant mainstream views within strategy literature, the study moves next to the discussion of competitive strategy. The discussion that follows will lead to more in-depth understanding of the resource-based logic.

\section{Creation of competitive advantage from the resource-based view}

The purpose of Chapter 3 is to outline the resource-based competitive strategies in more detail. The competitive strategy discussion is approached here from the viewpoint of three components: sources of competitive advantage (resources), position of competitive advantage and firm success. The main stress is on the first two components. Both resources and position of competitive advantage are first approached by looking at how they have been defined and classified in strategy literature. In this chapter, the relevant resource classifications are outlined and the potential of resources as sources of competitive advantage are considered. Additionally, a clas- 
Forsman, S. How do small rural food-processing firms compete?

sification scheme of resources to be applied in the present research context is established and argued. In the competitive advantage section, the nature, creation and position of competitive advantage is considered. It is also considered critically how the competitive strategy discussion can be related to the setting of the food industry and small, rural firms. The chapter also includes a brief overview of the performance outcomes of competitive advantage, i.e., success. The chapter concludes with establishing a framework for the study and providing some propositions to be tested in the empirical part of the study.

Competitive strategy can be approached from three components - resources, position of competitive advantage and firm success - and linkages between them (Fig. 3). Following resourcebased logic (Barney and Arikan 2001, see also Day 1990, p. 128-134, Day and Wensley 1988, Hunt and Morgan 1997, Hunt 2000a, p. 136138), these components are expected to be linked with each other in such a way that resources represent the potential sources of competitive advantage and that sustainable competitive advantage will result in firm success. Obviously, the linkages are not that literal. For example, not every resource is a potential source of competitive advantage. To have this potential, a resource

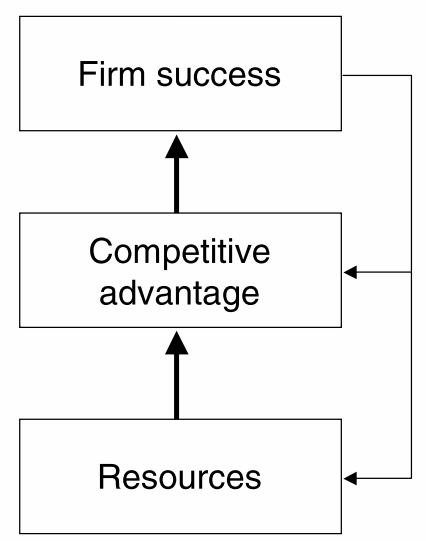

Fig. 3. Components of competitive strategy. or combinations of resources should fulfil specific requirements. Similarly, competitive advantage will not automatically lead to superior performance. Furthermore, it may be difficult to draw the line between resources and competitive advantage. In the following sections, each of these components and the relationships between them is studied and discussed in more detail.

\section{I Resources}

The key concepts of the RBV include such concepts as resources, competences, core competences, capabilities, and dynamic capabilities (Rugman and Verbeke 2002). In the RBV literature, however, resources have been defined and classified in numerous ways, both broadly and in more a detailed way, which may confuse the reader. Still there is no coherent understanding of how the key concepts within the RBV are defined (Foss 1997b, Mäkinen 2000, Rugman and Verbeke 2002). In addition, the definitions within the RBV differ to some extent from the definitions employed in the competence-based view or in other related views.

The basic concept resource itself is often confusing. On the one hand, it can be used in a general sense to refer specific resources, capabilities or competencies, etc. On the other hand, it may refer only to a specific resource such as a piece of equipment or a skill of a particular employee. Classifications have not necessarily value per se, but can provide a useful starting point to approach resources and competencies and theories and views based on them. Yet, in the RBV, according to Barney (1991), it is more important to describe attributes that a firm's valuable resources should have to become sources of sustainable competitive advantage. These attributes will be discussed in more detail later on. First, resources and related concepts are considered to understand the full range of resources a firm may possess. 
Vol. 13 (2004): Supplement 1.

\section{I.I Various definitions and classifications of resources and related concepts}

In economic theory resources are typically limited to categories such as labour, capital, and land. Within strategic management, however, resources can be defined to mean any strength or weakness of a given firm (Wernefelt 1984). Accordingly, strengths are derived from superior resources that give a firm or business an ability to do more or better than its competitors. These resources can be used to exploit opportunities and to ward off threats. Weaknesses, on the contrary, are deficiencies or constraints that restrict the ability of a firm to do better than, or even equal to, competitors (Day 1990, p. 71).

In general, resources can be defined as assets that firms use to develop and implement their strategies (Ray et al. 2004). Resources are often categorised into homogenous categories such as financial capital, physical capital, human capital and organisational capital (Barney 2002, p. 156, cf. Hofel and Schendel 1978, p. 145, Grant 1991, Greene et al. 1997). Financial capital consists of all the monetary resources a firm may need to implement its strategies. Physical capital refers to a firm's plant and equipment, geographical location, access to raw materials or necessary technology. Human capital is an attribute of single individuals referring to their experience, intelligence, insights and relationships. Finally, organisational capability is an attribute of collection of individuals including a firm's culture and reputation; formal and informal planning, and controlling and co-ordinating systems (Barney 2002, p. 156).

Typical approaches in the RBV are a distinction between resources and capabilities/competences (Grant 1991, Amit and Schoemarker 1993) and a distinction between tangible and intangible resources (Hall 1992, 1993), tradable and non-tradable resources (Dierickx and Cool 1989) or firm-specific and firm-addressable resources (Sanchez et al. 1996). Some authors use the terms resources and capabilities interchange- ably. For example, Barney (2002, p. 155) defines resources as "all assets, capabilities, competencies, organizational processes, firm attributes, information, knowledge, and so forth that are controlled by a firm and that enable the firm to conceive of and implement strategies designed to improve its efficiency and effectives". Others (e.g., Grant 1991, Javidan 1998, Rosenbröjer 1998) take the view that resources and capabilities are distinct concepts. Resources can then bee seen as tangible or intangible inputs in a firm's value chain (Javidan 1998). Resources are either owned or controlled by a firm (Amit and Schoemaker 1993) and they can be either firm-specific or firm-addressable. Firm-specific resources are those assets that a firm owns or controls, whereas firm-addressable resources are those assets that may exist in other firms or organisations (Sanchez et al. 1996, p. 7-8, see also Teece et al. 1997). In terms of resources a firm can then be considered as a hybrid organisation where assets (resources) can be derived from heterogeneous sources. Examples of individual resources are financial capital, skills of individual employees, or brand name. Individual resources, in themselves, however, are seldom productive (Grant 1991, 1998, p. 111).

To make resources productive, co-operation and co-ordination of resources are required. A capability can, thus, be defined as a capacity or a set of resources to carry out some activity or task (Grant 1991, 1998, p. 111). Capabilities are embedded in an organisation and its processes, which means that it is not easy to transfer them from one firm to another (Makadok 2001). Hence, capabilities are firm-specific and developed over time based on human capital and the complex interaction of a firm's resources. Capabilities may be developed by combining different type of resources (Amit and Schoemaker 1993) or they can be functionally based such as production, marketing and logistics capabilities (Javidan 1998). Capabilities are then closely interlinked with organisational processes in the value chain (Day 1994). In addition, the dynamic capability view especially stresses that the function of capabilities is to improve the pro- 
Forsman, S. How do small rural food-processing firms compete?

ductivity of the resources a firm possesses or controls. From this view capability can be thought of as a special type of resource, more specifically, as "an organizationally embedded non-transferable firm-specific resource" (Makadok 2001).

In order to create competitive advantage, a firm needs to understand the interaction between resources or, more specifically, how individual resources available to a firm or firm-specific assets work together. Accordingly, the distinction between resources and capabilities means that resources represent the sources of capabilities and capabilities, in turn, are the main sources of competitive advantage (Grant 1991). What is of utmost importance is that the linkage between resources and capabilities should be seen as a dynamic, two-way phenomenon. This means that a combination of individual resources is needed to create a capability and capabilities are needed to create new resources or strengthen existing resources (see Rosenbröjer 1998). For example, let us consider marketing capability. Marketing capability presumably plays a significant role in building a superior firm reputation which is a firm-specific intangible resource. Therefore, the dynamic nature of linkage between resources and capabilities is important to consider.

Organisational capabilities are one type of capability. They are based on organisational routines, the concept used in the evolutionary approach (Nelson and Winter 1982, ref. Grant 1998, p. 125). As Foss et al. (1995, p. 5) state: "Within this evolutionary framework, firms have primarily been conceptualised as possessing path-dependent knowledge-based (bundles of hierarchically arranged) 'routines" ". Organisational routines are analogous to individual skills. They are often based on tacit knowledge and carried out without conscious co-ordination (Grant 1998, p. 125-126).

Some authors make even distinction between the terms capability and competence. For example, Javidan (1998) defines competence as a cross-functional integration and co-ordination of capabilities (Javidan 1998). According to Hamel and Prahalad (1996, p. 219-228, see also Prahalad and Hamel 1990) a competence is a bundle of individual production skills and technologies that makes it possible for a firm to provide a particular benefit to customers. In turn, Teece et al. (1997), use the term competences to mean organisational routines and processes such as quality process. Competencies, according to Javidan (1998), can be better understood in a multi-business context in which there are usually several strategic business units. A particular business unit may have, for example, competence at developing successful, new products. In practise, the terms capabilities and competences (compare e.g., marketing capability and marketing competence) are often used interchangeably. As suggested by Hamel and Prahalad (1992), the distinction between competences and capabilities is simply semantic. In this study these terms are used interchangeably and often in parallel.

Core competence is also often mentioned in the context of resources. This concept was introduced by Prahalad and Hamel (1990). They defined core competencies as "the collective learning in the organization, especially how to co-ordinate diverse production skills and integrate multiple streams of technologies" (p. 82). Core competences relate usually to a firm's fundamental activities (Teece et al. 1997) and they should be in the key position in the corporate strategy decisions (Prahalad and Hamel 1990). An example of core competence is a skill at managing a brand (Hamel and Prahalad 1996, p. 228). According to Barney (2002, p. 157, 414), the discussion of core competences is applicable only in the context of diversification strategies.

As one can see the above definitions, the concepts of resources, capabilities and competences and core competence are far from clear. Some authors make a more specific distinction between different sub-concepts under resources, while some authors seem to prefer a more or less broad categorisation. Yet the concepts are to some extent overlapping. From the point of view of the present research phenomenon it is not so important to classify resources in the way that Javidan 
Vol. 13 (2004): Supplement 1.

(1998) does. For example, the difference between capabilities and competencies is difficult to establish in practise. Actually, they are often seen as synonyms and, because of this, the terms are used interchangeably in this study.

In this work, the definition of resources provided by Barney (2002) is adapted and used as an overall concept. However, the distinction between resources and capabilities (or competences) is also relevant to consider. Resources are then considered as tangible or intangible inputs in a firm's value chain (Javidan 1998) whereas capabilities (competences) are regarded as combinations of resources to carry out some activity or task (Grant 1991). Capabilities are always intangible and firm-specific. The dynamic interaction that has been highlighted by Rosenbröjer (1998, p. 39) is particular significant. That is to say, a small firm should also pay attention to the development of both resources and capabilities. The role of capabilities, such as marketing competence or an ability to build network relationships, is essential when developing new resources such as brand name or firm reputation. When it comes to core competence, the term is not applied here since it mainly relates to multi-business firms with several strategic business units (Javidan 1998), and implementation of corporate diversification strategies (Barney 2002, p. 157). Finally, in spite of the definitions used, more important from the point of view of the present research phenomenon is to consider to what extent and in which conditions certain resources have potential to become sources of competitive advantage.

\section{I.2 Tangible and intangible resources}

Most authors within strategy literature make a distinction between tangible and intangible resources or assets. Resources can be both tangible and intangible, whereas capabilities are always tangible (Foss and Eriksen 1995, p. 46). Examples of tangible resources include physical capital (e.g., machines and buildings); financial capital (Barney and Arikan 2001); a firm's location; distribution coverage, or brand name (Day and Wensley 1988). Examples of intangible resources include organisational culture; knowledge; competencies; networks, and the reputation of the product and firm (Hall 1992, 1993, Hunt and Morgan 1995). Intangible resources such as learning-by-doing and organisational culture tend to be more significant rent-generators since they cannot be purchased as such (Conner 1991).

Hall (1992, 1993) has studied the nature and role of intangible resources and their link to sustainable competitive advantage. He makes a distinction between "doing" capabilities and "having" capabilities. Doing capabilities are always people-dependent and based on competencies. They can be further classified into functional capabilities such as knowledge, skill and experience of employees, and cultural capabilities such as attitudes or an ability to learn. Having capabilities, on the other hand, are most often people-independent assets and they can be divided into positional capabilities and regulatory capabilities. Positional capabilities result from past actions such as data bases and firm reputation. Regulatory capabilities rise from the possession of legal entities such as contracts and patents (Hall 1993).

In small firms both tangible and intangible resources can be assumed to play a significant role as sources of competitive advantage. However, it can be expected that the role of intangible resources would be even more significant. Small food-processing firms compete with larger firms, but they also compete to some extent with other small firms that often may provide similar types of products based on similar type of tangible resources such as quality raw materials or traditional handicraft manufacturing methods. Then intangible resources such as image factors and competences, for example, marketing competence, may become more important resources in developing competitive advantage. Intangible resources are often high-order resources that must be developed through time and therefore they are relatively immobile and cannot be acquired quickly by rivals (Hunt 2000a, 
Forsman, S. How do small rural food-processing firms compete?

Table 2. Typology of tangible and intangible resources with examples in the small-scale firm context (applied from Hooley et al. 1997, p. 3).

\begin{tabular}{lll}
\hline & Tangible resources & Intangible resources \\
\hline Physical resources & Quality raw-material originated from own farm & \\
Financial resources & Sufficient amount of own capital & Creditworthiness for borrowed capital \\
Human resources & People employed by a firm & Motivated personnel \\
Organisational resources & Non-hierarchical organisation structure & Firm culture \\
Technological resources & Modern machines and equipment & Processes adopted to ensure superior quality \\
Reputational resources & Brand name & Superior reputation of a firm \\
Systems resources & Customer register & $\begin{array}{l}\text { Knowledge about how to utilise customer } \\
\text { databases }\end{array}$ \\
\hline
\end{tabular}

p. 142). Table 2 provides an example of the distinction between tangible and intangible resources in the small food-processing firm.

\section{I.3 Resources as potential sources of competitive advantage}

A business can exist without any distinctive resources or competences. This may be the case if the supply is much stronger than the demand (Stoner 1987). However, if looking at a small food-processing firm, it can hardly survive in the market for a long time without any distinctive resources or competences.

Numerous resources exist in a single firm. Actually, at some level, everything in a firm can be seen as a resource (Conner 1991). Every firm has a resource portfolio, that is, a collection of all the resources a firm owns or controls (Ireland et al. 2003). However, resources in themselves have no value. They gain value only when a firm specifies how to use them (Hofel and Schendel 1978) and when they exhibit certain characteristics.

The RBV has a central focus on characteristics that make a firm's products different from those of its competitors. Whether a particular resource or a combination of resources is a potential source of competitive advantage can be assessed through a VRIO-framework that includes the questions of Value, Rarity, Imitability and $O$ rganisation. The point of departure for the framework is firm resource heterogeneity and firm resource immobility. (Barney 2002, p. 159160, see also Barney 1991).

First, only valuable resources have the potential to become sources of competitive advantage. Resources are valuable only if they can exploit opportunities and neutralise threats arising from the environment. The value of resources and capabilities can be assessed by considering whether they reduce a firm's costs or increase its revenues. It is also important to note that a resource may easily lose its value due to the changes within the competitive environment. (Barney 1991, 2002, p. 160-162).

Second, common resources do not have the potential to generate competitive advantage although they could be valuable. Only resources that are rare among a firm's current and potential competitors have this potential. Barney, however, states that it may be possible for a small number of firms in a particular industry to have a certain valuable resource and still have the potential to achieve competitive advantage. Firms with valuable and rare resources and capabilities are often strategic innovators that may gain the first-mover advantages. However, not all valuable resources are rare, but some may be rather common resources. If valuable resources 


\section{Vol. 13 (2004): Supplement 1.}

are not rare but common they do not have the potential to lead to a position of competitive advantage. Nevertheless, they may have an important function in ensuring a firm's survival by creating competitive parity. If a firm does not possess valuable but common resources it is likely to give an opportunity for competitors to achieve competitive advantage while finding itself at a competitive disadvantage. (Barney 1991, 2002, p. 162-164).

Third, in addition to being valuable and rare, resources should also be imperfectly imitable to have the potential to lead a sustained competitive advantage. Imperfect imitability means that competitors who do not possess valuable and rare resources cannot easily acquire them through direct duplication or substitution. Imperfect imitability can be result from the unique historical position of a firm, patents, social complexity or causal ambiguity. Patents may limit direct imitation for a time. Unique historical conditions refer to space- and time-dependent resources that may be based on the first-mover advantages or path dependency. Social complexity, in turn, refers to the situation in which a competitive advantage is based on such socially complex resources such as a firm's reputation and where the link between these socially complex resources and competitive advantage may be easy to identify but, in spite of this, competitors find it difficult to copy these resources (Barney 1991, 2002, p. 163-171). Causal ambiguity refers to the situation in which competitors do not understand the sources of competitive advantage. At the extreme, it may be difficult even for a firm's managers to fully identify the relationships between resources and competitive advantages. Sources of causal ambiguity are tacit knowledge, complexity and specificity. The existence of causal ambiguity can create a significant barrier to imitation (Reed and DeFillippi 1990).

Finally, the VRIO-framework includes the question of organisation. This means that to fully employ the potential that valuable, rare and costly-to-copy resources may provide as sources of competitive advantage, a firm should be organised in a way that supports the exploita- tion of these resources. The question of organisation thus relates to several components. A firm should be organised so that its structure, management control system or formal reporting structure that are not in conflict with firm resources. These components are kinds of complementary resources; they alone can hardly contribute to competitive advantage, but in combination with valuable, rare and imperfectly imitable resources they may be quite effective. (Barney 2002, p. 171-172, 182).

Black and Boal (1994) have criticised that the VRIO framework ignores how different resources are nested with one another and the nature of relationship between them, that is, the dynamic aspect of resource configurations and their implications to the RBV is not adequately addressed. To include the dynamic aspect, Black and Boal have divided resources into two categorisations: contained resources and system resources. A contained resource is "an identified simple network of resources factors that can be monetarily valued". It has definite boundaries and is unlikely to directly lead to a sustainable competitive advantage. A system resource, on the other hand, is a "complex network of firm resource factors". It is socially created and because of the complex nested system it cannot be monetarily valued and is thus more likely to contribute to sustainable competitive advantage. Consequently, strategic relationships between a firm' resources should specifically be examined when assessing whether a particular resource or a combination of resources is a potential source of competitive advantage.

Dierickx and Cool (1989) take also a slightly different view when considering the contribution of resources to competitive advantage. They suggest that the significance of resources in achieving competitive advantage is based on the accumulation of crucial resources through time rather than acquiring them in factor markets. Both tradable and non-tradable resources exist in the markets but, according to Dierickx and Cool, it is always non-tradable resources that contribute to competitive advantage. Tradable resources can be obtained quite easily in the 
Forsman, S. How do small rural food-processing firms compete?

markets whereas non-tradable resources are built and maintained through time. Non-tradable resources consist of asset "stocks" that are founded on "flows" over a period of time. For example, a firm may acquire "generic labour" from the market, but not people with firm-specific skills. Instead, firm-specific skills, knowledge, and values are accumulated over a period of time through job learning and training. The same is also true of a reputation for quality. In addition to non-tradeability, strategic stocks should be non-imitable and non-substitutable.

Amit and Schoemaker (1993) also stress resources that are non-tradable as sources of competitive advantage and that firm-specific assets are often history dependent. They state that some of a firm's resources, in particular capabilities, may be difficult to trade. Based on that, they use the concept "strategic assets" that refers to those resources and capabilities that are difficult to trade and imitate and that are scarce, appropriate and firm-specific. A firm should thus identify, ex ante, a set of strategic assets as potential sources of competitive advantage. Examples of possible strategic assets include firm reputation, superior access to distribution channels, a favourable cost structure and technological capability.

Quite similarly, Hunt and Morgan (1995) consider to what extent resources can be neutralised effectively and quickly by rivals. Those resources that cannot be neutralised easily include intangible, high-order resources, complex resources, interconnected resources, tacit resources, resources that require "critical mass" to be deployed or resources that take time to acquire, such as firm reputation. What is also important, according to Hunt and Morgan, is that a firm's comparative advantage in resources is influenced by market environmental factors. Changes in consumer preferences or competitive actions by rivals may turn a resource into a nonresource or contra-resource. Then, for example, a direct sale strategy that is common among onfarm meat processors may turn into a non-resource if other meat processors located nearby also establish direct sale businesses or if consumers are more and more willing to purchase meat products in supermarkets instead of farmshops.

From the competence-based view, a firm's relative abilities to target and co-ordinate its resources and competences are more important than just differences in resources. In the case of similar available resources, some firms may be better and more effective at creating distinctive competences based on their resource endowments. Therefore, it is not sufficient that resources available for a firm are unique, but a firm needs to co-ordinate and target these resources. The role of learning as a critical strategic factor is thus emphasised in the competence-based view. Accordingly, a firm's ability to learn and acquire new capabilities may be a more important determinant of its competitive success in dynamic markets than a firm's current endowment of unique resources. (Sanchez and Heene 1997a, p. 10-12).

\section{I.4 Distinction between strategic resources and basic resources}

In the previous sections various examples of how resources and related concepts are defined and classified were provided. Based on the review, we provide a summary of the central classifications (Table 3).

Many of the classifications provided by Table 3 make sense in the small business context, too. However, to gain a closer understanding of the contribution of firm resources to competitive advantage in small-scale food production, it might be fruitful to approach firm resources by applying the distinction between basic capabilities and critical resources provided by Rangone (1999). Based on empirical case study of SMEs in different industries Rangone (1999) proposed a model where a SME's sustainable competitive advantage is based on three basic capabilities: innovation, production and market management. The basic capabilities, in turn, are founded on a firm's critical resources. Critical resources include financial, human resources and 
Vol. 13 (2004): Supplement 1.

Table 3. Various classifications and terminology of resources.

\begin{tabular}{|c|c|c|}
\hline Author(s) & Main category & Dimensions and/or definition \\
\hline \multirow[t]{3}{*}{ Amit \& Schoemaker (1993) } & Resources & Stocks of available factors owned or controlled by a firm \\
\hline & Capabilities & A firm's capacity to deploy resources \\
\hline & Strategic assets & $\begin{array}{l}\text { Resources and capabilities that are difficult to trade and imitate, } \\
\text { scarce, appropriable and specialised }\end{array}$ \\
\hline Barney $(1991,2002)$ & Resources & $\begin{array}{l}\text { Physical capital resources, financial capital resources, human } \\
\text { capital resources, organisational capital resources }\end{array}$ \\
\hline \multirow[t]{2}{*}{ Black \& Boal (1994) } & Contained resources & $\begin{array}{l}\text { An identified simple network of resources factors that can be } \\
\text { monetarily valued }\end{array}$ \\
\hline & System resources & A complex network of firm resource factors \\
\hline \multirow[t]{2}{*}{ Day \& Wensley (1988) } & Superior skills & Distinctive capabilities of employees \\
\hline & Superior resources & $\begin{array}{l}\text { More tangible sources of advantage that enable a firm to carry on } \\
\text { its capabilities }\end{array}$ \\
\hline \multirow[t]{2}{*}{ Dierickx \& Cool (1989) } & $\begin{array}{l}\text { Asset flows (tradable } \\
\text { resources) }\end{array}$ & A resource that can be acquired or adjusted immediately \\
\hline & $\begin{array}{l}\text { Asset stocks (non- } \\
\text { tradable resources) }\end{array}$ & A resource which is built up over time from flows \\
\hline \multirow[t]{2}{*}{ Grant $(1991,1998)$} & Resources & $\begin{array}{l}\text { Inputs in the production process; tangible resources, intangible } \\
\text { resources, human resources }\end{array}$ \\
\hline & Capabilities & $\begin{array}{l}\text { The capacity for a combination of resources to carry out some } \\
\text { task or activity }\end{array}$ \\
\hline \multirow[t]{2}{*}{ Greene et al. (1997) } & $\begin{array}{l}\text { Resource types for } \\
\text { new ventures }\end{array}$ & Human, social, physical, organisational, financial \\
\hline & $\begin{array}{l}\text { Personal resources, } \\
\text { company resources }\end{array}$ & \\
\hline $\begin{array}{l}\text { Hofer \& Schendel } \\
(1978, \text { p. 145), }\end{array}$ & Resources & $\begin{array}{l}\text { Financial resources, physical resources, human resources, } \\
\text { organisational resources, technological resources }\end{array}$ \\
\hline \multirow[t]{2}{*}{$\begin{array}{l}\text { Hunt \& Morgan (1997), } \\
\text { Hunt (2000) }\end{array}$} & Resources & $\begin{array}{l}\text { Financial, physical, legal, human, organisational, } \\
\text { informational, relational }\end{array}$ \\
\hline & $\begin{array}{l}\text { Distinct, high-order } \\
\text { resources (competencies) }\end{array}$ & A distinct package of basic resources \\
\hline \multirow[t]{4}{*}{ Javidan (1998) } & Resources & Inputs into a firm's value chain \\
\hline & Capabilities & $\begin{array}{l}\text { A series of business processes and routines that manage the } \\
\text { interaction among a firm's resources }\end{array}$ \\
\hline & Competencies & $\begin{array}{l}\text { A cross-functional integration and co-ordination of } \\
\text { capabilities }\end{array}$ \\
\hline & Core competencies & Skills and knowledge shared across the business units \\
\hline \multirow[t]{2}{*}{ Penrose $(1959$, p. 25$)$} & Resources & $\begin{array}{l}\text { Physical resources, human resources } \\
\text { Human resources }\end{array}$ \\
\hline & Services & $\begin{array}{l}\text { Inputs in the production process, a function of the way in which } \\
\text { resources are used }\end{array}$ \\
\hline \multirow[t]{3}{*}{ Rangone (1999) } & Critical resources & $\begin{array}{l}\text { Financial, human resources and organisational resources, skills, } \\
\text { know-how and competences, brand and reputation }\end{array}$ \\
\hline & Basic capabilities & Innovation management \\
\hline & & $\begin{array}{l}\text { Production management } \\
\text { Market management }\end{array}$ \\
\hline Sanchez et al. (1996) & Assets & $\begin{array}{l}\text { Tangible and intangible assets, firm-specific and firm-addressable } \\
\text { assets, resources, competence (competence leveraging, } \\
\text { competence building) }\end{array}$ \\
\hline
\end{tabular}


Forsman, S. How do small rural food-processing firms compete?

organisational resources, skills, know-how and competencies, brand and reputation. To be critical, a resource should meet the five key dimensions: competitive superiority, imitability, duration, appropriality, and substitutability. Moreover, only critical resources that have an effect on key performances of a firm are relevant to consider.

In this study, Rangone's distinction is elaborated upon by taking his distinction of basic capabilities and critical resources as a starting point. In the case of small food-processing firms, we can assume that two types of resources can also be identified: strategic resources and basic resources. Instead of using the term "critical resources" as adopted by Rangone (1999) we prefer to use the term "strategic resources". The preliminary thoughts of this distinction were first introduced in the author's conference paper (Forsman 2000). In the following, the logic behind this distinction is further elaborated.

Small, rural food-processing firms aim to distinguish themselves from larger firms in terms of their products, services and/or activities. Differentiation from competitors is not possible unless a firm has some special resources or combinations of resources among its vast number of resource endowments. These special resources are often the key superior factors or means of competition and based on these a firm may have an opportunity to achieve a competitive advantage in its market. These resources can be regarded as strategic in a sense that they constitute the primary source of favourable or competitively-advantaged position in the market; that is to say, they represent the core idea around which the business is built in order for a firm to be positively different than its competitors. Without these resources a firm may find it difficult to establish a competitive advantage or let alone competitive parity. In terms of the VRIO dimensions (Barney 2002) to be strategic resources should at least be valuable in order to lead to competitive parity and, secondly, rare and costly to imitate to become sources of competitive advantage. Examples of potential strategic competitive resources in the small food-processing business context might be quality of raw material, a unique product recipe, mastering of a particular production method or farm-connection.

Strategic resources can be assumed to be mainly firm-specific because in order to be valuable for a firm they cannot be easily imitated by competitors (see Rangone 1999). It may be the case that an individual resource might be relatively easy to duplicate but strategic resources are assumed to be mainly collections of resources that, in order to become sources of competitive advantage, should have some causally ambiguous characteristics due to tacitness, complexity or specificity (Reed and DeFillippi 1990). Above all, strategic resources can be seen to be in a key position in competitive strategy choices, more specifically, in determining how a small foodprocessing firm can compete in a chosen market arena. Yet, strategic resources, no matter how distinctive or valuable they are, do not secure a firm's competitive position nor ensure success. Strategic resources must be supported with appropriate basic resources.

Basic resources, on the other hand, can be seen as resources that as such do not constitute an adequate basis for competitive advantage, but rather their function is to facilitate and support a firm in converting its strategic resources into a competitively advantaged position and, therefore, firm success. Basic resources are then seen as roughly analogous to capabilities in the dynamic capability view (Makadok 2001). Accordingly, their function is mainly to enhance the productivity of strategic resources. Basic resources are not necessarily rare but, rather, resources that Barney (1991) defines as 'common' resources or resources. Said differently, they are resources that are valuable although in isolation they do not contribute to competitive advantage, but without them a firm may find itself at a competitive disadvantage. Similarly, they can be thought of as complementary resources (Barney 2002) such as a firm's structure the function of which is can be thought of as supporting a firm to convert its strategic resources to competitive advantage. Examples of basic resources in the case of small food-processing firms may be fi- 
Vol. 13 (2004): Supplement 1.

nancial capability; competence in product development, marketing or distribution, or ability to build network relationships.

Basic capabilities are mainly intangible by their very nature. Dynamic capabilities or capabilities in general are often regarded as firm-specific (Amit and Schoemaker 1993, Makadok 2001). However, in the case of small foodprocessing firms, one can assume that resources need not be controlled or owned by a firm, but at least to some extent, they can also be firmaddressable (Sanchez et al. 1996, p. 7) and tradable (see Dierickx and Cool 1989) and thus available by networking with other firms or outsourcing. For example, a small firm producing innovative food products may lack marketing competence due to the size of the firm. Yet, it might have an opportunity to become a part of a network and utilise the network's marketing competence. Alternatively, a small rural firm with limited monetary resources may obtain financial support for investments in machinery or a public regional development subsidy for new product development or technology improvements. In order to get subsidies, a firm should, however, have marketing potential for its products. Table 4 summarises the connection between the distinction of resources and other relevant categorisations.

However, a distinction between these two types of resource categories may be difficult to establish in practice and is not necessarily as categorical as presented above and in Table 4 because a competitive advantage hardly can be based on any single resource. Rather it is based on a unique combination of resources including both strategic and basic resources. Hence, what is of utmost importance is that, following Rosenbröjer (1998), there is an interrelation between strategic resources and basic capabilities. Both of these resource types are needed to achieve a competitive advantage or at least competitive parity in the market. At best, interrelation between these two types of resources may enable a firm to generate innovative combinations of resources that may provide a basis for a sustained competitive advantage. In addition, it is important to note that we do not assume that this distinction is exhaustive; that is, these two resource categories do not necessarily cover the whole range of resources a firm may own or control.

The major difference between this categorisation scheme and those previously suggested is that in the present categorisation the distinction

Table 4. Attributes characterising strategic resources and basic resources and their connections to the other relevant categorisations.

\begin{tabular}{lll}
\hline Earlier reference & Strategic resources & Basic resources \\
\hline Barney (1991, 2002) & $\begin{array}{l}\text { Valuable, rare and costly to } \\
\text { imitate resources } \\
\text { Critical resources in terms of } \\
\text { competitive superiority, imitability, } \\
\text { sustainability, appropriability, } \\
\text { substitutability) }\end{array}$ & $\begin{array}{l}\text { Common resources, i.e., valuable but not rare, and } \\
\text { complementary resources and capabilities } \\
\text { Innovation capability, production capability, market } \\
\text { management capability }\end{array}$ \\
$\begin{array}{l}\text { Teece et al. (1997), } \\
\text { Makadok (2001) }\end{array}$ & $\begin{array}{l}\text { Other resources } \\
\text { Hall (1992, 1993) }\end{array}$ & $\begin{array}{l}\text { Tangible, intangible } \\
\text { Sanchez et al. (1996) }\end{array}$ \\
$\begin{array}{l}\text { Firm-specific } \\
\text { Dierickx \& Cool (1989) }\end{array}$ & Mainly non-tradable & $\begin{array}{l}\text { Intangible, mainly doing-type of capabilities } \\
\text { Firm-specific or firm-addressable }\end{array}$ \\
\hline
\end{tabular}


Forsman, S. How do small rural food-processing firms compete?

between two types of resources is based on their different contributions to competitive advantage and, further, firm success. Previous categorisations have mainly been based on classifications of resources into homogenous groups such as human resources, physical resources, etc. (e.g., Hofer and Schendel 1978, Barney 1991, Greene et al. 1997 et al.) or hierarchical classification such as resources and capabilities (e.g., Grant 1991) and resources and high-order resources (Hunt and Morgan 1997). The categorisation presented here has some affinities with Rangone's (1999) model. In his resource tree model innovation, production and market management capability could be considered as critical basic resources in the model presented here whereas critical resources in his model have some coherence with strategic competitive resources presented here. Still, Rangone's model is based largely on a resources-capabilities distinction and not on the reciprocal interrelation between two types of resources as in the present model.

The distinction presented here might be workable in the large-scale context as well. Yet, the logic behind this classification can be expected to be the most relevant in small firms. It can be assumed that differences, particularly in basic capabilities, are greater in small firms than in larger firms that have expertise in several fields of business. Moreover, it can be assumed that the resources that are critical for small foodprocessing firms are often basic types of resources. In larger firms the basic resources are often under control in which case the most critical resources for larger firms are perhaps more sophisticated resources.

\subsection{Competitive advantage}

In this section, the nature, creation and position of competitive advantage is considered. From the standpoint of this study, a relevant question is how a small food-processing firm could achieve a sustainable competitive advantage in its mar- ketplace. First, the concept of competitive advantage is defined and discussed. After that there will be an overview of strategies to create competitive advantages. The strategy review and discussion takes place in two stages. On the one hand, the focus is on a generic strategy approach by considering alternative strategy typologies from Porter's conceptualisation to a mixed-strategy approach. On the other hand, the focus is on the unique nature of strategies as stressed in the RBV. Finally, the competitive strategy discussion is considered critically in relation to the empirical setting of the food industry and small, rural firms.

\subsection{The concept of competitive strategy}

Creation of competitive advantage is the main goal of competitive strategies. Hence, to compete very successfully, a firm's strategies should have competitive advantage as a primary objective (Barney 2002, p. 10). Competitive advantage ${ }^{10}$ refers to some kind of superiority over rivals in the particular market. A firm has achieved a competitive advantage when its actions in a particular market create economic value and when few rivals follow similar actions (Barney 2002 , p. 9). This economic value is usually associated with a firm's ability to earn a persistently higher rate of profit or have the potential

${ }^{10}$ Competitive advantage is often associated with competitiveness. Strictly speaking they are not synonymous. The difference between these concepts is difficult to discern since both of them have no agreed-upon definition. Competitiveness such as competitive advantage is concerned with performance vis-à-vis competitors and is, thus, quite a relative concept (Pitts and Lagnevik 1998). Competitiveness, however, can be understood as a broader concept than competitive advantage. In addition to competitive advantage(s), a firm may have competitive disadvantage(s) and/ or competitive parity positions (see Barney 2002, p. 9-10, Hunt and Morgan 1997). Therefore, total competitiveness for a firm can be defined as a sum of competitive advantages, competitive disadvantages and competitive parities (Rope 2002, p. 35). 
Vol. 13 (2004): Supplement 1.

to earn higher rate of profit (Grant 1990, p. 174). Then the primary performance goal for firms is profitability and if a firm has an ability to outperform its competitors in terms of profitability, it has achieved a position of competitive advantage. The rationale here is that competitive advantage is correlated with higher performance, and if an advantage has been achieved it will automatically lead to high performance. Competitive advantage can then be seen as the objective of competitive strategy (Reed and DeFillippi 1990).

The essence of competitive strategy is thus not establishing a competitive advantage but also maintaining it. Competitive advantages are either temporary or persistent (Barney and Arikan 2001). Competitive advantage becomes persistent when it is sustainable, i.e., creates profit potential for a firm (Barney 1991). Sustainability means "keeping it going over time" (Reed and DeFillippi 1990). Thus, according to the RVB, a firm can achieve a sustainable competitive advantage when "it is implementing valuable product market strategies not currently being implemented by several other competing firms and where efforts to imitate those strategies have ceased" (Barney and Arikan 2001). How longterm a particular position in the market is depends on the sustainability of resources (Hunt 2000a, p. 140) or, said differently, on the maintenance of the barriers to imitation (Reed and DeFillippi 1990). This means that a firm may have an opportunity to obtain a sustainable competitive advantage when competitors lack an ability to imitate these resources (Amit and Schoemaker 1993). This actually indicates that, although the RBV emphasises internal firm factors as sources of competitive advantage, an external focus, specifically a focus on competitors, is also required in order for a firm to recognise and/or establish its unique resources (Hoffman 2000). However, in some cases it is not necessarily a question of rivals' inability to duplicate, but a lack of motivation on their part to imitate those valuable resources and capabilities (Amit and Schoemaker 1993). For example, in some situations larger firms may have an ability to imitate successful resource-deployment strategies of small firms, but they are not necessarily interested in competitive advantages related to products and services that are sold only in small volumes.

Consequently, the imitability of the competitive advantage depends on the imitability of resources and capabilities on which the competitive advantage is based (see Section 3.1.3). For example, if the product differentiation strategy is based on product features, it may be relative easy in many cases to imitate the resources and capabilities that are needed to make product features different from competitors. Product customisation, instead, might be more difficult to imitate if it a firm has developed close relationships with the customers. A source of competitive advantage may then be history-dependent. Location, reputation, service and distribution channels may, instead, provide a costly-to-copy basis for a differentiation strategy. Reputation, for example, is often very difficult to duplicate since it is developed over time based on trust and socially complex relationships between a firm and its customers (Barney 2002, p. 281-286). In general, it seems that intangible resources provide a more sustainable basis for competitive strategies that are not easy to imitate (Connor 1991, Hoffmann 2000).

It is also important to note that a firm's strategies may also lead to a competitive parity position or competitive disadvantage. In the former case, a firm succeeds in creating economic value through its actions but there are also other firms that follow similar strategies in a particular market. In the latter case, a firm fails to create economic value (Barney 2002, p. 9-10).

\subsubsection{Strategies to create competitive advantages}

In this section, the focus will be on the competitive strategy discussion, that is, the creation of competitive advantages. The focus of the competitive strategy discussion has changed over 
Forsman, S. How do small rural food-processing firms compete?

time. The review and discussion considers three approaches: "generic" strategy approach from Porter, a mixed-strategy approach and a "unique" resource-based strategy.

\section{Generic strategy approach}

In the 1970s the focus in the strategy discussion was mainly on the outcomes of the strategy. In the 1980 s attention was shifted to the positional advantages that firms have created in order to achieve lower costs or superior value in the market. At that time, strategic typologies, generic strategies, and dimensions of competitive advantage became major objects of interest (Day 1992). This classificatory approach has attempted to classify strategies on the basis of either $e x$ ante conceptual arguments or ex post empirically derived groupings (Morgan and Strong 2003). Well-known generic strategy typologies that originated at that time include Porter's (1980) typology of three generic strategies, Miles and Snow's (1978) typologies of different organisational forms of archetypes (defenders, prospectors, analysers, and reactors) and Walker and Ruekert's (1987) hybrid typology including prospectors, differentiated defenders and low cost defenders (see Tikkanen 1994 for a summary of these typologies).

Perhaps the most well-known strategy typology is Porter's (1985) ex ante description of three generic strategies: cost leadership, differentiation and focus. According to this typology, the primary types of competitive advantage are cost advantage and differentiation advantage (Porter 1980, 1985, Mathur 1992). In a cost-leadership strategy, a firm seeks to become the low-cost producer. A firm's overall cost position is influenced by the cost behaviour of its value activities ${ }^{11}$ which, in turn, depend on cost drivers, that is, structural factors affecting costs. Examples of cost drivers include economies of scale, learn-

11 According to Porter (1985, p. 33), understanding competitive advantage requires viewing a firm as a collection of several discrete activities, each of which can contribute a competitive advantage. ing effects and the pattern of capacity utilisation. In a differentiation strategy, a firm seeks to create uniqueness along the particular dimensions valued by customers. Uniqueness drives include the product itself, services provided, delivery system, marketing approach and many others. In order to create a competitive advantage position, a firm must convince the customers to pay a higher price - a price premium that exceeds the additional cost of the differentiation (Porter 1985, Grant 1998, p. 189). The third strategy is focus. It is based on a narrow competitive scope within an industry. The focus strategy has two variants: focused cost leadership and focused differentiation. In the former strategy, a firm seeks a cost advantage in a narrow segment or selected segments whereas in the latter strategy a firm seeks uniqueness in a narrow segment or selected segments (Porter 1985).

Cost-leadership and differentiation determine how to compete whereas focus dimension determines where to compete or how broadly to compete in terms of market segments (Faulkner and Bowman 1992). According to Porter (1985), in order to achieve a position of competitive advantage a firm must make a choice between these generic strategies. Otherwise it will be "stuck in the middle" without any competitive strategy. Only under three special conditions can both cost leadership and differentiation be combined: a firm's competitors are stuck in the middle; a firm's cost position is strongly influenced by market share or interrelationships, or a firm's innovation is significant.

Soon after launching, Porter's (1985) typology became a dominant paradigm in business literature (Hill 1988). In spite of its popularity, Porter's contribution has received a lot of criticism. One of the major critiques against the generic strategy typology is the argument that cost leadership and differentiation are not necessarily alternative, mutually exclusive strategies (Hill 1988, Murray 1988, Faulkner and Bowman 1992, Miller and Dess 1993). Porter's conceptualisation has also been regarded as oversimplified (Hill 1988), as insufficient to meaningfully describe the range of competitive strategies (Camp- 
Vol. 13 (2004): Supplement 1.

bell-Hunt 2000), as collectively incomplete because it excluded stuck-in-the-middle strategies (Chrisman et al. 1988) and as lacking generalisability (Miller and Dess 1993).

Contrary to Porter's model of viewing generic strategies as independent options, a growing body of literature suggests that a firm can establish competitive advantage also by combining both differentiation and cost leadership strategies (Hill 1988, Murray 1988, Faulkner and Bowman 1992, Miller 1992, Miller and Dess 1993, Dess et al. 1999). Hill (1988) has argued that there are many situations in which a firm can simultaneously pursue both low-cost and differentiation strategies if there is no low-cost position in an industry. This can be a case particularly in mature industries if the minimum-cost structures between the firms are similar. Hill takes a view that investment in differentiation has two effects on demand. First, differentiating a product can create customer loyalty thus decreasing the price elasticity of demand for the product. Second, it can broaden the appeal of a product, which may enable a firm to increase its market share at a given price. It is clear that differentiation increases unit costs but in the long run, however, unit costs may decline as the increasing volumes are sold due to the economies of scale and scope. Thus differentiation may allow a firm to establish a low-cost position. The extent to which differentiation impacts on demand depends on three aspects: a firm's ability to differentiate its products, the competitive nature of the market environment and consumers' commitment to the products of competitive firms.

Miller (1992) argues that very specialised strategies can be imitated more easily by competitors than mixed strategies if barriers to entry are low and economies of scale are minimal. Mixed strategies, instead, are based on the deployment of many resources and competences simultaneously thus providing more possibilities for creative and complex strategy combinations that are not necessarily that easy for rivals to copy. Firms that concentrate on pure strategies are more vulnerable to changes in the market environment and may have less flexibility and adaptability to adjust to changing market conditions. Especially in mature industries where differentiation based on innovative products or economical processes becomes difficult, a sustainable competitive advantage may be difficult to achieve by focusing on a single strength. Moreover, customers often consider many aspects of the product simultaneously, not only price or quality, which suggests that too narrow a view of strategy may cause weaknesses in product offerings from the customers' point of view.

Some authors (e.g., Faulkner and Bowman 1992, Miller and Dess 1993, Chrisnan et al. 1998, Parnell 2000) have reconceptualised Porter's model. In these models the number of generic strategies is larger compared to Porter's model and, in addition, mixed strategies have also been included. Miller and Dess (1993), for example, provided seven strategy types: 1) high differentiation + low cost + broad focus; 2 ) high differentiation + low cost + narrow focus; 3 ) high differentiation + broad focus; 4) high differentiation + narrow focus; 5) low cost + broad focus; 6) low cost + narrow focus, and 7) Stuck-in-themiddle. The first two strategy types represent the hybrid combinations of strategic advantages. The strategy types from 3 to 6 correspond to Porter's generic strategies and the last one is the stuckin-the-middle type of strategy not included in Porter's model. Miller and Dess also provided empirical evidence on these seven strategy types. They found that combination strategies are not only feasible but also profitable. The high differentiation + low cost + broad-focus strategy was the most profitable strategy type. They also found that not all businesses with recommended strategies (1-6) had better performance than the average stuck-in-the-middle business.

Parnell (2000) also takes a combination strategy approach to business strategies. He revised the business strategy framework by identifying three "first-level" and three "second-level" strategies based on six forms of competitive advantage found in the previous theoretical research. First-level strategies profile a business's general approach towards strategy. Strategies at this level include first-mover, second-mover and seg- 
Forsman, S. How do small rural food-processing firms compete?

ment control. Second-level strategies, on the other hand, refer to specific competitive means. Strategies at this level include product/service breadth, perceived uniqueness and production and distribution efficiency. A business may employ any combination of these strategies but based on empirical results some combinations turned out to be more effective than others.

Faulkner and Bowman (1992), on the other hand, have suggested that there are nine strategic options available for a firm to compete in the market. These options are based on two dimensions: perceived value (high, average or low) and price (high, average or low). Faulkner and Bowman question, among others, whether differentiation is associated only with competing in high-priced segments. Based on their critiques they have suggested an alternative generic strategy matrix with nine strategy options. The best strategy option is the combination of high-perceived value and low-perceived price. This strategy should lead to high market share. The combination of high value and high price refers to the premium-priced differentiator offering products to a small segment. This strategy corresponds with Porter's differentiation strategy. The combination of average value and average price refers to the average-priced differentiator offering a better product at only an average price. The combination of average value and low price represents a price competitor. The rest of the strategy options are "losers" in the sense that they do not have competitive advantage.

Differentiation is usually associated with high-price strategy. However, Faulkner and Bowman (1992) argue that differentiators can gain competitive advantage in addition to premium pricing through increasing market share at average or lower prices. Yet, in the case of small firms it is more likely that through differentiation the firms pursue the ability to follow high-price strategy. In practise, however, it is not necessarily easy to follow a high-price strategy. For example, a study by Forsman (1999) revealed that several differentiation/price-strategy options can be identified among small-scale food-processing firms.
Alongside the shift from the single-strategy approach towards the mixed-strategy view, there has been an increased interest towards the resource-based perspective of competitive strategy. The RBV underlines the uniqueness of competitive strategies.

\section{Unique strategy approach}

The significance of resources as a determinant of competitive advantage has already been highlighted by Hofer and Schendel (1978, p. 251). They defined competitive advantage as "the unique position an organisation develops vis-àvis competitors through its patterns of resource deployments". Along with the emergence of the RBV, resources became the unit of analysis in the creation of competitive advantage. The RBV is concerned with which types of resources can become potential sources of competitive advantage and under which conditions. The resourcebased competitive advantage results from valuecreating strategy; a firm can achieve a competitive advantage when "it is implementing valuable product market strategies not currently being implemented by several other competing firms" (Barney and Arikan 2001, p. 176). In addition, by considering resources in terms of their rent generating ability, a firm will have a competitive advantage if it generates higher returns than were expected by owners or stockholders (Barney 2001).

The emergence of the RBV has shifted the focus of the competitive strategy from the outcomes and positioning of the advantage into the sources of competitive advantage, that is, resources. The swing to the sources of advantage resulted from the fact that positional and performance superiority was recognised to be derived from relative superiority in resources and skills (Day 1992). According to the RBV, differences in firm success are assumed to be based on the differences in exploiting resources. The fundamental assumptions underlying resourcebased logic are resource heterogeneity and resource immobility. Resource heterogeneity means that competing firms may possess different collections of resources and that these are 
Vol. 13 (2004): Supplement 1.

scarce and non-substitutable. Resource immobility means that these resource differences may continue over time, or that the supply of some resources is inelastic (Barney 1991, Barney and Arikan 2001).

From the RBV, competitive strategy can, then, be defined as identifying valuable firm resources and translating them into a position of competitive advantage. According to Barney and Arikan (2001), the core of the valuable resources is in their ability to lower a firm's costs and/ or increase a firm's revenues in relation to competitors ${ }^{12}$ compared to if these resources would not have been exploited. Moreover, the value of resources can be assessed in terms of whether or not they enable firms to follow strategies that are appropriate to the particular market in which a firm competes. A link from the RBV to the combination strategy debate is that all businesses in a way employ combination strategies to varying degrees (Parnell 2000). The discussion, however, has evolved from combining strategies to combining resources.

The resource-based view has also influenced the marketing discipline. From the marketing perspective (e.g., Day and Wensley 1988, Day 1990) competitive advantage can be defined as positional and performance superiority that results from a firm's relative superiority in resources. To obtain a full picture of competitive advantage, Day and Wesley (1988) suggest that it should be divided into its competitive parts: sources of advantage, positions of advantage and performance outcomes. This logic is very similar to the RBV applied within strategic management.

The RBV regards strategies as unique to each firm and thus it is impossible to provide generalisations about them (Conner 1991). Hence,

\footnotetext{
${ }^{12}$ It is noteworthy that this definition also takes into account the existence of potential competitors and not only current ones. Including potential competitors in a firm's competition refers to the characteristics of contestable markets (Baumol 1982, Baumol et al. 1982, see also Barney 1991).
}

rather than providing any generic strategy typology, researchers have focused on suggesting which resources will lead to a persistent competitive advantage and under which circumstances. Moreover, the central assumptions of the RVB have been tested in numerous scientific articles (see Barney and Arikan 2000 for a list of articles testing the resource-based logic).

For Hunt and Morgan (1997, also Hunt 2000a, p. 137-140) competitive advantage results from a comparative advantage in resources. They have introduced a competitive position matrix with nine cells, that is, the competitive position shows nine possible competitive positions that a firm may attain. The market position for a firm is determined by the combination of a firm's relative resource-produced value (superior, parity or lower in relation to competitors) for some segment and relative resource costs (higher, parity or lower in relation to competitors) for producing such value. The most preferable position is naturally a superior relative resourceproduced value with relative resource costs. In addition, a positive competitive advantage position may result from a market offering of parity value with lower resource costs or a superior market offering with parity costs. Comparative disadvantage in resources, on the contrary, leads to a market position of competitive disadvantage (three sells). Moreover, there are also one parity position and two indeterminate positions in the matrix.

\subsubsection{Competitive advantage, food industry, small firms and rural connection}

As reviewed in the previous section, the competitive strategy discussion has mainly advanced on two levels. First, there has been a debate between Porter's typology and the mixed-strategy approach, and it seems that combined strategies are gaining more and more favour. At the same time, the focus has shifted from the generic strategy approach towards unique strategies based on 
Forsman, S. How do small rural food-processing firms compete?

a firm's idiosyncratic resources and capabilities. In this section we will consider how these developments and overall competitive strategy discussion can be related to the empirical setting of the food industry, small firms and firms' rural location. The main emphasis will be on the first two dimensions.

First, if we consider the juxtaposition between the differentiation and cost leadership strategies introduced by Porter $(1980,1985)$, a common view seems to be that because of the limited ability of small-scale firms to pursue a low-cost strategy, differentiation strategy is regarded as a more secure basis for competitive advantage (Pelham and Wilson 1996, Grant 1998, p. 230, Borch et al. 1999). From an entrepreneurship perspective, differentiation gains in importance since entrepreneurial type activities (e.g., renewal) are seen as closer to differentiation strategies than cost leadership strategies (Dess et al. 1999).

Differentiation is often associated narrowly with product differentiation based on physical product characteristics. In addition to actual differences, product differentiation can be based on perceptual differences (Dickson and Ginter 1987). Hence, to understand the unlimited opportunities for differentiation it is necessary to extend differentiation beyond the product characteristics. Actually, a firm can base its differentiation on every possible interaction between a firm and its customers (Grant 1998, p. 218). Such is the case with resources, differentiation can also be tangible or intangible (p. 219). As a matter of fact, it may be easier for many smallscale producers in local or regional markets to base their differentiation on factors other than physical product characteristics since they may be relatively easy to duplicate. For example, reputation, customisation, service and new types of distribution channels may provide more sustainable bases for differentiation (Barney 2002, p. 282). Associated services, in particular, may provide innovative bases for differentiation in smaller firms since due to the small firm size and often flexible organisation structures they might more easily adjust to changing customer expectations than their larger counterparts. This might provide an important source of differentiation especially in business-to-business marketing. For example, a local food-processing firm may be able to offer customised supplementary deliveries for a local restaurant or food service unit quicker than conventional wholesalers. One may even suggest that the emergence of small business "culture" has generated new types of combinations of resources and competences.

Differentiation opportunities should be analysed both from the supply and demand side. From the supply side the focus is on resources and a firm's capabilities (Grant 1998, p. 218). In small food-processing firms, resources largely determine what type of products to produce. Particularly in the firms operating in connection with a farm the resources for differentiation come most often from agricultural production. The supply side analysis, however, is not enough. Since a fundamental issue in differentiation is whether differentiation creates value for the customer, demand-side consideration is also needed. This requires that a firm identifies potential customers and their needs and preferences (Grant 1998 , p. 218). It is customers that ultimately determine how differentiated a firm's product or service is (Boulding 1994). A particular product may have a competitive advantage in some segments while being at a disadvantage in others (Coyne 1986).

Although the RBV emphasises a value-creating perspective of competitive strategy (Barney 1991, Barney and Arikan 2001), the customer-value perspective is not clearly defined in the RBV (e.g., Slater 1997). The value-creation view has emerged more clearly in marketing literature (e.g., Day 1990, Slater 1997, Slater et al. 1997, Hoffmann 2000, Slater and Narver 2000, Woodruff 1997) than in strategic management literature to such an extent that there has been discussion about customer value-based theory (see Slater 1997). Instead of creation of competitive advantage Slater et al. (1997) even emphasise that the most important function of competitive strategy is to create superior customer value. This customer value creation is then a pre- 
Vol. 13 (2004): Supplement 1.

requisite for competitive advantage (Slater and Narver 2000).

Second, in spite of the differentiation perspective, one may suggest that controlling costs is an increasingly important aspect of successful strategies in the context of small firms (Borch and Forsman 2001, cf. Dess et al. 1999 ${ }^{13}$ ). Food products are typically low-commitment products, which implies that no matter how differentiated products are the price variations cannot be large compared to the products provided by large food companies. Naturally, there are product- and firm-specific differences depending on the purpose of use of the product. Consequently, it is a differentiation-price relationship that matters more than just the degree of differentiation. Moreover, low prices based on low costs are likely to gain more in importance when a firm competes with similar type of small-scale firms. For example, when two small firms try to market products, that differ clearly from the products of larger companies, but are relatively similar compared to each other, to a local retail store it is more likely that the product with the lower price outcompetes the product with the higher price. Hence, it is not simply a matter of how to differentiate but how to differentiate in a competitive way. Referring to the previous example, it can be stated that cost advantage perspective combined with differentiation is important when competing with firms with similar product offerings. These insights are largely contrary to Porter's $(1980,1985)$ conceptualisation but consistent with mixed strategy approaches (Hill 1988, Murray 1988, Faulkner and Bowman 1992, Miller 1992, Parnell 2000). Accordingly, this study takes a view that there are various strategies available for a small firm in the food market in terms of differentiation and cost aspect and they need not be mutually exclusive.

Third, the theoretical starting point for the study has been the application of the RBV, which represents a different approach to competitive strategies than the generic strategy approach. As

${ }^{13}$ Dess et al. (1999) stress the cost control aspect in the context of corporate entrepreneurship. mentioned before, the RBV emphasises uniqueness of competitive strategies based on what already exists (ex post perspective) (Mintzberg et al. 1998, p. 280-283). However, instead of considering a confrontation between these two approaches, recent research has taken a step towards combining insights both from the industry-based theories and the RBV (Spanos and Lioukas 2001, Barney 2002). This may provide insights in the present research setting too. Although we accept that each firm's strategy, if analysed in-depth, might be very unique we may suggest that for research and development purposes it would be beneficial to provide a synthesis of strategies and then to analyse which types of resources and competences are connected to certain "generic" strategies.

Fourth, the concept of competitive advantage needs to be discussed too. Particularly, any expression of absoluteness relating to conditions that make certain resources or bundles of resources valuable requires further discussion. First, one may call in question whether a very small firm - from both a theoretical and a practical point of view - could build a competitive advantage that would be sustainable in the long run and yield profit. It is true that many small firms may obtain and sustain their position in specific market niches if these markets are unattractive for larger firms (Grant 1991). Still we may ask whether it is rational to talk about competitive advantage in the context of firms employing typically $1-2$ persons while another extreme is a discussion of competitive advantage of nations Porter (1990). Therefore, we may suggest that relativity is one of the key dimensions of competitive advantage in the case of very small firms. Moreover, in many cases the term competitive parity might be a more descriptive term for a favourable position established by a small firm. As mentioned earlier, a competitive parity position refers to the situation in which a firm may compete successfully, but there are also several other firms that follow similar strategies (Barney 2002, p. 9).

This question relates also to the absoluteness of the assumption of the resource heterogeneity 
Forsman, S. How do small rural food-processing firms compete?

(Barney 1991) in the case of small-scale firms. According to the RBV, resources or bundles of resources cannot be a source of competitive advantage if there are several firms that possess the same resources and exploit them with the same strategies. If we look at small-scale food production in rural areas, one can easily discover that there are firms each of which may emphasise, if not totally identical, very similar resources and follow similar strategies. It may well be the case that, let's say two farm-based meat processors operate in the same local market. We can assume that as long as these two firms remain relatively small, do not have big growth ambitions and are not considered as serious competitors from the viewpoint of larger firms within the meat industry, there may be an opportunity for both firms to succeed. If the firms try to increase market share, the significance of the resource heterogeneity can be considered more valid. Hence, it is essential to consider in which product market domain (Bamberger and Bonacker 1994, Hyvönen and Kola 1995) a firm operates. A firm may have a relative advantage in a narrowly defined market, but a disadvantage in a broader market area (e.g., local markets vs. national markets). Third, it is important to define a reference point and be clear about who the competitors are when talking about both resources and competitive advantage. In the case of small food processors, competitors may be larger firms, similar small-scale firms or both.

Relating to the assumption of resource heterogeneity, Hunt and Morgan's (1997, Hunt 2000a) resource-advantage theory of competition provides insights that are worth thinking about in a small business context. Particularly, emphasising comparative advantage in resources as sources of competitive advantage is an important point. It is obvious that it is difficult for very small firms to create absolute superiority in their resources and competencies in relation to larger firms. It can be assumed in many cases that it is not due to inability, but rather to the unwillingness of larger firms to imitate smaller firms. In order to pursue their own goals, larger firms are not necessarily interested in market niches or small segments, which may provide market opportunities for small-scale firms. Then, smaller firms may achieve a favourable position in the market, although this position would not represent a competitive advantage in terms of resource-based logic.

Fifth, one should critically ponder whether a firm can achieve a permanent competitive advantage in mature industries such as the food industry. This relates to resource immobility. Fiol (2001) has called in question the sustainability dimension of competitive advantage at the larger level. She argues that in today's competitive environment it is hardly possible to achieve a sustainable competitive advantage based on a particular set of resources, no matter how difficult to imitate they may be. According to Fiol, rather than obtaining a sustainable advantage a firm has an opportunity to gain temporary advantages. In a continually changing environment resources and the way a firm employs them changes constantly, which can lead to only temporary advantages. Superior rents, then, result from the continuous rebuilding of resources over time.

Fiol's (2001) argumentation is quite reasonable from the point of view of the industry-specific consideration. The food industry is a relatively mature industry (Hernesniemi et al. 1996, Volk et al. 1996, p. 151, Hyvönen and Kola 1998) compared to, for example, the information technology sector. Typical features that describe mature industries include (Porter 1980, p. 238240):

- Slow growth potential;

- Market savvy, repeat customers;

- Increased emphasis on cost- and serviceoriented competition;

- Overcapacity problems;

- Reoriented functional policies and strategic actions;

- Limited introduction of new products and services;

- Increased international competition, and

- Decreased industry profitability.

Thus, quantitative growth is limited and food manufacturers should put on emphasis on quali- 
Vol. 13 (2004): Supplement 1.

ty. There is room for product innovations but not to such an extent as, for example, in emergent industries. The most common type of opportunities in a mature industry is to refine a firm's current products, to increase the quality or service and to focus on reducing manufacturing costs and increasing quality through process innovations (Barney 2002, p. 116-117). On the other hand, there are continuous changes both on the supply side due to changing market conditions and on the demand side because of consumer preferences. Therefore, it may be difficult to build persistent competitive advantages. In some cases it may be even dangerous to try to build sustainable advantage if the resources on which the advantage is based cannot easily be adjusted to changing market challenges. This is an important standpoint for a small firm that may often concentrate on a limited number of products based on particular type of resources. In terms of the VRIO dimensions (Barney 2002, p, 173), resources that are valuable and rare but not necessarily costly to imitate have the potential to lead to temporary competitive advantage and above-normal performance. Therefore, we can suggest that it is more important for a small rural firm to pay attention to the ability to renew and rebuild competitive advantages than to create an advantage that is assumed to be persistent for a longer period. Sustainability should then be thought of as reinvesting in barriers to imitation (see Reed and DeFillippi 1990) which can be implemented by developing unique combinations of strategic resources.

In conclusion, based on what has been written above, we suggest that, when adapting the RBV as a theoretical frame, both industry-specific and firm-size dependent aspects be taken into account. That is to say that both the nature of valuable resources in contributing to competitive advantage and the nature of competitive advantage (e.g., the sustainability dimension) may be, at least to some extent, dependent on the size of the firms and the structure, dynamics and maturity of the industry. In addition, it is suggested that the RBV and the more traditional industry-based view should not be thought of as solely contrasting views but, rather, as views that could be useful when integrated.

\subsection{Performance outcomes of competitive advantage}

In the field of strategic management firm success (or performance) ${ }^{14}$ is assumed to be based on competitive advantage in the particular market. Success, thus, represents an outcomes component of the competitive advantage. In this study, the interest is, according to resource-based logic, in linkages between resources, competitive advantage and success. It is assumed that some small rural food-processing firms are more successful than others. It is further assumed that differences in resource deployments between more successful and less successful firms might exist. However, it is not assumed that competitive advantage is an absolute requirement for success. If the demand exceeds the supply a firm may be competitive and successful without any specific competitive advantage. Success can also be influenced by chance. On the other hand, the position of competitive advantage does not automatically lead to success. In the mature food industry characterised by oligopolistic market structure there might be external barriers to success.

Generally, success of performance is a very multidimensional concept. In the small firm context, firm success can be assumed to be even more complex. After briefly discussing success within the RBV, we will ponder and discuss the specific nature of the success and the problems relating to measuring success in the small-scale firm context. Yet, success is not considered here as in depth as resources and competitive advan-

${ }^{14}$ The concepts of success and performance are used interchangeably in this study although they can be defined differently (see e.g. Komppula 2002). 
Forsman, S. How do small rural food-processing firms compete?

tage. This is because the purpose is not to explain firm success by resources and competitive advantage, but to identify and examine a linkage between them.

\subsection{Resource-based view of success}

Strategic management has traditionally focused on business concepts that affect firm performance (Hoskisson et al. 1999). Thus, measuring performance of the firm or business is an essential part of strategic management research. Strategies are typically tested by performance implications (Venkatraman and Ramanujam 1986). Within the RBV, the interest is specifically on understanding performance differences between firms (Barney 1991). The common argumentation within the RBV is that a firm's success in the long run is mainly a function of its internal and unique competitive resources (Hoskisson et al. 1999).

In the RBV, the concept of "rents" is usually used instead of (economic) profits (Peteraf 1993). Rents can be defined "as return in excess of a resource owner's alternative use costs" (Mahoney 1995$)^{15}$. One approach of the RBV is thus interested in explaining the rent-earning capability of resources (Hooley et al. 1997, p. 1). In terms of rents, competitive strategy in the RBV can be viewed as a search for Ricardian rents ${ }^{16}$ that are associated with the position of superior resources (Grant 1991, Grant 1998, p. 110). Underlying the "rent earning" approach in the RVB is that rents result from exploiting scarce firm-specific resources rather than from economic profits from product-market positioning (Teece et al. 1997). Hence, the source of rents within the RBV is internal (Amit and Shoemaker 1993) and does not result from the industry

\footnotetext{
15 Another definition defined rent as "the surplus of revenue over the "real" or "opportunity" cost of the resources used in generating that revenue" (Grant 1991).

${ }^{16}$ Compare with the monopoly rents that are profits associated with limited or lack of competition (Grant 1998, p. 110).
}

structure (Connor 1991). Further, firms become profitable or earn rents because their costs are significantly lower or their products are of significantly high quality (Teece et al. 1997). In the case that resources decrease in value or can be easily imitated by competitors, they lose their rent-generating ability (Grant 1991).

\subsubsection{Small firm success}

The question of success in the small business context is very complex and problematic (Jennings and Beaver 1997). One of the central problems is that small businesses do not necessarily pursue profit maximisation in the sense that larger firms do. In many cases achievement of a moderate living standard may be more important than profit maximisation (Currant et al. 1997). As Bridge et al. (1998, p. 141) point out the main concern of small businesses may be that the business supplies the benefits entrepreneurs want from it. If these benefits are achieved satisfactorily, an optimal business goal may therefore be an ability to reach a level of comfort rather than achieving the business's maximum potential or having growth as a goal for (Bridge et al. 1998, p. 141). This view is supported by Juutilainen (2001, p. 117) who, based on the empirical study of strategic behaviour of small firms, concluded that entrepreneurs seem to feel themselves successful or satisfied with a modest financial achievement.

Growth is usually linked to financial performance and is, thus, considered as an appropriate survival strategy for small firms. The relation between growth and financial performance may, however, be relatively complex. Growing firms are not necessarily successful, and successful small firms do not necessarily grow (Wiklund 1998). Particularly in very small firms this connection can be expected to be quite complex. In the strategy literature it is assumed that there are no limitations for the increase of the production volumes. In the case of very small firms, however, the situation may be different. There is empirical evidence that small rural firms, that 


\section{Vol. 13 (2004): Supplement 1.}

are mostly family firms, are not very growth-oriented. Kaikkonen (2003), for example, has studied the growth of micro-sized rural food-processing firms. Only $39 \%$ of the sample firms $(\mathrm{N}=$ 103) were identified as growth-oriented; their goal was to grow and develop by searching for new business opportunities. For the rest of the firms, the goal of business was to make a reasonable living for the owner(s). In Kaikkonen's study, production difficulties, such as the availability of the appropriate machinery, were found to be the greatest impediments to grwoth. Increasing production volumes often requires that manual production be replaced by more technological production, but it is often difficult to find in the market more industrial-types of machines and facilities that still are suitable for small-scale production. Hence, production-related problems may become a kind of threshold for growth. Moreover, a major threshold for growth is the high price of employment because of high indirect employee costs. For many small rural entrepreneurs employing one worker would require a considerable increase in production volumes to cover the labour cost without any guarantee that there would be demand for the increased output (e.g., Forsman 1996, p. 72). Availability of capable labour (Hautamäki 2000) and a fear of increasing competition among the small-scale producers (Forsman 1996, p. 72) may also decrease the growth potential particularly in rural areas. Considering these limitations firm success is not associated explicitly with growth in this study.

By contrast, considering the specific nature of small rural firms, for many firms survival may be more important than growth. The ability to survive refers to firm continuity. Littunen et al. (1998), for example, analysed firm success in terms of whether or not the firm's goals had been achieved. They defined a successful firm as continued functioning; a continued functioning proves that a firm has been able to fulfil the expectations of the people involved in the business and this can be considered as a criterion of success. Similarly, success may be defined in terms of a firm's ability to survive and grow (Small- bone et al. 1999) or simply succeed or fail (Dess and Robinson 1984).

Success has been traditionally measured in terms of financial indicators although non-financial measures are increasingly used alongside financial measures. From a financial point of view, a business or firm is viewed as successful if it achieves robust financial performance and improves its position on its market (Doyle and Wong 1998). It is undeniably obvious that financial performance is the most critical determinant of firm success in the long term, also in the case of small firms. Although financial measures still dominate when measuring success other perspectives are gaining in importance. This has been also noted in strategic management theory (Cravens 1998). One promising framework for measuring strategic performance is the "balanced scorecard" approach originally created by Kaplan and Norton (1996). From the strategy perspective, this approach provides multiple indicators of how well a strategy is performing (Cravens 1998).

This multidimensional perspective is worth considering in the small business context too. It can be expected that by using different dimensions we can obtain a more complete description of the actual performance of the firm if success is studied from a multidimensional perspective instead of from a financial perspective alone. Some empirical studies have shown that entrepreneurs seem to perceive the success of their business from different perspectives and that the most important indicators or success are not necessarily financial measures. For example, in Komppula's (2002) study of rural tourism micro-businesses customer satisfaction and the creation of long-term customer relationships were found to be the most important indicators of success. Juutilainen (2000, p. 119-120), on the other hand, proposes that an entrepreneur's perception of success includes three dimensions: adequate financial survival, customers' satisfaction and loyalty, and opportunity for self-satisfaction.

Considering the complex and heterogenous nature of small-scale food-processing firms, the following decisions concerning the definition 
Forsman, S. How do small rural food-processing firms compete?

and measuring of success for the purpose of this study are made. First, the fact that a small firm is not necessarily a profit-maximising entity as is assumed also in the RBV (Barney and Arikan 2001) is accepted. Second, success is approached from the multidimensional perspective. Considering success from several perspectives may help to identify and understood the linkages between resources, competitive advantage and success. If financial measures are the only measures that matter, a firm can improve its short-term financial performance at the expense of long-term market opportunities. Hence, non-financial measures are also needed in order to identify drivers for future performance. Third, the availability of reliable objective measures of financial performance is difficult to obtain in the case of very small food-processing firms and, because of this, subjective indicators will be used. The two previous points (multidimensional nature of success and subjective vs. objective measures) are discussed in more detail in the context of the operationalisation of success in Section 4.3.

\subsection{Summary: Elaborating a conceptual framework of the study}

In this chapter, a conceptual framework is built based on the literature review and discussions presented in the previous chapter. There are two approaches to theory building: frameworks and models. Research in the strategy field is characterised by building frameworks rather than models (Porter 1991). Frameworks identify the relevant variables, their organisation and the interaction between them. In the models, on the other hand, the focus is only on a few key variables the interactions of which are examined in depth. It is impossible for a model to include all the variables of interest which implies that the applicability of any model is restricted.
The main interest in this study is to examine how small rural food-processing firms compete in the market, that is, what types of competitive strategies they follow. Figure 4 exhibits a conceptual framework for viewing competitive strategy in the context of small food processors and provides a standpoint for the empirical part of the study. It also shows the propositions presented below associated with the linkages. The framework links three main components of the resource-based strategy analysis: firm resources, competitive advantage, and firm success. The competitive strategy is not considered here as a separate construct (cf. Borch et al. 1999) but as a broader construct covering the above-mentioned linkages. The components and the linkages between them are considered in the specific competitive and local environment characterised by the food industry, small businesses and rural areas.

A starting point in the framework is a firm's resources. A basis for a firm's resource deployment is established in its strategic goals and visions. It is evident that numerous resources and capabilities exist in a single firm (Conner 1991) and each firm has a unique set of resources that can be tangible or intangible (Hall 1992) and firm-specific or firm-addressable (Sanchez et al. 1997, p. 7). Resources per se have no strategic or critical value. Value can only be attributed to those resources that contribute to a position of competitive advantage and, further, firm success (Barney 1991, Barney 2002, p. 160).

In the framework, resources are approached on the basis of the distinction introduced in Chapter 3.2.6, namely strategic resources and basic resources. Strategic resources are those resources that are expected to constitute the primary sources of competitive advantage in small food-processing firms, that is, they represent the core idea around which a business is built. They are assumed to be, to varying degrees, those resources that competitors lack an ability or desire to imitate. Basic resources, by contrast, are resources that facilitate and support a firm in converting its strategic core resources into a favourable position in the market. Basic resources 
Vol. 13 (2004): Supplement 1.

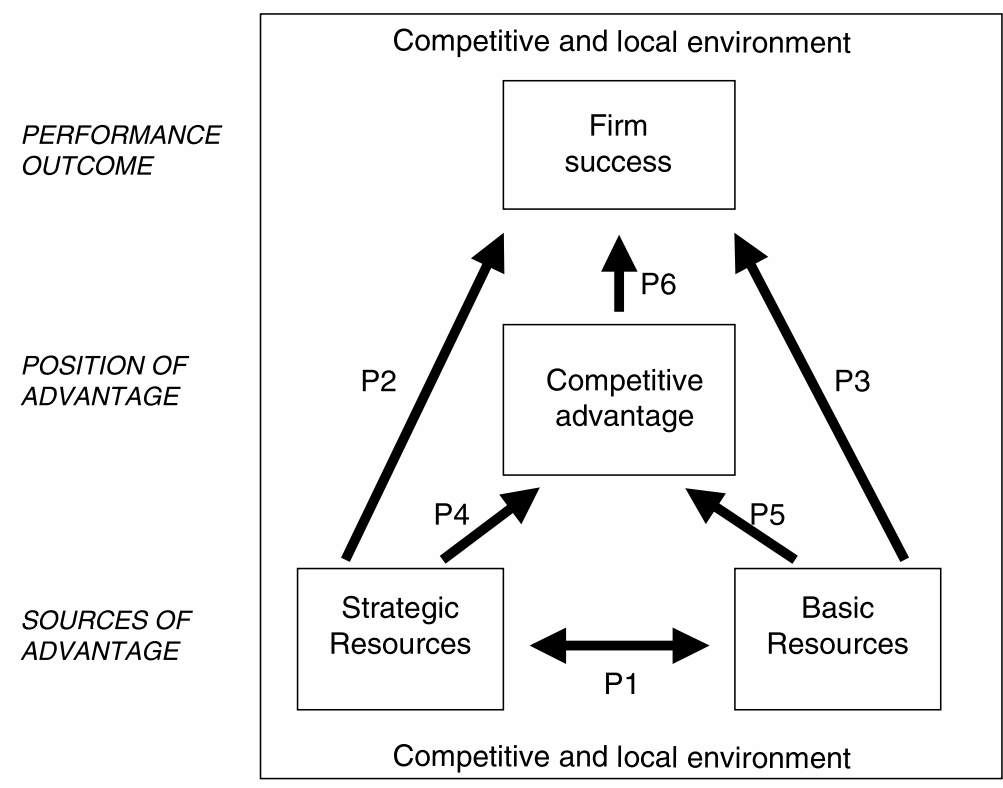

Fig. 4. Theoretical framework of the study.

P1: There is a positive relationship between strategic resources and basic resources.

It is evident that if a firm is to succeed in creating a favourable position in the market by exploiting its resources, it should do it in a successful way. In the framework, firm success is an ultimate goal. The RBV emphasises performance differentiation between different firms (see Barney 1991). It can be assumed that some firms are more successful than others are and that differences exist in resource deployments between more successful and less successful firms. This assumption is based on the common argumentation within the RBV, according to which a firm's success in the long run is mainly a function of its internal and unique resources and capabilities (Hoskisson et al. 1999). More specifically, it is a question of firms' rent-earning capability of resources (Amit and Shoemaker 1993, Mahoney 1995, Teece et al. 1997). To follow the empirical work accordant with the resourcebased logic (Barney and Arikan 2001, Ray et al. 2004) it is assumed in this study that both strategic resources and basic resources contribute to firm success. Consequently, the following propositions are to be tested: 
Forsman, S. How do small rural food-processing firms compete?

P2: There is a positive relationship between strategic resources and success.

P3: There is a positive relationship between basic resources and success.

Although a firm's ultimate goal is success, the main objective of competitive strategies is competitive advantage (Reed and DeFillippi 1990). Hence, to compete very successfully, a firm's strategies should have competitive advantage as a primary goal (Barney 2002, p. 10). Consequently, an intermediate construct between resources and success is a position of competitive advantage. It is assumed that a small foodprocessing firm seeks a position of competitive advantage or at least a position of competitive parity.

Whether a firm has achieved a competitive advantage and, particularly, whether a competitive advantage obtained is sustainable over time, is, however, very difficult to measure (Hoffmann 2000). Maybe for this reason competitive advantage is often considered in terms of high performance (Reed and DeFillippi 1990). In order to separate competitive advantage from success, it is considered here from the positioning perspective in terms of differentiation and cost dimensions. This comes very close to Porter's (1980, $1985)$ view. Yet, unlike Porter, the mixed strategy approach (Hill 1988, Murray 1988, Faulkner and Bowman 1992, Miller 1992, Parnell 2000) is adapted. Accordingly, it is assumed that small rural food-processing firms may have different types of competitive advantages in terms of differentiation and cost perspectives and also that a combination of differentiation and cost emphasis may exist which does not necessarily lead to the stuck-in-the-middle situation as stated by Porter. Yet, it is assumed that the differentiation strategy provides a more secure basis for competitive advantage in the case of smaller firms (Pelham and Wilson 1996, Grant 1998, p. 230, Borch et al. 1999). The point here, however, is that a firm's resources may be consistent with several alternative strategies (Barney and Arikan 2001). Accordingly, the most favourable strategies (e.g., Faulkner and Bowman 1992) are assumed to be linked to the existence of certain type of resources within a firm. Hence, following a resource-based logic and the categorisation scheme of the resources introduced in this study, the following propositions are provided:

P4: There is a positive relationship between strategic resources and the position of competitive advantage.

P5: There is a positive relationship between basic resources and the position of competitive advantage.

Above we have argued that both strategic resources and basic resources contribute to competitive advantage and firm success. Finally, it is assumed that favourable competitive advantage and success are correlated. Yet, as stated in Section 3.3 we do not assume that the position of competitive advantage would automatically lead to success (cf. Reed and DeFillippi 1990). Success is assumed to be influenced by many factors, not only by resources or competitive advantage. In the short run success can also be influenced by chance. Or, if the demand exceeds the supply, a firm may become successful without any specific competitive advantage. Consequently, although the linkage between competitive advantage and success is not assumed to be automatic, it is proposed that the following relationship can be identified in the case of small, rural food-processing firms:

P6: There is a positive relationship between the position of competitive advantage and success.

The postulated linkages are studied in the specific environment characterised by the food industry, small businesses and rural areas. The research design specified in the next chapter does not offer the opportunity to analyse the impacts of these dimensions on the competitive strategies of the target firms. Hence, the dimensions that characterise competitive and/or local environment are taken as given and their possible impacts can only be discussed theoretically.

The structure of the empirical part of the study is shown in Figure 5. The figure also shows which propositions are linked to various parts. First, the survey instrument is presented in Chapter 4 including reliability and validity assessment 
Vol. 13 (2004): Supplement 1.

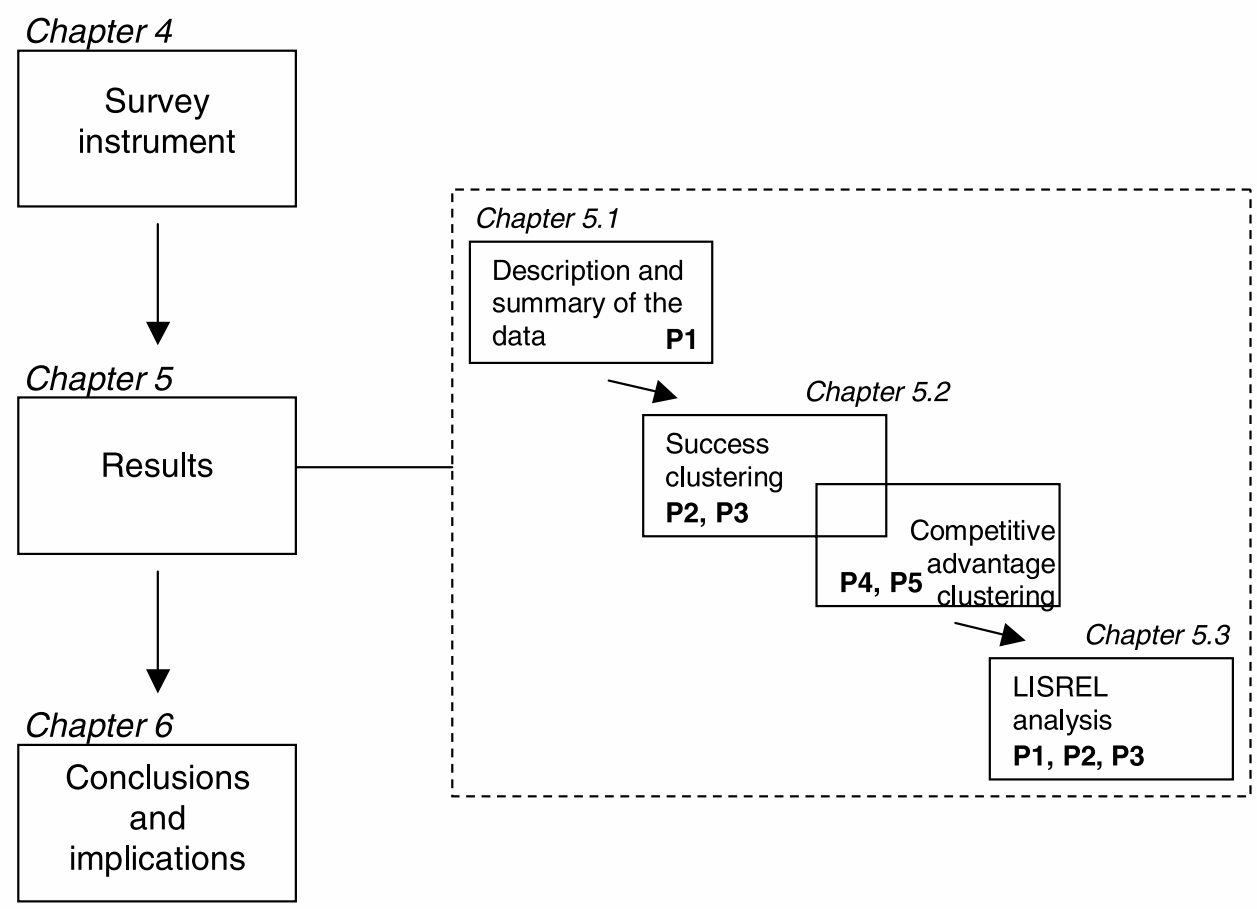

Fig 5. Structure of the empirical part of the study.

of the results and the study. The results are presented in Chapter 5. In Section 5.1, the data are described in terms of frequencies, means, etc. In addition, for the central variables of the study, the data are summarised by means of factor analysis and summated scale variables. In Section 5.2 two cluster analyses are conducted: success clustering and competitive advantage clustering. The cluster solutions are validated by analysing their linkages to resources and some other key variables. In addition, in order to study which strategies have the greatest potential to lead to success and which resources are linked to successful strategies, the relationship of success clustering and competitive advantage clustering is examined in more detail. In Section 5.3, central relationships of the constructs are further studied and modelled by using the LISREL application. Finally, conclusions and discussion of the results are provided in Chapter 6.

\section{Survey instrument and data}

The empirical part of the study is cross-sectional in nature, designed to look at relationships between resources, competitive advantage and firm success as postulated in the previous chapter. In this chapter, the research design and data collection procedure is first described. First, however, methodological challenges relating to the empirical testing of the RBV are briefly discussed. After describing the research design and data collection procedure, key constructs and 
Forsman, S. How do small rural food-processing firms compete?

variables measuring them are operationalised and derived. Finally, the reliability and validity of the study and results are discussed. The main analyses of the study are presented in Chapter 5 .

\section{I Methodological challenges}

It may seem that the RBV offers a very simple and even self-evident view about how resources are connected to strategies that a firm pursues. In many cases, however, the linkage between resources and strategies is not so obvious. For example, a firm's resources may be consistent with several alternative strategies (Barney and Arikan 2001). Empirical testing of the RBV is also made challenging by the idiosyncratic nature of a firm's resources and capabilities (Hoskisson et al. 1999). This means that each firm's valuable combination of resources is unique and because of this it is difficult or even impossible to provide any generalisations about resource-based competitive strategies (Conner 1991, Andrews 1997). The RBV has also received a lot of criticism, as have other strategy theories. Due to this, one has to be careful in empirical testing with causal relationships and the interpretation of them as well generalisability of the results. In the following, the main points of criticism of the RBV are briefly reviewed.

One of the central weaknesses of the RBV arises from the presence of causal ambiguity (Reed and DeFillippi 1990). This means that it may be difficult to recognise which of a firm's resources contributes to competitive advantage and firm success (Foss et al. 1995, p. 8, Hunt 2000a, p. 140, Barney and Arikan 2001) and what is the causal relationship between competitive advantage and firm success (Powell 2001). The problem is that in many empirical studies the existence of a particular competitive advantage is identified based on ex post performance observations and the conclusion is made that creating this particular competitive advantage will result in superior performance (Powell 2001,
Mintzberg et al. 1998, p. 280-283). That is to say, successful firms are successful because they have valuable resources and they should take care of these resources to be successful (Porter 1991). Empirical attempts in the RBV have thus met strong criticism for being tautological (e.g., Foss et al. 1995, p. 8, Porter 1991, Powell 2001). If the identification of valuable recourses were identified in another research setting, the resources might be valued differently (e.g., Foss et al. 1995 , p. 8). Barney (2001) has replied to this criticism that, in some sense, all theories within the strategic management are tautological.

What is also of utmost importance is the distinction between theoretical propositions and empirical testing. Powell (2001), who has considered competitive advantage from logical and philosophical points of view, argues that all the propositions of the RBV are analytic which means that they do not require empirical examination because analytical propositions do not make claims about how things really are. This, in turn, means that one cannot test the truth value of the propositions. Rather it is a question of looking for coincidence between empirical phenomena and phenomena formulated in propositions.

\subsection{Research design and data collection}

The target group of the study comprised foodprocessing firms that employ annually less than 20 persons and are located in rural areas. The data $(\mathrm{N}=238)$ were obtained via a structured questionnaire in the year 2000. The data included both on-farm processing firms and firms without a farm connection. In defining rural areas, the definition that has been used in the creation of the Rural Business Register in Finland ${ }^{17}$ was

17 The farm register, a new database, was established by combining two databases. First, from the Business Regis- 
Vol. 13 (2004): Supplement 1.

used. Based on the register, $47 \%$ of food-processing firms with less than 20 persons were located in rural areas in 1996. The total number was about 900 , of which about 180 were located on a farm (Rantamäki-Lahtinen 1999, p. 27, see also Section 1.3).

The questionnaire was aimed at those persons who are in charge of running the food-processing business. The sample was chosen from the Business Register maintained by Statistics Finland based on information from 1996. The sample was chosen from all the Finnish-language firms included in SIC 15 (manufacture of food products and beverages) excluding SIC 157 (manufacture of prepared feeds for farm animals and pet foods) that employ less than 20 persons and are located in rural areas. Consequently, the original sample size was 843 firms. The final sample size, however, was 742 firms after excluding those firms that could not be included in the sample because of extenuating circumstances such as firm failure.

The questionnaire was distributed by post in the Spring 2000. A prepaid envelope and a cover letter were included. Respondents were motivated by a promise to send them a summary report of the results of the study. In addition, they were encouraged to fulfil the questionnaire by a lottery for a gift certificate worth about EUR 500. After three weeks, a reminder letter with the questionnaire was sent to the firms that had not responded by the requested date. Three weeks after that, a second reminder was sent. Three separate mailings resulted in 238 useful cases with a response rate of $32 \%$ (Table 5). The re-

ter administered by the Statistics Finland all enterprises whose sales in 1996 were over EUR 8,241, whose personnel numbered fewer than 20 persons, and which were located in rural areas (zipcode areas with less than 50 persons per $\mathrm{km}^{2}$ ) were picked up. Second, from the Farm Register maintained by the Information Centre of the Ministry of Agriculture and Forestry, all farms which have applied for financial support for agriculture in 1997 were selected. These two databases were combined in order to find out how many of the firms that are located in rural areas are actually located on a farm and are run by a farmer or by family members (see Rantamäki-Lahtinen 1999).
Table 5. Development of sample data.

\begin{tabular}{lc}
\hline & Number of cases \\
\hline Total population & 843 \\
$\quad$ No activities at the time of the & 61 \\
survey; ended firm activities/ & \\
$\quad$ firm failure/entrepreneur(s) retired & \\
$\quad$ Firm not included in the target group & 35 \\
$\quad$ (different industry/number of & \\
$\quad$ employees 20 or over) & \\
$\quad$ Same firm registered several times & 4 \\
Revised total population & $742(100 \%)$ \\
Number of responses & $253(34 \%)$ \\
$\quad$ of which 15 forms were & -15 \\
$\quad$ insufficiently fulfilled & \\
Number of useful responses $=$ & $238(32 \%)$ \\
Sample data &
\end{tabular}

sponse rate can be considered moderate if compared with similar type of research within the field (e.g., Hyvönen et. al 1995, Carter 1999, Forsman 1999).

The non-response bias was tested by examining the differences in mean turnovers and number of employees between firms that responded to the survey and firms that did not (see Park and Krishnan 2001). The non-parametric Mann Whitney $U$ test revealed no systematic differences between respondents and non-respondents in the original sample (see Forsman 2001, p. 12-13 for more details). In this respect the profile of the respondents was close to the intended target group and, hence, the final sample of the 238 firms is relatively representative of the total population.

\subsection{Operationalisation of the theoretical constructs}

In this section, operational measures for the theoretical concepts are introduced. The measures were generated through a review of the litera- 
Forsman, S. How do small rural food-processing firms compete?

ture on strategic management, particularly on the RBV as well as previous studies within the field. The author's earlier case study with qualitative interviews of rural meat-processing firms in different regions of Finland (Forsman 1996) as well a survey conducted in Finland in 1997 (Forsman 1999) and a similar type of survey conducted in Norway and Sweden (Borch and Iveland 1997, 1998) have been helpful because they have acquainted the researcher with the characteristics and problems of the small food-processing sector.

On the basis of items used in the literature, previous research, and definitions established in this study, several pools of measures were generated. Most of the items were measured on fivepoint Likert-type scales, with anchors of, for example, $1=$ Totally dissatisfied and $5=$ Totally satisfied. In addition, some dichotomy and multiple choice questions were used, mainly in background questions. The entire questionnaire included 57 questions or pools of questions of which 31 were employed in this study. The questions utilised in this study are listed in Appendix B.

The questionnaire was designed to focus on a firm's main products. Main products referred to those food products that contribute most to a firm's turnover. In the following, the main constructs of the study are operationalised. An important notion is that the lists of the dimensions and measures to be presented below are not exhaustive, but include potential alternatives that a particular construct may cover.

\subsection{Resources}

As discussed earlier in this study, "resources" is very complex concept. Resources are very firmspecific and a single firm can have an endless number of different combinations of resources. The RBV has been criticised because there is no clear basis for choosing which of the huge number of a firm's resources are really those that contribute to rent generation and, further, firm performance. In general, operationalising con- cepts of the RBV is difficult as there is no objective way to identify unique resources and what determine them valuable (Mosakowski and McKelvey 1997, p. 66). This difficulty may be due to the fact that it is impossible to measure the value of resources in isolation. Moreover, the value of resources changes over time. In addition, the value of an individual resource is dependent on the presence or absence of other, complementary resources (Foss et al. 1995).

Thus, when trying to operationalise resources some problems undoubtedly will arise. For example, for measurement purposes it is difficult to make a distinction between resources and capabilities (Chandler and Hanks 1994b), the linkage of which should be seen as a dynamic, two-way phenomenon (Rosenbröjer 1998). Due to this confusion, resources and capabilities (competences) are treated as a joint concept (see Wiklund 1998). Moreover, because of the infinite number of possible resources and combinations of them, it is impossible to try to include them all in a single study. Rangone (1999) also argues that the resource-based strategy analysis should not be too complex in the case of small firms. This follows that number of variables included in the analysis should be limited; only those variables with an important contribution to competitive advantage should be included. Hence, some choices have to be made. First, because the unit of observation in this study is a firm entity, resources related to entrepreneurs were omitted (cf. Wiklund 1998). Nor is the distinction made between organisational resources and capabilities and entrepreneurial and managerial competence (see Chandler and Hanks 1994a). Hence, the focus is on the resources of the firm. Yet, as discussed in the theoretical part of the study, it is clear that the strategic behaviour of a small firm can reflect the personal characteristics of its entrepreneur and consequently resources related to the entrepreneur are to some extent included in the resources related to a firm. Second, in an earlier section of this study, a distinction between two types of resources that may be considered as relevant in the case of small food-processing firms was presented. Therefore, 
Vol. 13 (2004): Supplement 1.

the interest is particularly on strategic resources and basic resources. They will be operationalised for the purpose of this study next.

\section{Strategic resources}

As defined previously, strategic resources are defined resources that constitute the primary source of competitive advantage, that is, they represent the core idea around which the business is built in order for a firm to be positively different than its competitors. In this study, strategic competitive resources are identified in terms of such superior factors that, from a firm's point of view, differentiate a firm or its products from its main competitors. For the questionnaire variables representing possible and potential superior factors were drawn from literature and previous studies (e.g., Stoner 1987, Haahti 1989, Hall 1993, Hyvönen and Kola 1995, Hyvönen et al. 1995, Forsman 1996, 1999, Borch and Iveland 1997, 1998, Traill 2000). It is important to point out that in a postal survey it is difficult to distinguish resources from capabilities, competitive advantages and strategies. Traill (2000), for example, when exploring the sources of competitive advantage within the EU food industry, included in the variable list both resources and competencies (e.g., company image, high quality raw materials) and variables that represent more competitive strategies or actions than resources (e.g., competitive pricing). According$1 y$, in the present study strategic resources are associated with a firm's superior factors. The respondents were asked: "To what extent do you consider the following items to be superior factors that differentiate your main products or firm from your principal competitors" (Question 16). The scale ranged from Considerably low importance to Considerably high importance. The items included in the question are described below ${ }^{18}$.

Small food-processing firms, in particular onfarm processors, often stress the quality of the

\footnotetext{
${ }^{18}$ Note that an item may be included in several dimensions.
}

raw material as a competition factor. To capture this dimension the following items were included in the question pool: excellent quality of raw material; selected raw material suppliers, and knowledge of product/raw material origin.

Superior quality is a dimension that small entrepreneurs used to emphasise as a competition tool. Superior quality can be associated in this context with product differentiation rather than physical or microbiological quality. This type of quality may result from production methods such as a traditional manufacturing method or the different raw material composition in a product. It may also result from the outward appearance of the products or product packages. The following factors were included to measure this dimension: superior product quality, manufacturing methods, different raw material composition of the products, outward appearance of the products, product packages, unique product idea, and creativity or innovation in product development.

Ethical and environmental factors are often related to small-scale food production. The use of organic raw material and environmentallyfriendly products or policies is a potential source of differentiation for small actors. Moreover, small food processors often emphasise the knowledge of the origin of the product or raw material. Knowledge of origin is often connected to a short distribution chain from producer to customer. Accordingly, the following factors were included to measure the ethical and environmental dimension: short distribution chain from producer to customer, environmentally friendly products or environmentally sound way of doing business, use of organic raw materials, and knowledge of product or raw material origin.

The majority of small food-processing firms are very locally oriented. Local orientation is often associated with traditional products and short distribution chains. For the local dimension, the following factors were included: local production (produced near customers), traditional product recipes, and short distribution chain from firm to customer. 
Forsman, S. How do small rural food-processing firms compete?

Customer focus is a core of market orientation (Slater and Narver 1994). Flexibility and customised service are factors that are usually connected to small firms. Small firms often lack excessive bureaucracy and hierarchical organisational structures due to the small number of employees, which may make it possible for a small actor to be more customer-oriented than larger firms. Customer focus is then a potential way to differentiate one's firm from larger firms. The following factors were chosen to measure this dimension: consideration of customers' special wishes (customising), flexibility of the business from customers' point of view, personal customer service (face-to-face contacts), short distribution chain from firm to customer, and wide product range.

The distribution dimension relates partly to customer focus. The widely accepted fact is that small firms often have difficulties to access to mainstream marketing channels. Yet some firms may have been succeeded in building new types of marketing channels in the local market. For example, a firm processing vegetables may have built a customer relationship based on a short distribution chain and personal contacts with a local restaurant. Direct sales to customers with face-to-face sales may also be a strength for many small food processors. Moreover, reliability of delivery is often emphasised by small firms as one of their competitive tools. The distribution dimension was measured by the following factors: distribution channels used, sales modes, delivery reliability, and short distribution chain from firm to customer.

Reputation is a potential strategic competitive resource that may result from long-term business and/or efforts in marketing. It often takes time to create a good reputation in the eyes of customers and requires investing in marketing actions. A good reputation is a non-tradable resource; it cannot be purchased in the market. Reputation was measured in terms of the following factors: firm reputation in the market area, excellent product reputation, and reputation of the trade name or trade mark.

Moreover, professional competence or knowhow can be seen as a potential source of com- petitive advantage. For example, a firm may possess a skill of a traditional manufacturing method resulting from cumulative experience. Professional competence or know-how was measured in general level in terms of special competence of an entrepreneur and/or family members, and other employees.

Finally, competitive prices was included in the set measures. The study by Forsman (1999) pointed out that there do exist firms that follow a strategy with a high degree of differentiation but relatively low prices.

\section{Basic resources}

As defined in Section 3.2.4, basic resources are in this study though of as resources that as such do not constitute an adequate basis for competitive advantage, but rather their function is to facilitate and support a firm in converting its strategic resources into a competitively advantaged position and, therefore, firm success. Basic resources are mainly capabilities (cf. the dynamic capability view, e.g., Teece et al 1997, Makadok 2001) and not necessarily rare but, rather, "common" resources (Barney 1991, 2002, p. 81) that are valuable but in isolation do not contribute to competitive advantage; however, without them a firm may find itself at a position of competitive advantage. In addition, basic resources are not strategic in the sense that they are often tradable, at least to some extent, and many of them can be acquired by education, co-operation with other firms and actors, as well outsourcing.

Basic resources were operationalised in terms of some basic capabilities in different fields of business. Variables were drawn from literature and previous research (e.g., Hoy and Vaught 1988, Hall 1993, Hyvönen and Kola 1995, Hyvönen et al. 1995, Borch and Iveland 1998, Forsman 1999, Traill 2000). In measuring the basic resources, the achievement and maintenance of a competitive position in a firm's marketplace was used as a reference point. In addition, a rationale that a deficiency of something may indicate knowledge of its importance was adapted. Thus, the respondents were asked: "To what extent do you consider the following factors to be 
Vol. 13 (2004): Supplement 1.

weaknesses in your firm that make it difficult for you to achieve and maintain a competitive position in your markets?" The scale ranged from Not a weakness to Significant weakness (Question 27). The items included in the question are described below.

Financial capability is often considered as one of the main weaknesses in small firms. A lack of financial capability may limit investments and marketing efforts. Financial capability was measured in terms of two variables: sufficiency of own financial capital, and availability of liabilities.

An inability to reach potential customers may be a disadvantage for firms that are located far away from large growth centres and have difficulty in accessing mainstream marketing channels. This dimension was measured in terms of the following variables: unfavourable location relative to customers, and insufficiency of customers in a firm's market area.

Availability of production resources may also be problematic firm firms located in rural areas. For this dimension, the following measures were used: availability of appropriate raw material suppliers, availability of skilled employees, and availability of new production methods or technologies. Availability of skilled employees is of utmost importance for growth-oriented firms. Moreover, availability of employees may be connected to employment costs; many small firms find it too expensive to hire non-family employees. Adapting new production methods or technologies may also help to increase production volumes.

Although a deeper examination of entrepreneurship in terms of entrepreneur characteristics is not included in the study, a few more or less personal characteristics are considered in the context of basic resources. These characteristics may relate to the entrepreneur or employees or both. Entrepreneurial characteristics were measured in terms of the following factors: staff motivation, ability to take risks, innovation and creativity, previous experience within the field, and a clear view about a firm's future prospects. Staff motivation measures to what extent the employ- ees engage themselves in food-processing business. It also measures indirectly an entrepreneur's ability to motivate the staff. An ability to take risks, at least at a moderate level, is always needed when running the business. A clear view about a firm's future prospects, in turn, may help in the creation of strategies.

Availability of counselling may be a critical issue for those firms that have no previous experience in the food-processing business or as a small business in general. Availability of counselling, however, does not necessarily measure only the existence of counselling but also evaluates an entrepreneur's ability to utilise available knowledge and counselling services.

An ability to co-operate may be considered as one of the critical factors that may help to increase the bargaining power of small food producers. Co-operation ability was measured through two factors: amount and quality of cooperation with other firms or organisations.

Running a food-processing business requires competences in several areas of business. As basic resources, competence was considered in the areas of product development, production, marketing, chain management and financial management. For each area a few items were created (see Question 27, Appendix B).

In addition to basic resources, firm competence in different fields of business in terms of education and/or earlier experience was measured. The respondents were asked: "To what extent do the employees, including the owner/manager, on average have competence in the following fields of business based on education or earlier experience?" The scale ranged from Not at all to To a high degree (Question 28). This competence was considered in product development, production processes, package development, marketing and selling skills, price setting and financial management.

\subsubsection{Competitive advantage}

As is the case with resources, competitive advantage is also a difficult construct to operation- 
Forsman, S. How do small rural food-processing firms compete?

alise and, thus, difficult to measure (Hoffman 2000). In some studies (e.g., Traill 2000) resources were considered as equal to competitive advantages. In this study, however, resources are seen as sources of competitive advantage that can lead to a position of competitive advantage. Competitive advantage, instead, is considered from the positioning perspective. The main types of competitive advantage are cost advantage (low-price orientation) and differential advantage (Porter 1980, 1985, Mathur 1992). One of the starting points for this study is that small food processors need to be differentiated in order to survive and succeed in the mature food industry.

Consequently, competitive advantage was studied here from the competitive positioning approach. Based on the earlier empirical evidence (Forsman 1999), the study takes the view that alternative competitive advantages among the sample firms can be identified and that these advantages are connected to different types of resource deployments. It is clear that in this type or research setting it is not possible to recognise firm-specific unique resources and competitive advantages, but by looking at different types of positioning strategies and resources related to them, one can gain some understanding about the creation of competitive advantage in small food-processing firms. Thereby, in order to examine the positioning of competitive advantage the following measures were elaborated.

Differentiation orientation was measured in terms of product differentiation, services differentiation and overall differentiation (see Doyle and Wong 1998, Forsman 1999). Product differentiation was measured by asking to what extent the concrete product characteristics of a firm's main products were differentiated from: 1) ordinary products provided by large firms, 2) special products provided by large firms, and 3) products provided by similar types of small or rural firms (Question 17). Services differentiation (Question 18) and overall differentiation (Question 19) were measured in a similar manner. The response scale ranged from Low degree of differentiation to High degree of differentia- tion. Positioning in terms of price level was measured by asking the respondent to assess the price level for a firm's main products compared with: 1) ordinary products of large firms, 2) special products of large firms, and 3) products of similar types of small or rural firms (Question 25). The response scale ranged from Our prices are lower to Our prises are higher.

Studying how the firms are positioned in the market with regard to the price level and the degree of differentiation does not reveal how sustainable the positioning is. Therefore, the purpose was to broaden the differentiation - price approach (see Forsman 1999) by including measures by which this sustainability dimension can be captured, at least to some degree. One dimension of sustainability is inimitability. This was measured by asking respondents how easily they competitors can imitate: 1) the concrete product characteristics or 2) the competence that differentiates their main products from competitors (Question 20). The response scale ranged from Very easy to imitate to Very difficult to imitate. Also the willingness of competitors to imitate was measured by asking the respondents how threatening they perceive imitations in their marketplace among: 1) large- and medium-sized firms and 2) similar types of small firms (Question 21). The response scale ranged from Not threatening at all to Extremely threatening. Moreover, sustainability was measured by the degree to which a firm's products could be substituted by other firms' products by using a scale of Our products are easy to substitute to Our products are difficult to substitute (Question 24).

In addition, firms' strategic actions or choices were measured. Respondents were asked how much efforts they have put into different strategic actions over the three last years (Question 22). The scale ranged from Insignificant effort to Significant effort. Responses to this question can reveal a business's market orientation that can, according to Slater and Narver (1994) be outlined in three components: customer orientation, competitor focus, and inter-functional coordination. In addition, an emphasis on differentiation strategy or low-cost strategy (see Pel- 
Vol. 13 (2004): Supplement 1.

ham and Wilson 1996) was revealed. A total of 22 items were included in the questionnaire (see Appendix 2).

\subsubsection{Small firm success}

One way to begin to measure success is to apply a multidimensional set of measures. One promising framework for measuring strategic performance is the "balanced scorecard" approach originally created by Kaplan and Norton (1996). From the strategy perspective, this approach provides multiple indicators of how well a strategy is performing (Cravens 1998). The central idea of the balanced scorecard approach is that financial measures are inadequate in building longrange competitive capabilities and creating future value. Financial indicators measure the events of the past, not the investments in the capabilities that provide value for the future. The balanced scorecard does retain traditional financial performance measures, but it complements them with non-financial measures that can be seen as drivers of future performance. In the original balanced scorecard approach firm performance is viewed from four perspectives: financial, customer, internal business process, and learning and growth ${ }^{19}$. These four perspectives enable a firm to reach a balance between short- and long-term objectives and between outcomes desired and the performance drivers of those outcomes. However, financial objectives are still the focus and every measure in all the other perspectives should be part of a link of a cause-and-effect relationship that culminates in improved financial performance (Kaplan and Norton 1996, p. 7-9, 18-19, 25, 47). From the point of view of the present study, considering success as a combination of several dimensions may help to identify the relationships between resources, competitive advantage and success.

${ }^{19}$ Slater et al. (1997) use the term innovation perspective.
Another central issue related to measuring success is the choice between objective and subjective indicators. In this study, the empirical analyses are based on subjective measures. There are several reasons for this. First, the fact is that measuring success in terms of financial indicators within the small food-processing firms is expected to be problematic, especially with onfarm businesses. Several studies (e.g., Vihtonen and Haverinen 1995, Forsman 1996) have shown that a lack of reliable and uniform information about annual accounts of small rural firms makes it difficult to study their financial performance from an objective perspective. Particularly in small-scale on-farm businesses that are under the Agricultural Act Tax, annual accounts do not necessarily exist and are thus not available.

Second, even if annual accounts were available, a common problem in small business research is that firms are often reluctant to deliver confidential objective information about financial performance for the purpose of research (Pelham and Wilson 1996). Third, most rural firms are relatively young, which may complicate obtaining a reliable and valid picture of a firm's financial state. Fourth, the objective evaluation of financial performance is hampered by the fact that many small entrepreneurs, as well family members working for the business, do not always take into account the value of their own work contribution. This means that their work contribution is not included in the firm's bookkeeping and, further, does not appear as part of a firm's financial result (Forsman 1997, Pasanen 1999, p. 28). This omission may lead to an inaccurate picture of a firm's financial state, particularly, if its products are largely hand-made and thus require a lot of working hours to produce.

In the absence of objective measures of financial performance, subjective perceptual measures have often been used instead (Dess and Robinson 1984, Lehtomaa 1995, Pelham and Wilson 1996, Juutilainen 2001, p. 120, Morgan and Strong 2003). The use of subjective perceptual measures can be justified since several studies have shown that there exists a correspondence between subjective perceptions and objec- 
Forsman, S. How do small rural food-processing firms compete?

tive measures (Dess and Robinson 1984). For example, in Lehtomaa's (1995, p. 151) empirical study, the results revealed that small entrepreneurs' perceptions of a firm's profitability were consistent with objective financial assessments although the entrepreneurs' perceptions were slightly more optimistic than the financial assessments. It has to be noted, however, that subjective measures are not interchangeable with objective measures, and objective measures should be used when available (Dess and Robinson 1984).

When using subjective, self-reported measures, it is useful to have some reference point. Pelham and Wilson (1996, p. 33) measured performance (profitability and business position) based on the respondents' assessments of whether results were above or below expectations. Doyle and Wong (1998) measured performance instead by asking respondents to judge performance of their firms against companies considered as "excellent" in the same industry or sector. Morgan and Strong (2003) used major, direct competitors as reference points when asking about the assessment of business performance. Rue and Ibrahim (1998), on the other hand, asked respondents whether the firm's performance over a particular time period was below the industry average, equal to the industry average or better than the industry average. By using a reference point it may be easier for a small firm owner or manager to make comparisons than without any references. However, for very small firms it may be difficult to assess the business against an industry average.

Consequently, a multiple set of measures was created for the study. The indicators were chosen from Kaplan and Norton's (1996) balanced scorecard framework. Complementary measures or indicators were chosen from other sources (e.g., Pelham and Wilson 1996, Chow et al. 1997, Slater et al. 1997, Forsman 1999). Accordingly, a pool of measures for success-measuring was built on four perspectives following the balanced scorecard set of measures. The respondents were asked: "To what extent were you satisfied with the following items during the last three years?" (Ques- tion 41). The five-point scale ranged from Highly satisfied to Highly dissatisfied. The items included in the set of success measures were as follows.

Financial perspective was measured in terms of business revenue, business profit, return-oninvestment, sales volumes of the products, development of units costs, level of raw material costs, level of labour costs and level of capital costs. Customer perspective was measured in terms of development of market share and customer demand, customer retention, number of new customers, customer satisfaction, price level, ability to command a price premium, and price-quality relationship perceived by customers. Internal-firm-process perspective ${ }^{20}$ was measured in terms of number of new products launched to the market, product quality compared to competitors, unit costs of the products compared to competitors, utilisation rate of the capacity, stock turnover, reliability of the delivery, quality of co-operation with other actors and amount of co-operation with other actors. Finally, learning and growth perspective was measured in terms of entrepreneur's and employees' competence compared to competitors, and keeping track of the development within the field.

Success was also measured in terms of the respondents' subjective view of the overall profitability of the firm (Question 36). Respondents were asked to evaluate the profitability of their business during the three last years with regard to: 1) the objectives set to the business, 2) similar types of small firms, and 3) the industry average. The scale ranged from Not profitable to Highly profitable. Moreover, profitability was also measured in terms of a respondent's subjective assessment of the average liquidity position and solidity during the last three years by using the scale from Very weak to Very good (Question 38). In addition, respondents were asked to note the turnover, business profit and balance sheet of their business during the last three years (Question 37).

\footnotetext{
${ }^{20}$ As small-scale firms rarely have any separate business units, we used the term internal-firm-process perspective instead of internal-business-process perspective.
} 
Vol. 13 (2004): Supplement 1.

\subsubsection{Business environment}

A firm interacts with its business environment (Pasanen 1999, p. 15). The business environment is comprised of all the external influences that impact a firm's strategic choices and performance (Grant 1998, p. 52). Business environment can be divided into local environment and competitive environment (Niittykangas 1992, p. 18). Local environment refers to the physical location of a firm whereas competitive environment refers to the marketplace in which a firm competes. Competitive environment can be apart from local environment. For example, a rural food processor may market its products in large growth centres through national retail chains. In many cases, however, the difference between local environment and competitive environment is not necessarily so clear since smaller firms often serve the local markets.

A deep understanding of the competitive environment is a common element of successful competitive strategies (Grant 1998). The competitive environment was approached from two viewpoints: scope of the market and intensity of competition. The competitive environment, from a geographical perspective, was studied by looking at the firms' scope of the market in the local-regional-national-international market axis (Question 32). The scope of the market in terms of the marketing channels was also studied (Question 34).

Intensity of competition is the central feature of the competitive environment (see Pelham and Wilson 1996). Intensity of competition was measured by several indicators. First, respondents were asked to what extent the firms compete with 1) ordinary foodstuffs of large firms, 2) special products of large firms, 3) products of other similar small or rural firms, and 4) to what extent they perceive that they do not have competitors at all (Question 12). The response scale ranged from Totally agree to Totally disagree. Second, respondents were asked how their perceived competition in terms of 1) price, 2) quality and 3) access to conventional marketing channels (Question 13). The scale ranged from In- tensity of competition is extremely low to Intensity of competition is extremely high. Third, respondents were asked whether they perceived the current competition as a threat to the continuity of their business (Question 15). The scale ranged from No threat at all to Very significant threat.

\subsubsection{Background information}

As background information the following items were included in the questionnaire:

- Main branch within the food sector (Question 1)

- Connection to a farm (Question 6)

- Firm age (Question 4)

- Objectives for the food-processing business (Question 9)

- Stage of the life cycle of the firm (Question 8)

- Number of employees (Question 52)

- Firm location (Question 53)

- Respondent's basic education (Question 54)

- Respondent's professional education (Question 55)

- Respondent's age (Question 57)

- Respondent's gender (Question 56)

\subsection{Reliability and validity of the study and the results}

Each study should aim to have good correspondence between the results and reality. Reliability means repeatability or consistency of the results; that is, the results are non-random. A measure is reliable if it will lead to the same results repeatedly (Trochim 2003). Validity, on the other hand, means the ability of a research method or measurement to measure what it is meant to measure (Eskola 1969, p. 55-56). When a measurement is valid it does not include systematic or random error (Churchill 1991, p. 488). Next different types of reliability and validity relating to this type of research are discussed. 
Forsman, S. How do small rural food-processing firms compete?

The external validity relates to generalising (Trochim 2003). The external validity of the study depends on the degree to which the data represent the population on which the sample is based (Valkonen 1984, p. 53). Since the original sample covered all the firms in the population and the response rate was $32 \%$, the sample is a rather good representation of food-processing businesses in rural areas. A rather long questionnaire might have decreased the response rate. The response rate is, however, moderate in comparison to similar types of surveys within the field (e.g., Hyvönen et al. 1995, Forsman 1999, Rantamäki-Lahtinen 2004).

The good generalisability is supported by the fact that the main branches of the food industry in rural Finland were represented in the sample and that the distribution of them largely matched their distribution in the population. Yet, it is important to be aware that non-responses, including 15 forms insufficiently completed may cause distortion in the data. The non-responding firms might, for example, be, on average, weaker-performing firms than the firms in the data. Moreover, it is important to note that many on-farm food businesses are not registered by Statistics Finland. The fact is that a considerable number of the on-farm processing businesses is under the Agriculture Tax Act and these firms are not included in the firm register by Statistics Finland. Hence, the actual number of small rural foodprocessing ventures is higher than the number of firms in the population of this study.

Construct validity also relates to generalising (Trochim 2003). Construct validity means the correspondence of the theoretical concept and the measures measuring this concept (Eskola 1969, p. 34). It is an assessment of how well the theories and ideas in the study are translated into actual measures or words representing this concept, that is to say, how well the concepts have been operationalised (Trochim 2003). The construct validity of the instruments used in the questionnaire was ensured in several ways. First, items and variables included in the questionnaire were built on the theories adapted in the study and some previous studies relating to the topic of the study. Second, the author's earlier qualitative case study based on personal interviews of small rural meat-processors (Forsman 1996) was a great help in gaining an understanding of the world view of small-scale entrepreneurs. This experience ensured that the items in the questionnaire were designed using language that was well understood by the respondents. Third, some of items were already used in a survey conducted in Finland (Forsman 1999) as well in a survey carried out in Norway and Sweden (Borch and Iveland 1997). The target group of both of these surveys matched the target group of the present study and, thus, the experiences from these surveys could be exploited here. Fourth, a few scholars in the field reviewed the questionnaire. They suggested some improvements in the content and clarity of the questionnaire. Finally, the questionnaire was pre-tested as a mail survey with the sample of 40 firms. Based on the pre-testing results and respondents comments about the clarity of the questions, the final version was devised.

When it comes to the concepts of strategic resources and basic resources, one should take a more critical approach to the construct validity. The concepts of strategic resources and basic resources were operationalised by trying to cover some central dimensions that might make resources strategic or basic in determining the competitive advantage and success of small foodprocessing firms. As described in Section 3.1.4, the concepts introduced in this study have affinities with the concepts presented in the RBV literature. Yet, the distinction between strategic resources and basic resources is not stringent, which is important to consider when interpreting the results. In addition, as was mentioned in Section 4.3.1, it is important to note that it was impossible to produce an exhaustive list of resources and competences that might have the potential to be strategic or basic resources for a firm. Hence, the number of resource items included in the questionnaire was limited and it was deemed more important to find indicators with which to analyse the relevance of the assumed distinction between strategic resources 


\section{Vol. 13 (2004): Supplement 1.}

and basic resources in the context of this study. In any case, other sets of resource items could have been employed, which might have affected the results differently (see Borch et al. 1999).

The content validity, which refers to the validity of the data, can be considered good, as well; those issues that relate to research problems were measured. Content validity was ensured by thorough orientation in the theoretical literature within the field. In addition, those actions that were taken to ensure the construct validity simultaneously improved the content validity of the data. In addition, the main constructs and themes were measured with several items.

The use of subjective measures of strategic positioning and performance may weaken the reliability of the data, since subjective measures are not interchangeable with objective measures. However, some studies have shown that a positive connection between subjective perception and objective measures exists (e.g., Dess and Robinson 1984, Lehtomaa 1995). To increase the validity of this study, multiple measures were employed to reflect the nature of the construct. Moreover, anonymity of the respondents was promised which can be expected to increase the validity and reliability of the responses. However, subjectivity is important to consider when interpreting the results.

A cross-sectional research design may also limit the interpretation of the results. Accumulation of firm-specific resources and competences takes place over time. Hence, studying relationships - input versus output - at a particular point in time does not necessarily reveal how long-term deployment of certain resources and competences might have influenced the output of the business. Therefore, to obtain a more detailed picture of the relationships between resources, competitive advantage and success, a longitudinal research design should be preferred in the future studies.

The reliability of the analysis is influenced by the degree of normal distribution of the variables and the sample size. Multivariate analysis usually requires that variables are normally distributed. Most of the multivariate analysis tech- niques are, however, quite robust, which means that small departures from normality do not necessarily cause severe problems (Ranta et al. 1989, p. 460). Most of the original variables of this study do not meet the strict requirements of normal distribution. To avoid problems that departures from normality may cause, the following actions were made. First, to decrease the number of variables for further analysis and to obtain stronger variables, a factor analysis was conducted. Principal axis factoring was chosen as an extraction method as it does not require the normality of the variables to such an extent as, for example, the commonly used maximum likelihood extraction method. Second, for further analysis, summated scale variables were created which improved the degree of normality. Third, when comparing the group means of variables along the clusters, non-parametric tests were used in the case of original variables. In addition, non-parametric tests were used in the case of summated scale variables if the assumption of the equality of the variances between the clusters could not been accepted.

The analysis of frequency data can be accomplished even with a small sample. Multivariate and correlative analysis techniques, by contrast, require large samples. A sample should then include at least 100 observations; in some cases the lowest limit is as high as 200 observations (Nummenmaa et al 1997, p. 35). For the LISREL analysis, an optimal sample size is about 200 observations. In this respect, the study fills the requirements. Group sizes in the cluster comparisons were naturally smaller, but comparisons were based then on non-correlative tests.

The methods used can also set limits for generalising. For example, the cluster analyses conducted were data-based. Empirically-based groupings are less frequently generalisable into the population (Hunt 1991, p. 183). Therefore, the results of the cluster analyses are, in the first place, only generalisable into the sample firms. The same can be said of the results of the LISREL modelling. Moreover, the empirical setting did not provide the possibility to use time series, the use of which might have provided in- 
Forsman, S. How do small rural food-processing firms compete?

formation of the persistence of the structural model. The limitations of the LISREL analysis are considered also in Section 5.3.2.

To summarise, the sample represents the population indicating a moderate external validity. The construct and content validity of the data was ensured in several ways. Still one should take a critical approach to the construct validity of the concepts of strategic resources and basic resources employed in this study. The cross-sectional nature of the research design and multivariate methods used may also set some limits for the generalisability of the results.

\section{Results}

\section{I Description of the data}

In this section the data are described. First, some central background characteristics are provided. After that the frequencies of the variables related to the key constructs of the study are described. In some sets of questions, the option $D o$ not know was chosen (see Appendix B), and if so, it was replaced by a missing value. Some sets of measures such as strength factors contain quite a long list of items and therefore exploratory factor analysis is undertaken to reduce the number of the variables. Based on the factor solution summated scale variables are then created to obtain stronger variables for the main analyses of the data. The most important decision criteria related to factor analysis and the creation of summated scale variables are presented in connection with the first factor analysis to be conducted.

\section{I.I Background characteristics of the data}

The data were elicited from 238 firms. Thirtynine per cent of the firms operated in connection with a farm. The firms were classified into eight branches (Table 6). The largest group is involved in the production of bread and bakery products following the distribution of the branches in the original population. Due to the small number of responses, firms that do not constitute a group of their own (e.g., production of sweets, production of honey products) were classified in a group designated as "others".

The firms were comparatively young. The firms averaged 18 years of age, with a median of 10 and a mode of five. Almost half of the firms $(47 \%)$ were established in the 1990s. The farmbased firms were on average younger than the other rural firms, 14 and 21 years, respectively. The average number of employees in 1999, including family members, was 3.3 persons, with a median of 2.0. The majority of the firms (82\%) employed less than five persons per year. Only six per cent of the firms employed at least 10 , but less than 20 persons. Sixty-three percent of the firms employed non-family members. The number of employees was slightly higher in the farm-based firms in comparison to the rest of the firms, 2.4 and 3.9 persons respectively.

When looking at the life cycle of the sample firms, we noted that half of the respondents reported that their business was in a stable production phase. This was a little surprising in view of the fact that the firms were, on average, quite young. Only $27 \%$ of the firms regarded their business to be in a growth stage. The rest of the firms were up to redirect their business, downsize the business, or end the business entirely (numbers 13\%, 6\%, 4\% respectively).

The firms were also small in terms of the annual turnover. The average turnover in 1999 was about $€ 315,000$. The highest numbers of 
Vol. 13 (2004): Supplement 1.

Table 6. Food-processing branches and the number of farm-based firms represented by the sample data.

\begin{tabular}{lccc}
\hline Branch & Total data & \multicolumn{2}{c}{ Firms with farm connection } \\
& Number & $\%$ & $\%$ \\
\hline Processing of meat and meat products & 27 & 11 & 48 \\
Processing of fish and fish products & 15 & 6 & 38 \\
Production of grain mill products & 21 & 9 & 27 \\
Production of bread and bakery products & 94 & 39 & 40 \\
Processing of milk & 10 & 4 & 66 \\
Processing of vegetables and potatoes & 29 & 12 & 60 \\
Processing of berries and fruit & 25 & 11 & 38 \\
Others & 17 & 7 & 39 \\
Total & 238 & 100 & \\
\hline
\end{tabular}

turnovers were found in the meat-processing firms; the smallest in the firms producing grain mill products. One should interpret these numbers with caution since only about two-thirds of the respondents reported their turnover for 1999.

The most important factors that were considered in goal setting were: to achieve a moderate living standard; to employ the entrepreneur him/ herself or other family members; to maintain as high profitability as possible, and to utilise experience, competence and independence relating to entrepreneurship (Fig. 6). By contrast, employing other people was not considered as important. Moreover, growth orientation was not emphasised very much in goal setting. The results indicate that small rural food processors may have other important goals in addition to financial goals.

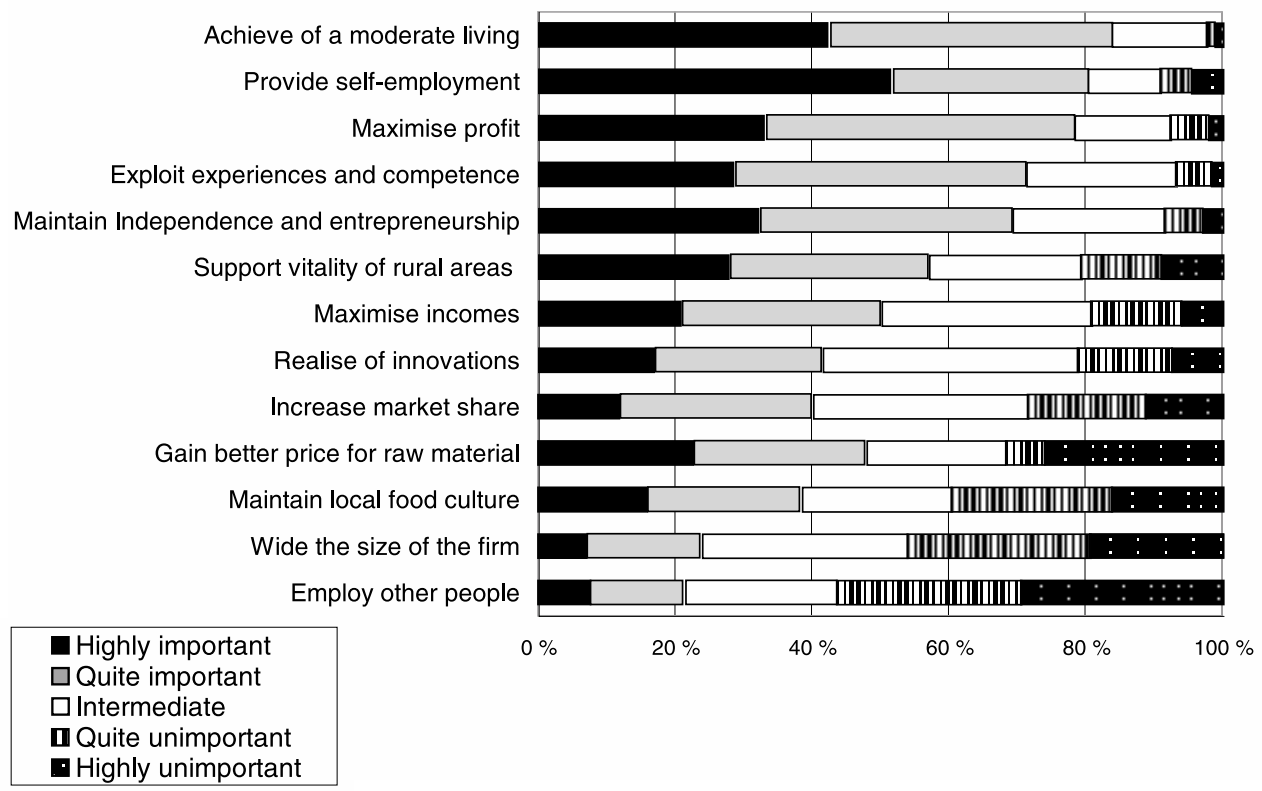

Fig. 6. Weight of the various items in goal setting. (Question 9: "What weight do the following items have in setting your goals?" Scale: $1=$ Highly unimportant, $5=$ Highly important) . 
Forsman, S. How do small rural food-processing firms compete?

Forty percent of the respondents were female. Two thirds (65\%) belonged to the age group 3554 . The professional education of the respondents was mainly vocational (vocational school, vocational institute, short-term vocational courses). Only five per cent of the respondents had taken a university degree, whereas $13 \%$ of the respondents reported that they had no professional education at all.

\subsubsection{Resources}

\section{Strategic resources}

The weight of the total of 28 strategic resource items in the sample firms was examined. In general, some of the items such as delivery reliability, excellent quality of products, flexibility and excellent product reputation were perceived to be high in importance in the majority of the firms (Fig. 7). Hence, these resources seem to be typical of small-scale firms. Yet, there are plenty of items the weight of which varied among the firms. For instance, traditional recipes or locality, which are often associated with rural smallscale processing, are not self-evident competitive strengths for small food processors. The least importance was placed on the use of organic raw materials indicating that the majority of the sample firms was using "conventional" raw materials or did not see any significant value added in using organic raw materials. Also attractive packages, different raw material composition, creativeness and wide product range were relatively low priorities in general.

To obtain stronger factors for further analyses, factor analysis on respondents' ratings of the $25^{21}$ strategic resources was conducted by using

\footnotetext{
${ }^{21}$ Two variables (Q1607, Q1621) were excluded in the analysis because of low communality. Communality means the total amount of variance an original variable shares with all other variables included in the analysis (Hair et al. 1998, p. 88). Moreover, one variable (Q1615) was omitted because it loaded simultaneously on several factors without any high loading.
}

principal-axis extraction method ${ }^{22}$ and the pairwise deletion option. Six factors were selected by the eigenvalue criterion (e.g., Hair et al. 1998, p. 103), altogether being found to explain $53 \%$ of the total variance. An orthogonal Varimax rotation $^{23}$ was then carried out to clarify factor loadings and to achieve a simpler, theoretically meaningful factor pattern. Table 7 shows the resulting factor loadings.

Variables with the highest factor loadings are most representative of the factor (e.g., Hair et al. 1998, p. 111-112). For each factor there were some high loadings. The factors were labelled as follows to reflect the variables loading high on each factor:

Factor 1 Superior reputation

Factor 2 Quality raw materials

Factor 3 Innovative products

Factor 4 Customer orientation

Factor 5 Way of distribution

Factor 6 Locality

Having identified six underlying factors, the next step involved a creation of summated scale variables. The role of factor analysis was to indicate which original variables are strongly interrelated and form a clear dimension. Then variables with high factor loadings (marked in bold in Table 7) were combined into a single composite measure. The average score of the variables was then used as a replacement. A summated scale variable provides two specific benefits in compared with the use of original variables. On the one hand, it decreases measurement error by using several variables to reduce the reliance on a single response. On the other hand, it represents the multiple aspects of a concept in a single measure. The summated scale variable has the advantage over factor scores options, for ex-

\footnotetext{
${ }^{22}$ The principal-axis method does not require multinormality of variables to such a degree as does the commonly used Maximun Likelihood method.

${ }^{23}$ In an orthogonal rotation factors remain uncorrelated, whereas an oblique rotation allows factors to be correlated (Nummenmaa et al. 1997, p. 245-247, Hair et al. 1998, p. 106-110).
} 


\section{AGRICULTURAL AND FOOD SCIENCE}

\section{Vol. 13 (2004): Supplement 1.}

Delivery reliability

Excellent quality of the products

Flexibility of the business from customers' point of view

Excellent product reputation

Personal customer service

Short chain of distribution from firm to customer

Excellent quality of raw material

Special know-how of entrepreneur/family

Consideration of customers' special wishes

Knowledge of product/raw material origin

Product appearance

Reputation of the trade name or trade mark

Firm reputation in the market area

Selected raw material suppliers

Local production

Manufacturing methods

Competitive prices

Sales techniques

Environmentally-sound products or practises

Distribution channels

Unique product idea

Product receipes based on traditions

Wide product-range

Creativeness/innovativeness in product development

Different raw material composition

Product packages

Use of organic raw materials

$0 \%$
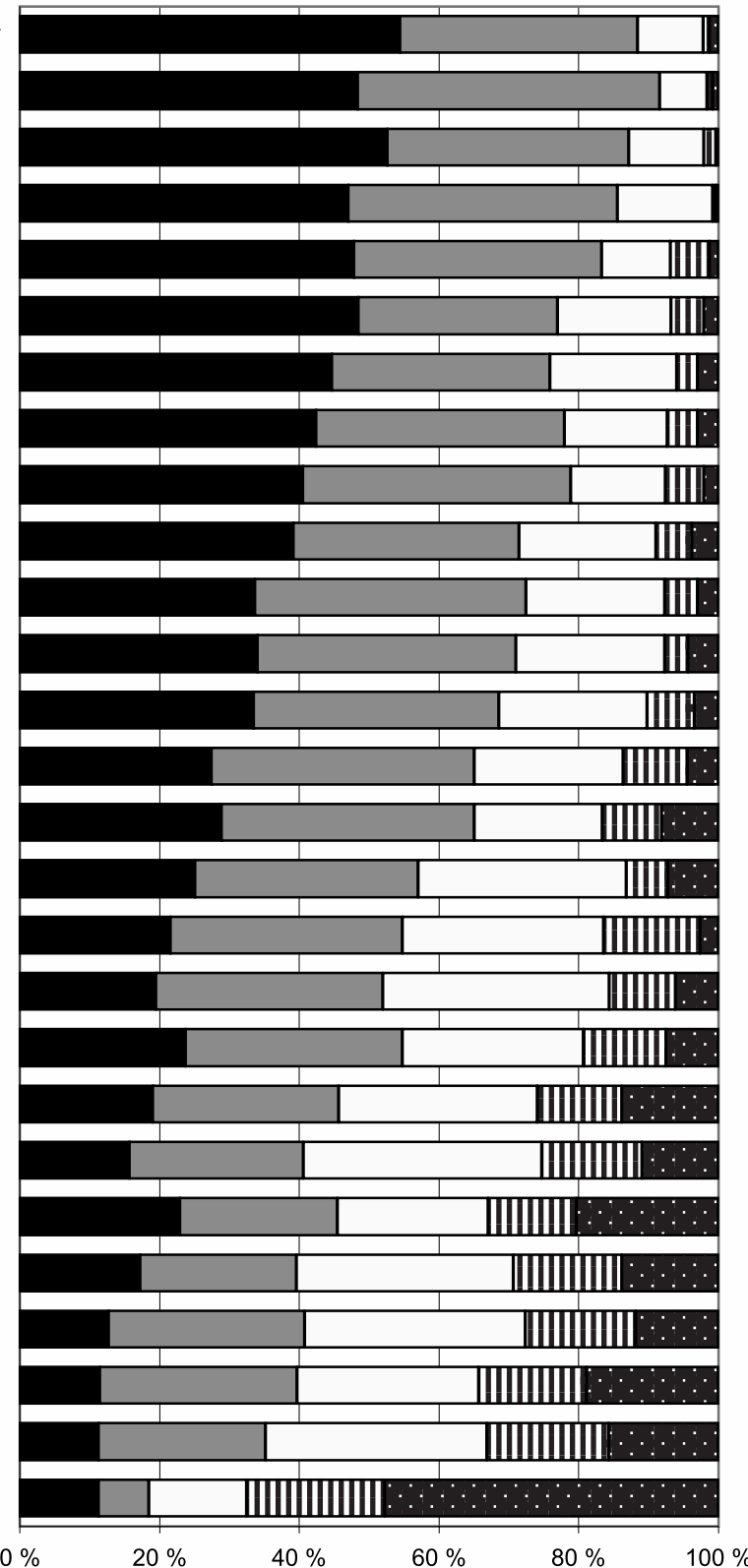

Considerably high importance

口High importance

$\square$ Intermediate

प Low importance

- Considerably low importance

Fig. 7. Weight of strategic resources in the sample firms. (Question 16: "To what extent do you consider the following items to be superior factors that differentiate your main products or firm from your principal competitors?" Scale: 1 = Considerably low importance, 5 = Considerably high importance. ) 
Forsman, S. How do small rural food-processing firms compete?

Table 7. Factor loadings for strategic resources.

\begin{tabular}{|c|c|c|c|c|c|c|c|}
\hline & $\begin{array}{l}\text { Factor } 1 \\
\text { Superior } \\
\text { reputation }\end{array}$ & $\begin{array}{l}\text { Factor 2 } \\
\text { Quality } \\
\text { raw } \\
\text { materials }\end{array}$ & $\begin{array}{l}\text { Factor } 3 \\
\text { Innovative } \\
\text { products }\end{array}$ & $\begin{array}{l}\text { Factor } 4 \\
\text { Customer } \\
\text { orientation }\end{array}$ & $\begin{array}{l}\text { Factor } 5 \\
\text { Way of } \\
\text { distribution }\end{array}$ & $\begin{array}{l}\text { Factor } 6 \\
\text { Locality }\end{array}$ & $\begin{array}{l}\text { Commu- } \\
\text { nality }\end{array}$ \\
\hline Excellent product reputation (Q1608) & 0.766 & & & & & & 0.652 \\
\hline Excellent quality of the products (Q1604) & 0.569 & 0.458 & & & & & 0.601 \\
\hline $\begin{array}{l}\text { Reputation of the trade name or trade } \\
\text { mark (Q1628) }\end{array}$ & 0.542 & & & & & 0.301 & 0.473 \\
\hline $\begin{array}{l}\text { Firm reputation in the market area } \\
\text { (Q1618) }\end{array}$ & 0.537 & & & & 0.308 & & 0.485 \\
\hline $\begin{array}{l}\text { Special know-how of entrepreneur/family } \\
\text { (Q1620) }\end{array}$ & 0.508 & & & 0.334 & & & 0.511 \\
\hline Delivery reliability (Q1619) & 0.485 & & & & & & 0.442 \\
\hline Product appearance (Q1613) & 0.459 & & & 0.337 & 0.300 & & 0.491 \\
\hline $\begin{array}{l}\text { Manufacturing methods of the products } \\
\text { (Q1606) }\end{array}$ & 0.455 & & & & & & 0.442 \\
\hline Excellent quality of raw material (Q1601) & & 0.807 & & & & & 0.750 \\
\hline Selected raw material suppliers (Q1602) & & 0.669 & & & & & 0.532 \\
\hline $\begin{array}{l}\text { Knowledge of product/raw material origin } \\
\text { (Q1625) }\end{array}$ & & 0.629 & & & & & 0.555 \\
\hline $\begin{array}{l}\text { Creativeness/innovativeness in product } \\
\text { development (Q1605) }\end{array}$ & & & 0.764 & & & & 0.656 \\
\hline $\begin{array}{l}\text { Different raw material composition } \\
\text { (Q1611) }\end{array}$ & & & 0.643 & & & & 0.505 \\
\hline Unique product idea (Q1603) & & & 0.637 & & & & 0.506 \\
\hline Use of organic raw materials (Q1610) & & 0.321 & 0.414 & & & & 0.341 \\
\hline $\begin{array}{l}\text { Consideration of customers' special } \\
\text { requests }(\mathrm{Q} 1622)\end{array}$ & & & & 0.741 & & & 0.595 \\
\hline $\begin{array}{l}\text { Flexibility of the business from customers' } \\
\text { point of view (Q1623) }\end{array}$ & & & & 0.712 & & & 0.606 \\
\hline Personal customer service (Q1624) & & & & 0.694 & & & 0.619 \\
\hline $\begin{array}{l}\text { Short chain of distribution from firm to } \\
\text { customer (Q1626) }\end{array}$ & & 0.393 & & 0.406 & & & 0.451 \\
\hline $\begin{array}{l}\text { Distribution channels of the products } \\
\text { (Q1616) }\end{array}$ & & & & & 0.768 & & 0.618 \\
\hline Sales techniques (Q1617) & & & & & 0.613 & & 0.528 \\
\hline Product packages (Q1614) & & & 0.405 & & 0.462 & & 0.406 \\
\hline Local production (Q1609) & & & & & & 0.616 & 0.446 \\
\hline Traditional product recipes (Q1612) & 0.327 & & & & & 0.520 & 0.454 \\
\hline $\begin{array}{l}\text { Environmentally-sound products or } \\
\text { practises (Q1627) }\end{array}$ & 0.493 & & & & & 0.515 & \\
\hline Eigenvalues & 7.4 & 2.4 & 2.1 & 1.5 & 1.4 & 1.2 & \\
\hline Percentage of variance (\%) & 12.1 & 10.0 & 9.3 & 9.2 & 7.0 & 5.8 & \\
\hline Cronbach's alpha ${ }^{1}$ & 0.84 & 0.81 & 0.77 & 0.80 & 0.74 & 0.63 & \\
\hline
\end{tabular}

Factor loadings derived by principal axis extraction, eigenvalue criterion and Varimax rotation. For the sake of simplicity only factor loadings higher than 0.3 are shown.

${ }^{1}$ The value of Cronbach's alpha for each factor is based on the variables with loadings marked in bold. 
Vol. 13 (2004): Supplement 1.

ample, of making interpretation easier; in the case of factor scores all variables have some degree of influence in computing the factors scores. Summated scale variables are also more appropriate if generalisability is desired (Hair et al. 1998, p. 118-120). When doing comparisons between groups they are also easier for a reader to interpret than factor scores. For the sake of simplicity, the summated scale variables created are referred to as factors hereafter.

When creating summated scale variables, case-specific missing values were treated as follows. If the number of missing values for a particular summated scale variable was only minor, the average score of those variables with a value from 1 to 5 was accepted as a replacement. If the number of missing values was significant for a particular case, no summated scale variable was calculated.

The reliability of the summated scale variables was measured by Cronbach's alpha which is a widely used reliability coefficient that assesses the consistency of the entire scale (Hair et al. 1998, p. 118). For all the summated scale variables excluding Factor 6 , the reliability coefficient can be found acceptable, since it exceeds the generally accepted lower limit, 0.70 . In addition, the item-to-total correlation (the correlation of the item to the summated scale score) exceeded 0.50 and the inter-item correlations (the correlation among items) exceeded 0.30 , which supports the good internal consistency of the summated scale variables (see Hair et al. 1998, p. 118).

Factor 6 (Locality dimension) is somewhat problematic since the reliability coefficient is only 0.63 . In exploratory research, yet, even 0.60 as a lower limit could be accepted (Hair et al. 1998, p. 188). Hence, the consistency of the summated scale variable based on Factor 6 can be considered moderate. Furthermore, the item-tototal correlation went slightly below 0.50 for all the variables in this factor indicating a lack of good reliability.

\section{Basic resources}

Alongside strategic resources a weight of a total of 26 basic resources items in the sample firms was investigated. Since the basic resources were measured in terms of weakness factors the scale was reversed for the analysis. Accordingly, hereafter a value of 1 (not a weakness at all) means significant weakness and vice versa. There was more heterogeneity of the respondents in the set of basic resources than in the set of strategic resources. Availability of capital and customers in the market area as well as firm location relative to customers were perceived as resource factors with the most significant weaknesses (Fig. 8). Also marketing and distribution competence was often considered as a weakness while production competence was found to be the least significant weakness.

Factor analysis was also undertaken for the basic resources. Six factors were extracted accounting for $56 \%$ of the variance of the 25 items $^{24}$ (Table 8). The factor solution can be found quite clear, although there are some items that load on several factors simultaneously. The factors were assigned the following names to reflect the variables loading high on each factor:

Factor 1 Business competence

Factor 2 Customer knowledge and accessibility

Factor 3 Production competence

Factor 4 Co-operation capability

Factor 5 Availability of production resources Factor 6 Financial capability

Summated scale variables were built based on the items marked with bold in Table 8. For all the summated scale variables excluding Factor 5 , the reliability coefficient can be considered acceptable, since it exceeds 0.70 . In addition, the item-to-total correlation for these variables exceeded 0.50 and the inter-item correlation exceeded 0.30 supporting the food internal consistency of the summated scale variables. Factor 5 (Availability of production resources) is somewhat problematic since the reliability coefficient is below 0.70 . In addition, item-to-

${ }^{24}$ One item (Q2714, Employees' motivation) was excluded because of the poor interpretation of the factor solution. 
Forsman, S. How do small rural food-processing firms compete?

Sufficiency of own capital
Sufficiency of customers in the market area
Firm location relative to customers
Marketing competence
Distribution competence

Availability of skilled employees

Amount of co-operation with other firms/organisations

Ability to take risks

Keeping track of changes in the competitive environment

Acquisition of customer and market knowledge

Quality of co-operation with other firms/organisations

Sales skills

Pricing competence

Adapting new production methods/techologies

Availability of counselling

Competence needed in defining target groups

Product development competence

Availability of liabilities

Innovativeness/creativeness

Clear view of the firm's prospects

Customer-orientation in product development and marketing

Financial management competence

Finding suitable raw material suppliers

Employees' motivation

Sufficiency of experience within the field

Production competence
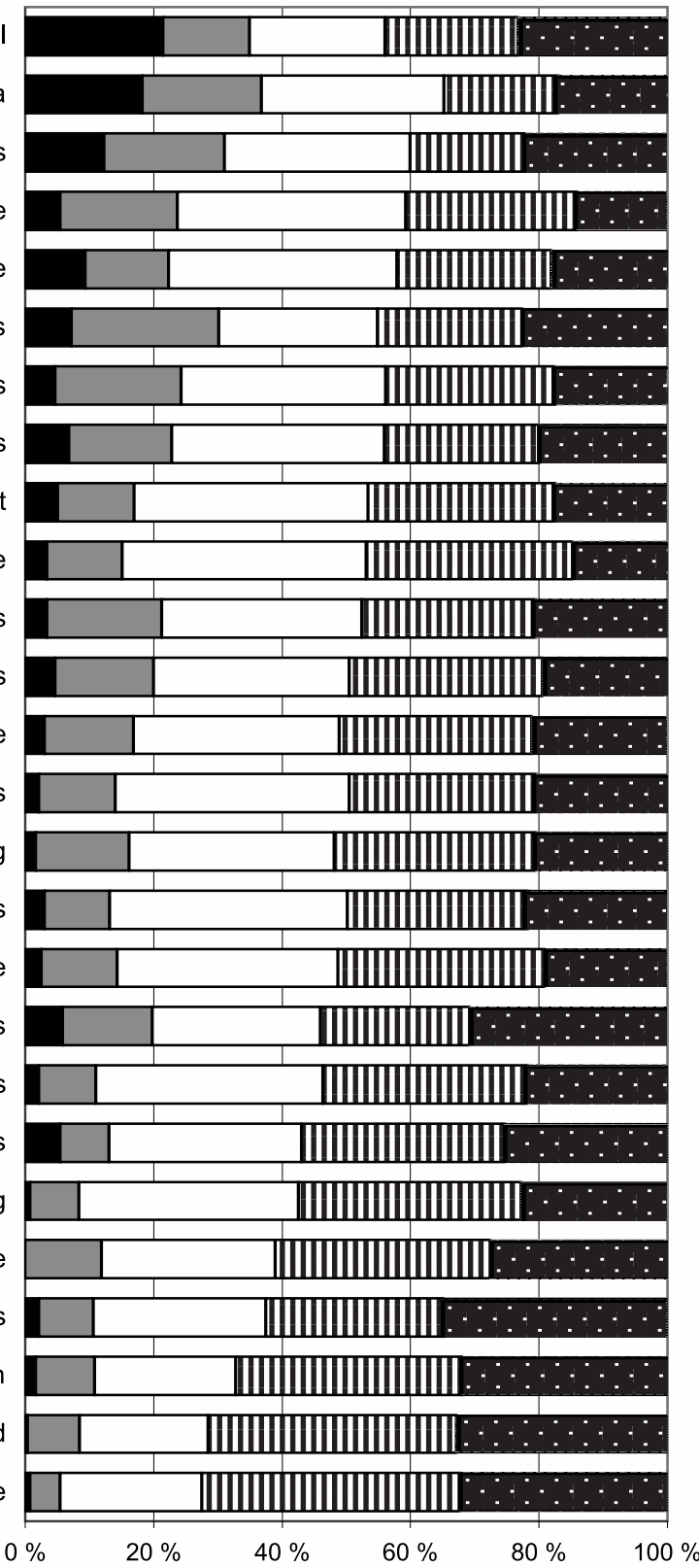

Significant weakness

$\square$ Major weakness

$\square$ Intermediate

m Minor weakness

Not a weakness

Fig 8. Weight of basic resources in the sample firms. (Question 27: "To what extent do you consider the following factors to be weaknesses in your firm that make it difficult for you to achieve and maintain a competitive position in your market area?" Scale: 1 = Not a weakness, 5 = Significant weakness.) 
Vol. 13 (2004): Supplement 1.

Table 8. Factor loadings for basic resources.

\begin{tabular}{|c|c|c|c|c|c|c|c|}
\hline Variable & $\begin{array}{l}\text { Factor } 1 \\
\text { Business } \\
\text { competence }\end{array}$ & $\begin{array}{l}\text { Factor } 2 \\
\text { Customer } \\
\text { knowledge } \\
\text { and } \\
\text { accessibility }\end{array}$ & $\begin{array}{l}\text { Factor } 3 \\
\text { Production } \\
\text { competence }\end{array}$ & $\begin{array}{l}\text { Factor } 4 \\
\text { Co-operation } \\
\text { competence }\end{array}$ & $\begin{array}{l}\text { Factor } 5 \\
\text { Availability } \\
\text { of } \\
\text { production } \\
\text { resources }\end{array}$ & $\begin{array}{l}\text { Factor } 6 \\
\text { Financial } \\
\text { capability }\end{array}$ & $\begin{array}{l}\text { Commu- } \\
\text { nality }\end{array}$ \\
\hline Sales skills (Q2710) & 0.729 & & & & & & 0.669 \\
\hline Ability to take risks (Q2720) & 0.630 & & & & & 0.378 & 0.613 \\
\hline Marketing competence (Q2709) & 0.598 & 0.436 & & & & & 0.655 \\
\hline $\begin{array}{l}\text { Financial management competence } \\
\text { (Q2718) }\end{array}$ & 0.590 & & 0.304 & & & 0.315 & 0.587 \\
\hline Pricing competence (Q2711) & 0.580 & & 0.340 & & & & 0.501 \\
\hline Availability of counselling (Q2719) & 0.515 & & & & 0.330 & & 0.480 \\
\hline Distribution competence (Q2712) & 0.511 & 0.397 & & 0.330 & & & 0.557 \\
\hline Innovativeness/creativeness (Q2721) & 0.503 & & & & & & 0.470 \\
\hline $\begin{array}{l}\text { Keeping track of changes in the } \\
\text { competitive environment (Q2726) }\end{array}$ & 0.482 & 0.376 & & & & & 0.493 \\
\hline $\begin{array}{l}\text { Clear view of the firm's prospects } \\
\text { (Q2725) }\end{array}$ & 0.427 & & & & 0.306 & & 0.418 \\
\hline $\begin{array}{l}\text { Sufficiency of customers in the } \\
\text { market area (Q2703) }\end{array}$ & & 0.688 & & & & & 0.544 \\
\hline $\begin{array}{l}\text { Firm location relative to customers } \\
\text { (Q2704) }\end{array}$ & & 0.509 & & & & & 0.380 \\
\hline $\begin{array}{l}\text { Acquisition of customer and market } \\
\text { knowledge (Q2708) }\end{array}$ & 0.408 & 0.505 & 0.301 & & & & 0.586 \\
\hline $\begin{array}{l}\text { Competence needed in defining } \\
\text { target groups (Q2705) }\end{array}$ & 0.306 & 0.440 & 0.374 & & & & 0.520 \\
\hline Production competence (Q2707) & & & 0.686 & & & & 0.634 \\
\hline $\begin{array}{l}\text { Product development competence } \\
\text { (Q2706) }\end{array}$ & 0.310 & & 0.552 & & & & 0.522 \\
\hline $\begin{array}{l}\text { Sufficiency of experience within } \\
\text { the field (Q2715) }\end{array}$ & 0.380 & & 0.529 & & & & 0.524 \\
\hline $\begin{array}{l}\text { Customer-orientation in product } \\
\text { development and marketing (Q2713) }\end{array}$ & 0.382 & 0.372 & 0.469 & & & & 0.569 \\
\hline $\begin{array}{l}\text { Amount of co-operation with other } \\
\text { firms/organisations (Q2716) }\end{array}$ & & & & 0.868 & & & 0.892 \\
\hline $\begin{array}{l}\text { Quality of co-operation with other } \\
\text { firms/organisations (Q2717) }\end{array}$ & & & & 0.808 & & & 0.756 \\
\hline $\begin{array}{l}\text { Finding appropriate raw material } \\
\text { suppliers (Q2723) }\end{array}$ & & & & & 0.676 & & 0.484 \\
\hline $\begin{array}{l}\text { Adapting new production } \\
\text { methods/technologies (Q2724) }\end{array}$ & 0.381 & & & & 0.592 & & 0.549 \\
\hline $\begin{array}{l}\text { Availability of skilled employees } \\
\text { (Q2722) }\end{array}$ & & & & & 0.539 & & 0.367 \\
\hline Availability of liabilities (Q2702) & & & & & & 0.745 & 0.601 \\
\hline Sufficiency of own capital (Q2701) & & & & & & 0.703 & 0.612 \\
\hline Eigenvalues & 9.5 & 1.8 & 1.5 & 1.3 & 1.3 & 1.1 & \\
\hline Percentage of variance $(\%)$ & 16.7 & 9.3 & 8.7 & 7.8 & 6.9 & 6.5 & \\
\hline Cronbach's alpha ${ }^{1}$ & 0.89 & 0.77 & 0.76 & 0.91 & 0.67 & 0.76 & \\
\hline
\end{tabular}

Factor loadings derived by principal axis extraction, eigenvalue criterion and Varimax rotation. For the sake of simplicity only factor loadings higher than 0.3 are shown.

1 The value of Cronbach's alpha for each factor is based on the variables with loadings marked in bold. 
Forsman, S. How do small rural food-processing firms compete?

total correlation for two variables underlying Factor 5 went below 0.50 indicating that the reliability of this variable is only moderate.

\section{I.3 Competitive-advantage related variables}

The perceived degree of product, services and overall differentiation of the sample firms is displayed in Figure 9. The average degree of product differentiation compared to larger firms was quite high. By contrast, in comparison to similar types of small or rural firms, the average degree of product differentiation was clearly lower. The trend was the same when looking at services and overall differentiation. In terms of price levels (Fig. 10), the prices were most often perceived to be higher or average compared to larger firms. When compared to other small firms, $56 \%$ of the respondents considered that their prices were at the same level.
Thirty-eight per cent of the respondents thought that the product characteristics of their products were quite difficult (options 4 and 5) for competitors to imitate. The corresponding number for the imitability of the competence underlying differentiation was 40\% (Question 20). Similarly, for $44 \%$ of the firms, products were perceived as difficult to substitute (Question 24). However, only $22 \%$ of the respondents thought that the threat for imitability was considerable (options 4 and 5) among larger firms. The corresponding number for the threat of imitability among similar types of small firms was clearly higher, 36\% (Question 21).

In the comparison of strategic actions over the last three years, increasing customer satisfaction, maintaining customer relationships actively and systematic quality control received the highest average scores (Fig. 11). The least effort had been put into price reductions and cutting down the product range. In most items, however, there was substantive variation.

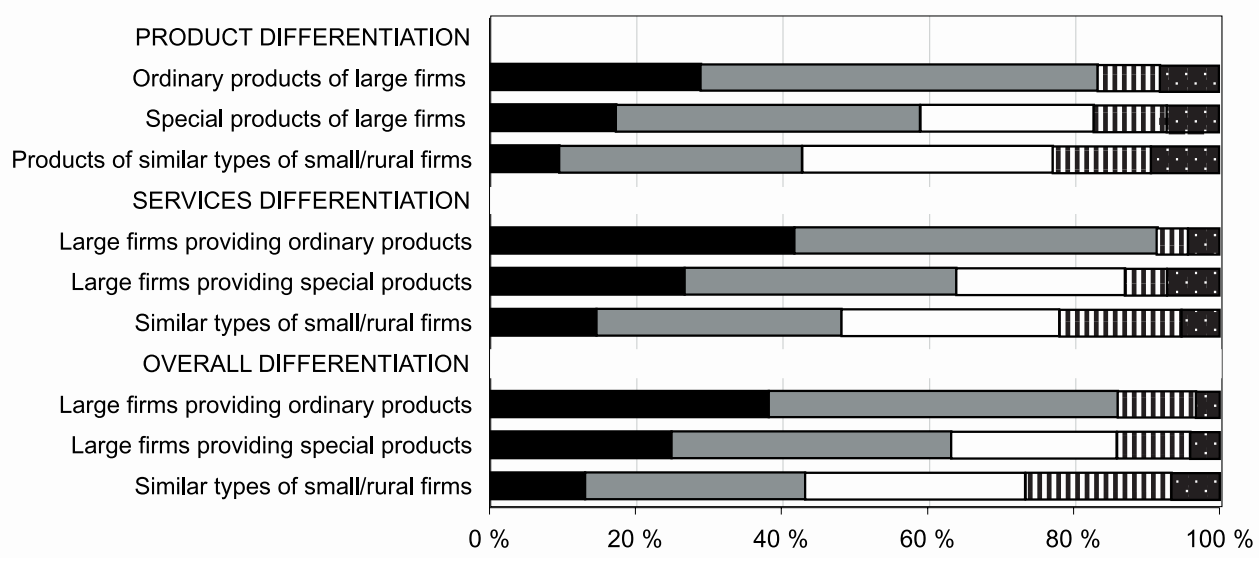

- High degree of differentiation

$\square$ Average degree of differentiation

口 Low degree of differentiation $\square$ Quite high degree of differentiation

mQuite low degree of differentiation

Fig. 9. Degree of product, services and overall differentiation compared to the reference groups. (Questions 17, 18 and 19. Scale: 1 = Low degree of differentiation, 5 = High degree of differentiation.) 


\section{AGRICULTURAL AND FOOD SCIENCE}

\section{Vol. 13 (2004): Supplement 1.}

Fig. 10. Price level compared to the reference groups. (Question 25: "How do you perceive the price level of your products in comparison to...?" Scale: 1 = Our prices are lower, $5=$ Our prices are higher.)

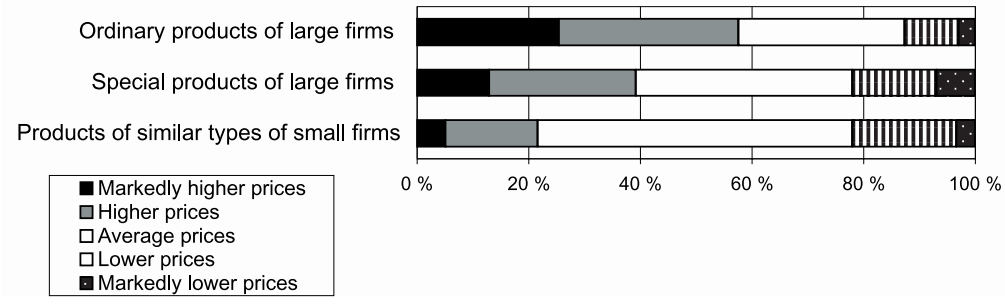

Increasing customer satisfaction Actively maintaining customer relationships

Systematic quality contro

Development of own/employees' comptence Modification or improvement of products

Acquiring new customers

Monitoring changes in the competitive environment

New product development

Development of new production methods/processes

Reducing unit costs

Increasing the degree of product differentiation in relation to competitors

Acquiring knowledge of customers/markets Customer or marketing channel-specific planning of marketing

Widening market area

Defining or specifying the target group Looking actively for co-operation partners

Widening product range

Focusing on only a few customers/customer groups Increasing prices in relation to main competitors Finding out competitors' strengths and competences Responding to competitors' marketing actions Price reductions in relation to main competitors Cutting down product range

Significant effort

$\square$ Above-average effort

$\square$ Average effort

口 Below-average effort

口 Insignificant effort
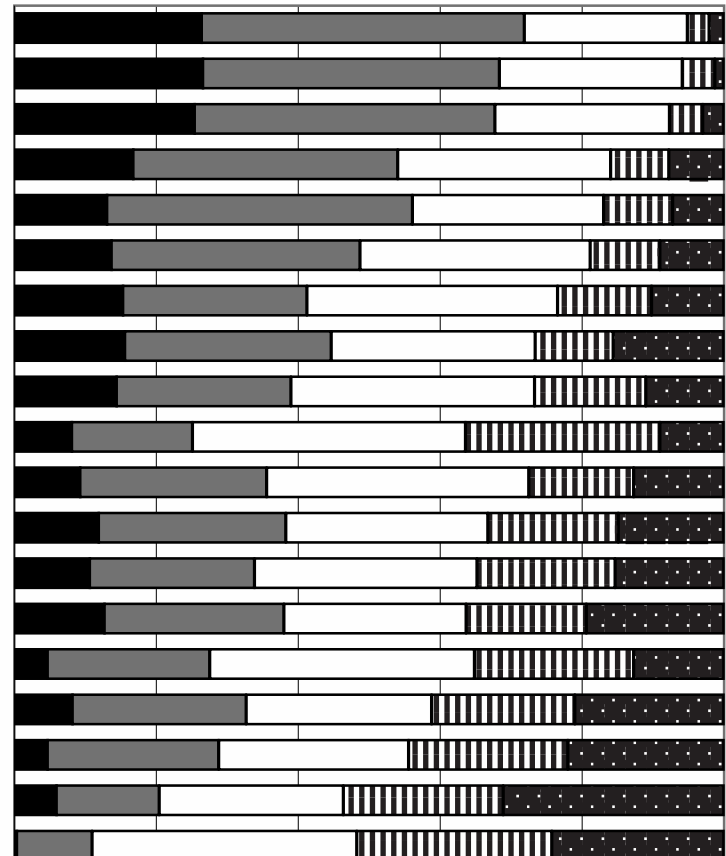

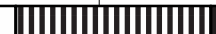
|ाIIIIIIIIIIIIIIII

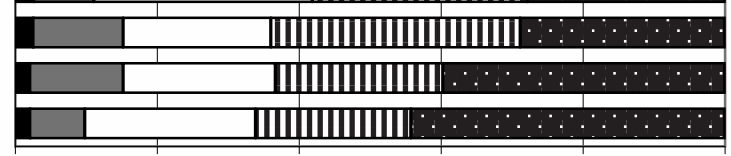

$\begin{array}{llllll}0 \% & 20 \% & 40 \% & 60 \% & 0\end{array} \%$

Fig. 11. Strategic actions in the sample firms. (Question 22: "To what extent have you put effort into the following actions over last three years? Scale: 1 = Insignificant effort to $5=$ Significant effort).

Factor analysis was conducted for the strategic actions items. A pattern of four factors was accepted as a final solution accounting for $52 \%$ of the variance of 22 items (Table 9). The factors were labelled as follows:
Factor 1 Customer-based market development Factor 2 Improvement of customer satisfaction

Factor 3 Active product development

Factor 4 Competitor orientation 
Forsman, S. How do small rural food-processing firms compete?

Table 9. Factor loadings for strategic actions.

\begin{tabular}{|c|c|c|c|c|c|}
\hline Variable & $\begin{array}{l}\text { Factor 1 } \\
\text { Customer- } \\
\text { based market } \\
\text { development }\end{array}$ & $\begin{array}{l}\text { Factor } 2 \\
\text { Improvement } \\
\text { of customer } \\
\text { satisfaction }\end{array}$ & $\begin{array}{l}\text { Factor } 3 \\
\text { Active product } \\
\text { development }\end{array}$ & $\begin{array}{l}\text { Factor } 4 \\
\text { Competitor } \\
\text { orientation }\end{array}$ & Communality \\
\hline Widening market area (Q2223) & 0.711 & & 0.414 & & 0.698 \\
\hline Acquiring new customers (Q2213) & 0.693 & & & & 0.622 \\
\hline $\begin{array}{l}\text { Customer or marketing channel-specific } \\
\text { planning of marketing (Q2208) }\end{array}$ & 0.653 & 0.427 & & & 0.719 \\
\hline $\begin{array}{l}\text { Acquiring knowledge of customers and } \\
\text { markets (Q2207) }\end{array}$ & 0.622 & 0.407 & & & 0.687 \\
\hline $\begin{array}{l}\text { Looking actively for co-operation partners } \\
\text { (Q2212) }\end{array}$ & 0.511 & & 0.307 & 0.329 & 0.528 \\
\hline $\begin{array}{l}\text { Defining or specifying the target group } \\
\text { (Q2211) }\end{array}$ & 0.487 & 0.379 & & 0.378 & 0.592 \\
\hline Increasing customer satisfaction (Q2216) & & 0.721 & & & 0.550 \\
\hline $\begin{array}{l}\text { Development of own/employees' } \\
\text { competence (Q2215) }\end{array}$ & & 0.634 & 0.312 & & 0.522 \\
\hline $\begin{array}{l}\text { Actively maintaining customer } \\
\text { relationships (Q2220) }\end{array}$ & & 0.541 & & & 0.353 \\
\hline Systematic quality control (Q2204) & & 0.527 & & & 0.325 \\
\hline $\begin{array}{l}\text { Monitoring changes in the competitive } \\
\text { environment (Q2214) }\end{array}$ & 0.389 & 0.513 & & 0.330 & 0.565 \\
\hline New product development (Q2201) & 0.304 & & 0.799 & & 0.752 \\
\hline Widening product range (Q2222) & 0.428 & & 0.632 & & 0.585 \\
\hline $\begin{array}{l}\text { Modification or improvement of } \\
\text { products (Q2202) }\end{array}$ & & 0.430 & 0.535 & & 0.556 \\
\hline $\begin{array}{l}\text { Development of new production } \\
\text { methods/processes (Q2203) }\end{array}$ & & & 0.510 & & 0.419 \\
\hline $\begin{array}{l}\text { Increasing the degree of product } \\
\text { differentiation in relation to competitors } \\
\text { (Q2206) }\end{array}$ & & 0.365 & 0.469 & & 0.486 \\
\hline $\begin{array}{l}\text { Responding to competitors' marketing } \\
\text { actions (Q2209) }\end{array}$ & 0.336 & & & 0.627 & 0.546 \\
\hline $\begin{array}{l}\text { Finding out competitors' strengths and } \\
\text { competences (Q2218) }\end{array}$ & 0.412 & & & 0.596 & 0.595 \\
\hline Cutting down product range (Q2217) & & & & 0.588 & 0.357 \\
\hline $\begin{array}{l}\text { Focusing on only a few customers/customer } \\
\text { groups (Q2219) }\end{array}$ & & & & 0.574 & 0.369 \\
\hline $\begin{array}{l}\text { Price reductions in relation to main } \\
\text { competitors (Q2205) }\end{array}$ & & & & 0.498 & 0.312 \\
\hline Reducing unit costs (Q2210) & 0.346 & 0.350 & & 0.361 & 0.375 \\
\hline Eigenvalues & 8.5 & 2.0 & 1.7 & 1.2 & \\
\hline Percentage of variance (\%) & 36.8 & 6.9 & 5.5 & 3.9 & \\
\hline Cronbach's alpha ${ }^{1}$ & 0.90 & 0.78 & 0.83 & 0.75 & \\
\hline
\end{tabular}

Factor loadings derived by principal axis extraction, eigenvalue criterion and Varimax rotation. For the sake of simplicity only factor loadings higher than 0.3 are shown.

1 The value of Cronbach's alpha for each factor is based on variables with boldface factor loadings. 
Vol. 13 (2004): Supplement 1.

Summated scale variables were built based on the items with factor loadings marked in bold in Table 8. Their reliability, based on Cronbach's alpha, inter-item and item-to-total correlations, can be considered acceptable.

\section{I.4 Performance}

A question pool measuring firm performance included 26 items. As shown by Figure 12, the respondents were most often satisfied with delivery reliability, customer satisfaction with the products, product quality relative to competitors and customer retention. Items related to costs, on the other hand, were most often the factors with which the respondents were dissatisfied. Labour costs, in particular, seem to cause dissatisfaction among the sample firms; close to $60 \%$ of the respondents were unsatisfied with their labour costs.

To obtain stronger factors for further analyses, a factor analysis was undertaken. Two variables measuring the amount and quality of cooperation with other firms or actors (Q4123, Q4124) were, however, omitted in the analyses because they were found to be unclear indicators for success. Thus, the factor analysis was based on 24 items.

As a result, six factors were extracted. The six-factor solution accounted for $55 \%$ of the variance of the 25 items (Table 10). The factor solution can be found quite clear, although there were some items that load on several factors simultaneously. For each factor, however, there were some high loadings. The factors were assigned the following names:

Factor 1 Financial performance

Factor 2 Quality performance

Factor 3 Market performance

Factor 4 Cost performance

Factor 5 Price performance

Factor 6 Overall competence performance

Based on the results of the factor analysis, summated scale variables were built based on the items with factor loadings marked in bold in Table 10. For all the summated scale variables excluding Factor 5, the reliability coefficient can be considered acceptable, since they are over 0.70 . In addition, the item-to-total correlation for the variables exceeded 0.50 and the inter-item correlations exceeded 0.30 , which supports the good internal consistency of the summated scale variables.

Success was also considered in terms of subjective perceptions of profitability in comparison to three reference points: 1) industry average, 2) similar types of small businesses in the same industry, 3) objectives set for the business (Question 36), and 4) in terms of liquidity position and solidity (Question 38). The most common opinion was that the business is averagely profitable. The assessments of liquidity position and solidity were on average somewhat higher than the profitability assessments (Fig. 13).

\section{I.5 Competitive environment}

The firms most often operated in local markets. On average, $58 \%$ of the sales came from the home or neighbouring municipalities. Twentyseven per cent of the firms sold their products solely in the local markets. A quarter of the sales ( $24 \%$ ), on average, came from the national markets outside the local market area. Eight per cent of the firms exported, but the share of the export in terms of sales proceeds was generally marginal. The firms in bakery production and grain mill production operated most often on the local markets while the firms in meat production mostly marketed their products on the national market level. The most important marketing channels (Question 34) for the firms were direct sales, retail stores, restaurants and institutional catering units.

Figure 14 shows that small food processors are competing not only with larger firms, but also with other similar types of small or rural firms. Only $11 \%$ of the respondents perceived that their products have no competitors at all. The competition in the small-scale food production is intense (Question 13). Price competition and competition in access to conventional marketing 


\section{AGRICULTURAL AND FOOD SCIENCE}

Forsman, S. How do small rural food-processing firms compete?

\begin{abstract}
Delivery reliability
Customer satisfaction with the products

Product quality relative to competitors
\end{abstract}

Customer retention

Employees' competence in relation to competitors

Price/quality relationship perceived by customers

Stock turnover

Keeping track of the development of the field of business

Sales volume

Number of new customers

Development of the demand for the products

Developmemt of market share

Price level of the products

Utilisation rate of the capacity

Unit costs relative to competitors

Business revenue

Quality of co-operation with other firms/organisations

Amount of co-operation with other firms/organisations

Number of new products

Ability to command a price premium

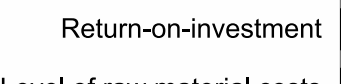

Level of raw material costs

Level of capital costs

Development of unit costs

Business profit

Level of labour costs
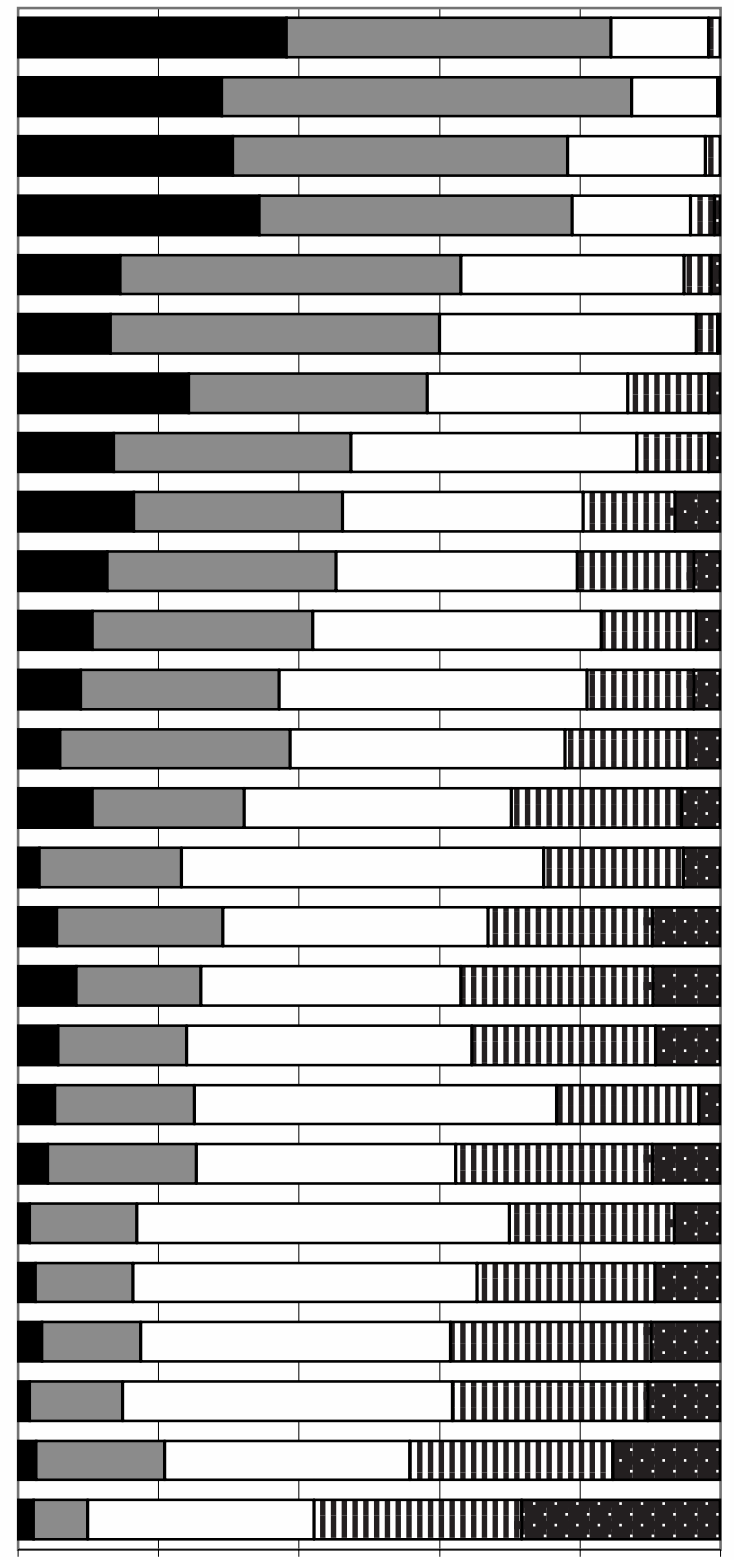

$0 \%$

$40 \%$

$60 \%$

$80 \%$

$100 \%$

Highly satisfied

$\square$ Satisfied

$\square$ Intermediate

m Dissatisfied

- Highly dissatisfied

Fig. 12. Weight of performance variables in the sample firms. (Question 41: "To what extent are you satisfied with the following items over the last three years?" Scale: 1 = Highly dissatisfied, 5 = Highly satisfied.) 
Vol. 13 (2004): Supplement 1.

Table 10. Factor loadings for performance factors.

\begin{tabular}{|c|c|c|c|c|c|c|c|}
\hline Variable & $\begin{array}{l}\text { Factor } 1 \\
\text { Financial } \\
\text { performance }\end{array}$ & $\begin{array}{l}\text { Factor } 2 \\
\text { Quality } \\
\text { performance }\end{array}$ & $\begin{array}{l}\text { Factor } 3 \\
\text { Market } \\
\text { performance }\end{array}$ & $\begin{array}{l}\text { Factor } 4 \\
\text { Cost } \\
\text { performance }\end{array}$ & $\begin{array}{l}\text { Factor } 5 \\
\text { Price } \\
\text { performance }\end{array}$ & $\begin{array}{l}\text { Factor } 6 \\
\text { Overall } \\
\text { competence } \\
\text { performance }\end{array}$ & $\begin{array}{l}\text { Commu- } \\
\text { nality }\end{array}$ \\
\hline Business profit (Q4108) & 0.773 & & & & & & 0.729 \\
\hline Business revenue (Q4102) & 0.759 & & & & & & 0.735 \\
\hline $\begin{array}{l}\text { Sales volume of the products } \\
\text { (Q4101) }\end{array}$ & 0.591 & 0.349 & 0.462 & & & & 0.708 \\
\hline Return-on-investment (Q4107) & 0.576 & & & 0.367 & & & 0.535 \\
\hline $\begin{array}{l}\text { Utilisation rate of the capacity } \\
\text { (Q4120) }\end{array}$ & 0.448 & 0.412 & & & & & 0.487 \\
\hline Delivery reliability (Q4122) & & 0.668 & & & & & 0.533 \\
\hline $\begin{array}{l}\text { Product quality relation to } \\
\text { competitors (Q4119) }\end{array}$ & & 0.662 & & & & & 0.539 \\
\hline $\begin{array}{l}\text { Customer satisfaction with } \\
\text { the products (Q4112) }\end{array}$ & & 0.636 & & & & & 0.573 \\
\hline Stock turnover (Q4121) & 0.365 & 0.533 & & & & & 0.482 \\
\hline $\begin{array}{l}\text { Price/quality relationship } \\
\text { perceived by customers (Q4114) }\end{array}$ & & 0.513 & & & 0.475 & & 0.567 \\
\hline Customer retention (Q4109) & & 0.410 & 0.351 & & & & 0.370 \\
\hline $\begin{array}{l}\text { Number of new customers } \\
\text { (Q4110) }\end{array}$ & & & 0.706 & & & & 0.605 \\
\hline $\begin{array}{l}\text { Development of the demand } \\
\text { for the products (Q4116) }\end{array}$ & & 0.346 & 0.646 & & & & 0.670 \\
\hline $\begin{array}{l}\text { Development of market share } \\
\text { (Q4111) }\end{array}$ & 0.312 & & 0.611 & & & & 0.578 \\
\hline Number of new products (Q4117) & & & 0.468 & & & & 0.323 \\
\hline Level of capital costs (Q4106) & & & & 0.741 & & & 0.637 \\
\hline Level of labour costs (Q4105) & & & & 0.628 & & & 0.435 \\
\hline Level of raw material costs (Q4104) & & & & 0.542 & & & 0.401 \\
\hline $\begin{array}{l}\text { Development of unit costs } \\
\text { (Q4103) }\end{array}$ & 0.392 & & & 0.439 & & & 0.504 \\
\hline $\begin{array}{l}\text { Unit costs relative to } \\
\text { competitors (Q4118) }\end{array}$ & & & & 0.382 & & & 0.335 \\
\hline $\begin{array}{l}\text { Ability to command a price } \\
\text { premium (Q4115) }\end{array}$ & & & & & 0.682 & & 0.557 \\
\hline Price level of the products (Q4113) & 0.384 & & & & 0.569 & & 0.624 \\
\hline $\begin{array}{l}\text { Employees' competence in } \\
\text { relative to competitors (Q4125) }\end{array}$ & & 0.364 & & & & 0.723 & 0.684 \\
\hline $\begin{array}{l}\text { Keeping track of the development } \\
\text { of the field of business (Q4126) }\end{array}$ & & 0.305 & 0.364 & & & 0.596 & 0.662 \\
\hline Eigenvalues & 8.4 & 2.5 & 1.6 & 1.2 & 1.1 & 1.0 & \\
\hline Percentage of variance $(\%)$ & 12.6 & 11.9 & 10.9 & 9.1 & 5.9 & 5.0 & \\
\hline Cronbach's alpha ${ }^{1}$ & 0.86 & 0.80 & 0.81 & 0.77 & 0.72 & 0.76 & \\
\hline
\end{tabular}

Factor loadings derived by principal axis extraction, eigenvalue criterion and Varimax rotation. For the sake of simplicity only factor loadings higher than 0.3 are shown.

1 The value of Cronbach's alpha for each factor is based on the variables with loadings marked in bold. 
Forsman, S. How do small rural food-processing firms compete?

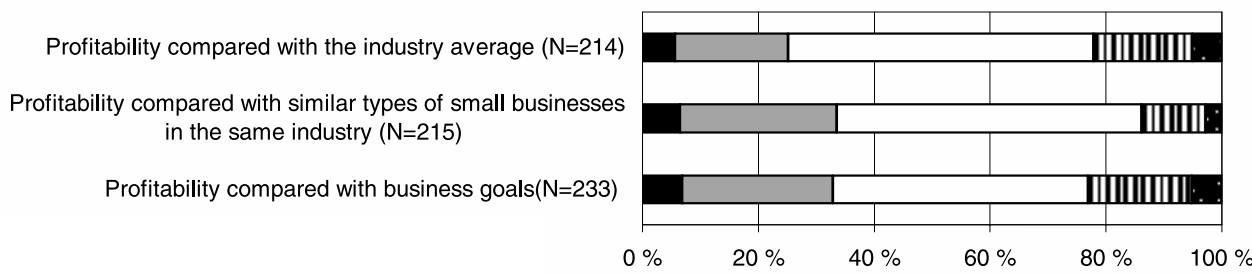
Hihgly profitable
$\square$ Above-averagely profitable
$\square$ Intermediate
$\square$ Below-averagely profitable
Not profitable

Fig 13. Respondents' perceptions of the profitability of their business (\% of firms). (Question 36: "How do you assess the average profitability of your business during the last three years in relation to...?". Scale: 1

= Not profitable, $5=$ Highly profitable .

channels was found to be extremely tough (option 5) by $45 \%$ and $46 \%$ of respondents, respectively. Quality competition was found to be extremely difficult by $25 \%$ of respondents. Moreover, $41 \%$ of respondents saw the intensity of competition as a considerable threat (options 4 and 5) to the continuity of the business (Question 15).

\section{I.6 Summary}

The main characteristics of the data have now been described. In summary, out of 238 sample firms $39 \%$ had a farm connection. The firms were comparatively young: almost half of them were established in the 1990s. The average number of employees was 3.3. Despite the small size in

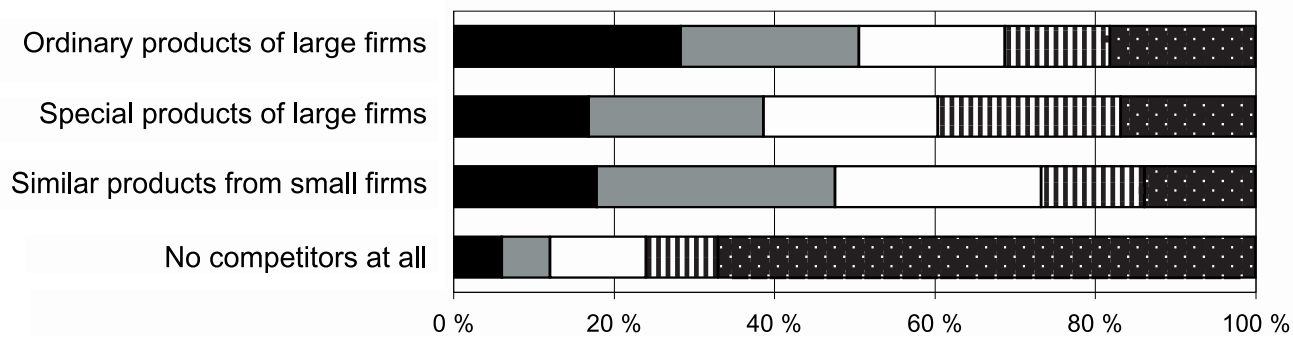

Totally agree

$\square$ Agree

$\square$ Not agree, not disagree

mDisagree

Totally disagree

Fig. 14. Competitors of the sample firms. (Question 12: "To what extent do the following statements describe the competitors of your main products?" Scale: $1=$ Totally disagree to $5=$ Totally agree) . 
Vol. 13 (2004): Supplement 1.

terms of employees and turnover and the young firm age, the number of firms in the growth stage was relatively small, only $27 \%$. The highest importance in goal setting of the business was placed on achieving a moderate standard of living and self-employment.

The firms were relatively local-market oriented. Among their competitors, there were both larger companies and similar small firms. The intensity of competition, particularly in terms of price and access to conventional marketing channels, was found to be extremely tough and even threatened the continuity of the business.

Certain strategic resources seem to be typical to small food processors. In addition to overall product quality, the highest priorities related mainly to service factors and flexibility. The most significant basic resources perceived by the firms related to financial capability in terms of capital sufficiency and the availability of customers. Marketing and distribution competence were also relatively high priorities as weaknesses, whereas production competence was a low priority.

Product, services and overall differentiation were perceived relatively high in relation to "ordinary" products provided by large food companies. Products were also perceived as comparatively difficult to copy and substitute. Prices of the products, in turn, were most often perceived as higher or average compared to large firms. Increasing customer satisfaction and retention as well as quality control issues had been given the most attention as strategic actions. Instead, it appeared that the firms had not been very competitor-oriented in their strategic activities.

When it comes to firm performance, the firms were in general more satisfied with non-financial than financial factors. Items related to customers and quality obtained the highest scores, whereas items related to costs and profit obtained the lowest scores.

In addition, based on the results of the factor analyses, the number of the variables for the key constructs has been reduced by creating summated scale variables. The measures of the key constructs are displayed in Table 11 . The rest of this chapter will focus on a more detailed analysis of the relationships of the key constructs.

\subsection{Linkages between resources, the position of competitive advantage and success: cluster analysis application}

In this chapter linkages between resources, competitive advantage and success are investigated. For the analysis the sample firms are first divided into four success clusters according to the underlying performance factors (summated scale variables) revealed in the previous section. Cluster analysis was used to simplify data and identify relationships. By clustering the firms into homogenous groups it may be possible to reveal relationships among firms that, perhaps, would not be possible with individual observations (see Hair et al. 1998, p. 481). In the second stage, the firms are classified into competitive advantage clusters. Both cluster solutions are validated by analysing their linkages to resources and other key variables. Finally, in order to study which strategies have the greatest link to success and which resources are linked to successful strategies, the relationship between success clustering and competitive advantage clustering is examined in more detail. Before moving on to the analysis, the basics of cluster analysis are briefly presented.

\subsection{Basics of cluster analysis}

Cluster analysis has been a popular multivariate method in strategic management research when the objective is to identify groups of organisations with similar characteristics (Ketchen and Shook 1996). The core of cluster analysis is to combine observations or cases in such a way that each object with respect to some predetermined 
Forsman, S. How do small rural food-processing firms compete?

Table 11. Summary of the central measures of the study.

\begin{tabular}{|c|c|c|}
\hline Main construct & Sub-construct & Measure \\
\hline \multirow[t]{2}{*}{ Resources } & Strategic resources & $\begin{array}{l}\text { Superior reputation } \\
\text { Quality raw materials } \\
\text { Innovative products } \\
\text { Customer Orientation } \\
\text { Way of distribution } \\
\text { Locality }\end{array}$ \\
\hline & Basic resources & $\begin{array}{l}\text { Business competence } \\
\text { Customer knowledge and accessibility } \\
\text { Production competence } \\
\text { Co-operation capability } \\
\text { Availability of production resources } \\
\text { Financial capability }\end{array}$ \\
\hline $\begin{array}{l}\text { Competitive advantage } \\
\text { positioning }\end{array}$ & $\begin{array}{l}\text { Price level } \\
\text { Differentiation } \\
\text { Sustainability } \\
\text { Strategic orientation }\end{array}$ & $\begin{array}{l}\text { Degree of price level } \\
\text { Degree of product differentiation } \\
\text { Degree of services differentiation } \\
\text { Degree of overall differentiation } \\
\text { Imitability } \\
\text { Threat of imitability } \\
\text { Substitutability } \\
\text { Customer-based market development } \\
\text { Improvement of customer satisfaction } \\
\text { Active product development } \\
\text { Competitor orientation }\end{array}$ \\
\hline Performance & & $\begin{array}{l}\text { Financial performance } \\
\text { Quality performance } \\
\text { Market performance } \\
\text { Cost performance } \\
\text { Price performance } \\
\text { Overall competence performance }\end{array}$ \\
\hline
\end{tabular}

selection criterion is very similar to others, i.e., the objective is to define the structure of the data by putting the most similar observations into groups. The resulting clusters of objects should demonstrate high internal (within-cluster) homogeneity and high external (between-cluster) heterogeneity. Hence, in a successful classification the cases within clusters should be close together when plotted geometrically, but different clusters should be far apart from each other (Hair et al. 1998, p. 473-475, Green et al. 1988, p. 577578).
In principle, there are two sets of different procedures for generating classifications: logical partitioning and grouping. Logical partitioning is also called "deductive classification" and "a priori classification". Grouping procedures, in turn, are often called "inductive classification", "ex post classification", "numerical taxonomy", or "quantitative classification". The fundamental difference between these two procedures is that with the logical partitioning the classification scheme is developed before the researcher analyses the data. In contrast, when 
Vol. 13 (2004): Supplement 1.

using grouping procedures, the classification scheme is generated inductively only after the data has been analysed (Hunt 1991, p. 177-178). In the present study, an empirical-based grouping procedure is adopted.

When grouping data inductively, a researcher needs less a priori knowledge of those specific characteristics that are likely to be dominant for classifying data. Moreover, there won't be empty classes since classes can only be formed from existing observations. However, when evaluating the validity of the resulting classification one should note that this type of inductive grouping is very data-based. That implies that one can seldom generalise the results beyond the original data. Rather than developing general classifications, this type of grouping procedure is mainly useful with highly situation-specific research phenomena (Hunt 1991, p. 183).

Several criteria can be used to evaluate successful classification. First, the classification schema should adequately specify the phenomenon under research. Second, the chosen characteristics should be adequately specified as appropriate and accurate for classification purposes. Third, all the classes at the same level of classification should be mutually exclusive. That is, no single item can belong to two or more different classes at the same level. Fourth, every case or item to be classified should have a "home", that is, the classification should be exhaustive. Finally, the classification should adequately serve its intended purposes (Hunt 1991, p. 184-188).

Cluster analysis is based on the distance between the groups and single cases. Those cases that are close enough in terms of their distances from the group centre are combined (Mustonen 1995 , p. 140). Naturally, a researcher must always resolve the trade-off - fewer clusters versus less homogeneity - when determining the final number of clusters to be formed. It is evident that within-cluster homogeneity increases when the number of clusters is increased (Hair et al. 1998, p. 476). In many cases, however, it may be reasonable to make compromises between homogeneity and the number of clusters. Findings may be more manageable and easier to communicate if number of the clusters is limited. Furthermore, the homogeneity of the clusters can be assessed with the help of Wilks' lamb$d a$ criterion. The smaller the lambda value, the better the within-cluster homogeneity (Mustonen 1995, p. 141).

The choice of the grouping variables is of utmost importance. There should always be some rationale upon which variables are selected. This rationale could be based on theoretical, conceptual or practical considerations. Only those variables that characterise the objects or cases being clustered and that relate specifically to the objectives of cluster analysis should be included in the analysis. This indicates that the variables that are not distinctive or do not differ significantly along clusters, should be eliminated (Punj and Stewart 1983, Hair et al. 1998, p. 481482). Basically, in an ideal case the number of grouping variables is small. In addition, what is of utmost important is the validation of the cluster solution. This can be achieved by assuring that the resulting clusters are connected to other variables in the data - those variables that have not been used as grouping variables (Punj and Stewart 1983, p. 146). In profiling the cluster solution, each cluster is described to explain how it may differ on relevant dimensions. In validation it is important that there be strong theoretical or practical support for selecting variables known to vary across the clusters (Hair et al. 1998, p. 500-501).

Assumptions in cluster analysis are not so strict as in other multivariate techniques. For instance, the requirements of normality, linearity, and homoscedasticity have little bearing on cluster analysis (Hair et al. 1998, p. 490). Instead, two other critical issues should be noted. First, the sample should be representative of the population so that the results are generalisable to the population of interest. The second critical issue is the impact of multicollinearity. Multicollinearity refers to the extent to which a variable can be explained by other variables in the analysis (Hair et al. 1998, p. 471, 490-491).

The interpretation of the cluster solution is often supported by discriminant analysis. By 
Forsman, S. How do small rural food-processing firms compete?

discriminant analysis one can assure to what extent the selected variables discriminate the chosen clusters. In this study, the cluster analysis was completed with the discriminant analysis. Because the nature of discriminant analysis is only supportive, the basics of this method are not presented here.

An alternative way to analyse the linkages between the constructs would have been multiple regression analysis which is perhaps the most widely used statistical technique. Multiple regression analysis is used to analyse the relationship between a single dependent and several independent variables. The independent variables whose values are known are used to predict the dependent variable (Hair et al. 1998, p. 217, 148). Multiple regression analysis in the competitive strategy research of small firms has been applied by, among others, Borch et al. (1999). Multiple regression analysis, however, has very strict assumptions when it comes to the linearity of the phenomenon, heteroscedasticity, independence of the error terms and normality of the error term distribution. In addition, multicollinearity, i.e., the correlation among the independent variables, may have substantial effects on the model. Some degree of multicollinearity is usually typical to this type of survey data. Because the purpose was to study linkages between the constructs and not to explain or predict the dependent variable (e.g., financial performance) by the independent variables (e.g., resources), the cluster analysis whose assumptions are not so strict (Hair et al. 1998, p. 490) was chosen as a starting point in this study.

\subsubsection{Success clusters}

The sample firms were clustered into homogeneous groups based on the performance dimensions extracted in Section 5.1.4. For the clustering analysis, four summated scale variables were selected to represent firm success from different approaches: Financial performance, Quality performance, Market performance and Price performance. Each of the dimensions comprised at least three original variables. Cost performance was excluded because it was strongly linked to Financial performance and it is not relevant to include more than one dimension measuring financial performance. In addition, Overall competence performance was excluded because it was not seen interpretatively as a strong dimension compared with the others.

Several cluster solutions were tried in terms of the number of clusters included in the analysis. A four-cluster solution was selected as the final solution because it allowed the most interpretation. Moreover, the decision can be justified based on the value of Wilks' lambda (see e.g., Mustonen 1995, p. 141, Hair et al. 1998, p. 362). The value does not considerably decrease from a four-cluster solution to a five-cluster solution (Table 12); the gap from three-cluster solution to four-cluster solution is clearly larger.

Cluster analysis was supported by discriminant analysis that, based on the four-cluster solution, resulted in three discriminant functions. Prior probabilities were computed from group sizes. The analysis was based on simultaneous

Table 12. Considering the homogeneity of different cluster solutions.

\begin{tabular}{lllllll}
\hline & \multicolumn{7}{c}{ Number of clusters } \\
& 2 & 3 & 4 & 5 & 6 & 7 \\
\hline Wilks' lambda & 0.371 & 0.192 & 0.099 & 0.076 & 0.045 & 0.032 \\
Per cent of original grouped cases correctly classified & 98.3 & 98.7 & 95.3 & 94.5 & 96.6 & 96.6 \\
Cross-validated grouped cases correctly classified & 97.5 & 97.8 & 94.5 & 91.9 & 94.5 & 94.9 \\
\hline
\end{tabular}


Vol. 13 (2004): Supplement 1.

estimation where all the independent variables were considered concurrently (Hair et al. 1998, p. 260). One of the key assumptions of discriminant analysis is equal covariance matrices between the groups (Hair et al. 1998, p. 259). In this case, the P-value of Box's $M$ indicates that the equality of the covariance matrix is not supported. Because discriminant analysis is a relatively robust method and the sample sizes within the groups are quite large, the possible violation effect of unequal covariance matrices is, however, decreased (Hair et al. 1998, p. 259). The other key assumption is multivariate normality of the independent variables. In the present case, all the independent variables correlate with each other to some extent. The multicollinearity problem is, however, less critical since simultaneous estimation procedure is used. It would be more critical if a stepwise procedure was used (Hair et al. 1998, p. 259). Moreover, one should note that discriminant analysis is used in this study only to support clustering analysis and to help to determine the relevant cluster solution.

The discriminant power of the first function in the prediction of group membership is over four times greater, $81.4 \%$ of variance, than the second function (Table 13). By contrast, the weight of the third function is only marginal indicating that classification is actually based on the first two functions. Each weight represents the relative contribution of its associated variable to the function (Hair et al. 1998, p. 272). When interpreting the discriminant weights of the first function one can see that all four variables are relatively relevant in determining the relationship (Table 14). In the second function, on the other hand, the dominant variable is Price performance with a negative sign. However, when examining discriminant loadings (structure correlations) that measure the simple linear correlation between each independent variable and the discriminant function ${ }^{25}$ (Hair et al. 1998,

25 In recent years, discriminant loadings have been considered relatively more valid than weights as a means of intepreting the disciminating power of independent variables because of their correlational nature. Discriminant load- p. 272), Market performance has the relatively largest contribution to the first function (Table 15). Price performance, by contrast, has clearly the largest contribution to the second function. Quality performance contributes to the third function, but because the weight of the third function it is only marginal; the discriminant power of Quality performance is unsubstantial. The structure correlations support the interpretation of discriminant weights. The output of cluster and discriminant analysis for the fourcluster solution is presented in Appendix C.

The resulting four clusters were labelled as follows on the basis of the profile characteristics of the clusters along performance dimensions (Fig. 15):

Cluster $1(\mathrm{~N}=40)$ : Weakest-performing firms

Cluster $2(\mathrm{~N}=58)$ : Average-performing firms, with emphasis on market performance

Cluster $3(\mathrm{~N}=78)$ : Average-performing firms, with emphasis on price performance

Cluster $4(\mathrm{~N}=62)$ : Best-performing firms

The best performing firms in Cluster 4 differed clearly from the other groups. It has the highest group means for the all independent variables. The weakest performing firms in Clus-

Table 13. Eigenvalues and percentage of variance of the discriminant functions

\begin{tabular}{lllll}
\hline $\begin{array}{l}\text { Function } \\
\text { value }\end{array}$ & $\begin{array}{l}\text { Eigen- } \\
\text { variance }\end{array}$ & $\begin{array}{l}\text { Cumulative } \% \\
\text { of variance }\end{array}$ & $\begin{array}{l}\text { Canonical } \\
\text { correlation }\end{array}$ \\
\hline 1 & 4.123 & 81.4 & 81.4 & 0.897 \\
2 & 0.918 & 18.1 & 99.5 & 0.692 \\
3 & 0.027 & 0.5 & 100.0 & 0.161 \\
\hline
\end{tabular}

ings or structure correlations can be interpreted like factor loadings in assessing the relative contribution of each variable to the discriminant function. However, discriminant loadings such as weights may be subject to instability and therefore one must be cautious when interpreting the discriminant functions (Hair et al. 1998, p. 272). 
Forsman, S. How do small rural food-processing firms compete?

Table 14. Standardised canonical discriminant functions.

\begin{tabular}{lccc}
\hline & Function 1 & Function 2 & Function 3 \\
\hline Financial performance & 0.455 & 0.273 & 0.293 \\
Quality performance & 0.358 & 0.234 & 0.841 \\
Market performance & 0.557 & 0.466 & -0.616 \\
Price performance & 0.495 & -0.868 & -0.156 \\
\hline
\end{tabular}

Table 15. Structure correlations between the discriminant functions and the variables.

\begin{tabular}{lccc}
\hline & Function 1 & Function 2 & Function 3 \\
\hline Market performance & 0.623 & 0.471 & -0.541 \\
Financial performance & 0.478 & 0.195 & 0.136 \\
Price performance & 0.592 & -0.803 & -0.049 \\
Quality performance & 0.400 & 0.129 & -0.736 \\
\hline
\end{tabular}

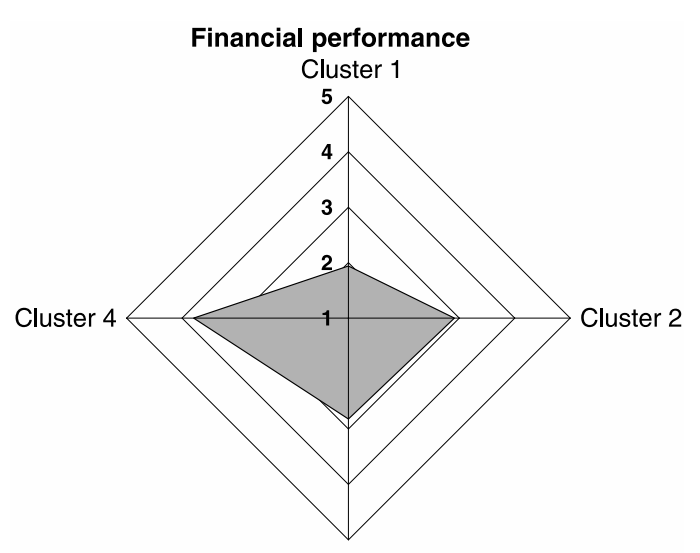

Cluster 3

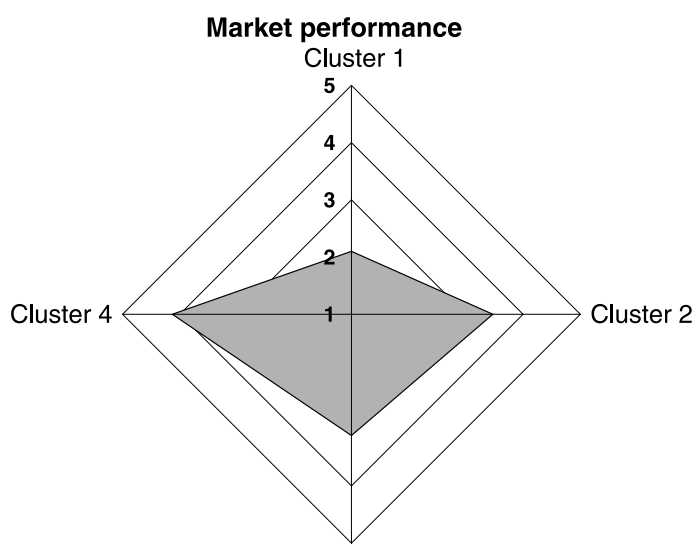

Cluster 3

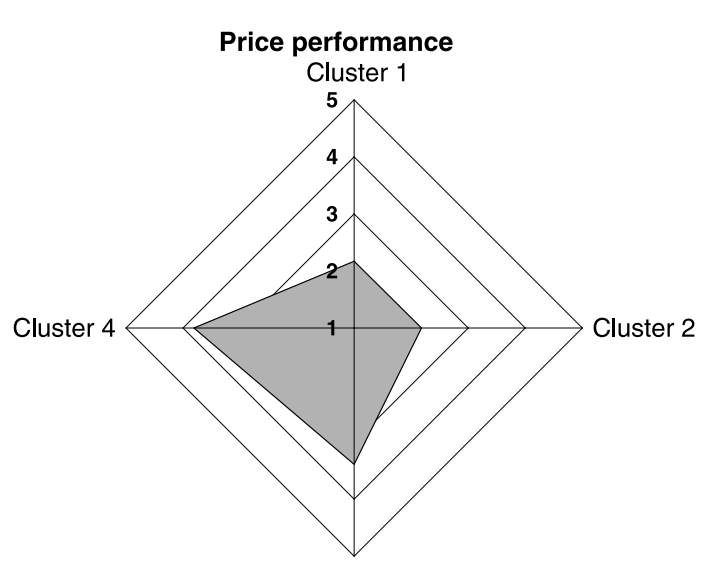

Cluster 3

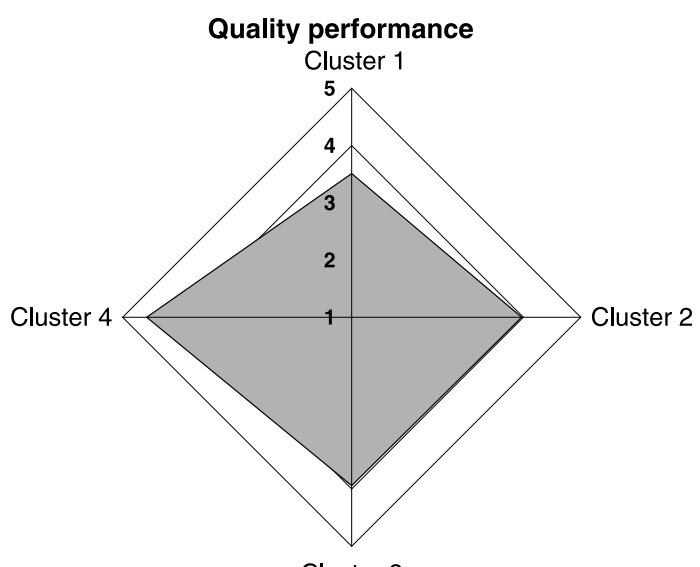

Cluster 3

Fig. 15. Profiles of the success clusters. 
Vol. 13 (2004): Supplement 1.

ter 1 also clearly differed from the other groups; it has the lowest group means for all the independent variables excluding the group mean of Price performance that did not differ from Cluster 2. The two remaining groups are average performing firms. For both groups, the group means were between the group means of Cluster 3 and Cluster 4. When comparing Cluster 1 and Cluster 2 with each other, the group mean of Price performance was clearly higher for Cluster 3 than for Cluster 2. For Cluster 2, by contrast, the group mean of Market performance was slightly higher than for Cluster 4. Accordingly, Cluster 3 was labelled as Average-performing firms, with emphasis on Price performance and Cluster 2 was labelled as Average-performing firms, with emphasis on Market performance.

The validity of the cluster solution was examined by comparing the respondents' perceptions of profitability, liquidity and capital adequacy of their business along the clusters. Table 16 shows that there are statistically significant differences between the clusters. When comparing two clusters at a time, differences between both Cluster 4 and Cluster 1, and Cluster 4 and Cluster 3 were statistically significant at $\mathrm{P}=$ 0.000 level. Between Cluster 4 and Cluster 2, there were differences at $\mathrm{P}<0.05$ level. Moreover, Cluster 1 and Cluster 2 differed from each other at $\mathrm{P}>0.05$ level. This was also the case between Cluster 1 and Cluster 3, excluding the variable capital adequacy. On the other hand, capital adequacy is the only variable separating Cluster 2 and Cluster 3.

The background characteristics of the clusters were also analysed (see summary in Table 17). What is interesting is that no statistically significant linkage between the cluster solution and farm-connection was found. By contrast, there were some branch-specific differences between the clusters although the chi squared analysis revealed that the result is not statistically significant. Because the sizes of the branches vary in the sample, the distribution of firms in different success clusters within a particular branch was analysed. The analysis showed that $44 \%$ of the meat processing firms belonged to the group of Best-performing firms, whereas Weakest-performing firms included no meat processors. The situation in terms of grain mill producers was almost the opposite. The largest share of milk-processing firms and berry and fruit processing firms belonged to Cluster 3 (Average-performing firms, with emphasis on Price performance). Most of the firms processing vegetables and potatoes belonged, on the other hand, to Cluster 2 (Average-performing firms, with emphasis on Market performance).

The firm age differed significantly between the clusters. The youngest firms were found in Best-performing firms and the oldest ones in Weakest-performing firms. Moreover, the stage

Table 16. Group means of the profitability, liquidity and capital adequacy along the success clusters.

\begin{tabular}{lcccccc}
\hline & $\begin{array}{c}\text { Cluster 1 } \\
(\mathrm{N}=40)\end{array}$ & $\begin{array}{c}\text { Cluster 2 } \\
(\mathrm{N}=58)\end{array}$ & $\begin{array}{c}\text { Cluster 3 } \\
(\mathrm{N}=78)\end{array}$ & $\begin{array}{c}\text { Cluster 4 } \\
(\mathrm{N}=62)\end{array}$ & F value & P value \\
\hline Profitability compared with the target set for the business $^{*}$ & 2.38 & 2.95 & 3.07 & 3.84 & 22.961 & $0.000 * * *$ \\
Profitability compared with the similar small-scale firms $^{1}$ & 2.67 & 3.02 & 3.22 & 3.85 & 51.797 & $0.000 * * *$ \\
Profitability compared with the industry average $^{1}$ & 2.54 & 2.94 & 2.96 & 3.60 & 34.384 & $0.000 * * *$ \\
Liquidity $^{1}$ & 2.64 & 3.45 & 3.28 & 4.05 & 37.159 & $0.000 * * *$ \\
Capital adequacy & 2.65 & 3.53 & 3.01 & 3.97 & 11.665 & $0.000 * * *$ \\
\hline
\end{tabular}

Success clusters: 1 = Weakest-performing firms, 2 = Average-performing firms, with emphasis on Market performance, 3 = Average-performing firms, with emphasis on Price performance, 4 = Best-performing firms

1) Kruskall-Wallis analysis with $\chi^{2}$ was used instead of ANOVA due to the non-equal variances along the clusters. $* * * \mathrm{P}<0.000, * * \mathrm{P}<0.01, * \mathrm{P}<0.05$ 
Forsman, S. How do small rural food-processing firms compete?

Table 17. Background characteristics of firms, by Cluster.

\begin{tabular}{|c|c|c|c|c|c|c|}
\hline & $\begin{array}{l}\text { Cluster } 1 \\
(\mathrm{~N}=40)\end{array}$ & $\begin{array}{l}\text { Cluster } 2 \\
(\mathrm{~N}=58)\end{array}$ & $\begin{array}{l}\text { Cluster } 3 \\
(\mathrm{~N}=78)\end{array}$ & $\begin{array}{l}\text { Cluster } 4 \\
(\mathrm{~N}=62)\end{array}$ & $\begin{array}{l}\chi^{2} \text { value/ } \\
\text { F value }\end{array}$ & $\mathrm{P}$ value \\
\hline Farm connection & & & & & 6.053 & 0.109 \\
\hline Farm-based firms (\%) & 41.0 & 34.5 & 32.5 & 51.6 & & \\
\hline Non-farm connection $(\%)$ & 59.0 & 65.5 & 67.5 & 48.4 & & \\
\hline $\begin{array}{l}\text { Distribution of the firms according to } \\
\text { the branch within clusters }(\%)\end{array}$ & & & & & 27.657 & 0.150 \\
\hline Processing of meat and meat products & 0 & 19 & 44 & 37 & & \\
\hline Processing of fish and fish products & 7 & 27 & 33 & 33 & & \\
\hline Production of grain mill products & 38 & 19 & 38 & 5 & & \\
\hline Production of bread and bakery products & 17 & 26 & 30 & 28 & & \\
\hline Processing of milk & 20 & 10 & 40 & 30 & & \\
\hline Processing of vegetables and potatoes & 10 & 38 & 28 & 24 & & \\
\hline Processing of berries and fruit & 24 & 12 & 36 & 28 & & \\
\hline Others & 24 & 35 & 24 & 18 & & \\
\hline Average age of the firms (years) ${ }^{1}$ & 26.9 & 17.8 & 20.2 & 10.6 & 10.579 & $0.014 *$ \\
\hline Stage of the lifecycle & & & & & 41.686 & $0.000 * * *$ \\
\hline Growth $(\%)$ & 10.8 & 29.3 & 23.1 & 39.3 & & \\
\hline Stable $(\%)$ & 29.7 & 51.7 & 53.8 & 55.7 & & \\
\hline Decreasing/ending/reorienting (\%) & 59.5 & 19.0 & 23.1 & 4.9 & & \\
\hline Gender & & & & & 6.735 & 0.081 \\
\hline Female $(\%)$ & 27.5 & 42.1 & 35.9 & 51.6 & & \\
\hline Male $(\%)$ & 72.5 & 57.9 & 29.5 & 48.4 & & \\
\hline Total number of employees per year in 1999 & 3.1 & 4.0 & 3.1 & 3.0 & 0.702 & 0.873 \\
\hline
\end{tabular}

Success clusters: 1 = Weakest-performing firms, 2 = Average-performing firms, with emphasis on Market performance, $3=$ Average-performing firms, with emphasis on Price performance, 4 = Best-performing firms

${ }^{1)}$ Kruskall-Wallis analysis with $\chi^{2}$ was used instead of ANOVA due to the non-equal variances along the clusters.

*** $\mathrm{P}<0.000, * * \mathrm{P}<0.01, * \mathrm{P}<0.05$

of the lifecycle clearly differed between clusters. In Cluster 4, the share of the firms in the growth stage was noticeably the greatest while the smallest was in Cluster 1. In Cluster 1, 60\% of the firms planned to end the business, down-size production or reorient the business. Moreover, what is interesting is that, when compared, a significant difference in gender was discovered between Cluster 4 and Cluster 1. Over half of the respondents in Cluster 4 were female, while Cluster 1 was clearly dominated by male respondents. By contrast, there were no differences in basic and professional education and nor in age group of the respondents. Moreover, the number of employees did not vary between the clusters.

\subsubsection{Validation of success clusters}

The cluster solution was further validated by examining how the resulting clusters differed from each other on relevant dimensions. This was done by utilising data not previously included in the cluster solution.

\section{Resource profiles by success clusters}

From the viewpoint of the objective of this study, the aim was to determine to what extent firm resources, both strategic resources and basic resources, contributed to firm success. In this case, the purpose was not to explain success by resources, but rather to determine whether and to what extent statistically significant linkages be- 
Vol. 13 (2004): Supplement 1.

tween firm success and resources can be discovered. The propositions to be tested are:

P2: There is a positive relationship between strategic resources and success.

P3: There is a positive relationship between basic resources and success.

To test the hypothesis, the group means of the dimensions of the strategic resources and basic resources were compared along the clusters. The results revealed that there are statistically significant differences in these two types of resources between the clusters. When considering strategic resources, significant differences were found in Superior reputation, Customer service and Way of distribution (Table 18). Quality raw material and Innovative products also differed along the clusters, but the differences did not reach significance. Locality was the only dimension of the group mean which did not vary between the clusters. What is interesting is that there were some clear differences particularly between Best-performing firms and Weakestperforming firms. The group means for all the strategic resources excluding local production were higher $(\mathrm{P}<0.05)$ for Cluster 4 compared to Cluster 1. When comparing Cluster 4 and Cluster 2, there were statistically significant differences $(\mathrm{P}<0.05)$ in two dimensions: Superior reputation and Innovative products. Further, when comparing Cluster 4 and Cluster 3, there were statistically significant differences $(\mathrm{P}<$ 0.05) in Superior reputation, Customer service and Distribution. Cluster 1 and Cluster 2 also differed along these three dimensions. Cluster 1 and Cluster 3, on the other hand, differed from each other on the basis of Superior reputation and Quality raw material. Finally, when comparing Cluster 2 and Cluster 3, the former had slightly higher group means $(\mathrm{P}<0.05)$ in Customer service and Distribution.

When considering the basic resources, the differences between the clusters were greater compared to the strategic resources. All the dimensions, excluding Production resources, differed significantly along the clusters. The difference was marginally significant for Co-operation capability and highly significant for the other dimensions. When comparing two clusters

Table 18. Resource profiles by success clusters.

\begin{tabular}{|c|c|c|c|c|c|c|}
\hline & $\begin{array}{l}\text { Cluster } 1 \\
(\mathrm{~N}=40)\end{array}$ & $\begin{array}{r}\text { Cluster } 2 \\
(\mathrm{~N}=58)\end{array}$ & $\begin{array}{l}\text { Cluster } 3 \\
(\mathrm{~N}=78)\end{array}$ & $\begin{array}{c}\text { Cluster } 4 \\
(\mathrm{~N}=62)\end{array}$ & $\mathrm{F}$ value & $\mathrm{P}$ value \\
\hline \multicolumn{7}{|l|}{ Strategic resources } \\
\hline Superior reputation & 3.75 & 4.19 & 4.09 & 4.40 & 9.379 & $0.000 * * *$ \\
\hline Quality raw materials & 3.63 & 3.91 & 4.00 & 4.16 & 2.553 & 0.056 \\
\hline Innovative products & 2.85 & 2.95 & 3.13 & 3.44 & 2.483 & 0.062 \\
\hline Customer service & 3.85 & 4.41 & 4.12 & 4.40 & 6.937 & $0.000 * * *$ \\
\hline Way of distribution & 2.90 & 3.63 & 3.26 & 3.62 & 4.699 & $0.003 * *$ \\
\hline Locality $^{1}$ & 3.36 & 3.36 & 3.50 & 3.56 & 2.060 & 0.560 \\
\hline \multicolumn{7}{|l|}{ Basic resources } \\
\hline Business competence & 2.94 & 3.38 & 3.40 & 4.04 & 21.997 & $0.000 * * *$ \\
\hline Customer knowledge and accessibility ${ }^{1}$ & 2.66 & 3.18 & 3.24 & 3.85 & 44.110 & $0.000 * * *$ \\
\hline Production competence & 3.53 & 3.65 & 3.80 & 4.22 & 9.309 & $0.000 * * *$ \\
\hline Co-operation capability & 3.00 & 3.29 & 3.43 & 3.65 & 3.105 & $0.027 *$ \\
\hline Availability of production resources & 3.49 & 3.45 & 3.54 & 3.73 & 1.156 & 0.327 \\
\hline Financial capability & 2.80 & 3.14 & 3.14 & 3.76 & 7.345 & $0.000 * * *$ \\
\hline
\end{tabular}

Success clusters: 1 = Weakest-performing firms, 2 = Average-performing firms, with emphasis on Market performance, 3 = Average-performing firms, with emphasis on Price performance, 4 = Best-performing firms

1) Kruskall-Wallis analysis with $\chi^{2}$ was used instead of ANOVA due to the non-equal variances along the clusters. $* * * \mathrm{P}<0.000, * * \mathrm{P}<0.01, * \mathrm{P}<0.05$ 
Forsman, S. How do small rural food-processing firms compete?

at a time, the differences in the group means for all these five dimensions were statistically significant $(\mathrm{P}<0.05)$ between Cluster 4 and Cluster 1. Cluster 4 and Cluster 2, as well as Cluster 4 and Cluster 3 differed statistically significantly in four dimensions: Business competence, Financial capability, Production competence and Customer knowledge and accessibility. Cluster 2 differed from Cluster 1 in Business competence and Customer knowledge and accessibility. Cluster 3, on the other hand, differed from Cluster 1 in Business competence, Co-operation capability and Customer knowledge and accessibility. By contrast, no significant differences were discovered between Cluster 2 and Cluster 3 .

In addition, the clusters were compared by analysing to what extent the firms had acquired competence in the different fields of business. The results shown in Table 19 support the view that the differences in firm success are linked more to the lack of competence in marketing than to production. The Best-performing firms obtained the highest scores for competence in marketing, quality development, price setting and financial management. This group had also the highest group mean in product development.

In conclusion, as suggested, positive linkages between resources and success existed. The Best-performing firms had the strongest emphasis on Superior reputation, Quality raw material and Innovative products as strategic competitive resources. Moreover, the basic resources in terms of Business competence, Customer knowledge and accessibility, Production competence, Financial capability and Co-operation capability were perceived as relatively strong in the Best-performing firms. Based on the results one cannot state that the Best-performing firms are better because they own or control certain resources and capabilities, but it can be noted that there are linkages between them. The results, thus, are consistent with propositions P2 and P3. The linkages are studied in more detail through LISREL modelling in Chapter 5.3. In addition, the results revealed that success was linked more to a lack of competence in the marketing side than to a lack of competence in the production side.

\section{Position of competitive advantage by success clusters}

Next the study analysed the differences between the clusters and the firms' position of competitive advantage in the marketplace. An interesting question is whether there are statistically significant differences between the degree of differentiation and price level by success clusters. The analyses revealed (Table 20) that Product differentiation compared to larger firms was the highest in the Best-performing firms (Cluster 1) and lowest in the Weakest-performing firms

Table 19. Competence in different fields of business by success clusters. (Question 28: "To what extent do the employees, inc. the entrepreneur, on average, have competence in the following fields of business based on their education or earlier experience?" Scale: $1=$ Not at all, $5=$ To a high degree.

\begin{tabular}{lcccccc}
\hline & $\begin{array}{c}\text { Cluster 1 } \\
(\mathrm{N}=40)\end{array}$ & $\begin{array}{c}\text { Cluster 2 } \\
(\mathrm{N}=58)\end{array}$ & $\begin{array}{c}\text { Cluster 3 } \\
(\mathrm{N}=78)\end{array}$ & $\begin{array}{r}\text { Cluster 4 } \\
(\mathrm{N}=62)\end{array}$ & $\chi^{2}$ value & P value \\
\hline Product development (Q2801) & 3.08 & 3.17 & 3.12 & 3.54 & 8.249 & $0.041 *$ \\
Production processes (Q2802) & 3.60 & 3.66 & 3.38 & 3.69 & 2.622 & 0.454 \\
Package development (Q2803) & 2.75 & 2.86 & 2.64 & 2.97 & 3.721 & 0.293 \\
Marketing and sales skills (Q2804) & 2.88 & 3.25 & 3.13 & 3.62 & 16.853 & $0.001 * *$ \\
Quality development (Q2805) & 2.98 & 3.19 & 3.17 & 3.64 & 16.351 & $0.001 * *$ \\
Price setting (Q2806) & 3.18 & 3.16 & 3.23 & 3.77 & 16.419 & $0.001 * *$ \\
Financial management (Q2807) & 2.95 & 3.03 & 3.12 & 3.64 & 17.645 & $0.001 * *$ \\
\hline
\end{tabular}

Success clusters: 1 = Weakest-performing firms, 2 = Average-performing firms, with emphasis on Market performance, $3=$ Average-performing firms, with emphasis on Price performance, $4=$ Best-performing firms

$* * * \mathrm{P}<0.000, * * \mathrm{P}<0.01, * \mathrm{P}<0.05$ 
Vol. 13 (2004): Supplement 1.

(Cluster 4). Also, Services differentiation compared to larger firms providing ordinary products was the highest for Cluster 4. What is significant is that there was no linkage between the success clustering and price level compared to larger firms providing ordinary products. Furthermore, in the Best-performing firms competence underlying differentiation was perceived to be the most difficult to imitate and products were found difficult to substitute. In addition, as can be expected in Cluster 4, the threat of imitability among larger firms was minor.

In strategic actions some differences also arose. The Weakest-performing firms had the lowest emphasis on Improvement of Customer Satisfaction. The Best-performing firms, on the other hand, had the lowest emphasis on Competitor orientation. Based on this one could speculate that the Best-performing firms might have a more stable position than other firms have in their marketplace and thus they would be less threatened by competitors.

\section{Competitive environment and success clusters}

A market arena emphasis did not differ statistically significantly between the success clusters (Table 21). However, when comparing the Bestperforming firms (Cluster 4) with the Weakestperforming firms (Cluster 1) one can notice a difference that approached significance in national market orientation level; the Best-performing firms seem to operate on a broader market

Table 20. Position of competitive advantage by success cluster.

\begin{tabular}{|c|c|c|c|c|c|c|}
\hline & $\begin{array}{l}\text { Cluster } 1 \\
(\mathrm{~N}=40)\end{array}$ & $\begin{array}{l}\text { Cluster } 2 \\
(\mathrm{~N}=58)\end{array}$ & $\begin{array}{l}\text { Cluster } 3 \\
(\mathrm{~N}=78)\end{array}$ & $\begin{array}{l}\text { Cluster } 4 \\
(\mathrm{~N}=62)\end{array}$ & $\chi^{2}$ value & $\mathrm{P}$ value \\
\hline \multicolumn{7}{|l|}{ Product differentiation in relation to... (Q17) } \\
\hline larger firms providing ordinary products & 3.28 & 3.64 & 3.65 & 4.03 & 14.381 & $0.002 * *$ \\
\hline larger firms providing special products & 3.18 & 3.40 & 3.45 & 3.74 & 8.787 & $0.032 *$ \\
\hline similar types of small firms & 3.18 & 3.05 & 3.08 & 3.43 & 5.322 & 0.150 \\
\hline \multicolumn{7}{|l|}{ Services differentiation in relation to... (Q18) } \\
\hline larger firms providing ordinary products & 3.69 & 3.96 & 3.82 & 4.19 & 8.154 & $0.043 *$ \\
\hline larger firms providing special products & 3.49 & 3.68 & 3.57 & 3.89 & 5.582 & 0.134 \\
\hline similar types of small firms & 3.08 & 3.14 & 3.27 & 3.67 & 10.423 & $0.015 *$ \\
\hline \multicolumn{7}{|l|}{ Price level compared to (Q25) } \\
\hline larger firms providing ordinary products & 3.63 & 3.38 & 3.86 & 3.76 & 7.565 & 0.056 \\
\hline larger firms providing special products & 3.03 & 2.98 & 3.45 & 3.35 & 8.536 & $0.036 *$ \\
\hline similar types of small firms & 2.70 & 2.84 & 3.10 & 3.26 & 13.195 & $0.004 * *$ \\
\hline \multicolumn{7}{|l|}{ Degree of imitability (Q20) } \\
\hline concrete product characteristics & 2.95 & 2.86 & 3.03 & 3.35 & 6.937 & 0.074 \\
\hline competence & 2.98 & 2.83 & 3.14 & 3.58 & 13.445 & $0.004 * *$ \\
\hline \multicolumn{7}{|l|}{ Threat of imitability (Q21) } \\
\hline among larger firms & 2.58 & 2.62 & 2.80 & 2.13 & 12.415 & $0.006 * *$ \\
\hline among smaller firms & 2.95 & 3.16 & 3.12 & 2.61 & 7.665 & 0.053 \\
\hline Degree of substitutability (Q24) & 3.05 & 2.89 & 3.12 & 3.60 & 10.550 & $0.014 *$ \\
\hline \multicolumn{7}{|l|}{ Strategic actions (Q22) } \\
\hline Customer-based market development ${ }^{1}$ & 2.82 & 3.13 & 2.99 & 2.96 & 0.798 & 0.496 \\
\hline Improvement of customer satisfaction & 3.34 & 3.82 & 3.58 & 3.87 & 5.764 & $0.001 * *$ \\
\hline Active product development ${ }^{1}$ & 2.87 & 3.27 & 3.10 & 3.09 & 4.397 & 0.222 \\
\hline Competitor orientation & 2.32 & 2.42 & 2.28 & 1.93 & 3.548 & $0.015 *$ \\
\hline
\end{tabular}

Success clusters: 1 = Weakest-performing firms, 2 = Average-performing firms, with emphasis on Market performance, 3 = Average-performing firms, with emphasis on Price performance, 4 = Best-performing firms

${ }^{1)}$ Oneway ANOVA with F-value was used instead of Kruskall-Wallis analysis.

*** $\mathrm{P}<0.000, * * \mathrm{P}<0.01, * \mathrm{P}<0.05$ 
Forsman, S. How do small rural food-processing firms compete?

Table 21. Market arena emphasis by success clusters, $\%$ of sales.

\begin{tabular}{lcccccc}
\hline & $\begin{array}{r}\text { Cluster 1 } \\
(\mathrm{N}=40)\end{array}$ & $\begin{array}{c}\text { Cluster 2 } \\
(\mathrm{N}=58)\end{array}$ & $\begin{array}{r}\text { Cluster 3 } \\
(\mathrm{N}=78)\end{array}$ & $\begin{array}{r}\text { Cluster 4 } \\
(\mathrm{N}=62)\end{array}$ & F value & P value \\
\hline Local markets & 63.0 & 61.8 & 55.3 & 54.5 & 0.683 & 0.563 \\
Regional markets $_{\text {National markets }}{ }^{1}$ & 20.0 & 15.2 & 17.0 & 16.2 & 0.364 & 0.779 \\
International markets & 14.6 & 22.7 & 26.5 & 28.3 & 7.345 & 0.062 \\
\hline
\end{tabular}

Success clusters: 1 = Weakest-performing firms, 2 = Average-performing firms, with emphasis on Market performance, 3 = Average-performing firms, with emphasis on Price performance, $4=$ Best-performing firms

1) Kruskall-Wallis analysis with $\chi^{2}$ was used instead of ANOVA due to the non-equal variances along the clusters.

scope compared to the Weakest-performing firms. Instead, marketing channel choices did not differ between the clusters.

The Weakest-performing firms most often competed with ordinary products of large firms whereas in the Best-performing firms, the ordinary products of the large firms were considered competitive products in only a few of the cases (Table 22). Similarly, in Cluster 4 the opinion that a firm's products have no competitors was clearly more common than in Cluster 1 . Moreover, the intensity of competition and the threat of competition to the continuity of the business were perceived as lowest in the Best-performing firms.

\subsubsection{Competitive advantage clusters}

The analysis in the previous section revealed some statistical linkages between success clustering and firms' perception of their competitive situation and the position of competitive advantage in the market. To get a more detailed picture of competitive strategies and, more specifically, their linkages to resources and success, the sample firms were clustered into homogenous groups according to how they positioned themselves in the market. The positioning was considered in relation to larger firms and in terms of the differentiation and price level (cf. Faulkner and Bowman 1992, Hunt and Morgan 1997, Fors-

Table 22. Competitors and the intensity of competition along the success clusters.

\begin{tabular}{|c|c|c|c|c|c|c|}
\hline & $\begin{array}{l}\text { Cluster } 1 \\
(\mathrm{~N}=40)\end{array}$ & $\begin{array}{l}\text { Cluster } 2 \\
(\mathrm{~N}=58)\end{array}$ & $\begin{array}{l}\text { Cluster } 3 \\
(\mathrm{~N}=78)\end{array}$ & $\begin{array}{l}\text { Cluster } 4 \\
(\mathrm{~N}=62)\end{array}$ & $\chi^{2}$ value & $P$ value \\
\hline \multicolumn{7}{|l|}{ Competitors are (Q12)... } \\
\hline large firms providing ordinary products & 3.82 & 3.33 & 3.33 & 2.89 & 8.189 & $0.042 *$ \\
\hline large firms providing special products & 3.23 & 2.93 & 3.12 & 2.74 & 4.298 & 0.231 \\
\hline similar types of small firms & 3.38 & 3.53 & 3.13 & 3.06 & 4.543 & 0.208 \\
\hline no competitors & 1.23 & 1.50 & 1.87 & 2.11 & 15.528 & $0.001 * *$ \\
\hline \multicolumn{7}{|l|}{ Intensity of competition in terms of (Q13)... } \\
\hline price & 4.35 & 4.28 & 4.04 & 3.48 & 18.906 & $0.000 * * *$ \\
\hline quality & 3.83 & 3.88 & 3.46 & 3.32 & 8.890 & $0.031 *$ \\
\hline access to conventional marketing channels & 4.18 & 4.38 & 3.90 & 3.49 & 16.022 & $0.001 * *$ \\
\hline $\begin{array}{l}\text { Threat of competition to the continuity of } \\
\text { the business (Q15) }\end{array}$ & 3.90 & 3.28 & 3.23 & 2.32 & 42.370 & $0.000 * * *$ \\
\hline
\end{tabular}

Success clusters: 1 = Weakest-performing firms, 2 = Average-performing firms, with emphasis on Market performance, $3=$ Average-performing firms, with emphasis on Price performance, $4=$ Best-performing firms

$* * * \mathrm{P}<0.000, * * \mathrm{P}<0.01, * \mathrm{P}<0.05$ 
Vol. 13 (2004): Supplement 1.

Table 23. Considering the homogeneity of different cluster solutions.

\begin{tabular}{llccccc}
\hline & \multicolumn{7}{c}{ Number of clusters } & & \\
& 2 & 3 & 4 & 5 & 6 & 7 \\
\hline Wilks' lambda & 0.358 & 0.224 & 0.141 & 0.068 & 0.053 & 0.034 \\
Per cent of original grouped cases correctly classified & 99.6 & 95.7 & 91.9 & 95.3 & 95.3 & 99.1 \\
Cross-validated grouped cases correctly classified & 99.1 & 95.7 & 91.1 & 94.3 & 94.0 & 97.9 \\
\hline
\end{tabular}

man 1999). The propositions to be tested in this context are as follows:

P4: There is a positive relationship between strategic resources and the position of competitive advantage.

P5: There is a positive relationship between basic resources and the position of competitive advantage.

The clustering was based on two summated scale variables: Differentiation and Price level. Differentiation was based on six original items. Differentiation was considered in terms of Product (Q1701, Q1702), Services (Q1801, Q1802) and Overall differentiation (Q1901, Q1902). Respondents were asked how they perceived these three aspects of differentiation in relation to large firms providing a) ordinary products and b) special products. The scale ranged from $1=$ Not very much differentiated to $5=$ Totally differentiated. The Cronbach's alpha for the summated scale variable was 0.86 . Similarly, the Price Level was measured by asking respondents whether the prices of their products are higher or lower in comparison to a) ordinary and b) special products of large firms (Q2501, Q2502). The Cronbach's alpha for the summated scale variable was 0.83 . There was only a weak correlation between Differentiation and Price level $(\mathrm{r}=0.15, \mathrm{P}=0.018)$.

Several cluster solutions were tried. A fivecluster solution was accepted as a final solution based on the homogeneity criteria (Table 23) and interpretative considerations. The clustering procedure followed the same principles as in the creation of the success clusters and, thus, the description is not repeated here.

The discriminant analysis resulted in two discriminant functions. The power of the first func- tion in the prediction of group membership was the greatest, $69 \%$ of variance (Table 24 ). When interpreting the discriminant weights of the first function, the most discriminating variable appears to be Price level (Table 25). In the second function, on the other hand, the dominant variable is Differentiation, while Price level has a minor, but negative weight. When considering structure correlations (Table 26), the interpretation of the functions can be found quite similar. The output of cluster and discriminant analysis for the four-cluster solution is presented in Appendix D.

The position of competitive advantage was analysed by means of the nine-box matrix by adapting Faulkner and Bowman's (1992) extended generic strategy matrix and Hunt and Morgan's (1995, 1996, 1997) competitive position matrix. The resulting five clusters were named on the basis of the profile characteristics of the clusters along the competitive advantage dimensions (Fig. 16). In the following the strategies are described in more detail by using the original differentiation and price-level items (Table 27), some dimensions of sustainability (Table 28) and some background characteristics (Table 29). Moreover, the clusters were analysed by means of product characteristics, resources, strategic actions and success (Table 30).

Table 24. Eigenvalues and percentage of variance of the discriminant functions.

\begin{tabular}{lllll}
\hline Function & $\begin{array}{l}\text { Eigen- } \\
\text { value }\end{array}$ & $\begin{array}{l}\% \text { of } \\
\text { variance }\end{array}$ & $\begin{array}{l}\text { Cumulative } \% \\
\text { of variance }\end{array}$ & $\begin{array}{l}\text { Canonical } \\
\text { correlation }\end{array}$ \\
\hline 1 & 4.191 & 69.4 & 69.4 & 0.899 \\
2 & 1.847 & 30.6 & 100.0 & 0.805 \\
\hline
\end{tabular}


Forsman, S. How do small rural food-processing firms compete?

Table 25. Standardised canonical discriminant functions.

\begin{tabular}{lcc}
\hline & Function 1 & Function 2 \\
\hline Price Level & 0.958 & -0.288 \\
Differentiation & 0.303 & 0.953 \\
\hline
\end{tabular}

Table 26. Structure correlations between the discriminant functions and the variables.

\begin{tabular}{lcc}
\hline & Function 1 & Function 2 \\
\hline Price Level & 0.953 & -0.303 \\
Differentiation & 0.288 & 0.958 \\
\hline
\end{tabular}

\section{Cluster 1: Premium-priced differentiation} advantage $(N=59)$

In this cluster the firms provide a "better" product at a premium price. The firms have differentiated their offerings from larger firms in terms of products, services and their overall way of doing the business. The degree of differentiation from similar types of small firms is not perceived as high, but it is still the highest if compared to other clusters. Innovative products seem to be an important strategic resource in comparison to other clusters. The degree of imitability and substitutability obtained the highest scores in this group. This indicates that the competitive advantage of the firms in this group may be more difficult to copy, which means that it has the potential to be sustainable. Yet, when it comes to the threat of imitation by competitors, this cluster does not differ from the others. The firms in this group have also put more effort into active product development than the other firms. When considering success, Price performance clearly differs from the other clusters. In this strategy group all fields of industry are represented, but there are clear differences in relative numbers of the firms belonging to this group. For example, over half of the firms processing berries and fruits follow premium-priced differentiation. Moreover, the representation of meat processors is considerable in this group. In addition, the numbers of farm-based firms as well growth-orienting firms are the largest in this cluster.

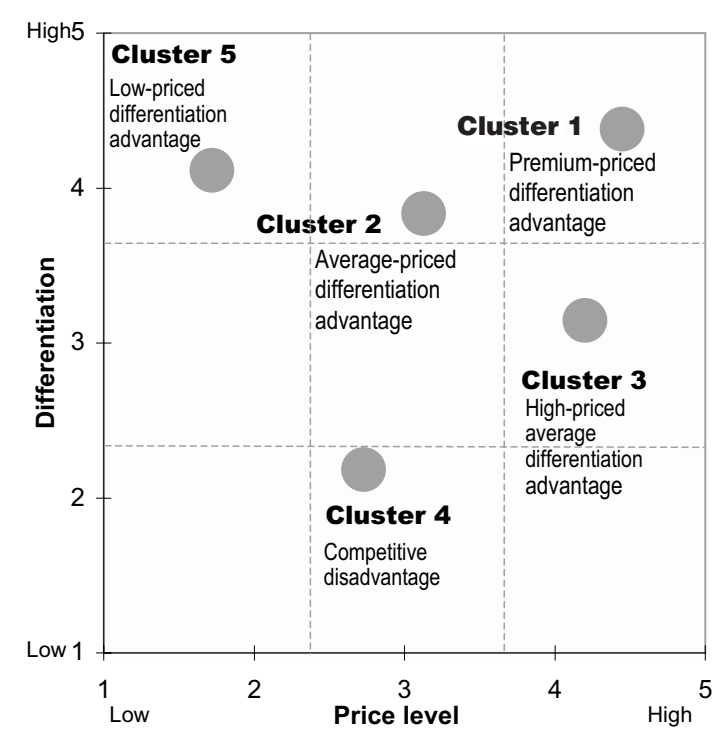

Fig. 16. Position of competitive advantage of the sample firms in a nine-cell matrix.

\section{Cluster 2: Average-priced differentiation advantage $(N=85)$}

In this cluster the firms provide quite highly-differentiated products at an average price. This strategy group is the largest one and includes firms from each field of industry. The average degree of substitutability of the products is the lowest in this group. When it comes to the other key variables, the cluster does stand out from the other clusters.

\section{Cluster 3: High-priced average differentiation advantage $(N=42)$}

In this cluster the firms provide medium-differentiated products at a relatively high price. This strategy group includes firms from each field of industry. Milk-processing firms are the largest single industry in this group. Also this group does not stand out from the other clusters in terms of key variables.

Cluster 4: Competitive disadvantage $(N=26)$ In this cluster the firms provide low-differentiated products at an average price. Differentia- 
Vol. 13 (2004): Supplement 1.

tion from other small firms is also low and there have not been considerable efforts in product development. Superior reputation, Innovative products, Way of distribution and Quality of raw material obtain the lowest scores as strategic resources. Moreover, the average degree of imitability for the firms in this group is the lowest. This cluster is also the least local-market oriented, but when it comes to the national scope of the market, the average market share is relatively the highest. It is noteworthy that no firms processing meat, milk or berries and fruit belong to this group. In addition, the number of growthoriented firms is the lowest whereas the number of firms intending to down-size, end or reorient the business is the largest in this cluster.

\section{Cluster 5: Low-priced differentiation advan-} tage $(N=25)$

In this cluster the firms provide relatively highly-differentiated products at a low price. Compared to the premium-priced differentiation ad- vantage (Cluster 1), there is more emphasis on services and overall differentiation than on product differentiation. Products are not as specialised as in firms that belong to Cluster 1, but they can be characterised as more normal types of products and, furthermore, they may be handmade products. In addition, the degree of imitability and substitutability is not as high as in Cluster 1 indicating that the competitive advantage is not necessarily that sustainable. Way of distribution and Superior Reputation are emphasised as strategic resources more than in the other clusters. Moreover, this strategy is clearly connected to local market orientation. It is noteworthy that no firms processing meat, milk or berries and fruit belong to this group. Market performance in this cluster is the highest in comparison to the other clusters whereas Price performance is the weakest. The number of farmbased firms is the lowest in this cluster.

Strong differentiation is usually stressed as a strategic starting point for small-scale food-

Table 27. Perceived differentiation and price-level by competitive advantage clusters.

\begin{tabular}{|c|c|c|c|c|c|c|c|}
\hline & $\begin{array}{l}\text { Cluster 1 } \\
(\mathrm{N}=60) \\
\text { Premium- } \\
\text { priced diff. } \\
\text { advantage }\end{array}$ & $\begin{array}{l}\text { Cluster } 2 \\
(\mathrm{~N}=85) \\
\text { Average- } \\
\text { priced diff. } \\
\text { advantage }\end{array}$ & $\begin{array}{l}\text { Cluster } 3 \\
(\mathrm{~N}=42) \\
\text { High-priced } \\
\text { average diff. } \\
\text { advantage }\end{array}$ & $\begin{array}{l}\text { Cluster } 4 \\
(\mathrm{~N}=26) \\
\text { Competitive } \\
\text { dis- } \\
\text { advantage }\end{array}$ & $\begin{array}{l}\text { Cluster } 5 \\
(\mathrm{~N}=25) \\
\text { Low-priced } \\
\text { diff. } \\
\text { advantage }\end{array}$ & F value & $P$ value \\
\hline \multicolumn{8}{|l|}{ Product differentiation in relation to...(Q17) } \\
\hline larger firms providing ordinary products & 4.42 & 3.84 & 3.12 & 2.20 & 3.80 & 82.856 & $0.000 * * *$ \\
\hline larger firms providing special products & 4.25 & 3.56 & 2.85 & 1.96 & 3.76 & 91.710 & $0.000 * * *$ \\
\hline similar types of small firms & 3.54 & 3.28 & 3.00 & 2.25 & 3.20 & 22.299 & $0.000 * * *$ \\
\hline \multicolumn{8}{|c|}{ Services differentiation in relation to... (Q18) } \\
\hline larger firms providing ordinary products & 4.43 & 4.09 & 3.30 & 2.80 & 4.32 & 59.296 & $0.000 * * *$ \\
\hline larger firms providing special products & 4.32 & 3.81 & 3.10 & 1.96 & 4.24 & 80.814 & $0.000 * * *$ \\
\hline similar types of small firms & 3.54 & 3.43 & 2.95 & 2.84 & 3.44 & 14.569 & $0.006 * *$ \\
\hline \multicolumn{8}{|c|}{ Overall differentiation in relation to... (Q19) } \\
\hline larger firms providing ordinary products & 4.50 & 3.88 & 3.34 & 2.29 & 4.40 & 81.554 & $0.000 * * *$ \\
\hline larger firms providing special products & 4.36 & 3.76 & 3.18 & 1.83 & 4.16 & 97.666 & $0.000 * * *$ \\
\hline similar types of small firms & 3.63 & 3.18 & 3.00 & 2.33 & 3.44 & 26.452 & $0.000 * * *$ \\
\hline \multicolumn{8}{|l|}{ Price level compared to (Q25) } \\
\hline larger firms providing ordinary products & 4.63 & 3.36 & 4.43 & 3.00 & 1.92 & 155.439 & $0.000 * * *$ \\
\hline larger firms providing special products & 4.31 & 2.89 & 3.95 & 2.46 & 1.52 & 167.661 & $0.000 * * *$ \\
\hline similar types of small firms & 3.41 & 2.85 & 3.29 & 2.73 & 2.48 & 34.517 & $0.000 * * *$ \\
\hline
\end{tabular}

$* * * \mathrm{P}<0.000, * * \mathrm{P}<0.01, * \mathrm{P}<0.05$ 
Forsman, S. How do small rural food-processing firms compete?

Table 28. Sustainability of competitive advantage by competitive advantage clusters.

\begin{tabular}{|c|c|c|c|c|c|c|c|}
\hline & $\begin{array}{l}\text { Cluster } 1 \\
(\mathrm{~N}=60) \\
\text { Premium- } \\
\text { priced diff. } \\
\text { advantage }\end{array}$ & $\begin{array}{l}\text { Cluster } 2 \\
(\mathrm{~N}=85) \\
\text { Average- } \\
\text { priced diff. } \\
\text { advantage }\end{array}$ & $\begin{array}{l}\text { Cluster } 3 \\
(\mathrm{~N}=42) \\
\text { High-priced } \\
\text { average diff. } \\
\text { advantage }\end{array}$ & $\begin{array}{l}\text { Cluster } 4 \\
(\mathrm{~N}=26) \\
\text { Competitive } \\
\text { dis- } \\
\text { advantage }\end{array}$ & $\begin{array}{l}\text { Cluster } 5 \\
(\mathrm{~N}=25) \\
\text { Low-priced } \\
\text { diff. } \\
\text { advantage }\end{array}$ & $\mathrm{F}$ value & $P$ value \\
\hline \multicolumn{8}{|l|}{ Degree of imitability (Q20) } \\
\hline concrete product characteristics & 3.47 & 2.85 & 2.90 & 2.70 & 3.04 & 3.381 & $0.010 *$ \\
\hline competence & 3.64 & 3.00 & 3.10 & 2.75 & 3.07 & 3.903 & $0.004 * *$ \\
\hline \multicolumn{8}{|l|}{ Threat of imitability (Q21) } \\
\hline among larger firms & 2.49 & 2.44 & 2.25 & 2.95 & 2.49 & 1.670 & 0.158 \\
\hline among smaller firms & 3.08 & 2.67 & 2.80 & 3.30 & 2.87 & 1.1513 & 0.199 \\
\hline Degree of substitutability (Q24) & 3.57 & 2.59 & 3.15 & 3.00 & 3.18 & 3.381 & $0.010 *$ \\
\hline
\end{tabular}

$* * * \mathrm{P}<0.000, * * \mathrm{P}<0.01, * \mathrm{P}<0.05$

Table 29. Background characteristics by competitive advantage clusters.

\begin{tabular}{|c|c|c|c|c|c|c|c|}
\hline & $\begin{array}{l}\text { Cluster } 1 \\
(\mathrm{~N}=60) \\
\text { Premium- } \\
\text { priced diff. } \\
\text { advantage }\end{array}$ & $\begin{array}{l}\text { Cluster } 2 \\
(\mathrm{~N}=85) \\
\text { Average- } \\
\text { priced diff. } \\
\text { advantage }\end{array}$ & $\begin{array}{l}\text { Cluster } 3 \\
(\mathrm{~N}=42) \\
\text { High-priced } \\
\text { average diff. } \\
\text { advantage }\end{array}$ & $\begin{array}{l}\text { Cluster } 4 \\
(\mathrm{~N}=26) \\
\text { Competitive } \\
\text { dis- } \\
\text { advantage }\end{array}$ & $\begin{array}{l}\text { Cluster } 5 \\
(\mathrm{~N}=25) \\
\text { Low-priced } \\
\text { diff. } \\
\text { advantage }\end{array}$ & $\begin{array}{l}\chi^{2} \text { value/ } \\
\text { F value }\end{array}$ & $\mathrm{P}$ value \\
\hline \multicolumn{8}{|l|}{ Farm connection } \\
\hline Farm-based firms (\%) & 45.0 & 38.1 & 38.1 & 40.0 & 32.0 & 1.455 & 0.835 \\
\hline Non-farm connection $(\%)$ & 55.0 & 61.9 & 61.9 & 60.0 & 68.0 & & \\
\hline $\begin{array}{l}\text { Distribution of the firms into different } \\
\text { branches within the clusters }\end{array}$ & & & & & $59.266^{2}$ & & $0.001 * *$ \\
\hline Processing of meat and meat products & 37.0 & 29.6 & 33.3 & 0.0 & 0.0 & & \\
\hline Processing of fish and fish products & 33.3 & 20.0 & 20.0 & 13.3 & 13.3 & & \\
\hline Production of grain mill products & 19.0 & 38.1 & 9.5 & 23.8 & 9.5 & & \\
\hline Production of bread and bakery produc & $\operatorname{cts} 20.2$ & 39.4 & 12.8 & 9.6 & 18.1 & & \\
\hline Processing of milk & 30.0 & 30.0 & 40.0 & 0.0 & 0.0 & & \\
\hline Processing of vegetables and potatoes & 13.8 & 37.9 & 24.1 & 24.1 & 0.0 & & \\
\hline Processing of berries and fruit & 56.0 & 28.0 & 12.0 & 0.0 & 4.0 & & \\
\hline Others & 5.9 & 47.1 & 11.8 & 17.6 & 17.6 & & \\
\hline \multicolumn{8}{|l|}{ Average age of the firms (years) ${ }^{1}$} \\
\hline Stage of the lifecycle & & & & & & 18.446 & $0.018 *$ \\
\hline Growth $(\%)$ & 44.1 & 21.4 & 17.1 & 15.4 & 33.3 & & \\
\hline Stable $(\%)$ & 39.0 & 59.5 & 53.7 & 50.0 & 37.5 & & \\
\hline Down-sizing/ending/reorienting (\%) & 16.9 & 19.0 & 29.3 & 34.6 & 29.2 & & \\
\hline \multicolumn{8}{|l|}{ Market arena (\% of sales) } \\
\hline Local markets & 50.8 & 61.6 & 58.0 & 45.1 & 75.3 & 10.383 & $0.034 *$ \\
\hline Regional markets & 20.1 & 17.6 & 14.0 & 20.3 & 7.5 & 9.782 & $0.044 *$ \\
\hline National markets ${ }^{1}$ & 28.8 & 19.5 & 27.5 & 34.4 & 12.7 & 10.345 & $0.035 *$ \\
\hline International markets & 0.3 & 1.2 & 0.6 & 0.2 & 4.5 & 4.026 & 0.403 \\
\hline
\end{tabular}

${ }^{1)}$ Kruskall-Wallis analysis with $\chi^{2}$ was used instead of ANOVA due to the non-equal variances along the clusters.

2) 24 cells $(60.0 \%)$ have expected count less than 5 . The minimum expected count is 1.05 .

$* * * \mathrm{P}<0.000, * * \mathrm{P}<0.01, * \mathrm{P}<0.05$ 
Vol. 13 (2004): Supplement 1.

Table 30. Resources, strategic actions and success by competitive advantage clusters, group means.

\begin{tabular}{|c|c|c|c|c|c|c|c|}
\hline & $\begin{array}{l}\text { Cluster } 1 \\
(\mathrm{~N}=60) \\
\text { Premium- } \\
\text { priced diff. } \\
\text { advantage }\end{array}$ & $\begin{array}{l}\text { Cluster } 2 \\
(\mathrm{~N}=85) \\
\text { Average- } \\
\text { priced diff. } \\
\text { advantage }\end{array}$ & $\begin{array}{l}\text { Cluster } 3 \\
(\mathrm{~N}=42) \\
\text { High-priced } \\
\text { average diff. } \\
\text { advantage }\end{array}$ & $\begin{array}{l}\text { Cluster } 4 \\
(\mathrm{~N}=26) \\
\text { Competitive } \\
\text { dis- } \\
\text { advantage }\end{array}$ & $\begin{array}{l}\text { Cluster } 5 \\
(\mathrm{~N}=25) \\
\text { Low-priced } \\
\text { diff. } \\
\text { advantage }\end{array}$ & F value & $\mathrm{P}$ value \\
\hline \multicolumn{8}{|l|}{ Strategic resources } \\
\hline Superior reputation & 4.29 & 4.03 & 4.09 & 3.90 & 4.38 & 3.862 & $0.005 * *$ \\
\hline Quality raw material & 4.13 & 3.90 & 4.08 & 3.54 & 3.97 & 2.468 & $0.046 *$ \\
\hline Innovative products & 3.50 & 3.16 & 2.91 & 2.46 & 3.07 & 5.450 & $0.000 * * *$ \\
\hline Way of distribution & 3.36 & 3.48 & 3.28 & 3.06 & 3.62 & 4.840 & $0.001 * *$ \\
\hline Customer service & 4.42 & 4.24 & 4.15 & 3.68 & 4.37 & 1.215 & 0.305 \\
\hline Local production & 3.32 & 3.58 & 3.42 & 3.15 & 3.76 & 1.857 & 0.119 \\
\hline \multicolumn{8}{|l|}{ Basic resources } \\
\hline Business competence & 3.56 & 3.44 & 3.30 & 3.70 & 3.51 & 1.332 & 0.259 \\
\hline Customer knowledge and accessibility & 3.29 & 3.38 & 3.13 & 3.41 & 3.09 & 0.970 & 0.425 \\
\hline Production competence & 3.85 & 3.76 & 3.82 & 3.95 & 3.82 & 0.322 & 0.863 \\
\hline Co-operation capability & 3.28 & 3.41 & 3.33 & 3.79 & 3.19 & 1.345 & 0.254 \\
\hline Availability of production resources & 3.50 & 3.56 & 3.40 & 3.92 & 3.56 & 1.561 & 0.186 \\
\hline Financial capability & 3.25 & 3.32 & 3.05 & 3.62 & 2.92 & 1.420 & 0.228 \\
\hline \multicolumn{8}{|l|}{ Success } \\
\hline Financial performance & 2.94 & 3.00 & 2.85 & 2.88 & 3.03 & 0.341 & 0.850 \\
\hline Quality performance & 4.18 & 4.00 & 4.04 & 3.78 & 4.11 & 2.657 & $0.034 *$ \\
\hline Market performance & 3.47 & 3.32 & 3.05 & 2.95 & 3.60 & 3.773 & $0.005 * *$ \\
\hline Cost performance & 2.65 & 2.62 & 2.55 & 2.64 & 2.45 & 0.407 & 0.804 \\
\hline Price performance ${ }^{1}$ & 3.41 & 2.91 & 3.06 & 2.65 & 2.58 & 26.864 & $0.000 * * *$ \\
\hline Overall competence performance & 3.78 & 3.56 & 3.52 & 3.46 & 3.54 & 1.194 & 0.314 \\
\hline \multicolumn{8}{|l|}{ Strategic actions } \\
\hline Customer-based market development & 3.12 & 2.97 & 3.02 & 2.72 & 2.93 & 0.810 & 0.520 \\
\hline $\begin{array}{l}\text { Improvement of customer } \\
\text { satisfaction and retention }\end{array}$ & 3.84 & 3.62 & 3.60 & 3.42 & 3.83 & 2.063 & 0.086 \\
\hline Active product development & 3.38 & 3.09 & 3.01 & 2.59 & 3.14 & 3.791 & $0.005 * *$ \\
\hline Competitor orientation & 2.10 & 2.20 & 2.32 & 2.41 & 2.33 & 0.769 & 0.546 \\
\hline
\end{tabular}

${ }^{1)}$ Kruskall-Wallis analysis with $\chi^{2}$ was used instead of ANOVA due to the non-equal variances along the clusters. $* * * \mathrm{P}<0.000, * * \mathrm{P}<0.01, * \mathrm{P}<0.05$

processing firms. Through differentiation a firm may have an opportunity for premium pricing. The results of the cluster analysis support the view that there are premium-priced differentiators among small rural food-processing firms; $25 \%$ of the sample firms belong to Cluster 1.The results revealed, however, that there are other strategies too. The majority of the firms seem to follow the average-priced differentiation strategy through by providing differentiated offerings at lower prices than the premium-priced differ- entiators. The results do not reveal whether the medium-level price is a strategic choice or whether it is determined by the competitive situation. The lower-priced differentiation strategy is also interesting since from a firm's point of view this strategy provided customers with the best combination of value and price. It should lead to high market share, but it requires that a firm be able to manage and control costs (see Faulkner and Bowman 1992). In the sample, 11\% of firms follow this strategy, although it is ques- 
Forsman, S. How do small rural food-processing firms compete?

tionable whether this strategy can be profitable for a small actor. In some branches, this strategy was not chosen at all.

In conclusion, there are different types of competitive advantages among small-scale foodprocessing firms. What is noteworthy is that not all the firms try to differentiate in terms of product differentiation. The results reveal, for example, that there is a group of firms that follow a local-market oriented strategy emphasising services differentiation based on superior reputation and way of distribution. The findings also show that there are firms following strategies that lead to a position of competitive disadvantage rather than competitive advantage.

Following a resource-based logic, resources and capabilities are thought of as sources of competitive advantage. The analyses show that strategic competitive resources in terms of Innovative Products, Way of distribution, Superior Reputation and Quality Raw Material were linked to the cluster solution, which supports P4. Contrary to expectations, there was not any statistically significant linkage between competitive positioning strategies and basic resources. Hence, P5 is not supported.

The results also reveal that there were some statistical linkages between the position of com- petitive advantage and success dimensions. The clusters with a high degree of differentiation (Cluster 1, 2 and 5), however, do not seem to have higher scores for the success dimensions, excluding Market performance, than Clusters 3 and 4. Consequently, following a particular strategy, for example premium-priced differentiation, does not automatically lead to success, at least in terms of financial performance.

\subsubsection{Linkage between success and competitive advantage clustering}

The analysis of the competitive advantage clusters did not reveal systematic statistical linkages between competitive strategies and success. In order to study which strategies have the greatest potential to lead to success and which resources are linked to successful strategies, the relationship of success clustering and competitive advantage clustering was analysed by means of cross tabulation. The hypothesis to be tested is P6: There is a positive linkage between competitive positioning strategies and success. As shown by Table 31, chi squared analysis revealed that the linkage is significant at the level of 0.05 . This indicates that there is support for P6.

Table 31. Linkage between competitive advantge clusters and success clusters.

\begin{tabular}{lccccc}
\hline Competitive advantage clusters & $\begin{array}{c}\text { Success clusters } \\
\text { Cluster 1 } \\
(\mathrm{N}=40)\end{array}$ & $\begin{array}{c}\text { Cluster 2 } \\
(\mathrm{N}=58)\end{array}$ & $\begin{array}{c}\text { Cluster 4 } \\
(\mathrm{N}=78)\end{array}$ & Total \\
\hline Cluster 1 $(\mathrm{N}=60)$ & 8.3 & 16.7 & 38.3 & 36.7 & 100.0 \\
Cluster 2 $(\mathrm{N}=85)$ & 14.1 & 30.6 & 32.9 & 22.4 & 100.0 \\
Cluster 3 $(\mathrm{N}=42)$ & 23.8 & 14.3 & 40.5 & 21.4 & 100.0 \\
Cluster 4 $(\mathrm{N}=26)$ & 34.6 & 26.9 & 23.1 & 15.4 & 100.0 \\
Cluster 5 $(\mathrm{N}=25)$ & 16.0 & 36.0 & 16.0 & 32.0 & 100.0 \\
\hline
\end{tabular}

$\chi^{2}=24.170, \mathrm{df}=12, \mathrm{P}=0.019$

Success clusters: 1 = Weakest-performing firms, 2 = Average-performing firms, with emphasis on Market performance, 3 = Average-performing firms, with emphasis on Price performance, $4=$ Bestperforming firms

Positioning clusters: $1=$ Premium-priced differentiation advantage, $2=$ Average-priced differentiation advantage, 3 = High-priced average differentiation advantage, $4=$ Competitive disadvantage, $5=$ Lowpriced differentiation advantage 
Vol. 13 (2004): Supplement 1.

Thirty-seven per cent of the firms following the innovative premium-priced differentiation belonged to the Best-performing firms (Success Cluster 4). This is $9 \%$ of the total sample. By contrast, only $8 \%$ of the firms following this strategy belonged to the Weakest-performing firms (Success Cluster 1). In the other competitive advantage groups, the difference was not that great. On the other hand, $32 \%$ of the firms with low-priced differentiation advantage also belonged to the Best-performing firms. In other words, there are firms that compete on price and still perceive their business as successful. In contrast, $35 \%$ of the firms that follow the averagepriced non-differentiation strategy belonged to the Weakest-performing firms and the share of these firms in the group of Best-performing firms is clearly the lowest in comparison to the other strategy clusters. In conclusion, it seems that the firms that follow low-priced differentiation and high-price strategy have good opportunities for success.

According to the results, high product differentiation and high-price strategy do not automatically imply that a firm will achieve success.
One might ask why some firms in the sample are more successful than other firms following the same strategy. Following the RBV, the study takes the view that differences in success result from differences in resources. To test this assumption with the sample data, some of the success-strategy clusters are investigated in more detail.

First, the firms belonging to the Competitive advantage Cluster $1(\mathrm{~N}=60)$ were divided into two groups: Best-performing firms (Success Cluster 4) and the other firms (Success Cluster 1, 2 and 3). Then the group means for strategic resources and basic resources were compared between the groups using the $t$-test as a statistical tool. The results are shown in Table 32. For strategic resources between the two groups, there was a statistically significant difference only for Innovative products; it was weighted more in Best-performing firms. For basic resources, by contrast, there were four measures - Business competence, Financial capability, Production competence and Customer knowledge and accessibility - the group means of which were considerably higher in Best-performing firms in

Table 32. Weights of resources (group means) in firms with the premium-priced differentiation advantage: comparison between the Best performing firms and the other firms $(\mathrm{N}=60)$.

\begin{tabular}{lcccc}
\hline & $\begin{array}{c}\text { Best- } \\
\text { performing } \\
\text { firms }\end{array}$ & $\begin{array}{c}\text { Other } \\
\text { firms }\end{array}$ & $t$ value & P value \\
\hline Strategic resources & & & & \\
$\quad$ Superior reputation & 4.39 & 4.26 & 0.850 & 0.389 \\
Quality raw material & 4.26 & 4.05 & 0.997 & 0.316 \\
Innovative products & 3.95 & 3.23 & 2.890 & $0.005 * *$ \\
Customer service & 4.39 & 4.43 & -0.217 & 0.829 \\
Way of distribution & 3.36 & 3.35 & 0.045 & 0.965 \\
$\quad$ Locality & 3.47 & 3.23 & 0.883 & 0.381 \\
Basic resources & 4.09 & 3.26 & 4.797 & $0.000 * * *$ \\
$\quad$ Business competence & 3.73 & 3.37 & 1.567 & 0.122 \\
Availability of production resources & 3.55 & 3.12 & 1.405 & 0.165 \\
Co-operation competence & 3.82 & 2.92 & 2.807 & $0.007 * *$ \\
Financial capability & 4.24 & 3.64 & 2.949 & $0.005 * *$ \\
$\quad$ Production competence & 3.72 & 3.04 & 3.360 & $0.001 * *$ \\
\hline Customer knowledge and accessibility & & & & \\
\hline
\end{tabular}

*** $\mathrm{P}<0.000, * * \mathrm{P}<0.01, * \mathrm{P}<0.05$ 
Forsman, S. How do small rural food-processing firms compete?

comparison to the other group. In conclusion, strategic resources may be valuable in product differentiation and creating arguments for a highprice strategy, but in order to turn them into firm success they should be supported by the basic resources, the most important of which in this sample data is business competence.

Similarly, the firms that belonged to Competitive advantage Cluster $5(\mathrm{~N}=25)$ were divided into two groups: Best-performing firms (Success Cluster 4) and the other firms (Success Cluster 1, 2 and 3). For strategic resources, there were statistically significant differences for Innovative products and Superior reputation; they obtained higher scores in Best-performing firms compared to the other group (Table 33). For basic resources, by contrast, the significance of Customer knowledge and accessibility and Business competence were emphasised considerably more in Best-performing firms than in the other firms.

Finally, the firms that belonged to Competitive advantage Cluster 4 (Competitive disadvantage, $\mathrm{N}=26$ ) were divided into two groups:
Weakest-performing firms (Success Cluster 1) and the other firms (Success Cluster 2, 3 and 4). For strategic resources, no statistically significant differences between the two groups were discovered (Table 34), but Way of distribution and Quality raw material approached significance. For basic resources, by contrast, the differences reached significance for Customer knowledge and accessibility and Business competence; the lowest scores were discovered in the Weakest-performing firms.

In conclusion, the findings presented in this section indicate that there are linkages between resources, position of competitive advantage and success. These linkages are not necessarily so clear at the aggregate level of the data, but when investigating the data in smaller groups the linkages become more obvious. It would appear, therefore, that firm success in small-scale food production is connected not only to particular types of competitive advantage, but also to underlying resources. Based on the results, the study may suggest that the most critical basic resources are Business competence, which can

Table 33. Weights of resources (group means) in firms with the low-priced differentiation advantage: comparison between the Best-performing firms and the other firms $(\mathrm{N}=25)$.

\begin{tabular}{lcccc}
\hline & $\begin{array}{c}\text { Best- } \\
\text { performing } \\
\text { firms }\end{array}$ & $\begin{array}{c}\text { Other } \\
\text { firms }\end{array}$ & $t$ value & P value \\
\hline Strategic resources & & & & \\
$\quad$ Superior reputation & 4.68 & 4.25 & 2.185 & $0.039 *$ \\
Quality raw material & 4.29 & 3.82 & 1.527 & 0.141 \\
Innovative products & 4.17 & 2.67 & 3.334 & $0.003 * *$ \\
Customer service & 4.42 & 4.35 & 0.182 & 0.857 \\
Way of distribution & 3.75 & 3.56 & 0.357 & 0.725 \\
$\quad$ Locality & 4.21 & 3.55 & 1.313 & 0.202 \\
Basic resources & & & & \\
$\quad$ Business competence & 4.10 & 3.23 & 2.739 & $0.012 *$ \\
Availability of production resources & 3.46 & 3.61 & -0.338 & 0.738 \\
Co-operation competence & 3.50 & 3.06 & 0.785 & 0.441 \\
Financial capability & 3.19 & 2.79 & 0.700 & 0.491 \\
Production competence & 4.33 & 3.61 & 1.960 & 0.063 \\
Customer knowledge and accessibility & 4.09 & 2.62 & 4.079 & $0.000 * * *$ \\
\hline
\end{tabular}

$* * * \mathrm{P}<0.000, * * \mathrm{P}<0.01, * \mathrm{P}<0.05$ 
Vol. 13 (2004): Supplement 1.

Table 34. Weights of resources in firms with competitive disadvantage: comparison between the Weakest performing firms and the other firms $(\mathrm{N}=26)$.

\begin{tabular}{lccrc}
\hline & $\begin{array}{c}\text { Weakest- } \\
\text { performing } \\
\text { firms }\end{array}$ & $\begin{array}{c}\text { Other } \\
\text { firms }\end{array}$ & $t$ value & P value \\
\hline Strategic resources & & & & \\
$\quad$ Superior reputation & 3.56 & 3.98 & -1.288 & 0.210 \\
Quality raw material & 3.07 & 3.78 & -1.880 & 0.072 \\
Innovative products & 2.74 & 2.30 & 1.269 & 0.217 \\
Customer service & 3.26 & 3.90 & -1.488 & 0.150 \\
Way of distribution & 2.50 & 3.35 & -1.973 & 0.060 \\
$\quad$ Locality & 3.15 & 3.16 & -0.021 & 0.983 \\
Critical resources & & & & \\
Business competence & 3.24 & 3.94 & -2.408 & $0.024 *$ \\
Availability of production resources & 3.67 & 4.06 & -0.893 & 0.390 \\
Co-operation competence & 3.28 & 4.06 & -1.957 & 0.062 \\
Financial capability & 3.61 & 3.62 & -0.012 & 0.990 \\
Production competence & 3.63 & 4.12 & -0.012 & 0.099 \\
Customer knowledge and accessibility & 2.72 & 3.78 & -1.716 & $0.009 * *$ \\
\hline
\end{tabular}

*** $\mathrm{P}<0.000, * * \mathrm{P}<0.01, * \mathrm{P}<0.05$

be largely associated with marketing-related factors, and Customer knowledge and accessibility. The significance of the strategic resources seems to be more connected to differentiation than non-differentiation strategies and innovative product ideas seem to play the most important role.

\subsection{Causal linkages between resources and success: LISREL application}

The results based on the success and competitive advantage clustering in the previous sections revealed that there are statistically significant linkages between resources and success. Based on the findings, one cannot yet suggest that the best-performing firms are better because they have certain resources, but only that there are linkages between them. In this chapter the aim is to study the structure of these linkages in more detail by using the same data at the aggregate level (correlation matrix as the input data) and a more confirmatory approach. Based on the theoretical considerations, a hypothesised model is elaborated. After that it is tested to see if the suggested structure can be identified in the sample model. The technique used is LISREL modelling that represents structural equation modelling. Since structural equation modelling has not been applied widely in this type of research context the main features of this technique are presented first.

\subsection{Basics of LISREL modelling}

Structural equation modelling is one of the most advantageous techniques for handling quantitative data and studying causal relations. Recently structural equation modelling has been used especially in business and marketing studies 
Forsman, S. How do small rural food-processing firms compete?

where causality is often a basic premise (Eriksson 2002). One of the applications of structural equation modelling is LISREL which is used in this study. ${ }^{26}$

The goal of LISREL modelling is to explain the structure among a set of latent or unobserved variables, each of which is measured by one or more observed indicators (Diamantopoulos 1994). A general LISREL model includes two major subsystems: the measurement model and the structural equation model. The measurement model specifies how underlying, latent indicators or hypothetical constructs are operationalised via the observed indicators, that is, how they depend on or are indicated by the observed indicators. The structural equation model, on the other hand, summarises the relationships between latent, underlying constructs and describes the causal effects between them (see Bollen 1989, p. 11, Jöreskog and Sörbom 1993, Diamantopoulos 1994, Kelloway 1998).

LISREL analysis is mainly confirmatory in nature as it seeks to determine the extent to which the hypothesised structure is consistent with empirical data (Diamantopoulos 1994). The LISREL is also often used in an exploratory fashion. LISREL process is data-driven if the relationships in the empirical data are used to suggest respecifications of the theory underlying the model of interest (Hughes et al. 1986). Thus, LISREL models also provide great potential for advancing and enhancing theory development (Anderson and Gerbing 1988).

LISREL modelling has many advantages over conventional multivariate techniques such as multiple regression and factor analysis. For example, in ordinary least-squares regression an underlying assumption is measurement without error. In business and marketing research, however, there rarely is measurement without error. Indicators of constructs have variance due to the

${ }^{26}$ LISREL stands for LInear Structural RELationships and is, strictly speaking, a well-known computer software for structural equation modelling. It is common to use LISREL as a synonym for structural equation modelling. construct being measured and variance due to the measurement error (Path analysis and Lisrel 2002). Hence, the fact is that measured variables usually contain at least moderate amounts of errors (Hughes et al. 1986). It follows that the reliability of the variables can be quite low, particularly when trying to capture very abstract concepts (Cote and Buckley 1987). In LISREL, however, observable variables may be assumed to be measured with error (Hughes et al. 1986), which increases the validity of the estimated coefficients (Path analysis and Lisrel 2002).

LISREL uses only a covariance or a correlation matrix as the input data. Thus, instead of individual observations the focus is on the pattern of relationships in a sample (Hair et al. 1998, p. 601). The purpose is to minimise the difference between the sample covariances (correlations) and the covariances (correlations) predicted by the model (Bollen 1989, p. 1). Moreover, LISREL allows the study of several dependent relations simultaneously (Hair et al. 1998, p. 578). In addition, the distributional assumptions of the observed variables are not so restrictive in LISREL (Bollen 1989, p. 79).

\section{Model conceptualisation, specification and identification}

Model conceptualisation focuses on the development of the substantive hypotheses linking the constructs (structural model) and the operationalisation of them in terms of empirical measures (measurement model) (Diamantopoulos 1994). Hence, a priori knowledge of theory is of utmost importance. A necessary prerequisite for the validity of the theory is that the relationships among variables are consistent with the proposals of the theory. Thus, the theory, if valid, should be able to explain the patterns of covariances (correlations) found in the sample data. However, an expected structure would not automatically imply that the theory is true, only that it is possible. There might be other theories that would result in the same structure (Kelloway 1998, p. 5-6).

In LISREL modelling, constructs are represented by latent variables (Bollen 1989, p. 179- 
Vol. 13 (2004): Supplement 1.

184). Latent variables can only be determined to exist as a combination of other measurable variables (Reisinger and Turner 1999). Examples of latent constructs are customer satisfaction and financial performance. LISREL models are usually very simple in terms of the number of the variables included in the model. An ideal situation would be that each construct could be operationalised in terms of 3-4 distinct observable variables (Diamontopoulos 1994, Baumgartner and Homburg 1996).

In model specification the nature and number of parameters to be estimated is described. This means that postulated relationships have to be converted to linear equations to obtain the formal specification of the model ${ }^{27}$. In model specification some parameters are usually set fixed and some parameters are set free. Fixed parameters are given a certain value in advantage, which imply that they are not estimated as part of the model (Diamontopoulos 1994).

Model identification focuses on the issue of whether the information provided by the sample data is sufficient to allow parameter estimation (Diamontopoulos 1994). A necessary, although insufficient condition for model identification is that there cannot be estimated more parameters than there are in the starting matrix (Bollen 1989, p. 93, Kelloway 1998, p. 14). If the number of equations equals the number of parameters to be estimated, the model is just-identified. This means that there is only one estimate for each parameter and, therefore, the model provides a unique solution. If the number of the parameters to be estimated is more than the number of equations, the model is unidentified. This implies that there is no unique solution and, therefore, the model cannot be determined in a meaningful way. If the number of equations exceeds the number of parameters to be estimated, the model is overidentified. This means that there are numerous possible solutions. The goal, then,

${ }^{27}$ In the presentation mathematical equations are minimised. For deeper and more mathematical information about structural equation modelling, see more detailed sources such as Bollen (1989). is to select the solution that best fits the empirical data (Diamontopoulos 1991, Kelloway 1998, p. 14-16).

\section{Assessing model fit}

Assessing model fit refers to the validity testing of the model, i.e., how well the model fits the data. There are three key dimensions through which the validity of the LISREL model is used to be estimated: 1) nomological validity, 2) discriminant validity, and 3) convergent validity (e.g., Eriksson et al. 2000, Eriksson and Sharma 2002).

Nomological validity refers to the validity of the entire model (Eriksson et al. 2000), that is, the degree to which predictions from a theoretical viewpoint are confirmed (Venkatraman and Grant 1986). The overall model fit and, thus, nomological validity is usually investigated by $\chi^{2}$ and degree of freedom. The $\chi^{2}$ test is used to test null hypothesis, i.e., whether the difference between the sample and the estimated covariance or correlation matrix is null or zero matrix (Sharma 1996, p. 157). Small P-values $(<0.05)$ denote that the postulated structure is not confirmed by the empirical data (Hughes et al. 1986). Jöreskog and Sörbom (1993, p. 122) suggest that in many cases it would be more useful to consider the $\chi^{2}$ test as "a measure of fit rather than as a test statistic".

Literature on LISREL modelling proposes a number of goodness-of-fit indices that are used to assess the nomological validity of the model in addition to the $\chi^{2}$ test (see Bollen 1989, Diamontopoulos 1994, Sharma 1996, Nummenmaa et al. 1997, Kelloway 1998). There are three types of goodness-of-fit measures: absolute fit measures, incremental fit measures and parsimonious fit measures. Absolute fit measures are used to assess only the overall model fit. By incremental fit measures the proposed model can be compared with another specified model. Parsimonious fit measures, on the other hand, can be used in comparison between two or more models with differing numbers of estimated coefficients (Hair et al. 1998, p. 611). It is recommended that one or more measures of each type 
Forsman, S. How do small rural food-processing firms compete?

be employed when assessing the model fit (Baumgartner and Homburg 1996, Hair et al. 1998, p. 611).

In this study, the following indices to assess the overall model fit are used:

- GFI (Goodness of Fit Index) is the absolute measure of fit and represents the amount of variances and covariances in the sample covariance matrix that are predicted by the model. If the GFI > 0.90, the model can be interpreted as adequate.

- AGFI (Adjusted Goodness of Fit Index) represents a parsimonious measure of fit. The AGFI is an extension of GFI that has been adjusted for degrees of freedom. A value of 0.90 is typically used as the cut-off value for good-fitting models (Hair et al. 1998, p. 622).

- CFI (Comparative Fit Index) is also a parsimonious measure of fit and is based on the noncentral $\chi^{2}$ distribution (Kelloway 1998). It is used to check for non-normal distributions. If CFI is $>0.90$, the model is adequate (Hair et al. 1998, p. 657).

- NFI (Normed Fit Index) represents an incremental measure of fit and it is used for a relative comparison of the proposed model to the null model (Hair et al. 1998, p. 657). The null model is the simplest model that can be theoretically justified. For a good model, the NFI should also exceed 0.90 (Hair et al. 1998, p. 582, 657).

In addition to the goodness-of-fit measures, there are also some other indices that are used to evaluate the overall model fit. In the present study, RMSEA and standardised RMR are referred to.

- RMSEA (Root Mean Error of Approximation) is based on the analysis of residuals. The model can be considered to be adequate if the RMSEA is below 0.08 . For a very good model fit, RMSEA should be below 0.05 (see Hair et al. 1998, p. 656).

- Standardised RMR is a measure for average correlation for residuals. The smaller the value of RMR, the better the fit between the model and the data. For a good model, the value should be below 0.05 (see Hair p. 622).
Convergent validity refers to homogeneity of constructs (Eriksson and Sharma 2002). Convergent validity is usually assessed by considering coefficients, $t$-values and $\mathrm{R}^{2}$ values (Eriksson 2002). Coefficients or "factor loadings" reflects the direct effects of the factor on the observed variables (Bollen 1989, p. 230). However, there are no definitive cut-off values for a coefficient. If theoretically relevant, then a low loading coefficient could be accepted. More important is that values of the coefficients are judged in association with substantive theoretical considerations (Eriksson 2002).

Convergent validity is also assessed by investigating if all parameters are statistically significant. Moreover, all the error variances should be positive (Reisinger and Turner 1999). Statistical significance of the estimated parameters is tested by $t$-values that indicate the value of the parameter divided by its standard error. The $\mathrm{t}$ value is statistically significant for the $0.05 \mathrm{lev}$ el if the value is not between -1.96 and 1.96 (Diamontopoulos 1994). For the 0.01 significance level, the critical value is $+/-2.576$ (Hair et al. 1998, p. 623). Hence, the high $t$-value indicates that the coefficient differs from zero.

Discriminant validity refers to the extent to which a construct separates from other constructs in the model (Venkatraman and Grant 1986, Eriksson et al. 2000, Eriksson and Sharma 2002). If the constructs are highly correlated, it is difficult to support the hypothesis that they represent distinct concepts (Hughes et al. 1986). Thus it is essential to make sure that all constructs are separate in their correlation with each other. This can be done by determining whether the confidence interval (+/- two standard errors) around the correlation estimate between the two factors includes a value of 1 (Anderson and Gerbing 1988). If the confidence interval does not exclude 1 , it could be concluded that the constructs do not measure the same thing (Eriksson 2002).

The squared multiple correlation, $\mathrm{R}^{2}$, for each variable indicates the reliability of the variable, that is, it is a measure of the strength of a linear relationship (Jöreskog and Sörbom 1993, p. 20, 121). It tells to what extent a variable "belongs" 
Vol. 13 (2004): Supplement 1.

to the measurement model (Hair et al. 1998, p. 612) and to what extent it is free from measurement error (Diamontopoulos 1994). The value of $\mathrm{R}^{2}$ ranges from 0 to 1 . If the value comes to near zero for a variable, it means that a variable is not a good measure of the construct. In general, if $\mathrm{R}^{2}$ values are 0.20 or bigger, the linearity of a relationship is acceptable (cf. Hair et al. 1998, p. 612). However, lower values can be accepted if satisfactory explanations for that can be found (Eriksson 2002). The coefficient of determination for the $y$ - and $x$-variables, on the other hand, indicates to what extent the observed variables as a group measure the latent variables. Again, the closer the value is to 1 , the better (Diamontopoulos 1994).

\section{Model modification}

Although confirmatory in nature, LISREL is most often used for the purpose of model generating rather than model testing. In many cases, a tentative initial model does not fit the sample data. It implies that a respecification of the model is needed. The respecification may be theory- or data-driven. The goal is often to find a model that is acceptable both statistically and theretically (Jöreskog and Sörbom 1993, p. 115).

Studying modification indices calculated for each nonestimated relationships provides guidance concerning how the estimated model could be modified to result in a better model fit (Path analysis and Lisrel 2002). What is of utmost importance is that decisions to reformulate the model should be made in conjunction with theory and content considerations and not based on statistical considerations alone (Anderson and Gerbing 1988). If the overall model fit is unacceptable, there are four basic means to respecify "problematic" indicators: 1) relating the indicator to a different construct; 2) deleting the indicator from the model; 3 ) relating the indicator to multiple constructs, or 4) letting the measurement errors of the indicators correlate with each other. The first two are preferred.

Adding correlated measurement errors to a model to improve the goodness-of-fit seems to be very general practise among researchers us- ing LISREL. If two or more measures of latent variables are systematically influenced by a factor that is not explicitly modelled, correlations may exist between the errors of the measures (Hughes et al. 1986). However, if correlated measurement errors are used, they are justified only when specified a priori; they should be interpreted and justified substantively (Jöreskog and Sörbom 1993, p. 96). Otherwise, the use of them based on statistical considerations alone may distort the interpretability of the model (Anderson and Gerbing 1988) as well as generalisability and comparability of the findings (Hughes et al. 1986). In practise, however, it is very common that correlated measurements are used without interpretation in order to improve overall model fit. Baumgartner and Homburg (1996), for example, found that in about half of the cases where correlated measurement errors were included in the model no justification was provided. As a rule of thumb, two modifications may be acceptable if a model is reasonably large. Moreover, modifications based on correlated errors between the constructs within the same level (dependent constructs or independent constructs) are more easily justified (Eriksson 2002).

\subsubsection{LISREL model of linkages between resources and success}

The LISREL model conceptualised and tested in this section is based on the same population and data as the analysis presented in Section 5.2.4. By adapting a more confirmatory approach, we next employ the data at the aggregate level.

\section{Conceptual model}

As mentioned earlier, linkages between firm resources and success are a basic premise in this study. Moreover, it is assumed that there are two types of resources, namely strategic resources and basic resources, that both have a direct linkage to firm success. Firm success is defined as a dependent factor. In addition, it is assumed that there is an interrelation between strategic and 
Forsman, S. How do small rural food-processing firms compete?

basic resources. The hypothesised model summarises the assumed linkages. The model proposes two exogenous latent constructs (strategic resources and basic resources) and an endegenous construct (firm success). Exogenous variables are not explained but represent the starting variables in the model. Endogenous variables are explained or predicted by the relationships included in the hypothesised model (Diamontopoulos 1994, Kelloway 1998, p. 8). Based on the conceptual framework statistically significant linkages between the constructs are assumed (Fig. 17):

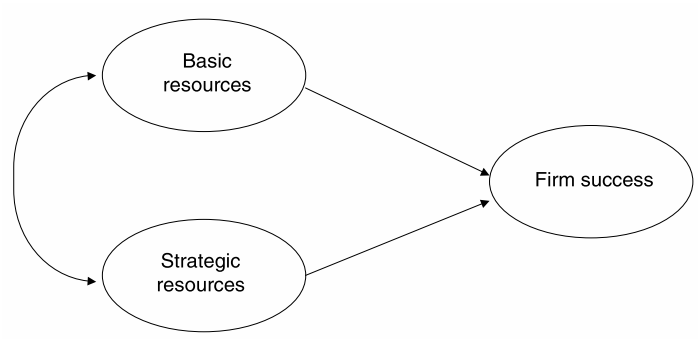

Fig. 17. Hypothesised model.

The measurement model for each construct is based on the summated scale variables created in Chapter 5.3. Hence, variables measuring basic resources include Business competence, Customer knowledge and accessibility, Production competence, Co-operation capability, Availability of production resources, and Financial capability. Variables measuring strategic resources include Superior reputation, Quality raw materials, Innovative products, Customer service, Way of distribution and Locality. For measuring success, four variables out of total of six performance variables were chosen: Financial, Quality, Market and Price.

\section{Model testing and redevelopment}

The conceptual model was tested in our sample data by using PRELIS 2.51 and LISREL 8.51 software. LISREL 8.51 provides several estimation methods for the parameter estimation. The
Maximum Likelihood (ML) is the most common method and was also used in this study. ML requires that variables are measured in terms of the interval scale and are normally distributed. The summated scale variables met the distribution requirements better than the original variables. The sample size was also large enough for the ML estimation (see Kelloway 1998, p. 20). The analysis was based on the correlation matrix of the variables. Missing values were treated by listwise deletion and gave more or less the same result as pairwise deletion. The sample size with listwise deletion treatment was 226 .

It is recommended by Anderson and Gerbing (1988) that the LISREL analysis be implemented in a two-step approach. First the measurement model should be built and evaluated and then the whole model including structural equations should be tested. This procedure has been followed in this study. In the presentation of the analysis, however, only the whole models are considered.

The first model based on the data is shown in Figure 18. The resulting model supports the assumed linkages. There are statistical linkages between the constructs as hypothesised and all the estimated parameters are statistically significant. Yet, the model fit is not very good (Table 35). The indices measuring overall model fit reach only the marginal acceptable level. In addition, the standardised RMR, a measure for average correlation for residuals (see Hair et al. 1998 , p. 622), is too high indicating that the fit between the model and the data is not good enough. However, because the statistical linkages support the theory, the model was modified.

For the model modification, the squared multiple correlation for the variables was considered first. The $\mathrm{R}^{2}$-value for Quality raw material (SR2) was as low as 0.15 indicating a poor reliability. This was also the variable that did not differ statistically significantly between the success clusters. The variable was then a candidate for deletion. Moreover, the $\mathrm{R}^{2}$-value for Availability of production resources (BR5) and Financial capability (BR6) was below 0.20 indicating poor reliability and thus they were omitted in the mod- 
Vol. 13 (2004): Supplement 1.

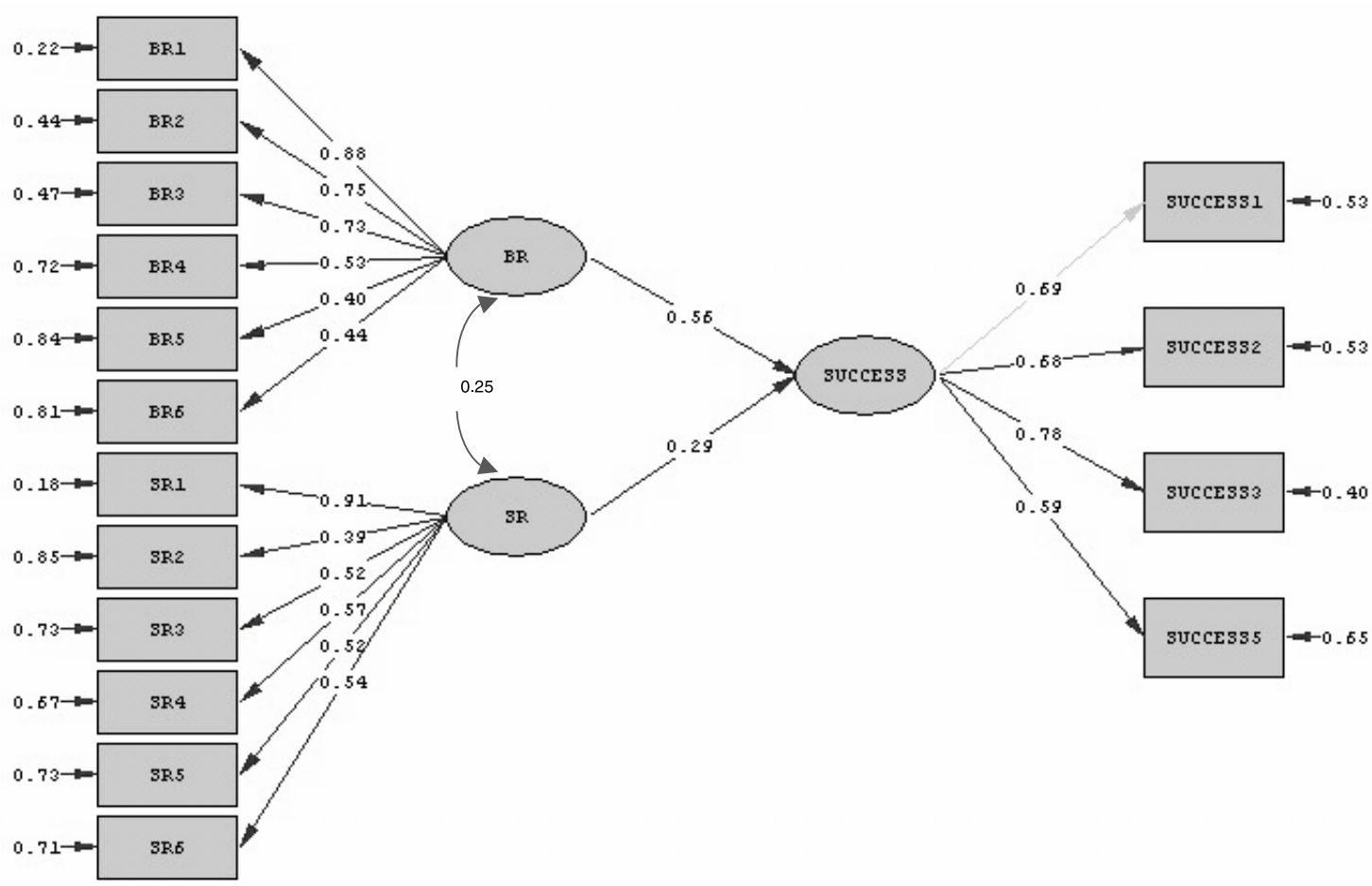

BR = BASIC RESOURCES; BR1 = Business competence, BR2 = Customer knowledge and accessibility, BR3 = Production competence, BR4 = Co-operation capability, BR5 = Availability of production resources, BR6 = Financial capability $\mathrm{SR}=$ STRATEGIL RESOURCES; SR1 = Superior reputation, SR2 = Quality raw material, SR3 = Innovative products, SR4 = Customer service, SR5 = Way of distribution, SR6 = Locality

FIRM SUCCESS; SUCCESS1 = Financial performance, SUCCESS2 = Quality performance, SUCCESS3 = Market performance, SUCCESS5 = Price performance

Fig. 18. Estimation results of the hypothesised model for the linkages between resources and success $(\mathrm{N}=226)$.

Table 35. Indicators4 for assessing model fit in testing the conceptual model.

\begin{tabular}{lcl}
\hline Measure & Model & $\begin{array}{l}\text { Acceptable } \\
\text { level }\end{array}$ \\
\hline$\chi^{2}$ with P value & $\begin{array}{l}\chi^{2}(101)=236.48, \\
\mathrm{P}=0.000\end{array}$ & $\mathrm{P}>0.05$ \\
GFI & 0.88 & $>0.90$ \\
AGFI & 0.84 & $>0.90$ \\
CFI & 0.88 & $>0.90$ \\
NFI & 0.81 & $>0.90$ \\
RMSEA & 0.077 & $<0.08$ \\
Standardised RMR & 0.070 & $<0.05$ \\
Critical N & 131.51 & \\
Model AIC & 306.48 & \\
\hline
\end{tabular}

el. Availability of production resources did not differ between the success clusters and thus its contribution to the model was found unsubstantial. Moreover, the reliability of this dimension as a summated scale variable was already found only moderate in Section 5.1.2. Yet, after deleting the three variables the model fit did not reach the acceptable level.

In such cases, when the model does not fit the data, further analysis of residual matrix can provide significant insights regarding a model fit. For a "good" model, all residuals should be near zero (Bollen 1989, p. 257). Standardised residuals that are greater than $+/-2.58$ are con- 
Forsman, S. How do small rural food-processing firms compete?

sidered to be statistically significant at the 0.05 level and, therefore, high. No more than five per cent of the standardised residuals should exceed this threshold value (Hair et al. 1998, p. 615, $625)$. If too many of the residuals exceed this value, a careful look at the data or the hypothesised model should be taken in order to identify possible reasons for lack of model fit (Sharma 1996). Standardised residuals can be investigated by looking at the Q-plot. A good model fit is obtained when all residuals lie approximately on a straight line. A non-linear pattern of residuals may indicate specification errors in the model or departures from normality or linearity (Jöreskog and Sörbom 1993, p. 146-147). An analysis of standardised residuals showed that $11 \%$ of the residuals exceeded the threshold value. Through analysing modification indices Cooperation capability (BR4), Locality (SR6) and Price performance (SUCCESS5) turned out to be candidates for deletion too. As a result model fit improved considerably. Now all the model fit measures excluding $\chi^{2}$ statistics exceeded the acceptable level and based on these the model fit could be considered acceptable. Investigation of standardised residuals showed still high negative residuals for Production competence (BR3) and Market Performance (SUCCESS3), which indicates that the error terms of these variables correlate. This means that these two variables are systematically affected by a factor that is not explicitly modelled (Hughes et al. 1986). The model was then modified by adding the correlated measurement errors in the model. The correlation was -0.16 with t-value -4.20 . A negative sign means that correlated errors are overspecified in the model compared to the model, that is, the link between the indicators is thus stronger in the model than in the data (see Eriksson 2002). The addition of correlated errors does not affect substantive conclusions and is, thus, justified. This model was then accepted as a final model.

\section{Final model}

The modified model that was accepted as a final model is presented in Figure 19 and in Table 36
(The LISREL output is displayed in Appendix E). Convergent validity of the model can be found acceptable. All the estimated parameters excluding Superior reputation (SR1) are statistically significant for the 0.01 level since the $t$ values exceed the critical value $+/-2.576$ (Hair et al. 1998, p. 623). Moreover, all the error variances are positive. In addition, convergent validity is usually assessed by considering coefficients and $\mathrm{R}^{2}$ values (Eriksson 2002). In the final model, coefficients or "factor loadings" are relatively high. Moreover, the $\mathrm{R}^{2}$-value for the exogenous variables range from 0.54 to 0.74 and for the endogenous variables from 0.24 to 0.86 exceeding thus the preferrable limit $(>0.20)$. Based on the previous criteria, the convergent validity of the model can be found good. Discriminant validity proved to be good too since the confidence interval around the correlation estimate between the constructs did not include 1 .

The constructs are largely related in the theoretically predicted manner, verifying the posited relationships among the indicators and constructs. There is a statistically significant link between basic resources and success $(r=0.61$, $\mathrm{t}$-value 6.80), providing additional support for $\mathrm{P} 3$. There is a statistically significant link between strategic resources and success $(r=0.29$, t-value 3.74 ), thus providing additional support for P2. However, the link between basic resources and success is considerably stronger that the link between strategic resources and success. What is important is that there is also a statistically significant correlation between critical basic resources and strategic competitive resources $(r=0.28$, $t$-value 3.81$)$, thus providing support for $\mathrm{P} 1$, that is, there is a positive relationship between strategic resources and basic resources.

The model fits the data well (Table 37). Goodness-of-fit indices (GFI, AGFI, CFI, NFI) are clearly above 0.90 indicating a good model fit. Moreover, the root mean square residual approximation (RMSEA) is small $(<0.05)$ indicating that the model is adequate and not too simple in its structure. The standardised RMR is also small $(<0.05)$ indicating a good model fit. Based 
Vol. 13 (2004): Supplement 1.

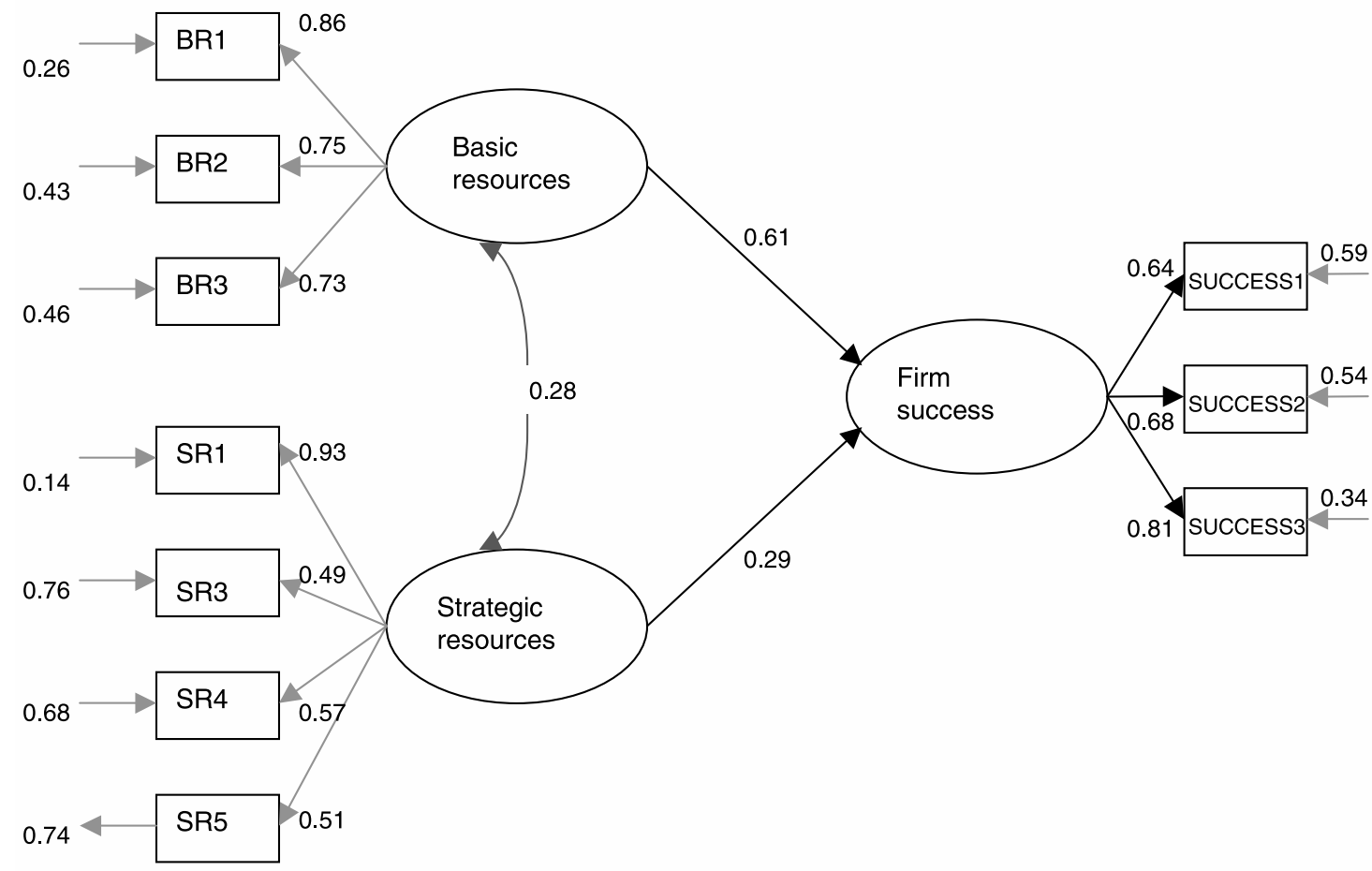

Correlated errors between BR3 and Success 3 added

$\mathrm{BR}=\mathrm{BASIC}$ RESOURCES; BR1 = Business competence, BR2 = Customer knowledge and accessibility, BR3 = Production competence

$\mathrm{SR}=$ STRATEGIC RESOURCES; $\mathrm{SR} 1=$ Superior reputation, $\mathrm{SR} 3$ = Innovative products, $\mathrm{SR} 4=$ Customer service, $\mathrm{SR} 5=$ Way of distribution

FIRM SUCCESS; SUCCESS1 = Financial performance, SUCCESS2 = Quality performance, SUCCESS3 = Market performance

Fig. 19. Estimation results of the final model for the linkages between resources and success $(\mathrm{N}=226)$.

on these criteria it can be concluded that the model fits the data quite well and is adequate. The $P$ value of the $\chi^{2}$ with df 31 does not however quite reach the level of 0.05 . Because the other overall fit indices support the model fit, the model can be accepted even though the $\chi^{2}$ value is statistically significant (Hughes et al. 1986, Anderson and Gerbing 1988). The fact is that for large sample sizes even small differences between the sample and the estimated covariance or correlation matrix may be statistically significant although the differences are not necessary practically meaningful (Hughes et al. 1986, Shar- ma 1996, p. 157). The use of $\chi^{2}$ statistics is recommended for sample sizes between 100 and 200 (Hair et al. 1998, p. 655). The sample size in this case is 225 . In the case that the sample size would have been 200 , the $\chi^{2}$ with df 31 would have been 45.74 with P level 0.04277 .

The analysis suggests an important role for strategic resources and basic resources in achieving superior firm success. Consistent with the RBV, the causal link between resources and success can thus be identified. The model succeeded in explaining $56 \%$ of the variation in firm success. Still $44 \%$ of the variation remains un- 
Forsman, S. How do small rural food-processing firms compete?

Table 36. The structure of the structural equation model of the linkages between resources and success.

\begin{tabular}{|c|c|c|c|c|c|}
\hline \multirow[t]{2}{*}{ Construct } & \multirow[t]{2}{*}{ Measures } & \multicolumn{2}{|c|}{ Factor loadings } & \multicolumn{2}{|l|}{ Error terms } \\
\hline & & Estimates & t-values & Estimates & t-values \\
\hline \multirow[t]{3}{*}{ Basic resources } & $\begin{array}{l}\text { Business competence } \\
\text { (BR1) }\end{array}$ & 0.86 & 14.74 & 0.26 & 5.50 \\
\hline & $\begin{array}{l}\text { Production competence } \\
\text { (BR5) }\end{array}$ & 0.75 & 12.44 & 0.43 & 8.22 \\
\hline & $\begin{array}{l}\text { Customer knowledge and } \\
\text { accessibility (BR6) }\end{array}$ & 0.73 & 11.86 & 0.46 & 8.21 \\
\hline \multirow[t]{4}{*}{ Strategic resources } & Superior reputation (SR1) & 0.93 & & 0.14 & 1.70 \\
\hline & Innovative products (SR3) & 0.49 & 6.51 & 0.76 & 9.92 \\
\hline & Customer service (SR4) & 0.57 & 7.37 & 0.68 & 9.37 \\
\hline & Way of distribution (SR5) & 0.51 & 6.71 & 0.74 & 9.82 \\
\hline \multirow[t]{3}{*}{ Firm success } & $\begin{array}{l}\text { Financial performance } \\
\text { (SUCCESS1) }\end{array}$ & 0.64 & & 0.59 & 9.01 \\
\hline & $\begin{array}{l}\text { Quality performance } \\
\text { (SUCCESS2) }\end{array}$ & 0.68 & 8.17 & 0.54 & 8.60 \\
\hline & $\begin{array}{l}\text { Market performance } \\
\text { (SUCCESS3) }\end{array}$ & 0.81 & 8.76 & 0.34 & 5.60 \\
\hline
\end{tabular}

Table 37. Indicators for assessing model fit in the final model.

\begin{tabular}{lcl}
\hline Measure & Model & $\begin{array}{l}\text { Acceptable } \\
\text { level }\end{array}$ \\
\hline$\chi^{2}$ with P-value & $\begin{array}{l}\chi^{2}(31)=51.72, \\
\mathrm{P}=0.01120\end{array}$ & $\mathrm{P}>0.05$ \\
GFI & 0.96 & $>0.90$ \\
AGFI & 0.92 & $>0.90$ \\
CFI & 0.97 & $>0.90$ \\
NFI & 0.93 & $>0.90$ \\
RMSEA & 0.054 & $<0.08$ \\
Standardised RMR & 0.045 & $<0.05$ \\
Critical N & 225.75 & \\
Model AIC & 99.72 & \\
\hline
\end{tabular}

explained. Some of the variation certainly arises from contextual factors that were not modelled, such as field of industry, a firm's stage of life cycle and external industry factors.
The analysis has naturally a number of limitations. The database restricted the choice of indicators of the constructs. One may also find the redevelopment of the model mainly technical, which is important to consider when interpreting the results. However, the chosen indicators can be considered relevant and appropriate and they demonstrate both relatively good convergent and discriminant validity. In this type of model it is hardly possible to provide an exhaustive representation of the research area when determining indicators for the constructs. Moreover, the analysis is based on cross-sectional data, which makes causal claims difficult. In order to study linkages between resources and success over time a longitudinal database with time series should be developed. In conclusion, LISREL modelling has provided some confirmatory evidence on the linkages between strategic and basic resources and success and, thus, may encourage the redevelopment of the measures and acquisition of new, preferably longitudinal, data. 


\section{Discussion and conclusions}

The aim of the study was to increase our understanding of how small rural food-processing firms compete in the market. More specifically, the main objective was to examine the relationships between resources, competitive advantage and firm success in small-scale food production. Competitive strategies were approached from the resource-based view (RBV) that is one of the current strategy theories in the area of strategic management. The development of the RBV has evolved largely as the countermovement to industry-based theories. The discussion in the study was based on contrasting the RBV and the industry-based approach and trying to find points of integration between them. The study focused, on the one hand, on resources as drivers for competitive advantage and success and, on the other hand, on the positioning of small rural foodprocessing firms in the market.

The study comprised theoretical and empirical parts. The aim of the theoretical part was to anchor the study in the research traditions within the field and to provide reasons for adopting the RBV as a theoretical starting point. Three aspects defined the scope of the study: 1) smallbusiness as a research target; 2) the food industry as a competitive environment, and 3) a rural area as a local environment. As a strategic choice, differentiation was specifically considered. Competitive strategies were analysed through sources of competitive advantage (resources), position of competitive advantage, and outcomes of competitive advantage (firm success). The study provided a theoretical contribution to the RBV by introducing a classification scheme for understanding the ambiguous nature the resources in the small-scale food production context. The classification was established on the distinction between strategic resources and basic resources and the interrelation between them. In addition, based on the literature review and theoretical discussion, a conceptual framework for the resource-based analysis of competitive advantage was elaborated and six propositions to be tested in the empirical part of the study were set.

The empirical part of the study was based on the quantitative analyses of the survey data collected from 238 small food-processing firms located in rural Finland. The sample firms represented different branches of the food industry and $39 \%$ of them operated in connection with a farm. The unit of analysis was a firm entity. The research objectives for the empirical part were as follows: 1) How do small food-processing firms stress different resources as differentiation tools? 2) What types of competitive strategies can be identified among the sample firms? 3) How are resources, competitive advantage and firm success linked? The empirical part was divided into three sections. First, the data were described and the key variables were summarised for further analyses. Second, relationships between key constructs of the study were investigated by using cluster analysis and mean comparisons as main methods. Third, relationships between strategic resources and basic resources and firm success were modelled by applying the LISREL technique. The use of various statistical methods enabled the examination of the same research phenomenon from different viewpoints.

This chapter presents conclusion and a discussion of the main findings of the study. First, the main empirical findings are summarised. Second, theoretical and methodological implications are suggested and discussed. Third, some managerial implications are provided. Finally, some limitations of the study are presented and some future research needs are proposed.

\section{I Main empirical findings}

The results of the study demonstrate that there are some typical features relating to small-scale food production in Finland. The examination of the sample data showed that small rural food- 
Forsman, S. How do small rural food-processing firms compete?

processing firms are relative young; nearly a half of the sample firms had been established in the 1990s. In spite of the young firm age, growth orientation among the firms was low, which is consistent with Kaikkonen's (2003) findings. The goals of the business related mostly to achievement of a moderate living standard, self-employment, profit maximisation, employment of existing resources and competences, and independence. The findings support the view that in addition to profit maximisation, small firms may stress other aspects as principal goals for the business (e.g., Currant et al. 1997, Bridge et al. 1998, Juutilainen 2001).

The firms were, to a large extent, local-market oriented; that is, most of the sales proceeds came from home or neighbouring municipalities. Still, the intensity of competition was found to be high by the firms. Intense competition related particularly to price and access to conventional marketing channels. What is remarkable is that for $41 \%$ of the firms, the intensity of competition was perceived as a considerable threat for the continuity of the business.

The average degree of differentiation of the products and associated services of the firms was perceived quite high in comparison to larger food companies. By contrast, in comparison to similar small firms the degree of differentiation was perceived lower. A similar tendency was discovered with the price level. In comparison to larger firms, firms perceived their price levels on average higher. In comparison to similar small rural firms, firms considered prices as average.

Most typical competitive factors that differentiated small rural food-processing firms from their competitors included delivery reliability, superior product quality and reputation, and flexibility. The most significant factors limiting the achievement of competitive position in the market were availability of capital and insufficiency of customers in the marketplace. When considering success in terms of satisfaction with various issues relating to business, delivery reliability, customer satisfaction with the products, product quality relative to competitors and customer retention obtained the highest scores. On the contrary, items relating to costs, labour costs in particular, obtained the lowest scores. Moreover, when considering success in terms of profitability, the most common opinion was that the business is only averagely profitable.

For the further analyses, several summated scale variables were built based on the key variables. Strategic resources were measured in terms of Superior reputation, Quality raw materials, Innovative products, Way of Distribution, Customer service and Locality. Basic resources were measured in terms of Business competence, Availability of Production resources, Co-operation capability, Financial capability, Production competence and Customer knowledge and accessibility. Firm success, in turn, was measured in terms of Financial performance, Quality performance, Market performance, Cost performance, Price performance and Overall competence performance.

The firms were clustered into four success clusters based on four performance variables: Financial performance, Quality performance, Market performance and Price performance. The cluster of Best-performing firms included 26\% of the sample firms while the cluster of Weakest performing firms included $17 \%$ of the firms. The rest of the firms were divided into two clusters between Best- and Weakest-performing firms. The cluster solution was validated by comparing the significance of the strategic resources and basic resources along the success groups. As hypothesised, statistically significant linkages between both resources types and success were discovered. For strategic resources, Superior reputation, Customer service and Distribution were linked to success. For basic resources, Business competence, Financial capability, Production competence, Customer knowledge and accessibility and Co-operation capability were linked to success. The comparison between Bestperforming firms and Weakest-performing firms revealed that differences in success were linked even more clearly on differences in basic resources than strategic resources. In addition, the results revealed that differences in success were connected more to a lack of marketing-related 
Vol. 13 (2004): Supplement 1.

competence than production-related competence.

The analysis of competitive advantage positioning profiles between the success clusters revealed that the connection between positioning in the market, in terms of differentiation and price level, and success is not so clear. The degree of product differentiation in relation to larger firms was perceived as highest in Best-performing firms and lowest in Weakest-performing firms. The direction was the same in the case of services differentiation, but the differences were not that large. Contrary to what might be expected, there was no connection between the price level in relation to large firms providing ordinary products and success. What is also interesting is that inimitability of competence rather than inimitability of concrete product characteristics differentiated Best-performing firms from the other clusters. Moreover, threat of imitability among larger firms was found the lowest and substitutability of the products was found the highest in Best-performing firms. In addition, Weakest-performing firms had put the least effort into improving of customer satisfaction.

What is also noteworthy is that a statistically significant linkage between success clustering and farm-connection was not discovered. Some branch-specific differences were found instead. For example, $37 \%$ of the meat processors belonged to Best-performing firms while Weakestperforming firms included no meat processors. In the production of grain mill products the direction was almost the opposite. In addition, the average firm age was the youngest in Best-performing firms. Weakest-performing firms, on the other hand, were the least national-market oriented.

The firms were also clustered into five competitive advantage clusters based on the degree of differentiation and price level. The strategy clusters were labelled as follows: 1) premiumpriced differentiation advantage $(25 \%$ of the firms); 2) average-priced differentiation advantage $(36 \%) ; 3)$ high-priced average differentiation advantage $(18 \%)$; 4) competitive disadvantage $(11 \%)$, and 5$)$ low-priced differentiation advantage (11\%). Hence, different types of competitive advantages from the positioning perspective can be identified among small-scale foodprocessing firms and, unexpectedly, not all the firms are trying to differentiate themselves from larger food companies. As hypothesised, strategic resources were linked to the positioning of competitive advantage excluding Customer service and Locality dimensions. Innovative products, for example, were clearly connected to a premium-priced differentiation advantage whereas Distribution was emphasised most by local-market oriented differentiators. Contrary to expectations, there was no statistically significant linkage between the position of competitive advantage and basic resources. Moreover, only partial support was found for the linkage between the position of competitive advantage and success. Financial performance, surprisingly, did not reach the significance which might have led to the conclusion that following a particularly strategy, for example premium-priced differentiation, automatically leads to success.

Farm connection had no linkage to the position of competitive advantage. There were some branch-specific differences instead. For example, the group of firms with competitive disadvantage and local-market oriented differentiation advantage did not include meat and milk processors, whereas over half of the firms processing berries and fruit were premium-priced differentiators. Some differences in market arena emphasis were also discovered. Low-price differentiators were predominantly local marketorientated while the scope of the market was the widest for average-priced non-differentiators.

The analysis of the competitive advantage clusters did not reveal systematic and complete support for the linkage between competitive advantage and success. In order to find out which types of competitive advantages have the greatest potential to lead to success and which resources are linked to successful advantages, the relationship of success clustering and competitive advantage clustering was investigated in more detail. The results revealed that firm success was connected not only to particular types 
Forsman, S. How do small rural food-processing firms compete?

of advantages, but rather to underlying resources. This indicates that there are several competitive strategy options for small food-processing firms. Based on the results, we may suggest that the most critical basic resources are business competence, which can be largely associated with marketing-related factors, and sufficient and appropriate customer base. The significance of the strategic resources seem to be connected more on differentiation than non-differentiation strategies, and innovative product ideas seem to have the most important role.

The LISREL model suggested an important role for the strategic resources and basic resources in achieving superior firm success. Consistent with the RBV, a link between resources and success was identified. The link between basic resources and success was considerably stronger than the link between strategic resources and success. There was also a statistically significant link between basic resources and strategic resources, which implies that the two resource types are strongly linked.

Altogether, six propositions were postulated in the study. Table 38 summarises whether the propositions are proven or disproven on the basis of the evidence presented in the study. Out of six propositions five were supported. One proposition (P5) was not supported indicating that, contrary to predictions, the phenomenon underlying these premises is more complex than assumed.

In conclusion, the results support the assumption that small, rural food-processing firms do not constitute a homogenous group of firms; different strategies in terms of resource deployments and types of competitive advantages can be identified. Contrary to the basic standpoint of the study, not all the firms try to differentiate. Moreover, following a particular strategy does not automatically ensure that a firm will achieve success. Instead, the more detailed analyses of the data demonstrate that a linkage between resources, competitive advantage and firm success can be identified and, moreover, that firm success has much to do with firm resources irrespective of the types of competitive advantage. Hence, the findings of the study are, in this respect, greatly consistent with resource-based logic.

\subsection{Theoretical and methodological implications}

The study represents one of the first studies to focus on competitive strategies specifically in small, rural food-processing firms. The study supports the earlier views about the strategic behaviour of small-scale food-processing firms in Finland (e.g., Hyvönen et al. 1995, Forsman 1999, Hyvönen and Erälinna 2002) and in the Nordic level (e.g., Borch and Iveland 1998) by revealing that there seem to be certain kinds of competition factors typical to these firms. In the

Table 38. Summary of the support for the propositions postulated in the study.

\begin{tabular}{lc}
\hline Propositions & Degree of Support \\
\hline P1: There is a positive relationship between strategic resources and basic resources. & Supported \\
P2: There is a positive relationship between strategic resources and success. & Supported \\
P3: There is a positive relationship between basic resources and success. & Supported \\
P4: There is a positive relationship between strategic resources and the position of & Supported \\
competitive advantage. & Not supported \\
P5: There is a positive relationship between basic resources and the position of & Supported \\
P6: There is a positive linkage between the position of competitive advantage and success.
\end{tabular}


Vol. 13 (2004): Supplement 1.

light of previous studies, one contribution of the study, however, comes from a more comprehensive adaptation of the RBV. In contrast some previous studies in which small firms have been investigated as a part of the whole food industry (e.g., Hyvönen and Kola 1995, Traill 2000) and in which the heterogeneous nature of small food processors may have been neglected, this study considered small food-processing firms as a group of their own. One of the assumptions of the study was that small firms do not constitute a homogenous group of their own, but that different strategies among small firms can be identified as well. The empirical findings of the study support this assumption which further indicates that Porter's $(1980,1985)$ conceptualisation of generic strategies is too broad in the case of small rural food-processing firms and, instead, suggests that the mixed-strategy approach (Faulkner and Bowman 1992, Miller and Dess 1993, Chrisnan et al. 1998, Parnell 2000) may be more appropriate.

The RBV, which has been the leading theory in this study, sees competitive strategies as unique rather than generic. However, due to the research setting employed in this study, evidence of this uniqueness could not been provided. Otherwise, the results support the resource-based logic by identifying the linkages between resources, competitive advantage and success. The study has provided groundwork for the understanding of resource building blocks in certain types of small firms. The study introduced two types of resources, namely strategic resources and basic resources as a relevant standpoint when considering competitive strategies of small foodprocessing firms. Strategic resources were defined as resources that constitute the primary source of competitive advantage, that is, they represent the core idea around which the food business is built. Basic resources, on the other hand, were defined as resources the function of which is to support and facilitate a firm in converting its strategic competitive resources into a position of competitive advantage. What was of utmost importance was that an interrelation between these two resource types was assumed.
According to the empirical results, it seems that strategic resources refer mainly to those factors based on which small food-processing firms can build uniqueness in relation to their larger counterparts. Basic resources, on the other hand, seem to represent, rather, factors that a firm should control as well as its competitors. If these factors are not under control, problems in achieving success may occur.

The major difference between the categorisation scheme of resources elaborated in the present study and those previously suggested is that in the present categorisation the distinction between two types of resources is based on their different contribution to competitive advantage and, further, firm success. Previous categorisations have mainly been based on classifications of resources into homogenous groups of resources such as human resources, physical resources, etc. (e.g., Hofer and Schendel 1978, Barney 1991, Greene et al. 1997 et al.), hierarchical classifications such as resources and capabilities (e.g., Grant 1991), and resources and high-order resources (Hunt 1997). The categorisation established in the present study has some affinities with the prior conceptualisations such as Rangone's (1999). Innovation, production and market management capability included in Rangone's resource tree model could be regarded as basic resources in the model presented here, whereas critical resources in his model have some coherence with strategic resources presented here. Still, Rangone's model is based largely on a resources-capabilities distinction and not on the reciprocal relationship between two types of resources as in our model.

The empirical findings support the assumption of the ambiguous nature of resources in the small rural food-production context. The LISREL model showed that both types of resources and firm success are related in the theoretically predicted manner thus verifying the postulated relationships among the indicators and constructs. Therefore, the results provide evidence of the important role of both strategic resources and basic resources in achieving superior firm success. Based on the data we could not provide 
Forsman, S. How do small rural food-processing firms compete?

any causality between strategic resources and basic resources. Based on the definition and nature of these two resources categories, we might however claim that basic resources are hierarchically at a lower level compared to the strategic resources. This might indicate that only when basic resources are under control, can strategic resources be developed. To prove this, a more advanced research design should be developed. In conclusion, the LISREL model succeeded in explaining $56 \%$ of the variations in firm success by resources. Still $44 \%$ of the variation remains unexplained. It is clear that firm success is affected by numerous factors. Some of the variation certainly arises from contextual factors that were not modelled.

The study has also discussed the nature of competitive advantage in the case of small firms. In the competitive strategy literature, the sustainable nature of competitive advantage has specifically been stressed. Sustainable or persistent advantage can be built upon the resources that are valuable, rare, and difficult to imitate or substitute (Barney 1991). However, as considered in Chapter 3, one can question whether a sustainable advantage is a relevant goal in the mature and dynamic food industry (see Fiol 2001). The market environment changes and new consumer trends evolve continuously. Hence, for small food-processing firms with flexible organisation structures, the ability to build temporary competitive advantages might even become an important resource. This, however, requires that a firm own or control resources and competences that are relatively easy to rebuild and adjust to new market needs. For example, sustaining active and permanent product development activities might become a key resource. The data, however, did not provide any evidence whether the idea of temporary competitive advantages applies to small-size food processors. This is an interesting research question to be addressed in the future.

The measures used and the results obtained in this study provide a good starting point to develop stronger measures for further research. If the purpose is to identify different strategies, items that are weak in differentiating firms into sub-groups should not be included in the questionnaire. A long questionnaire may decrease the response rate and, therefore it is important that all the measures to be used are relevant and strong. Moreover, in this study five-point Likert-type scales were mainly used. A longer scale, for example a seven-point scale, might reveal the differences between the firms more clearly and, thus, improve catching the variance of a phenomenon (Kujala 1992, p. 112).

The LISREL application proved to be useful in this type of research since it allows the study of several dependence relations simultaneously compared, for example, to conventional multiple regression analysis. Moreover, in the LISREL measurement errors are included in the model which is a benefit since variance due to measurement error cannot be avoided in this type of inquiry. It would have been interesting to compare the assumed relations between different groups (e.g., on-farm processors vs. other processors, or different branches within food industry), but the groups would have been too small for the LISREL modelling. In addition, the LISREL was used in the present study mainly in an exploratory fashion to advance theory development. In future LISREL applications in this field, the method should be applied in a more confirmatory way based on strong variables and by putting more emphasis on causality between the constructs.

Since resources are unique and firm-specific, resource-based strategy thinking could be advanced by developing a model or tool that would help small firms to assess their resource configurations in relation to their main competitors. The model could include the identification of strategic resources and basic resources, the weights of the resources as contributors to competitive advantage and success, and the assessment of how easy they are, on the one hand, to acquire and trade and, on the other hand, to imitate or substitute. The study has attempted to operationalise the VRIO dimensions (Barney 1991, 2002), among others, in terms of imitability and substitutability. In future research, fur- 
Vol. 13 (2004): Supplement 1.

ther operationalisation of the VRIO dimensions is advised. Additionally, the resource analyses could be integrated to the balanced scorecard type measures in order to obtain a better understanding of the causality between resources and different types of performance indicators.

In conclusion, the study has increased our understanding of how small rural food-processing firms compete in the Finnish food market. Based on theoretical considerations and the evidence presented in the study, we may conclude that resource deployment - in terms of both strategic resources and basic resources - should be balanced in order for a small food-processing firm to have the possibility to establish a relatively favourable value-added position in the market. That is to say, whatever competitive strategy a firm is to follow, it should be consistent with its resources and competences.

\subsection{Managerial implications}

The study has stressed the significance of resources as sources of competitive advantage and success. Based on the results, we may suggest that for a small rural food-processing firm the possession or control of basic resources is of utmost importance in building competitive advantage. Based on the indicators of strategic resources used in this study, there seem to be typical features such as delivery reliability, product quality and reputation, flexibility, personal customer service, short distribution chain that are common for most small-scale producers. Unique product ideas and innovativeness in product development, for instance, were considered high in importance as strategic resources by only about $40 \%$ of the firms. Yet, the innovative products dimension was connected to competitive advantage and success. In conclusion, small rural food-processors may benefit if they try to profile more from the main competitors including also other small actors competing for the same customers. Standpoints for profiling may provide regional identity and environmental values.

The results revealed that differences in success were connected more to a lack of marketing-related competence than a lack of production-related competence. That is not to say that production-related competence would not play a role in success, but that small rural food-processors have perhaps more experience with production than marketing. A lack of productionrelated competence such as finding appropriate technology may, instead, become more important when the firms pursue growth (see Kaikkonen 2003).

Success clustering and competitive advantage clustering conducted in the study may provide a basis for policy implications directed to particular types of firms. Based on the results, one may suggest that it would be important to support the growth-orientation among the Best-performing firms. The Weakest-performing firms, on the other hand, may benefit more from advice on the means to improve profitability. The evidence presented in the present study combined with findings from other studies can be utilised in building simple, concrete tools that would facilitate the firms' own learning processes.

Although certain resources are strongly connected to success, the industry effect cannot be totally excluded. The analysis revealed that there are some branch-specific differences in both success clustering and competitive-positioning strategies. Based on this, one may suggest that, for example, small meat processors have better opportunities to succeed and follow a premiumpriced strategy than small firms that produce grain mill products. Based on the study one cannot, however, state whether the possible industry effect depends on the external industry conditions or on the nature of the products. Related to the latter point one may question whether, for example, meat production provide more opportunities for value creation than grain mill production, or whether meat products are more easily associated with a high price image than grain mill products. Therefore, those planning new food business ventures should make him- or her- 
Forsman, S. How do small rural food-processing firms compete?

self familiar with the specific nature of the particular industry and assess whether the existing and available resources match the industry-specific features.

The study has suggested which resources are most likely to be connected with competitive advantage and firm success in small rural foodprocessing firms. Hopefully, existing and potential food entrepreneurs can use the findings to (re)establish their strategies towards more successful and growth-oriented food-processing businesses. According to resource-based logic, it is not, however, possible to provide any "rules for riches" (Barney and Arikan 2001). Yet, small food entrepreneurs can use the results to compare their strengths and weaknesses with the profiles of the successful firms. In addition, the results can be utilised by education and advisory organisations when planning seminars and courses for entrepreneurs.

\subsection{Limitations of the study and suggestions for further research}

The study also has some limitations that are important to consider when interpreting the results. Perhaps one of the main weaknesses is the crosssectional research design. The accumulation of firm-specific resources and competences takes place over time. Hence, studying linkages at a particular point in time does not necessarily reveal how the long-term deployment of certain resources and competences might influence the position of competitive advantage and success. One should also take a critical approach to the construct validity of the concepts of strategic resources and basic resources introduced in the study. Other sets of resource items could have been employed, which might have affected the results differently. When interpreting the results, it is also important to note that subjective measures of strategic positioning and performance were used in the questionnaire instead of objec- tive measures. The methods used may also set some limits for generalising. The results of cluster analysis, among others, are, in the first place only generalisable to the sample firms. Moreover, the empirical data did not provide the possibility to compare rural firms with urban firms. Hence, although the rural aspect was one of the perspectives outlining the study, the study did not provide much analysis on this dimension.

Despite its limitations, hopefully this study has provided some promising results relating to the ambiguous nature of the role of resources in rural small-scale food-production. This subject merits additional study. A challenging question is whether the findings on the significance of the strategic resources and basic resources are unique only for the data of this study or whether the results are also valid for other independent samples in small-scale food production or for small businesses in other industries. Moreover, it would be worthwhile of investigating whether a similar structure of resources is valid in the case of larger food companies. In addition, the food industry has some distinct features separating it from other industries and thus it would be interesting to examine how this distinction of resources hold true for other rural industries. This would provide evidence of the suggested argumentation that the RBV is, at least to some extent, dependent on the industry and firm size. Hence, cross-validation of the research design and the results, i.e., testing the model by other independent data, would be important for future research in this field.

It will be important for future work to include the aspect of dynamism in the research setting. In the present study, the measures of resources and the other key constructs represented a respondents' perspective at a particular point of time. Therefore, to obtain a more detailed picture of the relationships between resources, competitive advantage and success in the case of small food-processing firms, a longitudinal research design should be preferred in future research. The dynamic aspect relates also to the (complex) relationships between resources (Black and Boal 1994). Hence, it would be im- 
Vol. 13 (2004): Supplement 1.

portant to identify strategic relationships between resource factors and how their contribute to a competitive advantage.

This could be linked to organisational learning, more specifically, as pointed out by Hunt (2000a, p. 146-147), one could assess how the competition faced by a firm contributes to organisational learning. Through competition small firms come to know - or at least they believe they know - what their strengths are in resources and market position compared to their rivals. Based on this knowledge small firms can adjust and modify their resource configurations and strategies to respond better to present and potential market challenges. Studying the dynamic dimension of strategic behaviour needs, however, a longitudinal research design that combines both quantitative and qualitative research approaches.

The growth aspect is strongly connected to small firm success (e.g., Wiklund 1998). In the present study, the growth aspect was not specifically addressed. The results, however, revealed that small food-processing firms are not very growth-oriented, which is consistent with, for example, Kaikkonen's (2003) findings on similar of food-processing firms. From the point of view of industry development, it would be important to generate business and growth orienta- tion among small food-processing firms. Small actors without any growth objectives do not necessarily promote healthy competition within the food sector. To support the growth orientation in small food-processing firms, it would be important for future work to examine how various resources contribute to firm growth in the long run. One key question would be to ask what is the role of resource accumulation and investments, for example, investments on the more industrial types of production lines, in generating small firm growth. This also requires a longitudinal research strategy.

Finally, although the RBV emphasises value-creating perspective of competitive strategy (Barney 1991, Barney and Arikan 2001) the customer value perspective is not clearly pointed out in the empirical settings of the RBV. This was also the case in this study; the results obtained in the present study are based on the subjective perceptions of the persons who are charge of running the business. If the significance of resources and position of competitive advantage were considered from the customers' points of view, the results might be different. Hence, an important challenge for future work is to integrate both the firm's viewpoints as well as customers'.

\section{References}

Alsos, G.Y. \& Ljunggren, E. 2003. Creating a new business form an existing one: Farmers as portfolio entrepreneurs. In: Borch, O.-J. \& Rønning, L. (eds.). Entrepreneurship in Regional Food Production. Proceedings of $2^{\text {nd }}$ Nordic Workshop on Entrepreneurship in Regional Food Production. Bodø, May 2-6, 2003. NF-report no. 26. Bodø: Nordland Research Institute. p. 185-204.

Alvarez, S.A. \& Busenitz, L.W. 2001. The entrepreneurship of resource-based theory. Journal of Management 27, 7: 755-775.

Amit, R. \& Schoemaker, P. J. H. 1993. Strategic assets and organisational rent. Strategic Management Journal 14, 1:33-46

Andersen, J.C. \& Gerbing, D.W. 1988. Structural Equa- tion Modeling in Practise: A Review and Recommended Two-Step Approach. Psychological Bulletin 103, 3: 411-423.

Andrews, K. 1971. The concept of corporate strategy. Homewood, IL: Dow Jones-Irwin. 245 p. (Ref. Wernefelt 1984).

Andrews, K.E. 1997. The concept of corporate Strategy. A brief overview of themes and contributions. In: Foss, N.J. (ed.). Resources, firms and strategies. A reader in the resource-based perspective. New York: Oxford University Press. p. 3-18.

Ansoff, H.I. 1987. Corporate strategy. Revised edition (the original book in 1965). Harmondsworth, England: Penguin Books. 284 p.

Äyväri, A. \& Möller, K. 1999. Marketing capability of small 
Forsman, S. How do small rural food-processing firms compete?

firms operating in networks. Working papers W-227. Helsinki: Helsinki School of Economics and Business Administration. $31 \mathrm{p}$.

Bain , J.S. 1956. Barriers to new competition. Cambridge: Harvard University Press. 329 p.

Bain, J.S. 1968. Industrial organization. $2^{\text {nd }}$ edition. New York: John Wiley \& Sons. 678 p.

Bamberger, I. 1989. Developing competitive advantage in small and medium-size firms. Long Range Planning 22, 5: 80-88.

Bamberger, I. \& Bonacker, R. 1994. Strategies of small and medium-sized enterprises and their measurement. In: Bamberger, I. (ed.). Product/Market Strategies of Small and Medium-sized Enterprises. Aldershot: Avebury. p. 28-85

Bamberger, I. \& Wrona, T. 1994. The environment, competitive strategies and the performance of SMEs - A review of hypotheses based on contingency theory. In: Bamberger, I. (ed.). Product/Market Strategies of Small and Medium-sized Enterprises. Aldershot: Avebury. p. 198-245.

Barney, J. 1991. Firm resources and sustained competitive advantage. Journal of Management 17, 1: 99120.

Barney, J.B. 2001a. Is the resource-based "view" a useful perspective for strategic management research? Yes. Academy of Management Review 26, 1: 41-56.

Barney, J.B. 2001b. Resource-based theories of competitive advantage: A ten-year retrospective on the resource-based view. Journal of Management 27: 643650.

Barney, J.B. 2002. Gaining and sustaining competitive advantage. $2^{\text {nd }}$ edition. New Yersey: Prentice Hall. $600 \mathrm{p}$.

Barney, J.B. \& Arikan, A.M. 2001. The resource-based view: Origins and implications. In: Hitt, M. A. et al. (eds.). The Blackwell Handbook of Strategic Management. Oxford: Blackwell Publishers. p. 124-188.

Barney, J., Wright, M. \& Ketchen, D.J., Jr. 2001. The resource-based view of the firm: Ten years after 1991 . Journal of Management 27: 625-641.

Baumgartner, H. \& Homburg, C. 1996. Applications of structural equation modeling in marketing and consumer research: A review. International Journal of Research in Marketing 13: 139-161.

Baumol, W.J. 1982. Contestable markets: An uprising in the theory of industry structure. American Economic Review 72, 1: 1-15.

Baumol, W.J., Panzar, J.C. \& Willig, R.D. 1982. Contestable markets and the theory of industry structure. Harcourt Brace Jovanovich. 510 p.

Bergsten, H. 1998. Cooperation between small scale producers - experiences from Sweden. In: Borch, O.J. (ed.). Small Scale Food Production in a Nordic Context. Proceedings of the First Nordic Workshop on Regional Small Scale Food Production, Bodø, Norway, May 25-26, 1998. Nordland Research Institute. NF-rapport no. 19/98. p. 27-30.

Black, J.A. \& Boal, K.B. 1994. Strategic resources: traits, configurations and paths to sustainable competitive advantage. Strategic Management Journal 15: 131148.
Bollen, K.A. 1989. Structural equations with latent variables. New York: John Wiley \& Sons. 514 p.

Borch, O.J. (ed.). 1998. Small Scale Food Production in a Nordic Context. Proceedings of the First Nordic Workshop on Regional Small Scale Food Production, Bodø, Norway, May 25-26, 1998. Nordland Research Institute. NF-rapport no. 19/98. p. 9-20.

Borch, O.J. 1999. Business strategy in transitional industries. Entrepreneurial response to globalisation of a fragmented industry. In: Wright, R. (ed.). International Entrepreneurship: Globalisation of emerging businesses. Research in Global Strategic Management, Vol. 7. Stamford, Connecticut: JAI Press. p. 101-130.

Borch, O.J. \& Iveland, M. 1997. Fra hobby til næring? Utfordinger knyttet til etablering av småskala matvareproduksjon i Norge. NF-report nr. 24/97. Bodø: Nordland Research Institute. $132 \mathrm{p}$.

Borch, O.J. \& Iveland, M. 1998. Critical resources and competence in small scale food producing firms in Norway, Sweden and Finland. In: Borch, O.J. (ed.). Small Scale Food Production in a Nordic Context. Proceedings of the First Nordic Workshop on Regional Small Scale Food Production, Bodø, Norway, May 25-26, 1998. NF-report no. 19/98. Bodø: Nordland Research Institute. p. 95-106.

Borch, O.J., Huse, M. \& Senneseth, K. 1999. Resource configuration, competitive strategies and corporate entrepreneurship: An Emprical Examinations of Small Firms. Entrepreneurship Theory and Practise 24, 1: 49-70.

Boulding, W., Lee, E. \& Staelin, R. 1994. Mastering the mix: Do advertising, promotion, and sales force activities lead to differentiation? Journal of Marketing Research XXXI: 159-172.

Bridge, S., O'Neill, K. \& Cromie, S. 1998. Understanding enterprise, entrepreneurship \& small business. London: Macmillan Press. 301 p.

Campbell-Hunt, C. 2000. What have we learned about generic competitive strategy? A meta-analysis. Strategic Management Journal 21: 127-154.

Carson, D., Cromie, S., McGowan, P. \& Hill, J. 1995. Marketing and entrepreneurship in SMEs: An innovative approach. London: Prentice Hall. 296 p.

Carter, S. 1998. Portfolio entrepreneurship in the farm sector: indigenous growth in rural areas. Entrepreneurship \& Regional Development 10: 17-32.

Carter, S. 1999. Multiple business ownership in the farm sector: assessing the enterprise and employment contributions of farmers in Cambridgeshire. Journal of Rural Studies 15: 417-429.

Chandler, G.N. \& Hanks, S.H. 1994a. Founder competence, the environment, and venture performance. Entrepreneurship Theory and Practise 18, 3: 77-89.

Chandler, G.N. \& Hanks, S.H. 1994b. Market attractiveness, resource-based capabilities, venture strategies, and venture performance. Journal of Business Venturing 9: 331-349.

Chow, C.W., Haddad, K.M. \& Williamson, J.E. 1997. applying the balanced scorecard to small companies. Management Accounting (New York) (August): 2127. 
Vol. 13 (2004): Supplement 1.

Chrisman, J.J., Hofer, C.W. \& Boulton, W.R. 1988. Toward a system for classifying business strategies. Academy of Management Review 13, 3: 413-428.

Churchill, G.A., Jr. 1991. Marketing research. Methodological foundations. $5^{\text {th }}$ edition. The Dryden Press. $1070 \mathrm{p}$.

Conner, K.R. 1991. A historical comparison of resourcebased theory and five schools of thought within industrial organization economics: Do we have a new theory of the firm? Journal of Management 17, 1: 121-154.

Cote, J.A. \& Buckley, M.R. 1987. Estimating trait, method, and error variance: generalizing across 70 construct validation studies. Journal of Marketing Research XXIV: 315-318.

Covin, J.G. \& Miles, M.P. 1999. Corporate entrepreneurship and the pursuit of competitive advantage. Entrepreneurship Theory and Practice 23, 3: 47-63.

Coyne, K.P. 1986. Sustainable competitive advantage What it is, what it isn't. Business Horizons (JanuaryFebruary): 54-61.

Cravens, D.W. 1998. Implementation strategies in the market-driven strategy era. Journal of the Academy of Marketing Science 26, 3: 237-241.

Cravens, D.W., Greenley, G., Piercy, N.F. \& Slater, S. 1997. Integrating Contemporary Strategic Management Perspectives. Long Range Planning 30, 4: 493-506.

Curran, J. \& Storey, D. 1993. The location of small and medium enterprises: are there urban-rural differences? In: Curran, J. \& Storey, D. (eds.). Small Firms in Urban and Rural Locations. London: Routledge. p. 116.

Currant, J., Jarvis, R. Ktiching, J. \& Lightfoot, G. 1997. The pricing decisions in small firms: complexities and the deprioritising of economic determinants. International Small Business Journal 15, 2: 17-32.

Day, G.S. 1990. Market driven strategy. Processes for creating Value. New York: The Free Press. 405 p.

Day, G.S. 1992. Marketing's contribution to the strategy dialogue. Journal of the Academy of Marketing Science 20, 4: 323-329.

Day, G.S. 1994. The capabilities of market-driven organizations. Journal of Marketing 58: 37-52.

Day, G.S. \& Wensley, R. 1988. Assessing advantage: A framework for diagnosing competitive superiority. Journal of Marketing 52, April: 1-20.

Dess, G.G., Lumpkin, G.T. \& McGee, J.E. 1999. Linking corporate entrepreneurship to strategy, structure, and process: Suggested research directions. Entrepreneurship Theory and Practice 23, 3: 85-102.

Dess, G.G. \& Robinson, R.B., Jr. 1984. Measuring organizational performance in the absence of objective measures: The case of the privately-held firm and conglomerate business unit. Strategic Management Journal 5: 265-273.

Diamantopoulos, A. 1994. Modelling with LISREL: A guide for the unitiated. Journal of Marketing Management 10: 105-136.

Dickson, P.R. \& Ginter, J.L. 1987. Market segmentation, product differentiation, and marketing strategy. Journal of Marketing 51: 1-10.

Dierickx, I. \& Cool, K. 1989. Asset stock accumulation and sustainability of competitive advantage. Management Science 35, 12: 1504-1511.

Doyle, P. \& Wong, V. 1998. Marketing and competitive performance: an empirical study. European Journal of Marketing 32, 5/6: 514-535.

Eisenhardt, K.M. \& Martin, J.A. 2000. Dynamic capabilities: what are they? Strategic Management Journal 21, 10: 1105-1121.

Eriksson, K. 2002. LISREL for Business Analysis. Manuscript.

Eriksson, K., Johanson, J., Majkgård, A. \& Sharma, D.D. 2000. Effect on variation on knowledge accumulation in the internationalization process. International Studies of Management and Organisations 30, 1: 26-44.

Eriksson, K. \& Sharma, D.D. 2002. Modeling uncertainty in buyer-seller cooperation. Journal of Business Research 56: 961-978.

Eskola, A. 1969. Sosiologian tutkimusmenetelmät 1. $3^{\text {rd }}$ edition. Porvoo: WSOY. $187 \mathrm{p}$.

Fahey, L. \& Christensen, H.K. 1986. Evaluating the research on strategy content. Yearly Review of Management of the Journal of Management 12, 2: 167183.

Faulkner, D. \& Bowman, C. 1992. Generic strategies and congruent organisational structures: Some suggestions. European Management Journal 10, 4: 494-447.

Fiol, C.M. 2001. Revisiting an identity-based view of sustainable competitive advantage. Journal of Management 27: 691-699.

Finnish Food and Drink Industries' Federation 2003. The food industry in Finland. Cited 5 July 2003. Available on the Internet: http://www.etl./english/food_indu/ elinta.asp?akt=2

Finnish Rural Policy Committee 2000. Ihmisten maaseutu - tahdon maaseutupolitiikka. Maaseutupoliittinen kokonaisohjelma vuosille 2001-2004. Helsinki: Finnish Rural Policy Committee. $176 \mathrm{~s}$.

Forsman, S. 1996. Maaseudun pienyritysten hintastrategiat: esimerkkinä liha-alan pienyritykset. Abstract: Price strategies of small rural enterprises: a case of meat sector in Finland. Research Reports 213. Helsinki: Agricultural Economics Research Institute. $93 \mathrm{p}$.

Forsman, S. 1999. Erilaistaminen ja hintastrategiat elintarvikealan maaseutuyrityksissä. Abstract: Differentiation and price strategies of rural firms in food sector. Research Publications 93. Helsinki: Agricultural Economics Research Institute. 166 p.

Forsman, S. 2000. Linkages between Resources, Competitive Advantage, and Success within Small-Scale Food-processing Firms - a Theoretical Model. In: Trienekens, J.H. \& Zuurbier, P.J. P. (eds.). Chain Management in Agribusiness and the Food Industry. Proceedings of the Fourth International Conference. Wageningen, 25-26 May 2000. Wageningen: Wageningen University. p. 497-506.

Forsman, S. 2001. Elintarvikealan maaseutuyritysten nykytila: vahvuudet, heikkoudet ja kehitysnäkymät. Abstract: Current state of rural food-processing firms: strengths, weaknessess, and future prospects. Working papers 16/2001. Helsinki: Agrifood Research Finland, Economic Research. p. 5-55. 
Forsman, S. How do small rural food-processing firms compete?

Foss, N.J. 1997a. Resources and strategy. A brief overview of themes and contributions. In: Foss, N.J. (ed.). Resources, Firms and Strategies. A Reader in the Resource-Based Perspective. New York: Oxford University Press. p. 3-18.

Foss, N.J. 1997b. Resources and Strategy: Problems. Open Issues, and Ways Ahead. In: Foss, N.J. (ed.). Resources, Firms and Strategies. A Reader in the Resource-Based Perspective. New York: Oxford University Press. p. 345-365.

Foss, N.J. \& Eriksen, B. 1995. Competitive advantage and industry capabilities. In: Montgomery, C.A. (ed.). Resource-based and evolutionary theories of the firm: Towards a synthesis. Boston: Kluwer Academic Publishers. p. 43-63.

Foss, N.J., Knudsen, C. \& Montgomery, C.A. 1995. An exploratorion of common ground: integrating evolutionary and strategic theories of the firm. In: Montgomery, C.A. (ed.). Resource-based and evolutionary theories of the firm: Towards a synthesis. Boston: Kluwer Academic Publishers. p. 1-17.

Frank, H. \& Landström, H. 1997a. Entrepreneurship and small business in Europe - economic background and academic infrastructure. In: Landström, H. et al. (eds.). Entrepreneurship and small business research in Europe. An ECSB survey. Aldershot: Avebury. p. 113.

Frank, H. \& Landström, H. 1997b. Entrepreneurship and small business research in Europe - analysis and reflections. In: Landström, H. et al. (eds.). Entrepreneurship and small business research in Europe. An ECSB survey. Aldeshot: Avebury. p. 382-395.

Gartner, W.B. 1988. "Who is an entrepreneur?" is the wrong question. American Journal of Small Business 12, 4: 11-32.

Gartner, W.B. 1990. What are we talking about when we talk about entrepreneurship? Journal of Business Venturing 5: 15-28.

Grant, R.M. 1991. The resource-based theory of competitive advantage: Implications for strategy formulation. California Management Review 33, 3: 114-135.

Grant, R.M. 1998. Contemporary strategy snalysis. $3^{\text {rd }}$ edition. Oxford: Blackwell Publishers. $461 \mathrm{p}$.

Green, P.E., Tull, D.S. \& Albaum, G. 1988. Research for marketing decisions. $5^{\text {th }}$ edition. New Yersey. Prentice Hall, Inc.

Greene, P.G., Brush, C.G. \& Brown, T.E. 1997. Resources in small firms: an exploratory study. Journal of Small Business Strategy 8, 2: 25-40.

Grievink, J.-W, Josten, L. \& Valk, C. 2002. State of the art in food. The changing face of the worldwide food industry. The Netherlands: Reed Elsevier. 663 p.

Haahti, A.J. 1989. Entrepreneurs' strategic orientation: modeling strategic behavior in small industrial owner-managed firms. Acta Academiae Oeconomicae Helsingiensis. Series A. Dissertation. Helsinki: Helsinki School of Economics. 329 p.

Hair, J.F., Jr., Anderson, R.E., Tatham, R.L. \& Black, W.C. 1998. Multivariate data analysis. $5^{\text {th }}$ edition. New Yersey: Prentice Hall. 730 p.

Hall, R. 1992. The strategic analysis of intangible resources. Strategic Management Journal 13: 135-144.
Hall, R. 1993. A framework linking intangible resources and capabilities to sustainable competitive advantage. Strategic Management Journal 14: 607-618.

Hamel, G. 2000. Leading the Revolution. Boston, MA: Harvard Business School Press. 333 p.

Hamel, G. \& Prahalad, C.K. 1992. Letters to the editor. Harvard Business Review (May-June): 164-165, 170.

Hamel, G. \& Prahalad, C.K. 1996. Competing for the future. Boston: Harvard Business School Press. 357 p.

Hautamäki, L. 2000. Maaseudun menestyjät. Yritykset kehityksen vetureina. Kunnallisalan kehittämissäätiön tutkimusjulkaisut nro. 23. Helsinki: Kunnallisalan kehittämissäätiö. $148 \mathrm{~s}$.

Heene, A. \& Sanchez, R. (eds.). 1997. Competence-based strategic management. Chichester: John Wiley \& Sons. $337 \mathrm{p}$.

Hernesniemi, H., Lammi, M. \& Ylä-Anttila, P. 1996. Advantage Finland. The future of Finnish industries. The Research Institute of the Finnish Economy. Series $B$ 113. Helsinki: Taloustieto Oy. 236 p.

Hill, C.W.L. 1988. Differentiation versus low cost or differentiation and low cost: A contingency framework. Academy of Management Review 13, 3: 401-412.

Hitt, M.A., Ireland, R.D., Camp, S.M. \& Sexton, D.L. 2001. Strategic entrepreneurship: Entrepreneurial strategies for wealth creation. Strategic Management Journal 22, Special Issue: 479-491.

Hofer, C.W. \& Schendel, D. 1978. Strategy formulation: Analytical concepts. St. Paul: West Publishing Company. 219 p.

Hoffman, N.P. 2000. An examination of the "Sustainable competitive advantage" concept: Past Present, and Future. Academy of Marketing Science Review [online] 2000(4). Cited 9 January 2004. Available on the Internet: http://www.amsreview.org/articles/hoffman04-2000.pdf.

Hooley, G., Möller, K. \& Broderick, A. 1997. Competitive positioning \& the resource based view of the firm. Research Paper 9726. Birmingham, UK: Aston Business School. 23 p.

Hoskisson, R.E., Hitt, M.A., Wan, W.P. \& Yiu, D. 1999. Theory and research in strategic management: Swings of a pendulum. Journal of Management 25, 3: 417-456.

Hoy, F. \& Vaught, B.C. 1988. The rural entrepreneur - a study in frustration. Journal of Small Business Management 18, 1: 19-24.

Hughes, M.A., Price, R.L. \& Marrs, D.W. 1986. Linking theory construction and theory testing: Models with multiple indicators of latent variables. Academy of Management Review 11, 1: 128-144.

Hunt, S.H. 1991. Modern marketing theory. Critical issues in philosophy of marketing science. Cincinnati (Ohio): South-Western, cop. 499 p.

Hunt, S.H. 2000a. A general theory of competition. Resources, competences, productivity, economic growth. Thousand Oaks: Sages Publications. 303 p.

Hunt, S. 2000b. The competence-based, resource-advantage, and neoclassical theories of competition. Toward a synthesis. Advances in Applied Business Strategy 6A: 177-208.

Hunt, S.D. \& Duhan, D.F. 2002. Competition in the third 
Vol. 13 (2004): Supplement 1.

millennium. Efficiency or effectiveness? Journal of Business Research 55: 97-102.

Hunt, S.D. \& Morgan, R.M. 1995. The comparative advantage theory of competition. Journal of Marketing 59, April: 1-15.

Hunt, S.D. \& Morgan, R.M. 1996. The resource-advantage theory of competition: Dynamics, path dependencies, and evolutionary dimensions. Journal of Marketing 60, October: 107-114.

Hunt, S.D. \& Morgan, R.M. 1997. Resource-advantage theory: A snake swallowing its tail or a general theory of competition? Journal of Marketing 61, October: 74-82.

Hyvönen, S. 2001. Resurssiperusteinen kilpailuetu ja menestyminen lihanjalostusalan yrityksissä. Abstract: The resource-based advantage and performance of firms in the meat processing industry. Publications No. 32. Helsinki: University of Helsinki, Department of Economics and Management. $165 \mathrm{p}$.

Hyvönen, S. 2004. Johtavat päivittäistavarakaupan ketjut Euroopan markkinoilla. Kehittyvä Elintarvike 1: 45.

Hyvönen, S. \& Kola, J. 1995. The Finnish food industry facing European integration: Strategies and policies. European Review of Agricultural Economics 22, 3: 296-309.

Hyvönen, S. \& Kola, J. 1998. New policies, new opportunities, new threats: the Finnish food industry in the EU. In: Traill, W.B. \& Pitss, E. (eds.). Competitiveness in the Food industry. London: Blackie Academic \& Professional. p. 253-285.

Hyvönen, S., Kupiainen, T. \& Pietikäinen, P. 1995. Maaseudun pienyritysten strategiat, muutoskyvykkyys ja tuloksellisuus. Abstract: The strategies, flexibility, and organisational performance of small rural firms. $R e$ search reports 201. Helsinki: Agricultural Economics Research Institute. $70 \mathrm{p}$.

Hyvönen, S. \& Erälinna, L. 2002. Capabilities, strategic types and innovativeness: an emprical study in the small meat processing firms. $12^{\text {th }}$ Nordic conference on small business research. Creating welfare and prosperity through entrepreneurship. Kuopio, Finland, May 26-28, 2002. Kuopio: University of Kuopio. Available on the CD ROM.

Ireland, R.D., Hitt, M.A. \& Sirmon, D.G. 2003. A model of strategic entrepreneurship: the construct and its dimensions. Journal of Management 29, 6: 963-989.

Javidan, M. 1998. Core competence: What does it mean in practise? Long Range Planning 31, 1: 66-71.

Jennings, P. \& Beaver, G. 1997. The performance and competitive advantage of small firms: A management perspective. International Small Business Journal 15, 2: 63-75.

Jöreskog, K.G. \& Sörbom, D. 1981. LISREL V. Analysis of linear relationships by maximun likelihood and least squares methods. Uppsala: University of Uppsala. 220 p. (Ref. Leskinen 1987).

Jöreskog, K.G. \& Sörbom, D. 1993. LISREL 8: Structural equation modelling with the SIMPLIS Command Language. Chicago: Scientific Software International. $226 \mathrm{p}$.

Jöreskog, K.G. \& Sörbom, D. 1996. LISREL 8: User's
Reference Guide. Chicago: Scientific Software International. $378 \mathrm{p}$.

Juutilainen, A. 2001. Entrepreneur's perceptions of strategy and success in small firms of the tourism and hospitality industry. Research Report 24. Lappeenranta: Lappeenranta University of Technology, Department of Business Administration. 123 p.

Kaikkonen, V. 2003. Exploring the dilemma of small business growth: The case of rural food-processing micro firms. In: Borch, O.-J. \& Rønning, L. (eds.). Entrepreneurship in Regional Food Production. Proceedings of $2^{\text {nd }}$ Nordic Workshop on Entrepreneurship in Regional Food Production. Bodø, May 2-6, 2003. NFreport no. 26. Bodø: Nordland Research Institute. p. 205-223.

Kaplan, R.S. \& Norton, D.P. 1996. The balanced scorecard. Translating strategy into action. Boston: Harvard Business School Press. $322 \mathrm{p}$.

Kelloway, E.K. 1998. Using LISREL for structural equation modeling. A researcher's guide. California: SAGE Publications. 147 p.

Ketchen, D.J., Jr. \& Shook, C.L. 1996. The application of cluster analysis in strategic management research: An analysis and critique. Strategic Management Journal 17: 441-458.

Komppula, R. 2002. Success in rural tourism micro-business - financial or lifestyle objectives? In: Conference proceedings of RENT XVI "Research in entrepreneurship and small business", November 21-22, 2002, Barcelona, Spain. Universitat Autònoma de Barcelona. Vol. 1. p. 242-264.

Kor, Y.Y. \& Mahoney, J.T. 2000. Penrose's resource-based approach: the process and product of research creativity. Journal of Management Studies 37, 1: 109-139.

Kujala, J. 1992. Purchasing fresh foodstuffs; an example of repetitive choice behavior. Academic dissertation. EKT series 888. Helsinki: University of Helsinki, Department of Economics and Management. $165 \mathrm{p}$.

Kupiainen, T. 1996. Pienten elintarvikealan yritysten markkinointistrategiat. Abstract: The marketing strategies in small business: A case of food industry. Research reports 15. Helsinki: Agricultural Ecnomics Research Institute. $114 \mathrm{p}$.

Landström, H., Frank, H., Veciana, J.M. (eds.). 1997. Entrepreneurship and Small Business Research in Europe. An ECSB Survey. Aldeshort: Avebury. 395 p.

Lee, K.S., Lim, G.H. \& Tan, S.J. 1999. Dealing with resource disadvantage: Generic strategies for SMEs. Small Business Economics 12: 299-311.

Lehtomaa, A. 1995. Yrittäjän menestymismielikuva. Sahayrittäjän näkemyksen ja laskennallisen arvion vastaavuus yrityksen taloudellisesta tilasta. English summary: Entrepreneur's perception of success. Correlation between the sawmill owner's perception and the accounting value of the company's financial standing. Academic dissertation. Helsinki: Helsinki School of Economics and Business Administration. 363 p.

Littunen, H., Storhammar, E. \& Nenonen, T. 1998. The survival of firms over the critical first 3 years and the local environment. Entrepreneurship \& Regional Development 10, 3: 189-202.

Lumpkin, G.T. \& Dess, G.G. 1996. Clarifying the entre- 
Forsman, S. How do small rural food-processing firms compete?

preneurial orientation construct and linking it to performance. Academy of Management Review 21, 1: $135-172$.

Mahoney, J.T. 1995. The Management of resources and the resource of management. Journal of Business Research 33: 91-101.

Mahoney, J.T. 2001. A resource-based theory of sustainable rents. Journal of Management 27: 651-660.

Makadok, R. 2001. Toward a synthesis of the resourcebased and dynamic-capability views of rent creation. Strategic Management Journal 22: 387-401.

Mäkelä, J. 2002. Syömisen rakenne ja kulttuurinen vaihtelu. Dissertation. Helsinki: National Consumer Research Centre. $97 \mathrm{p}$.

Mäkinen, H. 2000. Competence-based view and market orientation: two perspectives in marketing. In: Reponen, T. (ed.). In commemoriation of the $50^{\text {th }}$ anniversary of the Turku School of Economics and Business Administration. Publications of the Turku School of Economics and Business Administration. Series $A-1:$ 2000. Turku: Turku School of Economics and Business. p. 183-193.

Marttila, J. 1996. The effect of oligopolistic competition on economic welfare in the finnish food manufacturing. Doctoral dissertation. Research Publications 80. Helsinki: Agricultural Economics Research Institute. $163 \mathrm{p}$.

Mathur, S.S. 1988. How firms compete: a new classification of generic strategies. Journal of General Management 14, 1: 30-57.

Mathur, S.S. 1992. Talking straight about competitive strategy. Journal of Marketing Management 8: 199-217.

McCartan-Quinn, D. \& Carson, D. 2003. Issues which impact upon marketing in the small firm. Small Business Economics 21: 201-213.

Miles, R.E. \& Snow, C.C. 1978. Organizational strategy, structure, and process. Tokyo: McGraw-Hill. 274 p.

Miller, D. 1992. The generic strategy trap. The Journal of Business Strategy 13, 1:37-41.

Miller, A. \& Dess, G.G. 1993. Assessing Porter's (1980) model in terms of its genesalizability, accuracy and simplicity. Journal of Management Studies 30, 4:553585.

Mintzberg, H. 1994. The Rise and fall of strategic planning. London: Prentice Hall. 458 p.

Mintzberg, H., Ahlstrand, B. \& Lampel, J. 1998. Strategy safari. A guided tour through the wilds of strategy management. London: Prentice Hall. 406 p.

Morgan, R.E. \& Strong, C.A. 2003. Business performance and dimensions of strategic orientation. Journal of Business Research 56: 163-176.

Mosakowski, E. \& McKelvey, B. 1997. Predicting rent generation in competence-based competition. In: Heene, A. \& Sanchez, R. (eds.). Competence-based strategic management. Chichester: John Wiley \& Sons. p. $65-85$.

MTT Agrifood Research Finland 2002. Finnish Agriculture and Rural Industries 2002. Helsinki: MTT Agrifood Research Finland, Economic Research. 94 p.

Murray, A.I. 1988. A contingency view of Porter's "generic strategies". Academy of Management Review 13, 3: 390-400.
Mustonen, S. 1995. Tilastolliset monimuuttujamenetelmät. Helsinki: Survo Systems Oy. 205 p.

Näsi, J. 1991. Strategic thinking as doctrine. Development of focus areas and new insights. In: Näsi, J. (ed.). Arenas of strategic thinking. Helsinki: Foundation for Economic Education. p. 26-64.

Nelson, R.R. \& Winter, S.G. 1982. An Evolutionary Theory of Economic Change. Cambridge, MA: Belknap. (Ref. Grant 1998).

Niittykangas, H. 1992. Maaseudun yritystoiminnan kehittymismahdollisuudet. Summary: The development of the firms in the rural areas of Finland. Academic dissertation. Jyväskylä Studies in Computer Science, Economics and Statistics 21. Jyväskylä: University of Jyväskylä. 335 p.

Niittykangas, H. 2003. Yrittäjä ja yrityksen toimintaympäristö. Julkaisuja N:o 134/2003. Jyväskylä: University of Jyväskylä, School of Business and Management. 294 p.

Nummenmaa, T., Konttinen, R., Kuusinen, J. \& Leskinen, E. 1997. Tutkimusaineiston analyysi. Porvoo: WSOY. 397 p.

Olson, P.D. \& Bokor, D.W. 1995. Strategy process-content interaction: effects on growth performance in small start-up firms. Journal of Small Business Management 1: 34-44.

Park, D. \& Krishnan, H.A. 2001. Supplier selection practises among small firms in the United States: Testing three models. Journal of Small Business Management 39, 3: 259-271.

Parnell, J.A. 2000. Reframing the combination strategy debate: defining forms of combinations: Journal of Applied Management Studies 9, 1: 33-54.

Pasanen, M. 1999. Monet polut menestykseen. Pk-yritykset Pohjois-Savossa. Abstract: Many ways to success: A study of SMEs in Northern Savo. Kuopio University Occasional Reports E. Social Sciences 15. Kuopio: University of Kuopio. 207 p.

Pasanen, M. 2002. Multiple entrepreneurship among successful SMEs: characterizing portfolio and serial entrepreneurship. In: $12^{\text {th }}$ Nordic conference on small business research. Creating welfare and prosperity through entrepreneurship. Kuopio, Finland, May 2628, 2002. Kuopio: University of Kuopio. Available on the CD ROM.

Pasanen, M . 2003. In search of factors affecting SME performance. The case of eastern Finland. Doctoral dissertation. Kuopio University Publications H. Business and Information Technology 1. Kuopio: University of Kuopio. $228 \mathrm{p}$.

Path analysis and Lisrel 2002. An interview with lowa State University's distinguished professor of business Dr. R. Kenneth Teas. Marketing Research 12, 2: 20-21.

Patterson, H. \& Anderson, D. 2003. What is really different about rural and urban firms? Some evidence from Northern Ireland. Journal of Rural Studies 19: 477490.

Pelham, A.M. \& Wilson, D.T. 1996. A longitudinal study of the impact of market structure, firm structure, strategy, and market orientation culture on dimensions of small-firm performance. Journal of the Academy of Marketing Science 24, 1:27-43. 
Vol. 13 (2004): Supplement 1.

Penrose, E.T. 1959. The theory of the growth of the firm. Oxford: Basil Blackwell. 272 p.

Peteraf, M.A. 1993. The cornerstones of competitive advantage: A resource-based view. Strategic Management Journal 14: 179-191.

Pitts, E. \& Lagnevik, M. 1998. What determines food industry competitiveness? In: Traill, W.B. \& Pitts, E. (eds.). Competitiveness in the food industry. London: Blackie Academic \& Professional. p. 1-34.

Porter, M.E. 1980. Competitive strategy: techniques for analyzing industries and competitors. New York: Free Press. 396 p.

Porter, M.E. 1985. Competitive advantage. Creating and sustaining superior performance. New York: Free Press. 557 p.

Porter, M. E. 1990. The competitive advantage of nations. London: Macmillan $855 \mathrm{p}$.

Porter, M. E. 1991. Towards a dynamic theory of strategy. Strategic Management Journal 12: 96-117.

Prahalad, C.K. \& Hamel, G. 1990. The core competence of the corporation. Harvard Business Review (MayJune): 79-90.

Powell, C.T. 2001. Competitive advantage: logical and philosophical considerations. Strategic Management Journal 22: 875-888.

Punj, G. \& Stewart, D.W. 1983. Cluster analysis in marketing research: Review and suggestions for application. Journal of Marketing Research XX, May: 134148.

Rajala, A. 1994. Basic types of business strategies and their implications on product development and marketing. Helsinki School of Economics and Business Administration. Working Papers W-77. Helsinki: Helsinki School of Economics and Business Administration. $32 \mathrm{p}$.

Rangone, A. 1999. A resource-based approach to strategy analysis in small-medium sized enterprises. Small Business Economics 12: 233-248.

Ranta, E., Rita, H. \& Kouki, J. 1989. Biometria. Tilastotiedettä ekologeille. 2nd edition. Helsinki:Yliopistopaino. $569 \mathrm{p}$.

Rantamäki-Lahtinen, L. 1999. Maaseudun pienyritysrekisteri. Abstract: The rural business register of Finland. Research reports 235. Helsinki: Agricultural Economics Research Institute. 85 p.

Rantamäki-Lahtinen, L. 2004. Maatilojen monialaistaminen - Empiirinen analyysi monialaisuuteen vaikuttavista tekijöistä. Abstract: On-farm non-agricultural diversification in Finland - Empirical analysis of decision-making process. Research Reports 50 . Helsinki: Agrifood Research Finland, Economic Research. $131 \mathrm{p}$.

Ray, G., Barney, J.B. \& Muhanna, W.A. 2004. Capabilities, business processes, and competitive advantage: choosing the dependent variable in empirical tests of the resource-based view. Strategic Management Journal 25: 23-37.

Reed, R. \& DeFillippi, R.J. 1990. Causal ambiguity, barriers to imitation and sustainable competitive advantage. Academy of Management Review 15, 1: 88102.

Reisinger, Y. \& Turner, L. 1999. Structural equation mod- eling with LISREL: application in tourism. Tourism Management 20: 71-88.

Robinson, R.B., Jr. \& Pearce, J.A., II. 1988. Planned patterns of strategic behaviour and their relationship to business-unit performance. Strategic Management Journal 9: 43-60.

Rope, T. 2002. Yrittäjän markkinointikirja. Hämeenlinna: Tietosykli Oy. 384 p.

Rosenbröijer, C.-J. 1998. Capability development in business networks. A study of distribution in the fine paper sector in the United Kingdom. Academic dissertation. Publications Nr 69. Helsinki: Swedish School of Economics and Business Administration. 255 p.

Rue, L.W. \& Ibrahim, N.A. 1998. The Relationship between planning sophistication and performance in small business. Journal of Small Business Management 36, 4: 24-32.

Rugman, A.M. \& Verbeke, A. 2002. Edit Penrose's contribution to the resource-based view of strategic management. Strategic Management Journal 23: 769780 .

Sanchez, R. \& Heene, A. 1996. A systems view of the firm in competence-based competition. In: Sanchez, R. et al. (eds.). Dynamics of competence-based competition. Theory and practise in the new strategic management. Oxford: Elsevier. p. 39-62.

Sanchez, R. \& Heene, A. 1997a. Reinventing strategic management: New theory and practise for competence-based competition. European Management Journal 15, 3: 303-317.

Sanchez, R. \& Heene, A. 1997b. Competence-based strategic management: Concepts and issues for theory, research, and practise. In: Heene, A. \& Sanchez, R. (eds.). Competence-based Strategic Management. Chichester: John Wiley \& Sons. p. 3-42.

Sanchez, R., Heene, A. \& Thomas, H. 1996. Introduction: towards the theory and practise of competencebased competition. In: Sanchez, R. et al. (eds.). Dynamics of competence-based competition. Theory and practise in the new strategic management. Oxford: Elsevier. p. 1-35.

Scherer, F.M. \& Ross, D. 1990. Industrial market structure and economic performance. $3^{\text {rd }}$ edition. Boston: Houghton Mifflin Company. 713 p.

Schumpeter, J.A. 1934. The theory of economic development. New Brunswick: NJ Transaction Publishers.

Selznik, P. 1957. Leadership in administration. New York: Harper \& Row. (Ref. Snow and Hrebniak 1980)

Sharma, P. \& Chrisnan, J.J. 1999. Toward a reconciliation of the definitional issues in the field of corporate entrepreneurship. Entrepreneurship Theory and Practice 23, 3: 11-27.

Sharma, S. 1996. Applied multivariate techniques. New York: John Wiley. 493 p.

Sirmon, D.G. \& Hitt, M.A. 2003. Managing resources: Linking unique resources, management and wealth creation in family firms. Entrepreneurship Theory and Practice (Summer): 339-358.

Slater, S.F. 1997. Developing a customer value-based theory of the firm. Journal of the Academy of Marketing Science 25, 2: 162-167.

Slater, S.F. \& Narver, J.C. 1994. Market orientation, cus- 
Forsman, S. How do small rural food-processing firms compete?

tomer value, and superior performance. Business Horizons (March-April): 22-28.

Slater, S.F. \& Narver, J.C. 2000. Intelligence generation and superior customer value. Journal of the Academy of Marketing Science 28, 1: 120-127.

Slater, S.F., Olson, E.M. \& Reddy, V.K. 1997. Strategybased performance measurement. Business Horizons (July-August): 37-44.

Smallbone, D., North, D. \& Kalantaridis, C. 1999. Adapthing to peripherality: a study of small rural manufacturing firms in northern England. Entrepreneurhip \& Regional Development 11: 109-127.

Smith, J.A. 1998. Strategies for start-ups. Long Range Planning 31, 6: 857-872.

Snow, C.C. \& Hrebniak, L.G. 1980. Strategy, distinctive competence, and organisational performance. Administrative Science Quarterly 25: 317-336.

Spanos, Y.E. \& Lioukas, S. 2001. An examination into the causal logic of rent generation: contrasting Porter's competitive strategy framework and the resourcebased perspective. Strategic Management Journal 22: 907-934.

Statistics Finland 2003. Business Register - Service Guide. Helsinki: Statistics Finland. $51 \mathrm{p}$.

Stoner, C.R. 1987. Distinctive competence and competitive advantage. Journal of Small Business Management (April): 33-39.

Storey, D.J. 1994. Understanding the small business sector. London: Routledge. 355 p.

Stubbart, C.I. \& Wilson, J.M., III. 1992. Strategy, environment, and intelligence. Advances in Strategic Management 8: 417-440.

Tainio, R. 1992. Pienyritysten moni-ilmeinen luonne. In: Jahnukainen, I. (ed.). Uudistuva pienyritys. Jyväskylä: Weilin+Göös. p. 28-38.

Taylor, G.S. \& Banks, M.C. 1992. Entrepreneurs, small Business executives, and large business executives: A comparison of the perceived importance of current business issues. Journal of Small Business Management (October): 24-40.

Teece, D.J., Pisano, G. \& Shuen, A. 1997. Dynamic capabilities and strategic management. Strategic Management Journal 18, 7: 509-533.

The European Commission 2003. SME Definition. Updated 23 May 2003. Cited 29 June 2003. Available on the Internet: http://europa.eu.int/comm/enterprise/ enterprise_policy/sme_definition/index_en.htm

The National Rural Programme 1991. The rural tripartition of Finland. Cited 15 August 2003. Available on the Internet: http://www.kake.oulu.fi/proj/alupro/ Pmkarkj.htm

Tike 2001. Maatalouslaskenta 2000. Muu yritystoiminta maatiloilla. Publication 2001: 4. Helsinki: Information Centre of the Ministry of Agriculture and Forestry. 24 p.

Tikkanen, I. 1994. Competitive behaviour of a firm environment, competitive strategy, and competitive advantage in the Finnish clothing industry. Academic dissertation. A-99. Helsinki: Helsinki School of Economics and Business Administration. $251 \mathrm{p}$.

Traill, B. 1998. Structural changes in the European food industry: consequences for competitiveness. In: Traill, W.B. \& Pitts, E. (eds.). Competitiveness in the food industry. London: Blackie Academic \& Professional. p. 35-57.

Traill, W.B. 2000. Strategic groups of EU food manufacturers. Journal of Agricultural Economics 51, 1: 4560.

Trochim, W.M. 2003. Research methods knowledge based. Cited 5 June 2003. Available on the Internet: http://trochim.human.cornell.edu/kb/.

Trondsen, T.J. 1997. Is it possible to identify success factors in young, growing firms? Small Business and Enterprise Development 4: 87-94.

Uusitalo, E. 1998. Elinvoimaa maaseudulle - miksi, kenelle ja miten? Maaseutupolitiikan perusteet. Helsinki: Otava. $311 \mathrm{p}$.

Valkonen, T. 1984. Haastattelu- ja kyselyaineiston analyysi sosiaalitutkimuksessa. $7^{\text {th }}$ edition. Helsinki: Gaudeamus. 159 p.

Vanhala, S., Laukkanen, M. \& Koskinen, A. 1994. Liiketoiminta ja sen johtaminen. Keuruu: KY-palvelu. $269 \mathrm{p}$.

Varadarajan, P.R. 1999. Strategy content and process perspectives revisited. Journal of the Academy of Marketing Science 27, 1:88-100.

Varadarajan, P.R. \& Clark, T. 1994. Delineating the scope of corporate, business, and marketing strategy. Journal of Business Research 31: 93-105.

Varadarajan, P.R. \& Jayachandran, S. 1999. Marketing strategy: An assessment of the state of the field and outlook. Journal of Marketing Science 27, 2:120-143.

Venkatraman, N. \& Ramanujam, V. 1986. Measurement of business performance in strategy research: a comparison of approaches. Academy of Management Review 11, 4: 801-814.

Venkatraman, N. \& Ramanujam, V. 1987. Measurement of business economic performance: An examination of method convergence. Journal of Management 13, 1: 109-122.

Venkatraman, N. \& Grant, J.H. Construct Measurement in organizational strategy research: $A$ critique and proposal. Academy of Management Review 11, 1: 7187.

Vihtonen, T. \& Haverinen, T. 1995. Monialaisen maatilayrityksen tuloslaskenta. Summary: Accounting of a diversified farm enterprise. Research reports 202. Helsinki: Agricultural Economics Research Institute. $110 \mathrm{p}$.

Volk, R. 1999. Maaseutupolitiikan ydintavoite on elinkeinotoiminnan monipuolistaminen. Maaseudun uusi aika 1: 67-72.

Volk, R., Laaksonen, K. \& Mikkola, H. 1996. Säätelystä kilpailuun. Elintarvikeklusterin kilpailukyky. Abstract: From Regulation to Competition - Competitiveness of the Finnish Food Cluster. Reports and Discussion Papers No. 140. Espoo: Pellervo Economic Research Institute. 166 p.

Volk, R., Laaksonen, K., Kallio, P. \& Mäkimattila, M. 2000. Elintarviketeollisuuden rakenteen, kannattavuuden ja kansainvälistymisen kehitys Suomen EU-jäsenyyden aikana. Summary: The structure, profitability and internationalisation of the Finnish food industry during the membership in the EU. Working Papers n:o 28. Helsinki: Pellervo Economic Research Institute. 78 p. 
Vol. 13 (2004): Supplement 1.

Walker, O.C. \& Ruekert, R.W. 1987. Marketing's role in the implementation of business strategies: A critical review and conceptual framework. Journal of Marketing 51, July: 15-33.

Weinrauch, J.D., Mann, O.K., Robinson, P.A. \& Pharr, J. 1991. Dealing with limited financial resources: a marketing challenge for small business. Journal of Small Business Management (October): 44-53.

Wernefelt, B. 1984. A resource-based view of the firm. Strategic Management Journal 5: 171-180.

Wiklund, J. 1998. Small Firm Growth and Performance: Entrepreneurship and Beyond. Academic Dissertation. Jönköping: Jönköping International Business School. 364 p.
Winter, S.G. 1995. Four r's of profitability: Rents, resources, routines, and replication. In: Montgomery, C.A. (ed.). Resource-based and evolutionary theories of the firm: Towards a synthesis. Boston: Kluwer Academic Publishers. p. 147-178.

Woodruff, R.B. 1997. Customer value: The next source for competitive advantage. Journal of the Academy of Marketing Science 25, 2: 139-153.

Working Group on Urban-Rural Interaction 2002. Urbanrural interaction. Helsinki: Ministry of the Interior. 34 p.

Yu, T.F.-L. 2001. Toward a capabilities perspective of the small firm. International Journal of Management Reviews 3, 3: 185-197.

\title{
SELOSTUS
}

\section{Kuinka pienet elintarvikealan maaseutuyritykset kilpailevat? Kilpailustrategioiden resurssipohjainen tarkastelu}

\author{
Sari Forsman \\ MTT (Maa- ja elintarviketalouden tutkimuskeskus), Taloustutkimus
}

Suomen elintarviketeollisuus on rakenteeltaan polarisoitunut. Lähes jokaisella elintarviketeollisuuden alatoimialalla toimii muutama suuri yritys ja lukumääräisesti paljon liikevaihdoltaan ja työntekijöiden lukumäärältään hyvin pieniä yrityksiä. Merkittävä osa pienistä elintarvikealan yrityksistä sijaitsee maaseudulla. Elintarvikeyrittäjyys onkin jo reilun vuosikymmenen ajan ollut yksi keskeisimmistä maaseutuelinkeinoista. Innovatiivisen elintarvikeyrittäjyyden yhdessä muun vireän yritystoiminnan kanssa nähdään edesauttavan maaseutua säilymään elinvoimaisena. Pienimuotoista elintarvikkeiden jatkojalostusta on perustettu erityisesti maatilojen yhteyteen. Nostamalla tilalla tuotetun raaka-aineen jalostusastetta maatilayrittäjät ovat tavoitelleet raaka-aineelleen parempaa hintaa verrattuna siihen, että raaka-aine myytäisiin jalostamattomana perinteisiin markkinointikanaviin. Etenkin Euroopan Unionin jäsenyyden kynnyksellä jatkojalostus oli monille maatiloille keskeinen strateginen valinta varauduttaessa jäsenyydestä seuranneeseen tuottajahintojen laskuun.

Pienten elintarvikealan maaseutuyritysten alalla pääsy on ollut suhteellisen helppoa. Pienet yritykset ovat muun muassa hyödyntäneet markkina-aukkoja erikoistuotteiden valmistuksessa suurten elintarviketeollisuusyritysten keskittyessä ylläpitämään ja paran- tamaan omaa kilpailukykyään elintarvikemarkkinoilla, jotka Suomenkin näkökulmasta ovat muuttumassa yhä kansainvälisemmiksi ja maailmanlaajuisemmiksi. Kestävän kilpailuedun aikaansaaminen ja menestyminen niin kutsutulla kypsällä toimialalla, jolla määällistä kasvupotentiaalia ei juuri ole, on kuitenkin pienelle toimijalle usein haastava tehtävä. Vaikka elintarvikealan pienyritykset pyrkivät erilaistamaan tuotteitaan ja palvelujaan suurten yritysten tuotteista, mittakaavaetujen puute ja usein niukat resurssit muodostuvat helposti kompastuskiviksi perinteisiin markkinointikanaviin pääsyssä. Toisaalta markkinoillamme on lukuisia esimerkkejä elintarvikealan maaseutuyrityksistä, jotka ovat onnistuneet saamaan markkinaosuutta paikallisesti, valtakunnallisesti tai jopa vientimarkkinoilla. Tämä nostaa esiin kysymyksen yrityksen sisäisistä tekijöistä; onko muita paremmin menestyneillä yrityksillä sellaisia resursseja tai osaamista, joita heikommin menestyvillä ei ole?

Tutkimuksen tarkoituksena on lisätä ymmärrystä elintarvikealan pienyritysten kilpailustrategioista, toisin sanoen kuinka pienet, erityisesti maaseudulla sijaitsevat elintarvikealan yritykset voisivat rakentaa kilpailuetua vaativassa elintarvikealan toimintaympäristössä. Päätavoitteena oli tutkija elintarvikealan 
Forsman, S. How do small rural food-processing firms compete?

maaseutuyritysten resurssien, kilpailuedun ja menestymisen välistä yhteyttä. Kilpailustrategioita lähestyttiin resurssipohjaisen teorian näkökulmasta. Resurssipohjainen lähestymistapa on vallitsevia teoriasuuntauksia strategisen johtamisen alalla. Siinä tarkastelun kohteena ovat yrityksen sisäiset tekijät eli resurssit ja osaaminen. Yrityksen tulisi rakentaa kilpailuetuaan sille arvokkaisiin ja ainutlaatuisiin resurssien ja osaamisen yhdistelmiin, joita kilpailijoiden on vaikea jäljitellä. Resurssipohjainen teoria on pitkälti kehittynyt "vastaliikkeenä" toimialapohjaisille teorioille, joissa yrityksen ja menestymistä määrittää ensisijaisesti toimialan rakenne ja muiden yritysten kilpailukäyttäytyminen.

Tutkimuksen teoreettisessa osuudessa on yhtäältä kriittisesti tarkasteltu resurssipohjaisen ja toimialapohjaisen lähestymistavan välisiä eroja ja toisaalta yritetty löytää niitä yhdistäviä piirteitä. Resurssipohjaisen teorian logiikkaa soveltaen tutkimus keskittyi erityisesti resurssien tarkasteluun kilpailuedun ja yrityksen menestymisen taustalla sekä elintarvikealan maaseutuyritysten kilpailuedun asemointiin markkinoilla. Strategisena valintana tarkastellaan erityisesti erilaistamista. Tutkimusilmiötä lähestytään yritystason näkökulmasta.

Teoreettisessa osuudessa tarkastellaan resurssikäsitteistön soveltumista pienyrityskontekstissa. Tutkimuksessa esitetään elintarvikealan maaseutuyritysten resurssien tarkastelun lähtökohdaksi käsitteellinen malli, jossa resurssit luokitellaan kahteen ryhmään: strategisiin resursseihin ja perusresursseihin. Strategiset resurssit määritellään ainutlaatuisiksi resursseiksi, jotka muodostavat kilpailuedun ydinidean ja joiden varaan liiketoiminta ensisijaisesti perustuu. Perusresurssit puolestaan määritellään resursseiksi, jotka ovat yritykselle arvokkaita mutta eivät välttämättä ainutlaatuisia ja joiden varaan yritys ei yksinomaan pysty kilpailuetua rakentamaan. Perusresurssit ovat useimmiten "yleisiä" resursseja, joiden tehtävänä on lähinnä vahvistaa strategisten resurssien tuottavuutta. Perusresurssien puuttuminen voi johtaa kilpailuhaitan syntymiseen. Esitetyn resurssiluokittelun lähtökohtana on, että kilpailuedun luomiseksi elintarvikealan maaseutuyrityksessä tarvitaan sekä strategisia resursseja ja perusresursseja sekä ennen kaikkea niiden keskinäistä vuorovaikutusta.

Tutkimuksessa esitettyä resurssiluokittelua sovelletaan työn empiirisessä osassa, joka perustuu elintarvikealan maaseutuyrityksistä vuonna 2000 kerättyyn postikyselyaineistoon $(\mathrm{N}=238)$. Perusjoukon muodostivat maaseudulla sijaitsevat ja alle 20 henkeä työllistävät suomenkieliset yritykset, jotka kuu- luivat Tilastokeskuksen yritys- ja toimipaikkarekisterin toimialaluokitukseen elintarvikkeiden ja juomien valmistus (TOL 15). Maaseudulle toimiviksi yrityksiksi rajattiin Maaseudun pienyritysrekisterin mukaisesti ne yritykset, joiden kotipaikkakunnan postinumeroalueella asukastiheys oli alle 50 henkeä/ $\mathrm{km}^{2}$. Kyselyyn vastanneista yrityksistä $39 \%$ harjoitti yritystoimintaa maatilan yhteydessä. Aineistossa olivat edustettuina keskeisimmät elintarviketeollisuuden alatoimialat. Yritykset olivat iältään verraten nuoria; lähes puolet oli perustettu 1990-luvulla. Valtaosa yrityksistä työllisti alle 5 henkilöä. Nuoresta iästä ja yrityksen pienestä koosta huolimatta puolessa yrityksistä yritystoimintaa pidettiin vakiintuneena; vain $27 \%$ yrityksistä edusti liiketoiminnan kasvuvaihetta. Yritykset toimivat pitkälti paikallisilla markkinoilla. Tästä huolimatta kilpailu markkinoilla koettiin verraten kovaksi. Kilpailu liittyi erityisesti hintoihin ja markkinointikanaviin pääsyyn. Jopa neljä yritystä kymmenestä koki kilpailun uhkaksi yritystoiminnan jatkuvuudelle. Elintarvikealan maaseutuyritysten tärkeimmät kilpailutekijät tärkeimpiin kilpailijoihin verrattuna ovat toimitusvarmuus, laadukkaat tuotteet ja yrityksen hyvä maine sekä joustavuus. Kilpailuaseman saavuttamista markkinoilla rajoittivat useimmiten pääoman saatavuus ja asiakkaiden riittämättömyys.

Tutkimusaineistoa analysoitiin useammassa vaiheessa. Ensiksi yritykset jaettiin neljään ryhmään neljän menestymistä mittaavan summamuuttujan avulla: taloudellinen suorituskyky, laatusuorituskyky, markkinasuorituskyky ja hintasuorituskyky. Parhaiten menestyviin yrityksiin kuului $26 \%$ aineiston yrityksistä, kun taas heikoiten menestyviin yrityksiin kuului $17 \%$ aineiston yrityksistä. Loput yrityksistä sijoittuvat kahteen ryhmään näiden välillä. Tutkimuksessa luodut mittarit strategisille resursseille ja perusresursseille osoittivat, että kummatkin resurssityypit ovat yhteydessä menestymiseen, mutta perusresurssien yhteydessä tämä ero oli merkittävämpi. Perusresursseista liiketoimintaosaaminen, taloudelliset resurssit, tuotanto-osaaminen, asiakastiedon hallinta ja markkinoille pääsy sekä yhteistyö korostuivat parhaiten menestyvissä yrityksissä. Tulokset osoittavat myös, että erot menestymisessä ovat selvemmin yhteydessä markkinointiosaamisen kuin tuotanto-osaamiseen puutteeseen. Parhaiten menestyvät yritykset näyttävät myös olevan paremmin suojassa kilpailun voimilta kuin heikommin menestyvät.

Toisessa vaiheessa yritykset jaettiin viiteen kilpailueturyhmään: 1) korkea hinta + korkea erilaistamisaste (25\% yrityksistä), 2) keskimääräinen hinta + korkea erilaistamisaste $(36 \%), 3)$ korkea hinta + 
Vol. 13 (2004): Supplement 1.

keskimääräinen erilaistamisaste $(18 \%)$, 4) keskitason hinta + alhainen erilaistamisaste (kilpailuhaitta) $(11 \%)$ ja 5) alhainen hinta + korkea erilaistamisaste (11\%). Ryhmittely osoittaa, että elintarvikealan maaseutuyrityksissä voidaan tunnistaa erilaisia tapoja asemoitua markkinoille ja että kaikki yritykset eivät välttämättä tavoittele korkeaa erilaistamisastetta. Korkean hinnan ja erilaistamisasteen yrityksissä korostuivat erityisesti innovatiiviset tuotteet strategisina resursseina. Kilpailuhaittaryhmässä (keskitason hinta + alhainen erilaistamisaste) strategisiksi luokiteltuja resursseja oli muita vähemmän. Vastoin odotuksia perusresursseilla ei ollut selkeää yhteyttä kilpailueturyhmittelyyn.

Kolmanneksi tarkasteltiin menestymisryhmittelyn ja kilpailueturyhmittelyn välistä yhteyttä. Tulokset osoittavat, että yrityksen menestyminen ei liity vain tietyn tyyppiseen kilpailuetuasemointiin markkinoilla vaan ennen kaikkea asemoinnin taustalla oleviin resursseihin ja osaamiseen. Tässä tarkastelussa tärkeimmäksi strategiseksi resurssiksi osoittautuivat innovatiiviset tuotteet ja kriittisimmiksi perusresursseiksi liiketoimintaosaaminen sekä asiakastiedon hallinta ja markkinoille pääsy.

Lopuksi tehtiin kokonaisvaltainen tarkastelu LISREL-mallinnusta soveltaen. Mallinnuksen avulla tutkittiin resurssien ja menestymisen välistä riippuvuutta. Ensin rakennettiin konfirmatoriset mittausmallit latenteille muuttujille, joita olivat strategiset resurssit, perusresurssit ja menestyminen. Tämän jälkeen tarkasteltiin latenttien muuttujien välisiä keskinäisiä riippuvaisuuksia ja analysoitiin, missä määrin hypoteettinen malli sopii tutkimusaineistoon. Oletetun mallin mukainen rakenne oli aineistossa tunnistettavissa tietyin varauksin. LISREL-malli tukee muiden analyysien tavoin strategisten resurssien ja perusresurssien yhteyttä menestymiseen sekä kummankin resurssiryhmän keskinäistä vuorovaikutusta. Mallin mukaan perusresurssien ja menestymisen välinen riippuvuus on selvästi voimakkaampi kuin strategisten resurssien ja menestymisen välinen riippuvuus.
Tulosten tulkinnassa on otettava huomioon empiirisen aineiston poikkileikkausluonne. Myös tutkimukseen valitut käsitteiden mittarit ja mittauksen luonne voivat vaikuttaa saatuihin tuloksiin. Tämäntyyppiseen tutkimukseen liittyvistä rajoituksista huolimatta tutkimus on tarkastellut kriittisesti resurssien moniselitteistä luonnetta elintarvikealan maaseutuyrityskontekstissa.

Johtopäätöksenä todetaan, että elintarvikealan maaseutuyrityksissä voidaan tunnistaa useita vaihtoehtoisia kilpailustrategioita; toisin sanoen pieniä elintarvikealan maaseutuyrityksiä ei voi luokitella yhdeksi strategiseksi ryhmäksi. Kilpailustrategisesta asemoinnista riippumatta yrityksellä on mahdollisuus aikaansaada menestystä. Näyttää kuitenkin siltä, että erilaistamiseen panostavat yritykset ovat muita menestyneempiä. Ennen kaikkea strategioiden onnistunut toteuttaminen edellyttää, että yrityksellä on tarvittavat sekä strategiset resurssit ja perusresurssit kilpailukykyisen aseman aikaansaamiseksi. Vaikka tutkimus osoitti tietyntyyppisillä resursseilla olevan yhteyden menestymiseen, toimialan vaikutusta menestymiseen vaikuttavana tekijänä ei voida kokonaan sulkea pois. Tämä tukee strategisen johtamisen viimeaikaista kehitystä, jossa resurssi- ja toimialapohjaisia näkökulmia integroimalla pyritään samaan kilpailuetuun ja menestymiseen vaikuttavista tekijöistä entistä tasapainoisempi ja kokonaisvaltaisempi näkemys.

Jatkotutkimuksissa tulisi kiinnittää erityistä huomiota siihen, miten resurssien ja osaamisen kartuttaminen pitkällä aikavälillä on yhteydessä kilpailuetuun ja menestymiseen. Tarkasteluun voitaisiin myös liittää organisaation oppimisen näkökulma, jotta elintarvikealan maaseutuyritykset voisivat entistä paremmin hankkia, muuntaa ja sopeuttaa resurssejaan ja osaamistaan nykyisiin ja tuleviin markkinahaasteisiin. Toimialan kehittymisen näkökulmasta olisi myös tärkeä motivoida pieniä elintarvikealan yrityksiä kasvuuralle. Tähän liittyen tulisi tarkastella, millainen on resurssien rooli kasvun aikaansaamisessa. 
Appendix A

\section{Appendix A. Number of establishments in the food industry.}

Table A1. Number of establishments within manufacture of food products and beverages (SIC 15) in 2002; total number of establishments and number of establishments according to personnel size (Statistics Finland 2003).

\begin{tabular}{|c|c|c|c|c|c|}
\hline \multirow[t]{2}{*}{ SIC } & \multirow[t]{2}{*}{ Industry } & \multirow{2}{*}{$\begin{array}{l}\text { Total number of } \\
\text { establishments }\end{array}$} & \multicolumn{3}{|c|}{ Personnel size } \\
\hline & & & $0-4$ & $5-9$ & $10-19$ \\
\hline 15 & Manufacture of food products and beverages & 2,388 & 1,618 & 255 & 177 \\
\hline 1511 & Production and preserving of meat & 49 & 29 & 6 & \\
\hline 1512 & Production and preserving of poultry meat & 7 & 4 & 0 & 0 \\
\hline 1513 & Production of meat and poultry meat products & 249 & 148 & 16 & 29 \\
\hline 152 & $\begin{array}{l}\text { Processing and preserving of fish and fish } \\
\text { products }\end{array}$ & 185 & 153 & 16 & 5 \\
\hline 1531 & Processing and preserving of potatoes & 90 & 74 & 6 & 2 \\
\hline 1532 & Manufacture of fruit and vegetable juice & 25 & 20 & 0 & \\
\hline 1533 & $\begin{array}{l}\text { Manufacture and preserving of fruit and } \\
\text { vegetables n.e.c. }\end{array}$ & 136 & 108 & 9 & 6 \\
\hline 1541 & Manufacture of crude oils and fats & 9 & 5 & 1 & 1 \\
\hline 1542 & Manufacture of refined oils and fats & 10 & 9 & 0 & \\
\hline 1543 & Manufacture of margarine and similar edible fats & 4 & 0 & 0 & 1 \\
\hline 1551 & Operation of dairies and cheese making & 99 & 32 & 11 & \\
\hline 1552 & Manufacture of ice cream & 7 & 3 & 0 & 1 \\
\hline 1561 & Manufacture of grain mill products & 97 & 89 & 1 & 1 \\
\hline 1562 & Manufacture of starches and starch products & 10 & 3 & 1 & 2 \\
\hline 1571 & Manufacture of prepared feeds for farm animals & 81 & 48 & 7 & 12 \\
\hline 1572 & Manufacture of prepared pet foods & 13 & 8 & 2 & 3 \\
\hline 1581 & $\begin{array}{l}\text { Manufacture of bread; manufacture of fresh pastry } \\
\text { goods and cakes }\end{array}$ & 1,170 & 779 & 161 & 94 \\
\hline 1582 & $\begin{array}{l}\text { Manufacture of rusks and biscuits; manufacture } \\
\text { preserved pastry goods and cakes }\end{array}$ & 19 & 8 & 2 & 4 \\
\hline 1583 & Manufacture of sugar & 4 & 1 & 0 & 0 \\
\hline 1584 & $\begin{array}{l}\text { Manufacture of cocoa; chocolate and sugar } \\
\text { confectionery }\end{array}$ & 49 & 33 & 4 & 4 \\
\hline 1585 & $\begin{array}{l}\text { Manufacture of macaroni, noodles, couscous and } \\
\text { similar farinaceous products }\end{array}$ & 3 & 2 & 0 & 1 \\
\hline 1586 & Processing of tea and coffee & 5 & 0 & 0 & 1 \\
\hline 1587 & Manufacture of condiments and seasonings & 28 & 20 & 1 & 1 \\
\hline 1588 & $\begin{array}{l}\text { Manufacture of homogenised food preparations } \\
\text { and dietetic food }\end{array}$ & 4 & 3 & 0 & 0 \\
\hline 1589 & Manufacture of other food products n.e.c. & 101 & 74 & 10 & 10 \\
\hline 1591 & $\begin{array}{l}\text { Manufacture of distilled potable alcoholic } \\
\text { beverages }\end{array}$ & 10 & 7 & 2 & 0 \\
\hline 1592 & $\begin{array}{l}\text { Production of ethyl alcohol from fermented } \\
\text { materials }\end{array}$ & 2 & 2 & 0 & 0 \\
\hline 1594 & Manufacture of cider and other fruit wines & 44 & 40 & 1 & 0 \\
\hline 1596 & Manufacture of beer & 55 & 29 & 12 & 5 \\
\hline 1597 & Manufacture of malt & 5 & 2 & 0 & 0 \\
\hline 1598 & Production of mineral waters and soft drinks & 31 & 26 & 3 & \\
\hline
\end{tabular}




\section{Appendix B}

\section{Appendix B. A set of questions utilised in the study.}

The following question pools and items were employed in the study. The original questionnaire was the Finnish language. In spite of the fact that the translation from Finnish to English has been done as accurately as possible, there may be some nuances, that have been omitted.

\section{Question 1}

What is the branch of your main products? In the case you have main products in different branches, please, mark the branch which is in the financial sense the most important for you.
1) Processing and preserving of meat
2) Processing and preserving of fish and fish products
3) Manufacture of grain mill products (e.g., flours, flakes)
4) Manufacture of bread, pastry goods, biscuits etc.
5) Manufacture of dairy products (e.g., cheese)
6) Processing or preserving of vegetables, potatoes, etc.
7) Processing of preserving of berries and fruit
8) Manufacture of refined oil and fats
9) Manufacture of seasonings and condiments
10) Manufacture of other products

\section{Question 4}

In which year was your firm a) established b) transferred to the current owner(s)? Year 19

\section{Question 6}

Do you operate in connection with a farm? Scale: $1=$ Yes, $2=$ No

\section{Question 8}

Which stage best describes the current state of your business?
1) Starting stage
2) Growth stage
3) Maturity stage
4) Down-sizing stage
5) Redirecting stage
6) Ending stage

\section{Question 9}

What weight do the following items have in the goal setting of your business? Scale: $1=$ Highly unimportant to 5 = Highly important
1) Self-employment or employing family members
2) Increasing market share
3) Achievement of moderate living standard
4) Realisation of innovativeness or creativeness
5) Maximising incomes
6) Maximising profitability
7) Employing other people
8) Widening the size of the firm (in terms of turnover, number of employees)
9) Exploiting previous experience and competence
10) Independence relating to entrepreneurship
11) Supporting vitality of rural areas
12) Maintaining local food culture
13) Obtaining better price for raw material 
Appendix B

\section{Question 12}

To what extent do the following statements describe the competitors of your main products? Scale: $1=$ Totally disagree to $5=$ Totally agree

1) We compete with "ordinary" food products of large firms

2) We compete with special products of large firms

3) We compete with products of other small or rural firms

4) We compete with products belonging the same product group

5) We compete with products belonging to different product groups

6) Our products have no competitors

\section{Question 13}

How tough do you perceive the competition in your main markets towards your main products in terms of...?

1) Price

2) Quality

3) Access to mainstream marketing channels (e.g., retail stores, catering units etc.)

Scale: 1 = Intensity of competition is extremely low to $5=$ Intensity of competition is extremely high

\section{Question 15}

To what extent do you perceive the current competition as a threat for the continuity of your business? Scale: $1=$ No threat at all to $5=$ Very significant threat.

\section{Question 16}

To what extent do you consider the following items to be such superior factors that differentiate your main products or firm from your principal competitors?

Scale: 1 = Considerably low importance to $5=$ Considerably high importance; $9=$ Do not know

1) Excellent quality of raw material

2) Selected raw material suppliers

3) Unique product idea

4) Excellent quality of the products

5) Creativeness or innovativeness of the product development

6) Manufacturing methods of the products

7) Competitive prices of the products

8) Excellent product reputation

9) Local production (products produced near customers)

10) Use of organic raw materials

11) Different raw material composition

12) Traditional product recipes

13) Outward appearance of the products

14) Product packages

15) Wide product range

16) Distribution channels of the products

17) Sales techniques

18) Firm reputation in the market area

19) Delivery reliability

20) Special know-how of entrepreneur/family

21) Special know-how of non-family employees

22) Consideration of customers' special wishes

23) Flexibility of the business from customers' point of view

24) Personal customer service

25) Knowledge of product/raw material origin

26) Short chain of distribution from firm to customer

27) Environmentally-sound products or practises

28) Reputation of the trade name or trade mark 


\section{Appendix B}

\section{Question 17}

To what extent are the concrete product characteristics of your main products differentiated from...

1) ordinary products provided by large firms

2) special products provided by large firms

3) products provided by similar type of small or rural firms

Scale: 1 = Low degree of differentiation to $5=$ High degree of differentiation

\section{Question 18}

To what extent are is the services associated with your products (e.g., fast deliveries, customisation) differentiated from...

1) large firms providing ordinary products

2) large firms providing special products

3) similar types of small or rural firms

Scale: $1=$ Low degree of differentiation to $5=$ High degree of differentiation

\section{Question 19}

To what extent is your overall way of doing the business differentiated from...

1) large firms providing ordinary products

2) large firms providing special products

3) similar types of small or rural firms

Scale: $1=$ Low degree of differentiation to $5=$ High degree of differentiation

\section{Question 20}

How easily can your competitors imitate...

1) the concrete product characteristics that differentiate your main products from competitors

2) the competence that differentiates your main products from competitors

Scale: 1 = Very easy to imitate to 5 = Very difficult to imitate.

\section{Question 21}

How threatening do you perceive the imitation of your products to be in the marketplace among...

1) large and medium-sized firms

2) similar types of small or rural firms

Scale: $1=$ Not threatening at all to $5=$ Extremely threatening

\section{Question 22}

To what extent have you put effort into following actions over the last three years? Scale: $1=$ Insignificant effort to 5 = Significant effort

1) Developing new products

2) Modifying or improving existing products

3) Developing new production methods or processes

4) Systematising quality control

5) Reducing prices in relation to main competitors

6) Increasing the degree of product differentiation in relation to competitors

7) Acquiring knowledge of customers and markets

8) Customer or marketing channel specific planning of marketing

9) Responding to competitors' marketing actions (e.g., advertising, price reductions)

10) Reducing unit costs

11) Defining or specifying the target group

12) Looking actively for co-operation partners

13) Acquiring new customers

14) Following continuously changes in the competitive environment

15) Developing of own/employees' competence

16) Increasing customer satisfaction

17) Cutting down product range

18) Finding out competitors' strengths and competences

19) Focusing on only a few customers/customer groups

20) Actively maintaining customer relationships

21) Increasing prices in relation to main competitors

22) Widening product range

23) Widening market area 
Appendix $B$

\section{Question 24}

How easily do you think your customers can substitute your main products with some other firm's product? Scale: 1 = Our products are easily to substitute to $5=$ Our products are difficult to substitute

\section{Question 25}

What is the price level of your main products in comparison to....?

1) ordinary products of large firms

2) special products of large firms

3) products of similar types of small or rural firms

Scale: $1=$ Our prices are lower to $5=$ Our prices are higher

\section{Question 27}

To what extent do you consider the following factors to be weaknesses in your firm that make it difficult for you to achieve and maintain a competitive position in your markets?

Scale: 1 =Not a weakness to 5 = Significant weakness

1) Availability of liabilities

2) Sufficiency of own capital

3) Sufficiency of customers in the market area

4) Firm location relative to customers

5) Competence needed in defining target groups

6) Product development competence

7) Production competence

8) Acquisition of customer and market knowledge

9) Marketing competence

10) Sales skills

11) Pricing competence

12) Distribution competence (marketing products to mainstream marketing channels such as retail shops, catering units)

13) Customer-orientation in product development and marketing

14) Staff motivation

15) Own or employees' insufficient experience in the field

16) Amount of co-operation with other firms/organisations

17) Quality of co-operation with other firms/organisations

18) Financial management competence

19) Availability of counselling

20) Ability to take risks

21) Innovativeness or creativeness

22) Availability of skilled employees

23) Availability of appropriate raw material suppliers

24) Adapting new production methods/technologies

25) Clear view of the firm's future prospects

26) Tracking of changes in the competitive environment

\section{Question 32}

To what extent do the employees, including the entrepreneur, on average, have competence in the following fields of business based on education or experience? Scale: $1=$ Not at all to $5=$ To a high degree
1) Product development
2) Production processes
3) Package development
4) Marketing and sales skills
5) Quality development
6) Price setting
7) Financial management 


\section{Appendix $B$}

\section{Question 32}

How is the sales (in money) of your main products divided into different marketplaces? (\% of the sales)

1) Home and neighbouring municipalities

2) Own county outside home and neighbouring municipalities

3) Other parts of Finland excluding home county

4) Import

\section{Question 34}

Which distribution channels do you use? Scale: $1=$ Not at all to $5=$ To a great extent

Our products are sold...
1) in our own shop/farm directly to customers
2) in a co-operative shop
3) direct to local shops
4) direct to retail shops outside the home municipality
5) to retail chains or wholesalers (e.g., S-Group, K-Group)
6) direct to commercial restaurants, cafés, etc.
7) direct to institutional catering units (in schools, hospitals, day nurseries, old people's home etc.)
8) to other food-processing firms
9) in fairs
10) in marketplaces
11) by mail order
12) as business gifts to firms

\section{Question 36}

How do you assess the average profitability of your business during the last three years in relation to...

1) business objectives

2) similar types of small/rural firms

3) industry average

Scale: $1=$ Not profitable to $5=$ Highly profitable; $9=$ Do not know

\section{Question 37}

How large has your firm's turnover, business profit and balance sheet been in the last three calendar years or financial year?
1) Year 1997
2) Year 1998
3) Year 1999

\begin{tabular}{|c|c|c|c|}
\hline Turnover & & Business profit & Balanced sheet \\
\hline & FIM & FIM & $\begin{array}{r}\text { FIM } \\
\end{array}$ \\
\hline & FIM & FIM & FIM \\
\hline & FIM & FIM & FIM \\
\hline
\end{tabular}

\section{Question 38}

How do you assess 1 ) the average liquidity position and 2) solidity of your firm during the last three years? Scale: 1 = Very weak to $5=$ Very good; $9=$ Do not know 
Appendix B

\section{Question 41}

To what extent have you been satisfied with the following items during the last three years? Scale: $1=$ Highly satisfied to $5=$ Highly dissatisfied.

1) Sales of the products

2) Business revenue

3) Development of unit costs

4) Level of raw material costs

5) Level of labour costs

6) Level of capital costs

7) Return-on-investment

8) Business profit

9) Customer retention

10) Number of new customers

11) Development of the market share in your main marketplace

12) Customer satisfaction with your products

13) Selling prices of your products

14) Price-quality relationships perceived by customers

15) Ability to command a price premium

16) Development of the demand for your products

17) Number of new product launches

18) Unit costs of your products compared with competitors

19) Quality of your products compared with competitors

20) Utilisation rate of the capacity

21) Turnover of the stock

22) Delivery reliability

23) Amount of co-operation with other firms/organisations

24) Quality of co-operation with other firms/organisations

25) Your own and the employees' competence compared with competitors

26) Keeping track of the development of the field of business

\section{Question 46}

Which future development objectives have you set for your business? Scale: $1=$ Totally disagree to $5=$ Totally agree; 9 = Do not know

1) We will continue the business at the current level

2) Our objective is to increase production volumes

3) Our objective is to broaden into new markets

4) Our objective is to widen the product range

5) We plan to end the business gradually

\section{Question 52}

How many persons did your business employ in 1999? Please mark the numbers in terms of working months per year.

\section{Family members}

Non-family members

$$
\text { Full-time Part-time Seasonal }
$$

\section{Question 53}

How far away is your firm located from the nearest a) centre of the city or municipality, b) population centre with at least 15000 inhabitants? (kilometers)

\section{Question 54}

What is your basic education?

1) Elementary school

2) Comprehensive school or middle school

3) Matriculation examination 
Appendix B

\section{Question 55}

What is your professional education?

1) Short-term vocational courses

2) Vocational school

3) College-level

4) University degree or vocational high-school

5) No professional education

\section{Question 56}

Are you 1) female, 2) male?

\section{Question 57}

In which year were you born? 19 
Appendix $C$

\section{Appendix C. Cluster analysis and discriminant analysis outputs for success clustering, four-cluster solution.}

\section{Quick Cluster}

Initial Cluster Centers

\begin{tabular}{|l|c|c|c|c|}
\hline \multirow{2}{*}{} & \multicolumn{4}{|c|}{ Cluster } \\
\cline { 2 - 5 } & 1 & 2 & 3 & \multicolumn{1}{c|}{4} \\
\hline Financial performance & 1.00 & 2.00 & 2.00 & 5.00 \\
Quality performance & 3.80 & 5.00 & 4.00 & 5.00 \\
Market performance & 1.00 & 5.00 & 2.67 & 5.00 \\
Price performance & 1.00 & 1.00 & 4.00 & 5.00 \\
\hline
\end{tabular}

Iteration History ${ }^{2}$

\begin{tabular}{|l|r|r|r|r|}
\hline \multirow{2}{*}{ Iteration } & \multicolumn{4}{|c|}{ Change in Cluster Centers } \\
\cline { 2 - 5 } & 1 & \multicolumn{1}{|c|}{2} & \multicolumn{1}{c|}{3} & \multicolumn{1}{c|}{4} \\
\hline 1 & 1.558 & 1.703 & 1.354 & 1.471 \\
2 & .398 & .263 & $7.138 \mathrm{E}-02$ & .334 \\
3 & $8.378 \mathrm{E}-02$ & .133 & $5.860 \mathrm{E}-02$ & .101 \\
4 & .000 & .111 & $6.770 \mathrm{E}-02$ & $5.645 \mathrm{E}-02$ \\
5 & .000 & $9.154 \mathrm{E}-02$ & $6.116 \mathrm{E}-02$ & $1.627 \mathrm{E}-02$ \\
6 & .000 & $5.941 \mathrm{E}-02$ & $4.338 \mathrm{E}-02$ & .000 \\
7 & .000 & $5.427 \mathrm{E}-02$ & $4.229 \mathrm{E}-02$ & .000 \\
8 & .000 & .000 & .000 & .000 \\
\hline
\end{tabular}

a. Convergence achieved due to no or small distance change. The maximum distance by which any center has changed is .000 . The current iteration is 8 . The minimum distance between initial centers is 3.580 .

Final Cluster Centers

\begin{tabular}{|l|c|c|c|c|}
\hline \multirow{2}{*}{} & \multicolumn{4}{|c|}{ Cluster } \\
\cline { 2 - 5 } & 1 & 2 & 3 & 4 \\
\hline Financial performance & 1.94 & 2.91 & 2.82 & 3.79 \\
Quality performance & 3.51 & 3.97 & 3.94 & 4.58 \\
Market performance & 2.10 & 3.47 & 3.12 & 4.13 \\
Price performance & 2.17 & 2.18 & 3.39 & 3.81 \\
\hline
\end{tabular}

Number of Cases in each Cluster

\begin{tabular}{|ll|r|}
\hline Cluster & 1 & 40.000 \\
& 2 & 58.000 \\
& 3 & 78.000 \\
& 4 & 62.000 \\
Valid & & 238.000 \\
Missing & & .000 \\
\hline
\end{tabular}




\section{Appendix $C$}

\section{Discriminant}

Analysis Case Processing Summary

\begin{tabular}{|c|c|c|c|}
\hline \multicolumn{2}{|c|}{ Unweighted Cases } & $\mathrm{N}$ & Percent \\
\hline \multicolumn{2}{|c|}{ Valid } & 236 & 99.2 \\
\hline Excluded & $\begin{array}{l}\text { Missing or out-of-range } \\
\text { group codes }\end{array}$ & 0 & .0 \\
\hline & $\begin{array}{l}\text { At least one missing } \\
\text { discriminating variable }\end{array}$ & 2 & .8 \\
\hline & $\begin{array}{l}\text { Both missing or } \\
\text { out-of-range group codes } \\
\text { and at least one missing } \\
\text { discriminating variable }\end{array}$ & 0 & .0 \\
\hline & Total & 2 & .8 \\
\hline Total & & 238 & 100.0 \\
\hline
\end{tabular}

Group Statistics

\begin{tabular}{|c|c|c|c|}
\hline \multirow[b]{2}{*}{ Cluster Number of Cas } & & \multicolumn{2}{|c|}{ Valid N (listwise) } \\
\hline & & Unweighted & Weighted \\
\hline \multirow[t]{4}{*}{1} & Financial performance & 40 & 40.000 \\
\hline & Quality performance & 40 & 40.000 \\
\hline & Market performance & 40 & 40.000 \\
\hline & Price performance & 40 & 40.000 \\
\hline \multirow[t]{4}{*}{2} & Financial performance & 57 & 57.000 \\
\hline & Quality performance & 57 & 57.000 \\
\hline & Market performance & 57 & 57.000 \\
\hline & Price performance & 57 & 57.000 \\
\hline \multirow[t]{4}{*}{3} & Financial performance & 78 & 78.000 \\
\hline & Quality performance & 78 & 78.000 \\
\hline & Market performance & 78 & 78.000 \\
\hline & Price performance & 78 & 78.000 \\
\hline \multirow[t]{4}{*}{4} & Financial performance & 61 & 61.000 \\
\hline & Quality performance & 61 & 61.000 \\
\hline & Market performance & 61 & 61.000 \\
\hline & Price performance & 61 & 61.000 \\
\hline \multirow[t]{4}{*}{ Total } & Financial performance & 236 & 236.000 \\
\hline & Quality performance & 236 & 236.000 \\
\hline & Market performance & 236 & 236.000 \\
\hline & Price performance & 236 & 236.000 \\
\hline
\end{tabular}

\section{Analysis 1}

Box's Test of Equality of Covariance Matrices

Log Determinants

\begin{tabular}{|l|r|r|}
\hline Cluster Number of Case & Rank & $\begin{array}{c}\text { Log } \\
\text { Determinant }\end{array}$ \\
\hline 1 & 4 & -5.365 \\
2 & 4 & -5.895 \\
3 & 4 & -6.196 \\
4 & 4 & -5.608 \\
Pooled within-groups & 4 & -5.535 \\
\hline
\end{tabular}

The ranks and natural logarithms of determinants printed are those of the group covariance matrices. 


\section{Appendix $C$}

\section{Test Results}

\begin{tabular}{|ll|r|}
\hline Box's M & & 68.923 \\
F & Approx. & 2.221 \\
& df1 & 30 \\
& df2 & 99259.588 \\
& Sig. & .000 \\
\hline
\end{tabular}

Tests null hypothesis of equal population covariance matrices.

\section{Summary of Canonical Discriminant Functions}

Eigenvalues

\begin{tabular}{|l|r|r|r|r|}
\hline Function & Eigenvalue & \% of Variance & Cumulative \% & $\begin{array}{c}\text { Canonical } \\
\text { Correlation }\end{array}$ \\
\hline 1 & $4.123^{\mathrm{a}}$ & 81.4 & 81.4 & .897 \\
2 & $.918^{\mathrm{a}}$ & 18.1 & 99.5 & .692 \\
3 & $.027^{\mathrm{a}}$ & .5 & 100.0 & .161 \\
\hline
\end{tabular}

a. First 3 canonical discriminant functions were used in the analysis.

Wilks' Lambda

\begin{tabular}{|l|r|r|r|r|}
\hline Test of Function(s) & \multicolumn{1}{|c|}{$\begin{array}{c}\text { Wilks' } \\
\text { Lambda }\end{array}$} & Chi-square & \multicolumn{1}{c|}{ df } & \multicolumn{1}{c|}{ Sig. } \\
\hline 1 through 3 & .099 & 533.934 & 12 & .000 \\
2 through 3 & .508 & 156.524 & 6 & .000 \\
3 & .974 & 6.044 & 2 & .049 \\
\hline
\end{tabular}

\section{Standardized Canonical Discriminant Function Coefficients}

\begin{tabular}{|l|r|r|r|}
\hline & \multicolumn{3}{|c|}{ Function } \\
\cline { 2 - 4 } & 1 & \multicolumn{1}{|c|}{2} & \multicolumn{1}{c|}{3} \\
\hline Financial performance & .455 & .273 & .293 \\
Quality performance & .358 & .234 & .841 \\
Market performance & .557 & .466 & -.616 \\
Price performance & .495 & -.868 & -.156 \\
\hline
\end{tabular}

\section{Structure Matrix}

\begin{tabular}{|l|c|c|c|}
\hline & \multicolumn{3}{|c|}{ Function } \\
\cline { 2 - 4 } & 1 & 2 & \multicolumn{1}{|c|}{3} \\
\hline Market performance & $.623^{*}$ & .471 & -.541 \\
Financial performance & $.478^{*}$ & .195 & .136 \\
Price performance & .592 & $-.803^{*}$ & -.049 \\
Quality performance & .400 & .129 & $.736^{*}$ \\
\hline
\end{tabular}

Pooled within-groups correlations between discriminating variables and standardized canonical discriminant functions Variables ordered by absolute size of correlation within function.

* . Largest absolute correlation between each variable and any discriminant function 
Appendix $C$

Canonical Discriminant Function Coefficients

\begin{tabular}{|l|r|r|r|}
\hline & \multicolumn{3}{|c|}{ Function } \\
\cline { 2 - 4 } & \multicolumn{1}{|c|}{1} & \multicolumn{1}{c|}{2} & \multicolumn{1}{c|}{3} \\
\hline Financial performance & .752 & .452 & .486 \\
Quality performance & .830 & .542 & 1.949 \\
Market performance & 1.124 & .940 & -1.244 \\
Price performance & .990 & -1.737 & -.312 \\
(Constant) & -12.232 & -1.399 & -4.268 \\
\hline
\end{tabular}

Unstandardized coefficients

Functions at Group Centroids

\begin{tabular}{|l|r|r|r|}
\hline \multirow{2}{*}{ Cluster Number of Case } & \multicolumn{3}{|c|}{ Function } \\
\cline { 2 - 4 } & \multicolumn{1}{|c|}{1} & \multicolumn{1}{c|}{2} & \multicolumn{1}{c|}{3} \\
\hline 2 & -3.342 & -.422 & .225 \\
3 & -.699 & 1.546 & -.099 \\
4 & $2.627 \mathrm{E}-02$ & -.945 & -.164 \\
& 2.811 & $4.100 \mathrm{E}-02$ & .155 \\
\hline
\end{tabular}

Unstandardized canonical discriminant functions evaluated at group means

\section{Classification Statistics}

Classification Processing Summary

\begin{tabular}{|ll|r|}
\hline Processed & Missing or out-of-range & 238 \\
& $\begin{array}{l}\text { group codes } \\
\text { At least one missing } \\
\text { discriminating variable }\end{array}$ & 0 \\
Used in Output & & 236 \\
\hline
\end{tabular}

Prior Probabilities for Groups

\begin{tabular}{|c|c|c|c|}
\hline \multirow[b]{2}{*}{ Cluster Number of Case } & \multirow[b]{2}{*}{ Prior } & \multicolumn{2}{|c|}{ Cases Used in Analysis } \\
\hline & & Unweighted & Weighted \\
\hline 1 & .169 & 40 & 40.000 \\
\hline 2 & .242 & 57 & 57.000 \\
\hline 3 & .331 & 78 & 78.000 \\
\hline 4 & .258 & 61 & 61.000 \\
\hline Total & 1.000 & 236 & 236.000 \\
\hline
\end{tabular}


Appendix $C$

\section{Classification Function Coefficients}

\begin{tabular}{|l|r|r|r|r|}
\hline & \multicolumn{4}{|c|}{ Cluster Number of Case } \\
\cline { 2 - 5 } & \multicolumn{1}{|c|}{1} & \multicolumn{1}{c|}{2} & \multicolumn{1}{c|}{3} & \multicolumn{1}{c|}{4} \\
\hline Financial performance & 6.384 & 9.104 & 8.492 & 11.187 \\
Quality performance & 18.636 & 21.266 & 20.390 & 23.859 \\
Market performance & 6.735 & 11.959 & 10.515 & 14.175 \\
Price performance & 5.935 & 5.234 & 10.298 & 11.242 \\
(Constant) & -54.212 & -83.307 & -87.112 & -127.662 \\
\hline
\end{tabular}

Fisher's linear discriminant functions

\section{Canonical Discriminant Functions}

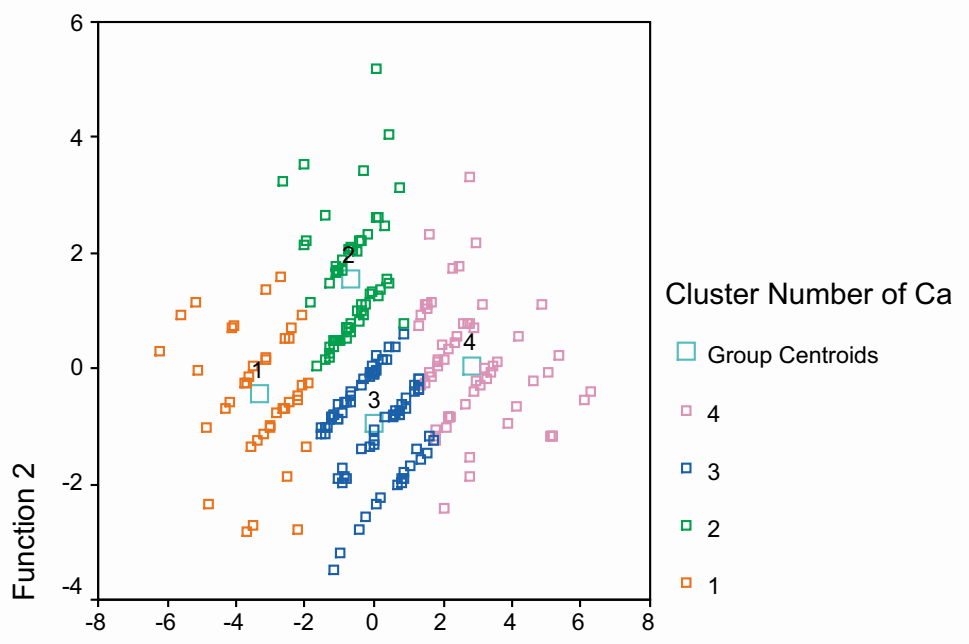

Function 1 
Appendix C

Classification Results,

\begin{tabular}{|c|c|c|c|c|c|c|c|}
\hline & & \multirow[b]{2}{*}{ Cluster Number of Case } & \multicolumn{4}{|c|}{ Predicted Group Membership } & \multirow[b]{2}{*}{ Total } \\
\hline & & & 1 & 2 & 3 & 4 & \\
\hline \multirow[t]{8}{*}{ Original } & Count & 1 & 36 & 2 & 2 & 0 & 40 \\
\hline & & 2 & 0 & 55 & 2 & 0 & 57 \\
\hline & & 3 & 0 & 0 & 77 & 1 & 78 \\
\hline & & 4 & 0 & 1 & 3 & 57 & 61 \\
\hline & $\%$ & 1 & 90.0 & 5.0 & 5.0 & .0 & 100.0 \\
\hline & & 2 & .0 & 96.5 & 3.5 & .0 & 100.0 \\
\hline & & 3 & .0 & .0 & 98.7 & 1.3 & 100.0 \\
\hline & & 4 & .0 & 1.6 & 4.9 & 93.4 & 100.0 \\
\hline \multirow[t]{8}{*}{ Cross-validated $^{a}$} & Count & 1 & 36 & 2 & 2 & 0 & 40 \\
\hline & & 2 & 0 & 54 & 3 & 0 & 57 \\
\hline & & 3 & 0 & 0 & 77 & 1 & 78 \\
\hline & & 4 & 0 & 1 & 4 & 56 & 61 \\
\hline & $\%$ & 1 & 90.0 & 5.0 & 5.0 & .0 & 100.0 \\
\hline & & 2 & .0 & 94.7 & 5.3 & .0 & 100.0 \\
\hline & & 3 & .0 & .0 & 98.7 & 1.3 & 100.0 \\
\hline & & 4 & .0 & 1.6 & 6.6 & 91.8 & 100.0 \\
\hline
\end{tabular}

a. Cross validation is done only for those cases in the analysis. In cross validation, each case is classified by the functions derived from all cases other than that case.

b. $95.3 \%$ of original grouped cases correctly classified.

c. $94.5 \%$ of cross-validated grouped cases correctly classified. 
Appendix D

\section{Appendix D. Cluster analysis and discriminant analysis outputs for competitive advantage clusters, five-cluster solution.}

\section{Quick Cluster}

Initial Cluster Centers

\begin{tabular}{|l|r|r|r|r|r|}
\hline & \multicolumn{6}{|c|}{ Cluster } \\
\cline { 2 - 6 } & 1 & 2 & 3 & \multicolumn{1}{c|}{5} \\
\hline Price level (k2501+k2502) & 5.00 & 3.00 & 5.00 & 1.00 & 1.00 \\
DIFFER & 5.00 & 3.83 & 2.67 & 2.00 & 5.00 \\
\hline
\end{tabular}

\begin{tabular}{|c|c|c|c|c|c|}
\hline \multirow[b]{3}{*}{ Iteration } & \multicolumn{4}{|c|}{ Iteration History ${ }^{2}$} & \\
\hline & \multicolumn{5}{|c|}{ Change in Cluster Centers } \\
\hline & 1 & 2 & 3 & 4 & 5 \\
\hline 1 & .643 & .194 & .661 & 1.138 & .616 \\
\hline 2 & .175 & .081 & .158 & .383 & .411 \\
\hline 3 & .034 & .016 & .086 & .111 & .179 \\
\hline 4 & .012 & .026 & .083 & .099 & .000 \\
\hline 5 & .000 & .000 & .035 & .055 & .000 \\
\hline 6 & .000 & .000 & .000 & .000 & .000 \\
\hline
\end{tabular}

a. Convergence achieved due to no or small change in cluster centers. The maximum absolute coordinate change for any center is .000 . The current iteration is 6 . The minimum distance between initial centers is 2.315 .

Final Cluster Centers

\begin{tabular}{|l|r|r|r|r|r|}
\hline & \multicolumn{5}{|c|}{ Cluster } \\
\cline { 2 - 6 } & \multicolumn{1}{|c|}{1} & \multicolumn{1}{c|}{3} & \multicolumn{1}{c|}{3} & \multicolumn{1}{c|}{5} \\
\hline Price level (k2501+k2502) & 4.45 & 3.13 & 4.20 & 2.73 & 1.72 \\
DIFFER & 4.38 & 3.83 & 3.14 & 2.18 & 4.11 \\
\hline
\end{tabular}

ANOVA

\begin{tabular}{|l|r|r|r|r|r|r|}
\hline & \multicolumn{2}{|c|}{ Cluster } & \multicolumn{2}{c|}{ Error } & \multirow{2}{*}{ Sig. } \\
\cline { 2 - 7 } & Mean Square & df & Mean Square & df & \multicolumn{1}{c|}{ F } & Sig \\
\hline Price level (k2501+k2502) & 44.876 & 4 & .195 & 231 & 230.458 & .000 \\
DIFFER & 25.961 & 4 & .218 & 232 & 118.945 & .000 \\
\hline
\end{tabular}

The $\mathrm{F}$ tests should be used only for descriptive purposes because the clusters have been chosen to maximize the differences among cases in different clusters. The observed significance levels are not corrected for this and thus cannot be interpreted as tests of the hypothesis that the cluster means are equal.

\section{Number of Cases in each Cluster}

\begin{tabular}{|ll|r|}
\hline Cluster & 1 & 60.000 \\
& 2 & 85.000 \\
& 3 & 42.000 \\
& 4 & 26.000 \\
& 5 & 25.000 \\
Valid & & 238.000 \\
Missing & & .000 \\
\hline
\end{tabular}


Appendix D

\section{Discriminant}

Analysis Case Processing Summary

\begin{tabular}{|c|c|c|c|}
\hline \multicolumn{2}{|c|}{ Unweighted Cases } & $\mathrm{N}$ & Percent \\
\hline \multicolumn{2}{|c|}{ Valid } & 235 & 98.7 \\
\hline Excluded & $\begin{array}{l}\text { Missing or out-of-range } \\
\text { group codes }\end{array}$ & 0 & .0 \\
\hline & $\begin{array}{l}\text { At least one missing } \\
\text { discriminating variable }\end{array}$ & 3 & 1.3 \\
\hline & $\begin{array}{l}\text { Both missing or } \\
\text { out-of-range group codes } \\
\text { and at least one missing } \\
\text { discriminating variable }\end{array}$ & 0 & .0 \\
\hline & Total & 3 & 1.3 \\
\hline Total & & 238 & 100.0 \\
\hline
\end{tabular}

Group Statistics

\begin{tabular}{|c|c|c|c|}
\hline \multirow[b]{2}{*}{ Cluster Number of Case } & & \multicolumn{2}{|c|}{ Valid N (listwise) } \\
\hline & & Unweighted & Weighted \\
\hline \multirow[t]{2}{*}{1} & Price level (k2501+k2502) & 60 & 60.000 \\
\hline & DIFFER & 60 & 60.000 \\
\hline \multirow[t]{2}{*}{2} & Price level (k2501+k2502) & 85 & 85.000 \\
\hline & DIFFER & 85 & 85.000 \\
\hline \multirow[t]{2}{*}{3} & Price level (k2501+k2502) & 40 & 40.000 \\
\hline & DIFFER & 40 & 40.000 \\
\hline \multirow[t]{2}{*}{4} & Price level (k2501+k2502) & 25 & 25.000 \\
\hline & DIFFER & 25 & 25.000 \\
\hline \multirow[t]{2}{*}{5} & Price level (k2501+k2502) & 25 & 25.000 \\
\hline & DIFFER & 25 & 25.000 \\
\hline \multirow[t]{2}{*}{ Total } & Price level (k2501+k2502) & 235 & 235.000 \\
\hline & DIFFER & 235 & 235.000 \\
\hline
\end{tabular}

Analysis 1

Box's Test of Equality of Covariance Matrices

Log Determinants

\begin{tabular}{|l|r|r|}
\hline Cluster Number of Case & Rank & $\begin{array}{c}\text { Log } \\
\text { Determinant }\end{array}$ \\
\hline 1 & 2 & -3.532 \\
2 & 2 & -3.839 \\
3 & 2 & -3.448 \\
4 & 2 & -2.077 \\
5 & 2 & -2.514 \\
Pooled within-groups & 2 & -3.148 \\
\hline
\end{tabular}

The ranks and natural logarithms of determinants printed are those of the group covariance matrices.

Test Results

\begin{tabular}{|ll|r|}
\hline Box's M & & 51.490 \\
F & Approx. & 4.187 \\
& df1 & 12 \\
& df2 & 79640.939 \\
& Sig. & .000 \\
\hline
\end{tabular}

Tests null hypothesis of equal population covariance matrices. 
Appendix D

\section{Summary of Canonical Discriminant Functions}

Eigenvalues

\begin{tabular}{|l|r|r|r|r|}
\hline Function & Eigenvalue & \% of Variance & Cumulative \% & $\begin{array}{c}\text { Canonical } \\
\text { Correlation }\end{array}$ \\
\hline 1 & $4.191^{\mathrm{a}}$ & 69.4 & 69.4 & .899 \\
2 & $1.847^{\mathrm{a}}$ & 30.6 & 100.0 & .805 \\
\hline
\end{tabular}

a. First 2 canonical discriminant functions were used in the analysis.

Wilks' Lambda

\begin{tabular}{|l|r|r|r|r|}
\hline Test of Function(s) & $\begin{array}{c}\text { Wilks' } \\
\text { Lambda }\end{array}$ & Chi-square & df & \multicolumn{1}{c|}{ Sig. } \\
\hline 1 through 2 & .068 & 620.802 & 8 & .000 \\
2 & .351 & 241.166 & 3 & .000 \\
\hline
\end{tabular}

Standardized Canonical Discriminant Function Coefficients

\begin{tabular}{|l|r|r|}
\hline \multirow{2}{*}{} & \multicolumn{2}{|c|}{ Function } \\
\cline { 2 - 3 } & 1 & \multicolumn{1}{|c|}{2} \\
\hline Price level (k2501+k2502) & .958 & -.288 \\
DIFFER & .303 & .953 \\
\hline
\end{tabular}

\section{Structure Matrix}

\begin{tabular}{|l|c|c|}
\hline \multirow{2}{*}{} & \multicolumn{2}{|c|}{ Function } \\
\cline { 2 - 3 } & 1 & 2 \\
\hline Price level (k2501+k2502) & $.953^{*}$ & -.303 \\
DIFFER & .288 & $.958^{*}$ \\
\hline
\end{tabular}

Pooled within-groups correlations between discriminating variables and standardized canonical discriminant functions Variables ordered by absolute size of correlation within function.

*. Largest absolute correlation between each variable and any discriminant function

Canonical Discriminant Function Coefficients

\begin{tabular}{|l|r|r|}
\hline \multirow{2}{*}{} & \multicolumn{2}{|c|}{ Function } \\
\cline { 2 - 3 } & \multicolumn{1}{|c|}{1} & \multicolumn{1}{l|}{2} \\
\hline Price level (k2501+k2502) & 2.167 & -.652 \\
DIFFER & .646 & 2.033 \\
(Constant) & -9.888 & -5.287 \\
\hline
\end{tabular}

Unstandardized coefficients 
Appendix D

Functions at Group Centroids

\begin{tabular}{|l|r|r|}
\hline \multirow{2}{*}{ Cluster Number of Case } & \multicolumn{2}{|c|}{ Function } \\
\cline { 2 - 3 } & \multicolumn{1}{|c|}{1} & \multicolumn{1}{c|}{2} \\
\hline 1 & 2.582 & .711 \\
3 & -.630 & .468 \\
4 & 1.243 & -1.635 \\
5 & -2.540 & -2.635 \\
\hline
\end{tabular}

Unstandardized canonical discriminant functions evaluated at group means

\section{Classification Statistics}

Classification Processing Summary

\begin{tabular}{|ll|r|}
\hline Processed & Missing or out-of-range \\
Excluded & $\begin{array}{l}\text { group codes } \\
\text { At least one missing } \\
\text { discriminating variable }\end{array}$ & 3 \\
Used in Output & & 235 \\
\hline
\end{tabular}

Prior Probabilities for Groups

\begin{tabular}{|l|r|r|r|}
\hline \multirow{2}{*}{ Cluster Number of Case } & \multirow{2}{*}{ Prior } & \multicolumn{2}{|c|}{ Cases Used in Analysis } \\
\cline { 3 - 4 } & .255 & Unweighted & Weighted \\
\hline 1 & .362 & 60 & 60.000 \\
2 & .170 & 45 & 85.000 \\
3 & .106 & 40 & 40.000 \\
4 & .106 & 25 & 25.000 \\
5 & 1.000 & 25 & 25.000 \\
Total & & 235 & 235.000 \\
\hline
\end{tabular}

Classification Function Coefficients

\begin{tabular}{|l|r|r|r|r|r|}
\hline & \multicolumn{5}{|c|}{ Cluster Number of Case } \\
\cline { 2 - 6 } & \multicolumn{1}{|c|}{1} & \multicolumn{1}{|c|}{2} & \multicolumn{1}{c|}{3} & \multicolumn{1}{c|}{4} \\
\hline Price level (k2501+k2502) & 23.114 & 16.311 & 21.742 & 14.194 & 9.115 \\
DIFFER & 20.244 & 17.676 & 14.610 & 10.135 & 18.837 \\
(Constant) & -97.105 & -60.432 & -70.391 & -32.750 & -48.821 \\
\hline
\end{tabular}

Fisher's linear discriminant functions 
Appendix D

\section{Canonical Discriminant Functions}

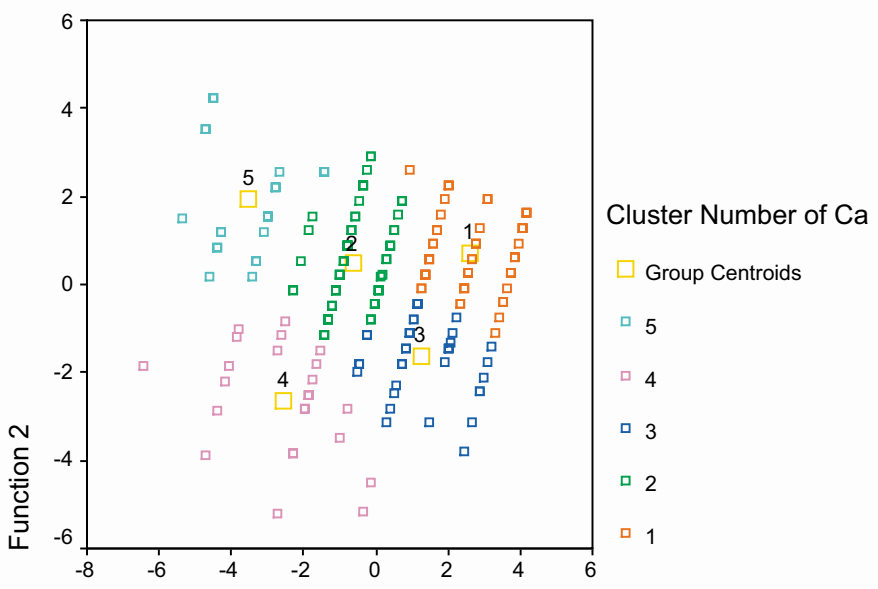

Function 1

Classification Results,c

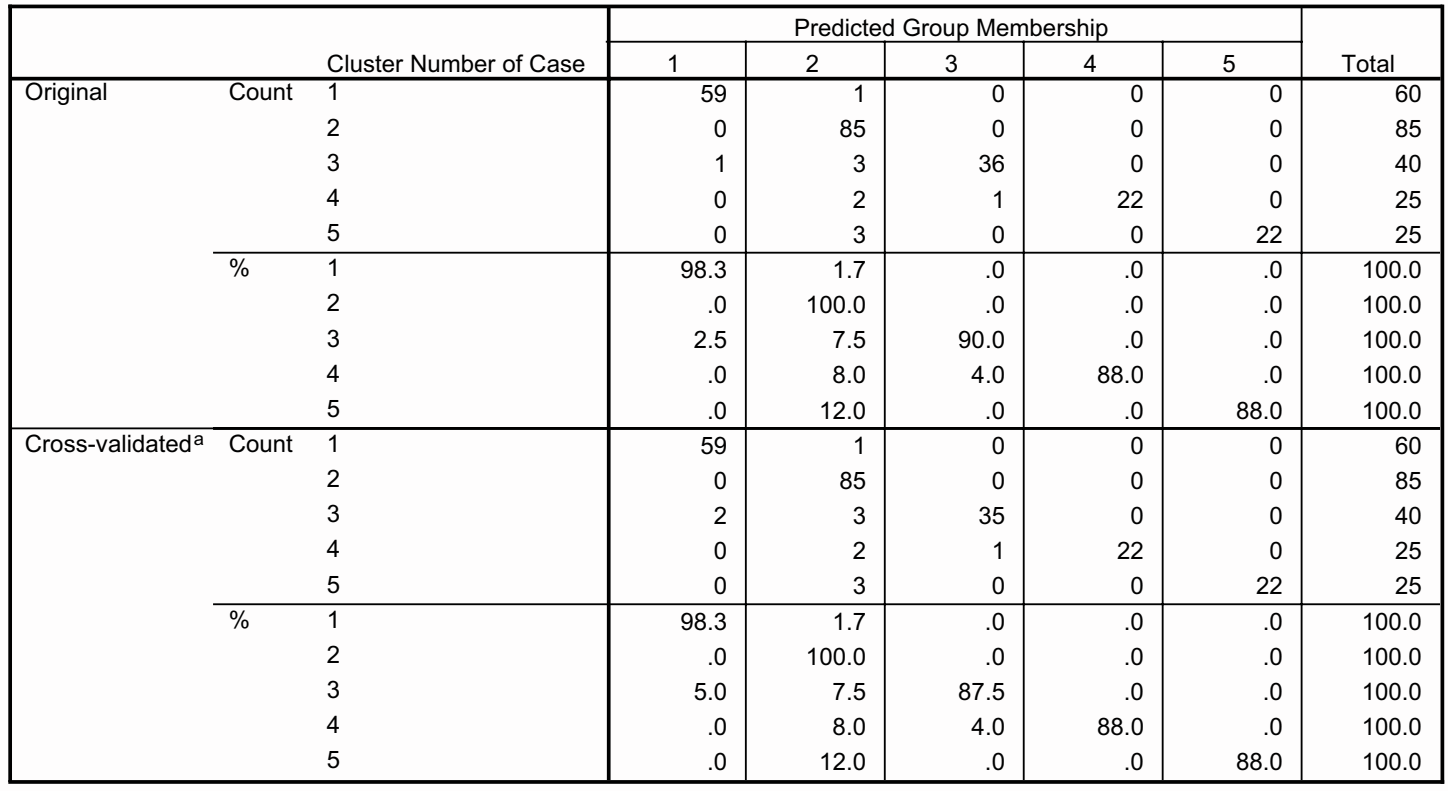

a. Cross validation is done only for those cases in the analysis. In cross validation, each case is classified by the functions derived from all cases other than that case.

b. $95.3 \%$ of original grouped cases correctly classified.

c. $94.9 \%$ of cross-validated grouped cases correctly classified. 
Appendix E

\title{
Appendix E. LISREL output for final model.
}

\author{
DATE : $5 / 27 / 2004$ \\ TIME: 19:39 \\ L I S R E L 8.51
}

BY

Kar1 G. Jöreskog \& Dag Sörbom

This program is published exclusively by

Scientific Software International, Inc.

$7383 \mathrm{~N}$. Lincoln Avenue, Suite 100

Lincolnwood, IL 60712, U.S.A.

Phone: (800)247-6113, (847)675-0720, Fax: (847)675-2140

copyright by Scientific Software Internationa1, Inc., 1981-2001

Use of this program is subject to the terms specified in the

Universal Copyright Convention.

website: www.ssicentral.com

The following lines were read from file $c: \backslash$ Documents and settings \SariF\omat

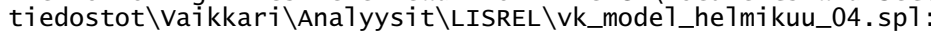

OBSERVED VARIABLES

SUCCESS1 SUCCESS2 SUCCESS3 SUCCESS5 BR1 BR2 BR3 BR4 BR5 BR6 SR1 SR2 SR3 SR4 SR5 SR6

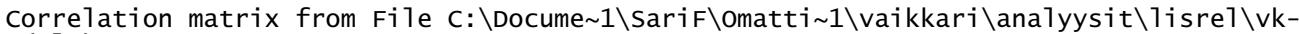
mode1. km

Sample size 226

Latent variables

SUCCESS SR BR

Relationships

$B R 1$ BR2 BR3 = BR

SR1 SR3 SR4 SR5 = SR

SUCCESS1 SUCCESS2 SUCCESS3 = SUCCESS

SUCCESS $=$ SR BR

LET THE ERRORS BETWEEN BR3 AND SUCCESS3 CORRELATE

Lisre1 output: SE TV RS MR FS MI

Path Diagram

End of Problem

Correlation Matrix

\begin{tabular}{rrrrrrr} 
& SUCCESS1 & \multicolumn{1}{l}{ SUCCESS2 } & SUCCESS3 & BR1 & BR2 & BR3 \\
SUCCESS1 & --1.00 & ---- & -----1 & & & \\
SUCCESS2 & 0.37 & 1.00 & & & & \\
SUCCESS3 & 0.57 & 0.54 & 1.00 & & & \\
BR1 & 0.40 & 0.40 & 0.46 & 1.00 & & \\
BR2 & 0.36 & 0.39 & 0.44 & 0.64 & 1.00 & \\
BR3 & 0.25 & 0.39 & 0.24 & 0.64 & 0.54 & 1.00 \\
SR1 & 0.26 & 0.37 & 0.30 & 0.27 & 0.12 & 0.20 \\
SR3 & 0.07 & 0.11 & 0.17 & 0.16 & -0.03 & 0.06 \\
SR4 & 0.13 & 0.32 & 0.27 & 0.17 & 0.09 & 0.13 \\
SR5 & 0.21 & 0.17 & 0.17 & 0.12 & 0.05 & 0.01
\end{tabular}

Correlation Matrix

$\begin{array}{lrrrr} & \text { SR1 } & \text { SR3 } & \text { SR4 } & \text { SR5 } \\ \text { SR1 } & ---1.00 & & & \\ \text { SR3 } & 0.46 & 1.00 & & \\ \text { SR4 } & 0.52 & 0.24 & 1.00 & \\ \text { SR5 } & 0.47 & 0.24 & 0.32 & 1.00\end{array}$

Parameter Specifications

LAMBDA-Y

SUCCESS

SUCCESS1

- 0

SUCCESS2 
Appendix E

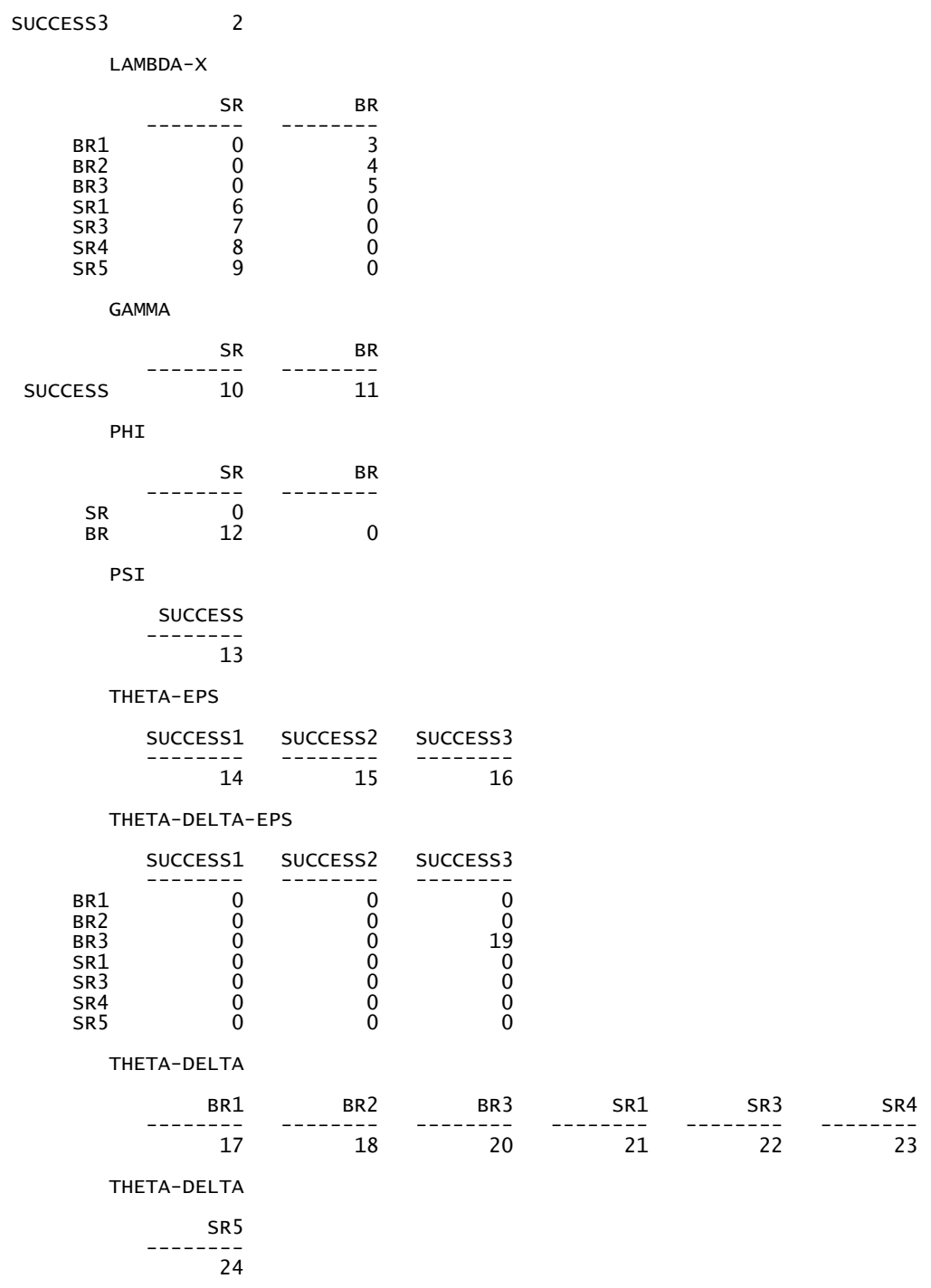

Number of Iterations $=7$

LISREL Estimates (Maximum Likelihood)

LAMBDA-Y

$\begin{array}{lr} & \text { SUCCESS } \\ \text { SUCCESS1 } & 0.64 \\ \text { SUCCESS2 } & 0.68 \\ & (0.08) \\ & 8.17 \\ \text { SuCCESS3 } & 0.81 \\ & (0.09) \\ & 8.76\end{array}$

LAMBDA-X

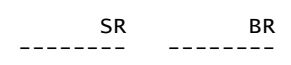


Appendix E

BR1

$$
\begin{array}{r}
0.86 \\
(0.06) \\
14.74
\end{array}
$$

BR2

0.75

$0.06)$
12.44

BR3 - - 0.73

11.86

SR1

$$
\begin{array}{r}
0.93 \\
(0.07) \\
13.90
\end{array}
$$

SR3

$$
0.49
$$$$
\begin{array}{r}
(0.07) \\
7.16
\end{array}
$$

SR4

$$
\begin{array}{r}
0.57 \\
(0.07) \\
8.40
\end{array}
$$

SR 5

$$
\begin{array}{r}
0.51 \\
(0.07) \\
7.43
\end{array}
$$

GAMMA

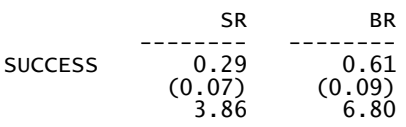

Covariance Matrix of ETA and KSI

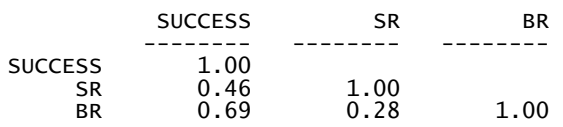

PHI

$$
\begin{array}{crr} 
& \text { SR } & \text { BR } \\
\text { SR } & 1.00 & \\
\text { BR } & 0.28 & 1.00 \\
& (0.07) & \\
& 3.81 &
\end{array}
$$

PSI

$$
\begin{array}{r}
\text { SUCCESS } \\
-0.44 \\
(0.11) \\
4.10
\end{array}
$$

Squared Multiple Correlations for Structural Equations

$$
\begin{array}{r}
\text { SUCCESS } \\
--\overline{0.56}
\end{array}
$$

Squared Multiple Correlations for Reduced Form

$$
\begin{array}{r}
\text { SUCCESS } \\
-0.56
\end{array}
$$

THETA-EPS

$$
\begin{array}{rrr}
\text { SUCCESS1 } & \text { SUCCESS2 } & \text { SUCCESS3 } \\
-0.59 & 0.54 & 0.34 \\
(0.07) & (0.06) & (0.06) \\
9.01 & 8.60 & 5.60
\end{array}
$$

Squared Multiple correlations for Y - variables 
Appendix E

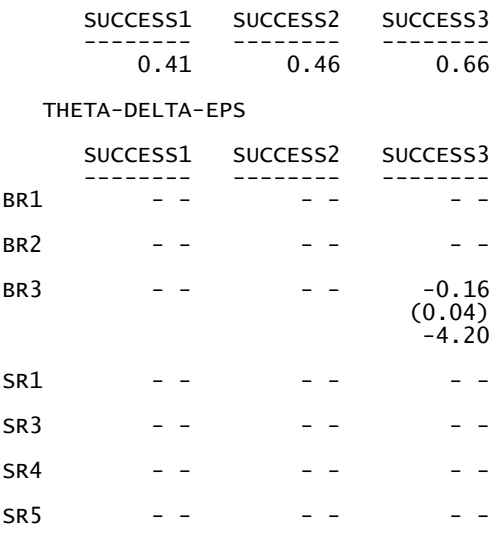

THETA-DELTA

$\begin{array}{rrrrrr}\text { BR1 } & \text { BR2 } & \text { BR3 } & \text { SR1 } & \text { SR3 } & \text { SR4 } \\ -0.26 & 0.43 & 0.46 & 0.14 & 0.76 & 0.68 \\ (0.05) & (0.05) & (0.06) & (0.08) & (0.08) & (0.07) \\ 5.50 & 8.22 & 8.21 & 1.70 & 9.92 & 9.37\end{array}$

THETA-DELTA

$$
\begin{array}{r}
\text { SR5 } \\
-0.74 \\
(0.08) \\
9.82
\end{array}
$$

Squared Multiple Correlations for $\mathrm{X}$ - Variables

$$
\begin{array}{rrrrrr}
\text { BR1 } & \text { BR2 } & \text { BR3 } & \text { SR1 } & \text { SR3 } & \text { SR4 } \\
-0.74 & 0.57 & 0.54 & 0.86 & 0.24 & 0.32
\end{array}
$$

Squared Multiple Correlations for $x$ - Variables

$$
\begin{array}{r}
\text { SR5 } \\
-0.26
\end{array}
$$

Goodness of Fit Statistics

Degrees of Freedom $=31$

Minimum Fit Function Chi-Square $=52.25(\mathrm{P}=0.0099)$

Normal Theory Weighted Least Squares Chi-square $=51.72(P=0.011)$

Estimated Non-centrality Parameter (NCP) $=20.72$

90 Percent Confidence Interval for NCP $=(4.75 ; 44.56)$

$$
\text { Minimum Fit Function value }=0.23
$$

Population Discrepancy Function Value (F0) $=0.092$

90 Percent Confidence Interval for $\mathrm{FO}=(0.021 ; 0.20)$

Root Mean Square Error of Approximation (RMSEA) $=0.054$

90 Percent Confidence Interva1 for RMSEA $=(0.026 ; 0.080)$

$\mathrm{P}$-Value for Test of close Fit (RMSEA $<0.05$ ) $=0.36$

Expected cross-Validation Index $(E C V I)=0.44$

90 Percent Confidence Interval for $\mathrm{ECVI}=\left(0.37^{\circ} ; 0.55\right)$

ECVI for saturated Mode $1=0.49$

ECVI for Independence Mode $1=3.55$

Chi-Square for Independence Mode1 with 45 Degrees of Freedom $=779.37$ Independence AIC $=799.37$

Mode1 AIC $=99.72$

saturated AIC $=110.00$

Independence CAIC $=843.58$

Mode 1 CAIC $=205.81$

Saturated CAIC $=353.13$

Normed Fit Index $(\mathrm{NFI})=0.93$

Non-Normed Fit Index (NNFI) $=0.96$ 


\section{Appendix E}

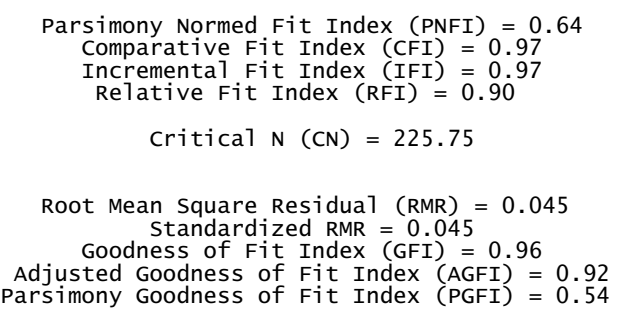

Fitted Covariance Matrix

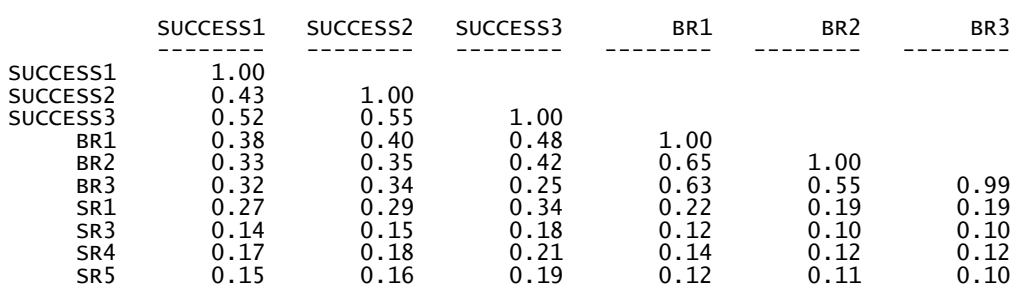

Fitted Covariance Matrix

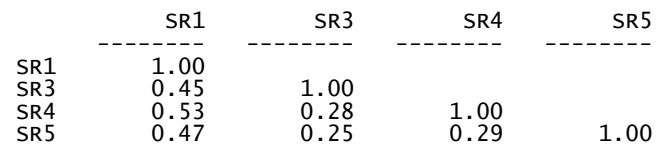

Fitted Residuals

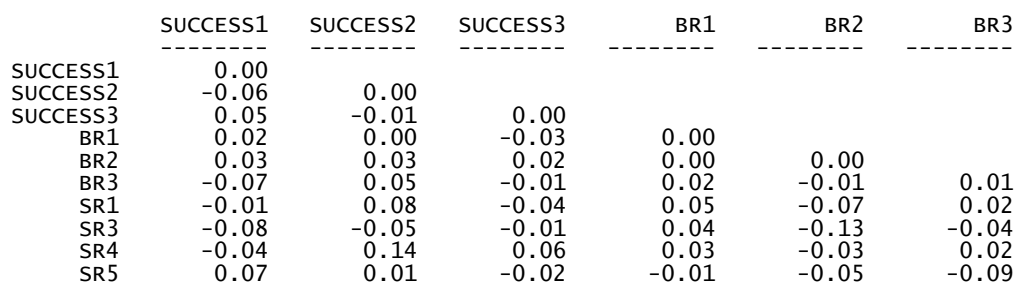

Fitted Residuals

$\begin{array}{lrrrr} & \text { SR1 } & \text { SR3 } & \text { SR4 } & \text { SR5 } \\ \text { SR1 } & 0.00 & & & \\ \text { SR3 } & 0.01 & 0.00 & & \\ \text { SR4 } & 0.00 & -0.04 & 0.00 & \\ \text { SR5 } & 0.00 & 0.00 & 0.03 & 0.00\end{array}$

Summary Statistics for Fitted Residuals

$\begin{array}{rr}\text { Smallest Fitted Residual }= & -0.13 \\ \text { Median Fitted Residual }= & 0.00 \\ \text { Largest Fitted Residual }= & 0.14\end{array}$

Stemleaf Plot

$-113$

- $0 \mid 444433211111100000000000000$

0| 1112222233334

$0 \longdiv { 5 5 5 6 7 8 }$

$1 \mid 4$

Standardized Residuals

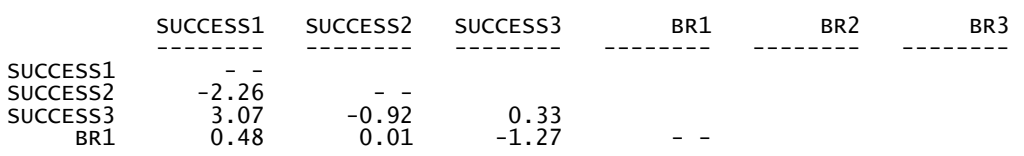


Appendix E

\begin{tabular}{|c|c|c|c|c|c|c|}
\hline $\begin{array}{l}\text { BR2 } \\
\text { BR3 } \\
\text { SR1 } \\
\text { SR3 } \\
\text { SR4 } \\
\text { SR5 }\end{array}$ & $\begin{array}{r}0.67 \\
-1.71 \\
-0.32 \\
-1.36 \\
-0.71 \\
1.16\end{array}$ & $\begin{array}{r}0.85 \\
1.26 \\
2.22 \\
-0.83 \\
2.63 \\
0.16\end{array}$ & $\begin{array}{r}0.52 \\
-0.80 \\
-1.70 \\
-0.27 \\
1.22 \\
-0.41\end{array}$ & $\begin{array}{r}-0.30 \\
1.52 \\
2.12 \\
0.74 \\
0.62 \\
-0.10\end{array}$ & $\begin{array}{r}--\overline{-} \\
-0.58 \\
-1.95 \\
-2.32 \\
-0.60 \\
-0.95\end{array}$ & $\begin{array}{r}0.85 \\
0.43 \\
-0.64 \\
0.32 \\
-1.63\end{array}$ \\
\hline
\end{tabular}

Standardized Residuals

$\begin{array}{lrrrr} & \text { SR1 } & \text { SR3 } & \text { SR4 } & \text { SR5 } \\ \text { SR1 } & ----1 & --1.52 & --\overline{4} & \\ \text { SR3 } & 1.52 & -1.04 & --\overline{8} & \\ \text { SR4 } & -0.83 & -0.09 & 0.68 & -- \\ \text { SR5 } & -0.36 & \end{array}$

Summary Statistics for standardized Residuals

$\begin{array}{rr}\text { Smallest Standardized Residual }= & -2.32 \\ \text { Median Standardized Residual }= & 0.00\end{array}$

Largest Standardized Residual $=3.07$

stemleaf plot

- 21330

- 117764300

- 0988876664433311000000000

$0 \mid 233455677799$

$1 \mid 22355$

$2 \mid 126$

Largest Positive Standardized Residuals

Residual for SUCCESS3 and SUCCESS1 3.07

$\begin{array}{lll}\text { Residual for SR4 and SUCCESS2 } 2.63 & \end{array}$

Modification Indices and Expected Change

No Non-Zero Modification Indices for LAMBDA-Y

Modification Indices for LAMBDA-X

$\begin{array}{lrr} & \text { SR } & \text { BR } \\ \text { BR1 } & 4.73 & -- \\ \text { BR2 } & 4.75 & -- \\ \text { BR3 } & 0.10 & --\overline{5} \\ \text { SR1 } & -- & 0.29 \\ \text { SR3 } & -- & 0.33 \\ \text { SR4 } & -- & 0.25 \\ \text { SR5 } & -- & 0.80\end{array}$

Expected Change for LAMBDA-X

$\begin{array}{lrr} & \text { SR } & \text { BR } \\ \text { BR1 } & 0.12 & -- \\ \text { BR2 } & -0.12 & -- \\ \text { BR3 } & -0.02 & -- \\ \text { SR1 } & -- & 0.04 \\ \text { SR3 } & -- & -0.04 \\ \text { SR4 } & -- & 0.03 \\ \text { SR5 } & -- & -0.06\end{array}$

No Non-Zero Modification Indices for BETA

No Non-Zero Modification Indices for GAMMA

No Non-Zero Modification Indices for PHI

No Non-Zero Modification Indices for PSI

Modification Indices for THETA-EPS

$\begin{array}{lrrr} & \text { SUCCESS1 } & \text { SUCCESS2 } & \text { SUCCESS3 } \\ \text { SUCCESS1 } & -\overline{1} & & \\ \text { SUCCESS2 } & 5.11 & -\overline{4} & -- \\ \text { SUCCESS3 } & 5.97 & 0.04 & \end{array}$

Expected Change for THETA-EPS

$\begin{array}{lrrr} & \text { SUCCESS1 } & \text { SUCCESS2 } & \text { SUCCESS3 } \\ \text { SUCCESS1 } & --\overline{1} & & \\ \text { SUCCESS2 } & -0.12 & --\overline{1} & \\ \text { SUCCESS3 } & 0.15 & -0.01 & -\end{array}$


Appendix E

Modification Indices for THETA-DELTA-EPS

\begin{tabular}{|c|c|c|c|}
\hline & SUCCESS1 & SUCCESS2 & SUCCESS3 \\
\hline BR1 & 0.74 & 0.63 & 2.30 \\
\hline $\begin{array}{l}\text { BR2 } \\
\text { BR3 }\end{array}$ & 0.48 & 0.23 & 0.68 \\
\hline SR1 & 0.02 & 2.82 & $4.6 \overline{8}$ \\
\hline & 1.22 & 2.16 & 1.24 \\
\hline SR4 & 2.90 & 2.79 & 2.11 \\
\hline SR5 & 4.23 & 0.23 & 0.50 \\
\hline \multicolumn{4}{|c|}{ Expected Change for THETA-DELTA-EP } \\
\hline & SUCCESS1 & SUCCESS2 & SUCCESS3 \\
\hline BR1 & 0.03 & -0.03 & -0.06 \\
\hline$B R 2$ & 0.03 & 0.02 & 0.03 \\
\hline $\begin{array}{l}\text { BR3 } \\
\text { SR1 }\end{array}$ & -0.08 & 0.07 & $-0-\overline{8}$ \\
\hline $\begin{array}{l}\text { SR3 } \\
\text { SR }\end{array}$ & $\begin{array}{l}-0.05 \\
-0.05\end{array}$ & -0.07 & 0.05 \\
\hline SR4 & -0.08 & 0.08 & 0.06 \\
\hline SR5 & 0.10 & -0.02 & -0.03 \\
\hline
\end{tabular}

Modification Indices for THETA-DELTA

\begin{tabular}{|c|c|c|c|c|c|c|}
\hline & BR1 & BR2 & BR3 & SR1 & SR3 & SR4 \\
\hline BR1 & - & & & & & \\
\hline BR2 & 0.09 & - & & & & \\
\hline BR3 & 0.74 & 0.30 & -- & & & \\
\hline SR1 & 1.11 & 1.03 & 0.28 & - & & \\
\hline $\begin{array}{l}\text { SR3 } \\
\text { SR4 }\end{array}$ & 3.56 & 5.23 & 0.01 & 2.32 & $--\overline{-}$ & \\
\hline $\begin{array}{l}\text { SR4 } \\
\text { SR5 }\end{array}$ & $\begin{array}{l}0.35 \\
0.16\end{array}$ & $\begin{array}{l}0.08 \\
0.19\end{array}$ & $\begin{array}{l}0.23 \\
4.24\end{array}$ & 0.69 & 1.07 & $\overline{0.47}$ \\
\hline
\end{tabular}

Modification Indices for THETA-DELTA
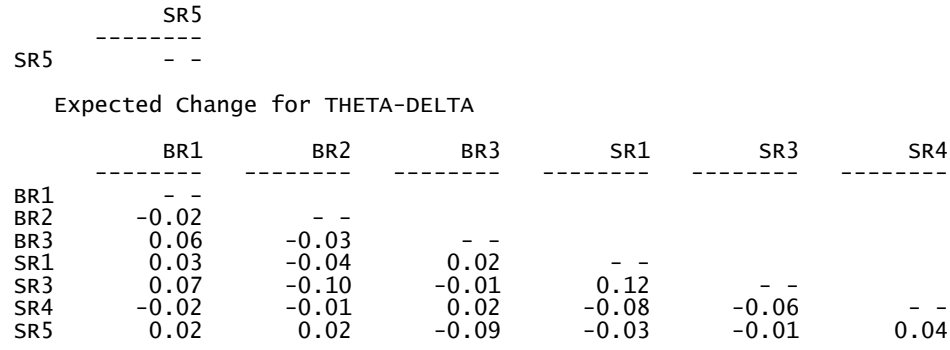

Expected change for THETA-DELTA

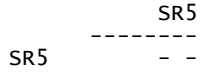

Maximum Modification Index is 5.97 for Element $(3,1)$ of THETA-EPS 


\section{Appendix E}

Covariances

$$
\begin{aligned}
& Y \text { - ETA }
\end{aligned}
$$

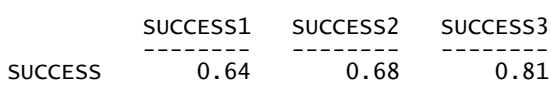

$$
\begin{aligned}
& \text { Y - KSI } \\
& \begin{array}{rrrr} 
& \text { SUCCESS1 } & \text { SUCCESS2 } & \text { SUCCESS3 } \\
\text { SR } & 0.29 & --31 & --1 \\
\text { BR } & 0.44 & 0.47 & 0.37 \\
& & &
\end{array} \\
& X \text { - ETA } \\
& \begin{array}{rr} 
& \text { BR1 } \\
\text { SUCCESS } & 0.59 \\
\text { X - ETA } & \text { SR5 } \\
\text { SUCCESS } & 0.23
\end{array} \\
& x-K S I
\end{aligned}
$$

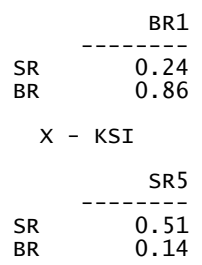

Factor Scores Regressions

$$
\begin{aligned}
& \begin{array}{rrrrrrr} 
& \text { SUCCESS1 } & \text { SUCCESS2 } & \text { SUCCESS3 } & \text { BR1 } & \text { BR2 } & \text { BR3 } \\
\text { SUCCESS } & 0.18 & 0.21 & 0.49 & 0.05 & 0.02 & 0.19
\end{array} \\
& \text { ETA }
\end{aligned}
$$

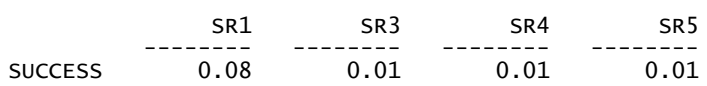

$$
\begin{aligned}
& \text { KSI } \\
& \begin{array}{rrrrrrr} 
& \text { SUCCESS1 } & \text { SUCCESS2 } & \text { SUCCESS3 } & \text { BR1 } & \text { BR2 } & \text { BR3 } \\
\text { SR } & --0.01 & --0.02 & 0.04 & 0.00 & 0.00 & 0.01 \\
\text { BR } & 0.02 & 0.02 & 0.16 & 0.44 & 0.24 & 0.27
\end{array} \\
& \text { KSI } \\
& \begin{array}{rrrrr} 
& \text { SR1 } & \text { SR3 } & \text { SR4 } & \text { SR5 } \\
\text { SR } & --178 & 0.08 & 0.10 & 0.08 \\
\text { BR } & 0.00 & 0.00 & 0.00 & 0.00
\end{array} \\
& \text { Time used: } \quad 0.080 \text { seconds }
\end{aligned}
$$

